Erster Beratungsgegenstand:

\title{
Deutschland nach 30 Jahren Grundgesetz
}

\author{
1. Bericht von Professor Dr. Rudolf Bernhardt, Heidelberg
}

Inhalt ${ }^{1}$

Seite

I. Anmerkungen zur Verfassungsauslegung . . . . . . . 9

1. Völkerrecht und internationale Lagen als Faktoren der Verfassungsauslegung . . . . . . . . . . . . 9

2. Verfassungsauslegung zugunsten politischer Gestaltungsmöglichkeiten . . . . . . . . . . . 11

3. Wandlungen der Verfassungsauslegung . . . . . . 11

4. Verfassungsauslegung und Bindung an die Rechtsprechung des Bundesverfassungsgerichts . . . . . . . 12

1 Der Vortragsstil wurde im wesentlichen beibehalten. Die Anmerkungen beschränken sich auf einzelne Hinweise und eine Auswahl aus der kaum noch übersehbaren Literatur.

An größeren Gesamtdarstellungen zur Rechtslage Deutschlands sind aus der Nachkriegszeit vor allem zu nennen (jeweils mit zahlreichen weiteren Nachweisen):

W. Grewe, Ein Besatzungsstatut für Deutschlan'd, 1948; R. Stödter, Deutschliands Rechtslage, $1948 ; F$. Klein, Neues deutsches Verfassungsrecht, 1949; W. Freiherr Marschall von Bieberstein, Zum Problem der völkerrechtlichen Anerkennung der beidien deutschen Regierungen, 1959; G. Scheuer, Die Rechtslage des geteilten Deutschland, $1960 ; R$. Schuster, Deutschlands staatliche Existenz im Widerstreit politischer und rechtlicher Gesichtspunkte 1945-1963, 1963; D. Blumenwitz, Die Grundlagen eines Fniedensvertrages mit Deutschland, 1966; Ostverträge - Berlin-Status - Münchner Abkommen - Beziehungen zwischen der BRD und der DDR, Vorträge und Diskussionen eines Symposiums, 1971 (Veröffentlichungen des Instituts für Intennationales Recht an der Universität Kiel, Bd. 66); H. Rumpf, Land ohne Souveränität, 2. Aufl. 1973; T. Schramm, Das Verhältnis der Bundesrepublik Deutschland zur DDR nach dem Grundvertarag, 2. Aufl. 1975; Finis Germaniae? Symposium aus Anla $\beta$ des 70. Geburtstages von Herbert Krüger, 1977; B. Guérin, L'évolution du statut juridique de l'Allemagne de 1945 au Traité fondamental, 1977; G. Ress, Die Rechtslage Deutschlands nach dem Grundlagenvertrag vom 21. Dezember 1972, 1978; H.-J. Bücking, Der Rechtsstbatus des Deutschen Reiches, 1979. 
II. Der völkerrechtliche Befund . . . . . . . . . . 13

1. Zwei Staaten und Völkerrechtssubjekte in Deutschland 13

2. Geltung des Völkerrechts zwischen der Bundesnepublik und der Deutschen Demokratischen Republik . . . . 15

3. Gibt es ein Völkerrechtssubjekt Gesamtdeutschland? . 15

4. Identität Deutsches Reich - Bundesrepublik? . . . . 16

5. Die alliierten Vorbehaltsrechte . . . . . . . . . 19

6. Das Selbstbestimmungsrecht . . . . . . . . . . 22

III. Gemengelagen von Staats- und Völkerrecht . . . . . . 22

IV. Hauptprobleme im Uberblick . . . . . . . . . . 24

1. Das Wiedervereinigungsgebot . . . . . . . . . . 24

2. Die Deutschen und ihre Staatsangehörigkeit . . . . 28

3. Deutschlands Grenzen . . . . . . . . . 34

4. Berlin . . . . . . . . . . . . . . . . 36

V. Einzelfragen in Auswah1 . . . . . . . . . . . . . 38

1. Auseinandiersetzungen um Deutschland im rechtlichen Alltag . . . . . . . . . . . . . . . . . . . 38

2. Der Inlandsbegriff des $\S 25$ Abs. 1 RuStAG . . . . . 40

3. Ein- und Ausbürgerungen in der DDR . . . . . . . 40

4. Der Inlandsbegriff in anderen einfachen Gesetzen . . 41

5. Die Grenzen auf amtlichen Karten . . . . . . . . 45

VI. Ausblick . . . . . . . . . . . . . . . . . . . 46 


\section{Anmerkungen zur Verfassungsauslegung}

Beginnen muß ich mit einigen Anmerkungen zur Verfassungsauslegung, zu ihren Prinzipien und Leitlinien, soweit sie in unserem Zusammenhang und für die hier angestellten Uberlegungen von Bedeutung sind. Dabei ist in Kauf zu nehmen, daß die Hinweise sehr knapp ausfallen müssen.

1. Die erste Bemerkung betrifft die Einbeziehung völkerrechtlicher Befunde und ,internationaler Lagen" in den ProzeB der Verfassungsauslegung. Speziell das Grundgesetz ist „weltoffen "2 zu interpretieren. Das heißt nicht, daß etwaige Widersprüche zwischen Völkerrecht und Verfassungsrecht stets zugunsten des Völkerrechts aufzulösen sind. Es kann vielmehr durchaus verfassungswidrige Verträge und es kann Vertragsauslegungen geben, die verfassungsrechtlich nicht akzeptiert werden können. Zuzustimmen ist auch der Warnung von Klaus Stern $n^{3}$ vor einer Überdehnung des Prinzips völkerrechtsfreundlicher Interpretation des Grundgesetzes. $\mathrm{Zu}$ betonen ist jedoch, daß bei der Verfassungsauslegung das Völkerrecht (und allgemein die internationale Situation) in die Prüfung einzubeziehen sind und nach einer widerspruchsfreien Lösung zu suchen ist ${ }^{+}$. In der Literatur und in der Verfassungsrechtsprechung ist diese Einbindung der Verfassung in die internationale Ordnung nicht immer hinreichend beachtet worden, doch scheint sie in letzter Zeit wieder stärker in das Bewußtsein zu dringen. Ernst Rudolf Huber beginnt den 5. Band seiner Deutschen Verfassungsgeschichte ${ }^{5}$ mit einer Betrachtung unter der Utberschrift „Nationale Verfassungsautonomie und internationaler Verfassungszusammenhang". Neuerdings haben z. B. Bleckmann und Häberle nachdrücklich auf den ,kooperativen Verfassungsstaat"

${ }^{2}$ H. P. Ipsen hat (Der Staat Bd. 17, 1978, 120 f.) zu Recht angeregt, nicht von umwelitoffen (so in meinem Beitrag zur Festgabe für das Bundesverfassungsgericht), sondern von weltoffen zu sprechen.

${ }^{3}$ K. Stern, Das Staatsrecht der Bundesrepublik Deutschland, Bd. 1, $1977,351$.

4 Sicher handelt es sich nicht nur um Einwirkungen des Völkerrechts auf das nationale Recht, sondern das Verfassungsrecht wirkt auch seinerseits auf das Völkerrecht ein. Das dürfte u. a. in Menschenrechtsfragen gelten, vgl. dazu L. Wildhaber, Erfahmungen mit der Europäischien Menschenrechtskonvention, Schweizer Juristenverein, Referate und Mitteilungen 1979, $231 \mathrm{ff}$., 238, und die dort zitierte Rechtsprechung des Schweizerischen Bundesgerichts.

5 E. R. Huber, Deutsche Verfassungsgeschichte seit 1789, Bd. V, $1978,3 \mathrm{ff}$. 
i.S. internationaler Kooperation aufmerksam gemacht ${ }^{6}$. Die Vereinigung der Deutschen Staatsrechtslehrer hat seit ihrer Neugründung erfreulich oft verfassungsrechtliche Probleme mit internationalen Aspekten behandelt ${ }^{7}$, zuletzt vor zwei Jahren in Basel $^{8}$.

Das Gebot völkerrechtsfreundlicher Interpretation des Grundgesetzes rechtfertigt und fordert die alsbald in diesem Bericht anzustellende völkerrechtliche Bestandsaufnahme zum Thema „Deutschland“. Sie wäre nur dann irrelevant, wenn das Grundgesetz selbst eindeutige Aussagen über Deutschland und seine Rechtslage enthielte. Das ist nicht der Fall. Das Grundgesetz spricht von Deutschland in der Präambel und in Art. 23. Vom Deutschen Reich in den Grenzen von 1937 ist in Art. 116 Abs. 1 die Rede; auch andere Vorschriften, insbes. Art. 16 und 146, nehmen Bezug auf die rechtliche und politische Situation in Deutschland. Diesen Vorschriften ist nicht zu entnehmen, daß das Grundgesetz den völkerrechtlichen Befund für irrelevant erklärt und das Deutschlandbild verfassungsrechtlich festschreibt. Auch die Entstehungsgeschichte des Grundgesetzes ist bemerkenswert unergiebig hinsichtlich des rechtlichen Deutschlandbildes seiner Schöpfer'; und soweit damals klare rechtliche

- A. Bleckmann, Die Völkerrechtsfreundilichkeit der deutschen Rechtsordnung, DƠV 1979, 309 ff.; P. Häberle, Der kooperative Verfassungsstaat, in: Recht und Gesellschaft, Festschrift für Helmut Schelsky zum 65. Gebuntstag, 1978, 141 ff. Vigl. auch W. Fiedler, Fortbildung der Verfassung durch das Bundesverfassungsgericht?, JZ 1979, 417 ff., 424 f., sowie $R$. Bernhardt, Verfiassungsrecht und internationale Lagen, DƠV 1977, $457 \mathrm{ff}$.

7 Speziell zum vorliegenden Thema ist von fortdauernder Bedeutung: A. Frh. v. d. Heydte und G. Dürig, Der deutsche Staat im Jiahre 1945 and seither, VVdStRL Heft 13, 1955. Andene Themen mit internationalen Aspekiten haben behandelt: W. Grewe und E. Menzel, Die auswärtige Gewalt der Bundesrepublik, Heft 12, 1954; G. Erler und $W$. Thieme, Das Grundgesetz und die öffentliche Gewalt internationaler Stalatengemeinschaften, Heft 18, 1960; $H$. Bülck und $P$. Lerche, Föderalismus als nationales und internationales Ordnungsprinzip, Heft 21,$1964 ; J$. H. Kaiser und P. Badura, Bewahrung und Vieränderung demoknatischer und rechtssitaatlicher Verfassungsstruktur in den interniationalen Gemeinschaften, Heft 23, 1966; $K$. Doehring und $J$. Isensee, Die staatsrechtliche Stellung der Ausländer in der Bundesrepublik, Heft 32, 1974.

8 C. Tomuschat und R. Schmidt, Der Verfassungsstaat im Geflecht der internationalen Beziehungen, VVdStRL Heft 36, 1978.

- Vgl. die Zusammenfassung der Entstehungsgeschichte im Jahrbuch des öffientlichen Rechts, N. F. Bd. 1, 1951, speziell zu der Präambel und zu den im Text genannten Artikeln des Gnundgesetzes. 
Vorstellungen bestanden, bezogen sie sich naturgemäß auf die damalige Situation.

Ergänzend und nur am Rande möchte ich einen weiteren internationalen Aspekt erwähnen: Die Auslegung der nationalen Verfassung sollte international möglichst glaubwürdig und verständlich sein.

2. Das Verhältnis zwischen Recht und Politik sowie zwischen verfassungsrechtlicher Bindung der staatlichen Organe einerseits und ihrer politischen Gestaltungsfreiheit andererseits ist ebenso komplex wie für unser Thema grundlegend; es kann hier nur in Thesenform angesprochen werden. Bei der Verfassungsauslegung ist weniger an den "judicial selfrestraint“ der Verfassungsrichter zu appellieren als festzustellen, daß jede auf Dauer angelegte Verfassung den politischen Kräften und den zur Gestaltung der Politik berufenen Staatsorganen den notwendigen Spielraum lassen muß und entsprechend zu interpretieren ist ${ }^{10}$. Diese Forderung kann offensichtlich bei der verfassungsrechtlichen Eingrenzung jeder Deutschlandoder Wiedervereinigungspolitik gravierende Konsequenzen haben. Gerade bei weit und unpräzise gefaßten Verfassungsbestimmungen mit besonders starkem politischen Gehalt und internationalen Berührungspunkten ist eine Interpretation geboten, die der politischen Gestaltung unter Berücksichtigung der internationalen Entwicklung Raum läßt.

3. Im Hinblick auf die älteste der derzeit geltenden Verfassungen, zur amerikanischen Verfassung von 1789, ist das Bild von der "living Constitution", der lebenden Verfassung, geprägt worden. Das Bild ist auch bei uns verwertbar und vielleicht besser als das viel genannte und zuweilen gescholtene Wort „Verfassungswandel“11 geeignet, eine Grundfrage der

10 Vgl. zuletzt W.-H. Schenke, Der Umfiang der bundesvierfassungsgericht:lichen Überprüfung, NJW 1979, $1321 \mathrm{ff} ., 1324 \mathrm{ff}$. - Der Begriff des "judicial self-restraint" ist deshalb problematisch, weil er den Gedanken an eine freiwillige Zurückhaltung nahelegt, wähnend es sich nach unserem Rechtsdenken eher um dive verfassungsrechtlich vorgegebene Aufgabenverteilung zwischen den staatlichen Organen und um verbindliche Auslegungsprinzipien handelt.

${ }_{11}$ Dazu u. a. P. Lerche, Stiller Verfassungswandel als aktuelles Politikum, in: Festgabe für T. Maunz, 1971, 285 ff.; K. Hesse, Grenzen der Vierfassungswandlung, in: Festschrift für U. Scheuner, 1973, 123 ff.; ders., Gmundzüige des Verfassungsnechts der Bundesrepublik Deutschland, 11. Aufl. 1978, $12 \mathrm{ff.;} P$. Häberle, Zeit und Verfassung, in: Verfassung als öffentlicher Prozeß, 1978, 59 ff. (= ZfP $21-1974$ - 111 ff.); W.-R. Schenke, Verfassung und Zeit - von der „entzeiteten" zur zeitgeprägten Verfassung, AÖR 103 (1978), $566 \mathrm{ff}$. 
Verfassungsauslegung $\mathrm{zu}$ verdeutlichen. Die Verfassungsauslegung muß sowohl bewahren als auch auf neue Entwicklungen und Notwendigkeiten reagieren. Das heißt: Die Interpretation der Verfassung ist einerseits an die Grundprinzipien und einen klaren Verfassungstext gebunden, andererseits kann und muß sich das Verfassungsverständnis innerhalb gewisser Grenzen bei gleichbleibendem Wortlaut ändern. Die Grenzziehung ist naturgemä $\beta$ besonders schwierig. Wenn in der Präambel des Grundgesetzes, in den Artikeln 23 und 146, auch in Art. 16 und 116, Aussagen zur deutschen Frage enthalten sind, so ist zu prüfen, ob diese Aussagen 1979 anders zu sehen sind als sie 1949, 1959 oder 1969 gesehen wurden.

4. Ich werde im folgenden in einigen wichtigen Fragen einen anderen Standpunkt einnehmen als es das Bundesverfassungsgericht insbesondere im Grundvertragsurteil ${ }^{12}$ getan hat $^{13}$. Gelegentlich stößt man auf Äußerungen, daß mit einem Spruch des Bundesverfassungsgerichts die Rechtslage nicht nur für die staatlichen Organe, sondern allgemein für die verfassungsrechtliche Diskussion geklärt sei. Allen Versuchen, die verfassungsrechtliche Diskussion in die Grenzen der Rechtsprechung des Bundesverfassungsgerichts $\mathrm{zu}$ zwingen, ist mit Nachdruck entgegenzutreten. Die kritische Auseinandersetzung mit dieser Rechtsprechung ist für den Staat und die Wissenschaft gleichermaßen unentbehrlich.

Natürlich wirft die grundsätzliche Bindung der staatlichen Organe an die Entscheidungen des Bundesverfassungsgerichts

12 Urteil vom 21. 7. 1973, BVierfGE 36, 1.

${ }^{13} \mathrm{Zu}$ der Entscheidung haben $\mathrm{u}$. a. - überwiegend kritisch Stellung genommen: U. Scheuner, Die staatsmechtliche Stellung der Bundesrepublik, DOV 1973, 581 ff.; W. A. Kewenig, Auf der Suche nach einer neuen Deutschland-Theorie, DOV 1973, $797 \mathrm{ff}$.; O. Kimminich, Das Urteil über die Grundlagen der staatsrechtlichen Konstruktion der Bundesrepublik Deutschland, DVBI. 1973, $657 \mathrm{ff}$.; T. Oppermann, Urteilsanmerkung, JZ 1973, 594 ff.; C. Tomuschat, Auswärtige Gewalt und verfassungsgerichtliche Kontrolle, DOV 1973, 801 ff.; W. Hoffmann-Riem, Beharrung oder Innovation - zur Bindungswirkung verfassungsgerichtlicher Entscheidungen, Der Staat 13 (1974), 335 ff.; B. Simma, Der Grundvertrag und das Recht der völkerrechtlichen Verträge, AOR Bd. 100 (1975), 4 ff.; R. Bernhardt, Völkermechtliche Bemerkungen zum Grundvertragsurteil des Bundesverfassungsgerichts, in: Recht im Dienst des Friedens, Festschrift für E. Menzel, 1975, $109 \mathrm{ff}$; J. Delbrück, Quo vadis Bundesverfassungsgericht?, ibid., 83 ff.; D. Wilke, G. H. Koch, Außenpolitik nach Anweisung des Bundesverfassungsgerichts? JZ 1975, $233 \mathrm{ff}$. Vgl. jetzt auch die Publikation: Fünf Jahre Grundvertragsurteil des Bundesverfassungsgerichts, 1979. 
dann besonders schwierige Fragen auf, wenn neue Entwicklungen und Gesichtspunkte eine veränderte Verfassungsauslegung nahelegen können. Das gilt speziell für das DeutschlandBild des Bundesverfassungsgerichts. Auf seine Verbindlichkeit für die staatlichen Organe und $\S 31$ des Gesetzes über das Bundesverfassungsgericht kann hier nicht eingegangen werden. Es kann nur angemerkt werden, da $B$ verstärkt nach Möglichkeiten gesucht werden sollte, von der Entwicklung überholte Rechtsauffassungen aufzugeben. Das würde dann leichter sein, wenn die überdehnte Bindung an die Entscheidungsgründe drastisch eingeschränkt würde ${ }^{14}$.

In diesem Zusammenhang noch eine letzte Bemerkung: Die Auffassung, die verfassungskonforme Interpretation eines Vertrages durch das Verfassungsgericht könne auch den Vertragspartner binden ${ }^{15}$, ist nicht haltbar. Das Völkerrecht kennt keine derartige Maxime. Es ist schon mehrfach darauf hingewiesen worden und muß nachdrücklich wiederholt werden, daß die einseitige, auch die verfassungsgerichtlich abgesicherte Vertragsauslegung niemals unmittelbar und ohne Zustimmung des Partners für diesen verbindlich ist. In diesem Zusammenhang wird in der Diskussion nicht immer hinreichend beachtet, daß der Partner dann auch seine eigene Interpretation für verbindlich ausgeben könnte, eine Konsequenz, die gerade im Ost-West-Verhältnis verhängnisvoll sein kann.

\section{Der völkerrechtliche Befund}

1. Die Bundesrepublik Deutschland und die Deutsche Demokratische Republik sind seit 1973 Mitglieder der Vereinten Nationen ${ }^{16}$. Schon lange zuvor war die Bundesrepublik Mit-

14 V.gl. u. a. W. Hoffmann-Riem, a. a. O. (oben Anm. 13); W. Ruppv. Brüneck, Wie weit reicht die Bindungswirkung des Grundvertnagsurteils des Bundesverfassungsgerichts?, in: Finis Germaniae? (Anm. 1), 62 ff.; W. Seuffert, Uber Gesetzgebung, Rechtsprechung und Bindungswirkungen, AOR 104 (1979), 169 ff., $187 \mathrm{ff}$.

15 Das klingt im Grundventragsurteil des Bundesverfassungsgerichts an, vgl. BVerfGE 36, 1 (36); dazu mein Beitrag zur Festschrift Menzel (oben Anm. 13), $117 \mathrm{ff}$.

18 Art. 4 der Satzung der Vereinten Nationen sieht vor, daß nur Staaten Mitglieder der Organisation werden können. Die Vorschrift ist je nach der politischen Konstellation großzügig gehandhabt worden, indem sowohl die Uknaine und Weiß-Rußland als auch seinerzeit (1945) noch abhängige Gebiete wie Indien zur Mitgliedschaft zugelassen wurden. Die Mitgliedschaft der beiden deutschen Staaten gibt daher allein keine Antwort auf die Frage nach der Rechtslage Gesamtdeutschlands. - Zum Beitritt der beiden deutschen 
glied der weltweiten Sonderorganisationen, die DDR ist es inzwischen weitgehend geworden. Beide Staaten unterhalten mit fast allen anderen Staaten der Welt diplomatische Beziehungen, sie gehören einer Vielzahl von universellen und regionalen Organisationen an, und sie sind Partner unzähliger zwischenstaatlicher Verträge. $\mathrm{Da} B$ beide Staaten nach innen wirksam Staatsgewalt ausüben, ist gleichfalls offensichtlich.

Die Existenz eines Staates als Völkerrechtssubjekt ist keine Frage der Sympathie oder demokratischer Legitimität, auch keine Frage des Zusammengehörigkeitsgefühls der Menschen über Grenzen hinweg, sondern der effektiven Machtausübung und der internationalen Respektierung. In keiner Hinsicht ist es heute noch möglich, an dem Vorhandensein zweier Staaten und Völkerrechtssubjekte ,in Deutschland“ zu zweifeln. Insofern hat sich Deutschland in den vergangenen Jahren drastisch verändert. Heute ${ }^{17}$ vor 30 Jahren stand das Inkrafttreten der DDR-Verfassung unmittelbar bevor. Vor 20 Jahren war die Bundesrepublik zum weltweit anerkannten Repräsentanten zumindest des westlichen Deutschlands geworden. Vor 10 Jahren hatte die DDR dies für ihren Teil Deutschlands noch nicht erreicht ${ }^{18}$. Inzwischen existieren eindeutig zwei deutsche Staaten ${ }^{10}$.

Staaten wurde klargestellt, „daß diese Mitgliedschafit die Rechte und Verantwortlichkeiten der Vier Mächte und die bestehenden diesbezüglichen vierseitigen Regelungen, Beschlüsse und Praktiken in keiner Weise berührt". (Erklärung der Vier Mächte vom 9. 11. 1972). Hieraus folgt, daß die beiden deutschen Staaten nicht über die volle Souveränität verfügen, die Formel besagt laber nicht, daß der Staat „Gesamtdeutschland" fortbesteht. - Anlarge IV zum VierMächte-Abkommen über Berlin erklärt es für zulässig, daß die Bundesrepublik die Intenessen der Westsektoren Berlins in internationalen Organisationen vertritt. Dies wurde bei dem Beitritt der Bundesrepublik zu den Vereinten Nationen bekräftigt. (Vgl. H. Schiedermair, Der völkerrechtliche Status Berlins nach dem Viver-MächteAbkommen vom 3. September 1971, 1975, $151 \mathrm{ff}$.)

17 D. h. am 4. 10. 1979, an dem der Bericht mündlich vorgetragen wurde; am 7. 10. 1949 wurde die erste Verfassung der DDR in Kraft gesetzt.

18 Zur Entwicklung der vertraglichen Beziehungen der DDR mit anderen Staaten zuletzt T. Schweisfurth, Völkerrecht als Instrument der Außenpolitik, in: Drei Jahrzehnte Außenpolitik der DDR, 1979, $275 \mathrm{ff}$., $279 \mathrm{ff}$. Im selben Band zahlreiche weitere Beiträge und Belege zur Entwicklung der internationalen Stellung der DDR.

10 Zur Diskussion des Fortbestehens einer Nation zuletzt $U$. Scheuner, Das Problem der Nation und des Verhältnisses zur Bundesrepublik Deutschland, ebenda (A.nm. 18), $87 \mathrm{ff}$. 
2. Auch im Verhältnis der beiden deutschen Staaten zueinander gilt zumindest weitgehend, vielleicht allein Völkerrecht; darauf ist noch zurückzukommen. Vorerst genügt die Feststellung, daß die Bundesrepublik und die DDR selbst bei Annahme fortbestehender gesamtdeutscher Staatlichkeit Staaten und Völkerrechtssubjekte auch in ihren Beziehungen zueinander sind. Wenn immer wieder betont worden ist, eine völkerrechtliche Anerkennung der DDR durch die Bundesrepublik komme nicht in Betracht, so ist das $\mathrm{m}$. E. eine - rechtlich zulässige - Weigerung, einen gegebenen und mit geschaffenen Sachverhalt förmlich ,,anzuerkennen "20. In der Sache haben die beiden deutschen Staaten mit dem Grundvertrag einen dem Völkerrecht zuzurechnenden Vertrag geschlossen ${ }^{21}$; in ihm haben sie sich gegenseitig die Staatlichkeit, die Unverletzlichkeit ihrer Grenzen, „,die Unabhängigkeit und Selbständigkeit jedes der beiden Staaten in seinen inneren und äußeren Angelegenheiten" (Art. 6) zuerkannt. Auf Vorbehalte und mögliche Einschränkungen der Staatlichkeit ist zurückzukommen, nur scheint es mir völkerrechtlich nicht möglich zu sein, die Staatlichkeit und Völkerrechtspersönlichkeit der DDR im Kern zu negieren. Um es nochmals zu betonen: Es geht nicht um $\mathrm{Zu}$ - oder Abneigungen, es geht auch nicht um die Bewertung der Politik, die zu dem Befund geführt hat, sondern es geht um eine möglichst nüchterne völkerrechtliche Bestandsaufnahme.

3. Gibt es neben oder über den beiden deutschen Staaten noch ein Völkerrechtssubjekt „Gesamtdeutschland"? Nachdem zuvor die verschiedenen Spielarten der Identitätstheorie im Vordergrund standen, wird das Fortbestehen eines nicht - jedenfalls nicht voll - mit der Bundesrepublik identischen gesamtdeutschen Staates seit etwa 10 Jahren von der Bundesregierung mehr oder weniger deutlich bejaht, und diese Ansicht wurde 1973 durch das Bundesverfassungsgericht festgeschrieben. Im Grundvertragsurteil heißt es bekanntlich: „Das Deutsche Reich existiert fort (...), besitzt nach wie vor Rechtsfähigkeit, ist allerdings als Gesamtstaat mangels Organisation, insbesondere mangels institutionalisierter Organe selbst nicht hand-

${ }^{20}$ In der Literabur wind z. T. angenommen, die völkerrechtliche Anerkennung der DDR durch die Bundesrepublik sei in Wahrheit konkludent erfolgt, vgl. etwa J. G. Gleich, Die Anerkennung der DDR durch die Bundesrepublik, 1975 (Augsburger Schriften zum Staats- und Völkerrecht, Band 3); H.-J. Bücking, a. a. O. (Anm. 1)

21 Vgl. W. Wengler, Gutachten, in Cieslar-Hampel-Zeitler, Der Streit um den Grundvertrag, 1973, 126 ff.; O. Kimminich, Der Grundvertrag, 1975 (Sonderausgabe des Anhangs im Bonner Kommentar, Rdnr. 24, 141, 155). 
lungsfähig“22. Als Belege zitiert das Gericht eigene frühere Entscheidungen; es übersieht, daß es sich um ein völkerrechtliches Problem handelt, über das die staatliche Rechtsordnung allein keine wirksame Entscheidung zu treffen vermag.

Nach den herkömmlichen völkerrechtlichen Regeln über Identität (und Kontinuität) ${ }^{23}$ von Staaten ist die Annahme, das Deutsche Reich sei weiter ein zwar rechts-, aber nicht handlungsfähiges Völkerrechtssubjekt, kaum noch begründbar. Nationalbewußtsein, menschliches Zusammengehörigkeitsgefühl, der vermutete Wunsch nach Wiedervereinigung in Freiheit und nach einer gemeinsamen demokratischen Staatsordnung können die harte Tatsache nicht verdrängen, daß die Existenz eines Staates eine wirksame Staatsgewalt erfordert und daß eine solche für Gesamtdeutschland seit knapp 35 Jahren weder existent noch in Sicht ist. Auch die historischen Beispiele der dreiBiger und vierziger Jahre (Äthiopien, Ósterreich, Tschechoslowakei, Polen), bei denen nach der zeitlich begrenzten Ausschaltung staatlicher Eigenständigkeit und der Wiedererrichtung der staatlichen Organisation eine ungebrochene Identität - zu Recht - bejaht wurde, führt angesichts der realen Situation in Deutschland nicht weiter. Ebensowenig ist der Hinweis beweiskräftig, daß Polen nach dem 1 . Weltkrieg eine staatliche Identität mit dem Ende des 18. Jahrhunderts aufgeteilten Polen behauptet hat, denn diese These ist ihrerseits völkerrechtlich nicht haltbar.

Vor einer abschließenden Antwort auf die Frage nach einem die beiden deutschen Staaten überwölbenden Gesamtdeutschland muß noch zu einigen weiteren Fragen Stellung genommen werden. Vorerst waren nur die Zweifel hervorzuheben, die sich aus den allgemeinen völkerrechtlichen Regeln über die Identität von Staaten ergeben.

4. Mit diesen Zweifeln sollte nicht angedeutet werden, daß allein die These vom Untergang des Deutschen Reiches zutref-

22 BVerfGE 36, 1 (16).

23 Auf die Zweifelsfrage, ob die Begriffe Identität und Kontinuität im Völkerrecht synonym gebraucht werden (so wohl die h. M.) oder unterschieden werden müssen, kann hier nicht eingegangen werden. Vgl. neuerdings vor allem W. Fiedler, Das Kontinuitätsproblem im Völkerrecht, 1978; ders., Staatskontinuität und Verfassungsrechtsprechung, 1970. - Nach der Auffassung, daß die beiden Begriffe und die dazugehörigen rechtlichen Aussagen zu unterscheiden sind, kann es Identität auch ohne ungebrochene Kontinuität geben. Danach könnte die Bundesrepublik wohl selbst dann mit dem Deutschen Reich identisch sein, wenn voriubengehend, etwa von 1945 bis 1949, kein deutscher Staat existierte. 
fend erscheint. Bekanntlich lautet die offizielle Doktrin in der DDR und bei ihren Verbündeten - nach anfänglichem Schwanken in den Jahren nach Gründung der $\mathrm{DDR}^{24}$ - , das Deutsche Reich sei am 8. 5. 1945 untergegangen. Im Westen neigt eine Minderheit derselben Meinung zu (zuerst Kelsen ${ }^{25}$ und $\mathrm{Na}$ wiask $y^{26}$, später $R u m p f^{27}$ ); in der Bundesrepublik hat neuerdings Helmut Ridder mit harschen Worten und unzureichender Begründung all diejenigen gerügt, die nicht mit ihm vom Untergang des Deutschen Reiches aufgrund einer debellatio ausgehen $^{28}$. Auch andere Jahre als 1945 sind für den Untergang des Deutschen Reiches genannt worden ${ }^{29}$, insbes. 1949 und 1955 oder neuerdings auch der 21. Juni 1973, der Tag des Inkrafttretens des Grundvertrages ${ }^{\mathbf{3 0}}$.

Bei dem Versuch einer eigenen Würdigung ist $m$. E. die Annahme einer echten Identität zwischen dem Deutschen Reich und der Bundesrepublik Deutschland bei gleichzeitiger Verselbständigung der DDR zu einem eigenen Staat noch immer

24 Vgl. die eingehende Untersuchung von J. Hacker, Der Rechtsstatus Deutschilands aus der Sicht der DDR, 1974. Seit Mitte der 50er Jahre ist die These vom Untergang des Deutschen Reiches am 8. 5. 1945 die offizielle Doktrin der DDR.

${ }^{25} \mathrm{H}$. Kelsen, The International Legal Status of Germany to be Established Immediately upon Termination of the War, American Journal of International Law Vol. 38 (1944), $689 \mathrm{ff}$; ders., The Legal Status of Germany According to the Declaration of Berlin, ibid. Vol. 39 (1945), $518 \mathrm{ff}$.

26 Vgl. H. Nawiasky, Die Grundgedanken des IGrundgesetzes für die Bundesrepublik Deutschlland, 1950.

${ }^{27}$ H. Rumpf, a. a. O. (Anm. 1), $103 \mathrm{ff}$; ders. Vom Niemandsland zum deutschen Kernstaat, 1979 (mit verschiedenen Beiträgen zur Rechtslage Deutschlands); vgl. auch $K$. Krakau, Feindstaatenklauseln und Rechtslage Deutschlands nach den Ostverträgen, 1975, $119 \mathrm{ff}$.

${ }^{28}$ H. Ridder, Die ,deutsche Staratsangehörigkeit" und die beiden deutschen Staaten, in: Gedächtnisschrift für Friedrich Klein, 1977, 437 ff., 444 f.; auf die völkemechtlichen Regeln über Kontinuität und Identität von Staaten - nach denen etwa die totale kriegerische Besetzung allein keinesfalls oum Untergang eines Staates führt geht Ridder nicht ein, vielmehr will er ider "wahrhaft banalen Einsichit" Geltung verschaffen, daß der Staat "Deutsches Reich" ,am 8. Mai 1945 tatsächlich durch Debellation untergegangen iist..." (Hervorhebung im Original).

29 Z. B. hat J. Peck, Zum völkerrechtlichen Status der Deutschen Demokratischen Republik, Berlin(-Ost) 1956, S. 7, es 1956 noch dahingestellt sein lassen, ob das Deutsche Reich 1945 untergegangen sei, zumindest sei das 1949 durch dismembratio geschehen.

30 So H.-J. Bücking, a.a. O. (oben Anm. 1), 124 ff., 192 ff., 236. 
am ehesten völkerrechtlich vertretbar und begründbar ${ }^{31}$. Die Begründung muB sich auf Stichworte beschränken und kann nur bekannte Argumente rekapitulieren. Die zeitweilige Ausschaltung deutscher Staatsgewalt seit Mai 1945 hatte angesichts des von den Alliierten bekundeten Willens, Deutschland nicht als Staat und als Einheit zu vernichten ${ }^{32}$, keine unmittelbaren Folgen für das Fortbestehen des Deutschen Reiches als Völkerrechtssubjekt. Bei der Gründung der Bundesrepublik wurde ein geographisch und bevölkerungsmäßig substantieller Teil des Reiches staatlich neu organisiert. Die Verfassung, die Bevölkerung, die staatlichen Organe und ein großer Teil der internationalen Gemeinschaft sahen und sehen in der Bundesrepublik die Fortsetzung früherer deutscher Staatlichkeit. Insgesamt ist eine echte Identität zwischen dem Deutschen Reich und der Bundesrepublik mit guten Gründen vertretbar. Sie ist aber nur vertretbar, wenn zugleich die eigene staatliche Existenz der Deutschen Demokratischen Republik bejaht wird, denn andernfalls geriete man in einen klaren Widerspruch zu den bestehenden Verträgen.

Es ist verschiedentlich behauptet worden, die Identitätsthese, die Annahme einer Fortsetzung des Deutschen Reiches durch die Bundesrepublik, sei auch in der dargestellten Beschränkung mit der souveränen Gleichheit der beiden Staaten und den vertraglichen Verpflichtungen unvereinbar, sie enthalte ein "aggressives" Element ${ }^{33}$. Das ist nicht richtig. Die Mehrzahl der heutigen Staaten ist dadurch entstanden, daß sie sich aus einer bisherigen staatlichen Einheit gelöst haben, das gilt für den ganzen Dekolonisierungsproze $B$. Der bisherige Mutterstaat und der Neustaat stehen nicht etwa deshalb auf unterschiedlichen Stufen, weil ersterer seine Identität trotz des Verlustes beträchtlicher Gebiete bewahrt hat. Indien hat seine Identität bei der Abspaltung Pakistans erhalten, Pakistan die seine bei der Lösung Bangladeshs. Es ist daher nicht zutreffend, wenn behauptet wird, die Identitätsthese verstoße im Falle Deutsch-

31 Die heftige Krnitik der Identitätsthese durch H.-J. Bücking, a. a. O., $65 \mathrm{ff}$., geht insoweit an den Problemen vorbei, als nicht allein die - zudem unterschiedlich deutbanen - Äußerungen der Alliiierten, sondern primär die allgemeinen völkerrechtlichen Regeln über Identität und Kontinuität von Staaten zu konsultieren sind.

32 Die Entscheidung, zwei separate Staten lauf deutschem Boden zu errichten, fiel mehrere Jahre nach Kriegsende, vgl. hierzu jetzt $J$. $H$. Backer, The Decision ito Divide Germany. American Foneign Policy in Transition, 1978.

${ }^{33}$ So etwa M. Kriele auf dem in Anm. 1 erwähnten Symposium von $1971(272,317)$. 
lands gegen geltendes Völkerrecht, immer vorausgesetzt, man billigt der DDR die eigene Staatlichkeit zu.

Auch vom Selbstverständnis der beiden deutschen Staaten her begegnet die Identitätsthese keinen durchgreifenden $\mathrm{Be}-$ denken. Die DDR leugnet ihre Identität mit dem Deutschen Reich. Das ist zu akzeptieren. Die Bundesrepublik ihrerseits kann sich (und sollte sich) ohne die Zuhilfenahme von Konstruktionen wie dem fortbestehenden Reichsdach darauf berufen, daß sie nicht nur von ihrer Bevölkerung und ihrem Gebiet her einen substantiellen Teil des Deutschen Reiches umfaßt, sondern daß sie die Lasten und Pflichten aus deutscher Vergangenheit zu beträchtlichen Teilen übernommen hat; sie kann legitimerweise auch etwaige Rechte des Deutschen Reiches für sich beanspruchen.

5. Zum völkerrechtlichen Befund gehören die alliierten Vorbehaltsrechte. Nach Art. 2 des Deutschlandvertrages „,behalten die Drei Mächte die bisher von ihnen ausgeübten oder innegehabten Rechte in bezug auf Berlin und auf Deutschland als Ganzes einschließlich der Wiedervereinigung Deutschlands und einer friedensvertraglichen Regelung“. Es kann angesichts dieses Wortlauts und vielfacher weiterer Äußerungen der Beteiligten keinen Zweifel daran geben, daß die drei westlichen Aliierten und die Bundesrepublik diese Vorbehalte als existent und weiter verbindlich ansehen. Im Verhältnis zur Sowjet-Union, zu Polen und zur DDR ist durch die einschlägigen Klauseln in den Ostverträgen klargestellt, daß die von den Partnern früher abgeschlossenen oder sie betreffenden zweiseitigen und mehrseitigen internationalen Verträge und Vereinbarungen durch die neuen Verträge nicht berührt werden ${ }^{34}$. Damit ist insbesondere Vorsorge dagegen getroffen, daß von östlicher Seite ein Widerspruch zwischen den neuen Verträgen und den vertraglich abgesicherten Vorbehaltsrechten behauptet wird.

34 Art. 4 des Moskauer Vertrages, Art. IV des Warschauer Vertrages und Art. 9 des Grundlagenvertrages. Vgl. auch dive verschiedenen Briefwechsel zu den Verträgen mit dem Finverständnis der Beteiligten, „daß die Rechte und Verantwortlichkeiten der Vier Mächte und die entsprechenden diesbezüglichen vienseitigen Vereinbarungen, Beschilüsse und Praktiken durch diesen Vertnag nicht berührt werden können". (So der Briefwechsel zum Grundvertrag - BGBl. 1973 II 429 -, auch abgedruckt bei Cieslar-HampelZeitler, Der Streit um den Grundvertrag, 1973, 336 f). Vgl. im übrigen zum Moskauer Vertrag: Bulletin der Bundesregierung 1970, 1059 und BGBl. 1972 II 356, 360; zum Wanschauer Vertrag: BGBI. 1972 II $364,368$. 
Hinsichtlich der Vier-Mächte-Verantwortung in bezug auf Berlin besteht zwischen West und Ost kein Streit darüber, daß es diese Verantwortung und entsprechende Vorbehaltsrechte weiter gibt, wenn auch über den geographischen und sachlichen Umfang der Rechte und damit zusammenhängende Fragen keine Einigkeit besteht. Darauf ist zurückzukommen.

Der "gesamtdeutsche" Vorbehalt im Deutschlandvertrag hat zwei wesentliche Bestandteile: die Wiedervereinigungsfrage und die friedensvertragliche Regelung. Das heißt, daß über beides ohne die Alliierten nicht entschieden werden kann. Das ist im Verhältnis zwischen den westlichen Alliierten und der Bundesrepublik unstreitig. Die Haltung der Sowjet-Union ist insoweit unklar und schwankend; Behauptungen, die „deutsche Frage" sei längst gelöst und es gebe insoweit keinen Raum mehr für Vorbehaltsrechte, stehen Äußerungen und Anhaltspunkte gegenüber, die den Schluß nahelegen, auch die Sowjet-Union halte an gewissen Vier-Mächte-Zuständigkeiten in Deutschland über Berlin hinaus fest ${ }^{35}$. Eine endgültige Aussage über die sowjetische Haltung ist hier weder möglich noch nötig. Wesentlich ist, daß zwischen den westlichen Alliierten und der Bundesrepublik im Grundsätzlichen Einigkeit besteht, daß diese Einigkeit im Verhältnis dieser Staaten zueinander vertraglich bekräftigt worden ist und daß diese Haltung in den Ostverträgen abgesichert wurde. Damit ist die Bundesrepublik völkerrechtlich gehalten, die alliierten Vorbehaltsrechte hinsichtlich gesamtdeutscher Fragen zu respektieren, sie ist zugleich berechtigt, auf sie auch im eigenen Interesse zu verweisen. Wir haben es ja überhaupt mit der eigenartigen Situation zu tun, daß die alliierten Vorbehaltsrechte nicht nur den Status der Bundesrepublik (und der DDR) mindern, sondern daß diese Statusminderung jedenfalls von der Bundesrepublik auch als Vorteil empfunden wird, da so die „deutsche Frage" rechtlich offen gehalten werden kann. Dabei muß gesehen werden, daß die Bundesrepublik durch die Vorbehaltsrechte in rechtlichen Abhängigkeiten steht, die zweifellos Gefahren enthalten. „Deutschland“ vermag nicht selbst über seine Zukunft zu bestimmen, sondern sein Schicksal ist auch rechtlich von Mächten abhängig, die naturgemä $\beta$ primär ihre eigenen Ziele und nicht die deutschen Anliegen im Auge haben.

Mit den alliierten Vorbehaltsrechten sind bekanntlich zahlreiche weitere Rechtsfragen verbunden, auf die hier nicht eingegangen werden kann. Nur thesenartig sei Folgendes ange-

${ }^{35}$ Vgl. die Hinweise bei J. Hacker, a. a. O. (Anm. 24), $419 \mathrm{ff}$. sowie G. Wettig, Die Sowjetunion, die DDR und die Deutschland-Frage 1965-1976, 1976, $172 \mathrm{ff}$. 
merkt: Mit der herrschenden Meinung und trotz der Zweifel von Doehring ${ }^{36}$ ist anzunehmen, daß der Deutschlandvertrag die alliierten Rechte nicht auf eine neue Rechtsgrundlage gestellt, sondern ihre Fortgeltung bekräftigt hat. Weiter besagen die alliierten Vorbehaltsrechte nicht, daß Regelungen ohne deutsche Mitwirkung getroffen werden könnten, vielmehr könnten über einen Friedensvertrag wie über eine etwaige Wiedervereinigung Alliierte und Deutsche nur gemeinsam entscheiden $^{37}$.

Es ist verschiedentlich überlegt worden, ob nicht die VierMächte-Verantwortung das staatsrechtliche Band $\mathrm{zu}$ liefern vermag, das zwischen den beiden deutschen Staaten bestehen und sie unter dem Reichsdach verbinden soll ${ }^{38}$. Eine solche Konstruktion halte ich für kaum möglich. Wie immer man die alliierten Rechte und Maßnahmen in den ersten Jahren nach dem 2. Weltkrieg qualifiziert, jedenfalls sind spätestens seit dem Ende des Besatzungsregimes die alliierten Vorbehaltsrechte nur noch völkerrechtlich zu erfassen. Sie beschränken die völkerrechtliche Stellung der Bundesrepublik (und der DDR) in gravierender Weise, aber mit ihrer Hilfe kann kein staatsrechtliches Band zwischen den beiden deutschen Staaten geknüpft werden.

Bei unserer völkerrechtlichen Betrachtung bleibt außer Betracht, ob man das Festhalten an der Vier-Mächte-Verantwortung für Deutschland als Ganzes noch für politisch sinnvoll hält. Die Existenz eines Rechtstitels, über den im übrigen nicht einseitig verfügt werden kann, ist gerade im Völkerrecht nicht davon abhängig, ob von ihm Gebrauch gemacht werden kann und ob das Festhalten politisch opportun erscheint. Im übrigen muß gerade die Lösung der deutschen Probleme mehr unter säkularen als unter Tages-Gesichtspunkten gesehen werden.

${ }^{36}$ V.gl. u. a. K. Doehring, Das Staatsrecht der Bundesrepublik Deutschiland, 1976, $62 \mathrm{ff}$.

${ }^{37}$ Daß dile Vorbehaltsrechte den Vier Mächten nicht die Befugnis geben, ohne die Zustimmung deutscher Repräsentanten zu entscheiden, ergibt sich teils aus iden eingegangenen Verträgen (vgl. Art. 7 des Deutschlandvertrages), teils aus dem Selbstbestimmungsrecht, teils aus Grundprinzipien der Völkerrechtsordnung wie der souveränen Gileichheit der Staaten, die nicht auf Dauer von der Siegerposition aus dem 2. Weltkrieg lausgeschaltet werden können.

38 Vgl. hierzu etwa F. Klein, Aktuelle Probleme der Vier-MächteVenantwortung für Gesamtdeutschland, in: Festschrift fürr Hermann Jahrreiß zum 80. Geburtstag, 1974, $97 \mathrm{ff}$., $103 \mathrm{ff}$., und jetzt C. Tomuschat, Die rechtliche Bedeutung der Vier-Mächte-Venantwortung, in: Fünf Jahre Grundvertragsurteil (Anm. 13), $71 \mathrm{ff}$. 
6. Zum vorläufigen Abschluß der völkerrechtlichen Bestandsaufnahme ist noch ein Hinweis zum Selbstbestimmungsrecht angebracht. Seine Bedeutung und seine Tragweite sind umstritten $^{39}$. Kein Zweifel kann jedoch daran bestehen, daß die Forderung nach Selbstbestimmung einer früher vereinten und nunmehr geteilten Nation grundsätzlich völkerrechtlich zulässig ist. Das deutsche Volk in seiner Gesamtheit hatte seit dem Ende des zweiten Weltkrieges noch niemals Gelegenheit, sich ausdrücklich für oder gegen die Wiederherstellung staatlicher Einheit auszusprechen. Wenn immer von Wiedervereinigung Deutschlands die Rede ist, führt der Hinweis auf frühere Einheit allein nicht weiter, sondern es muß auch nach dem Willen zur Einheit als Element des Selbstbestimmungsrechts gefragt werden. Solange das deutsche Volk nicht in freier Entscheidung auf seine Einheit verzichtet hat, ist die Forderung nach Selbstbestimmung legitim und völkerrechtlich zulässig.

\section{Gemengelagen von Staats- und Völkerrecht}

Soweit ich sehe, ist kein Völkerrechtler mehr der Auffassung, „innerdeutsche" Fragen und dabei insbesondere die Beziehungen der Bundesrepublik zur DDR könnten durchweg nur nach Staatsrecht und ohne direkte Anwendung des Völkerrechts beantwortet und beurteilt werden. Dieser eindeutige Befund wird durch Thesen, nach denen eine völkerrechtliche Anerkennung der DDR nicht in Betracht komme, daß die DDR für die Bundesrepublik nicht Ausland sei oder nach denen die innerdeutsche Grenze keine völkerrechtliche Grenze sei, verdeckt. Aber es gibt keine rechtlich vertretbare Möglichkeit, das Völkerrecht bei der Betrachtung der Rechtslage zwischen den beiden deutschen Staaten auszuschalten.

In der Diskussion der letzten Jahre ist jedoch - etwa von Ress $^{40}$ und Steinberger ${ }^{41}$ - verstärkt und mit guten Gründen darauf hingewiesen worden, daß Gemengelagen von Völkerrecht und staatlichem Recht in der geschichtlichen Entwicklung

39 Vgl. aus der neueren Literatur etwa E. Menzel, Die Ostverträge von 1970 und das Selbstbestimmungsrecht der Völker, ZRP 1970, 35; K. Rabl, Das Selbstbestimmungsrecht der Völker, 2. Aufl. 1973; K. Doehring, Das Selbstbestimmungsrecht der Völker als Grundsatz des Völkerrechts, 1974; D. Blumenwitz, Sellbstbestimmung und Menschenrechte im geteilten Deutschland, JIR Bd. 17 (1974), 11 ff.; $D$. Thürer, Das Selbstbestimmungsrecht der Völker, 1976.

40 G. Ress, Die Rechtslagie Deutschlands (oben Anm. 1), $160 \mathrm{ff}$.

${ }^{41} H$. Steinberger in: Finis Germaniae (oben Anm. 1), $94 \mathrm{f}$. 
keineswegs selten anzutreffen sind. Sowohl im Vorfeld von Staatsbildungen als auch beim Verfall bisheriger staatlicher Einheit treffen wir auf eine Vielzahl rechtlicher Regelungen und Erscheinungen, die sich einer rigorosen und vollständigen Zuordnung sei es zum Völkerrecht, sei es zum staatlichen Recht entziehen. Zwischen der amerikanischen Unabhängigkeitserklärung von 1776 und der Annahme der amerikanischen Verfassung oder auch im Deutschen Bund und zuvor im sich auflösenden Deutschen Reich mischten sich völkerrechtliche und staatsrechtliche Elemente. In unserem Jahrhundert bieten die Auflösung des Britischen Empire und die Dekolonisierung reiches Anschauungsmaterial für Prozesse, in denen staatsrechtliche Bindungen von völkerrechtlichen Entwicklungen durchsetzt und partiell ersetzt werden. Ein solcher Prozeß kann sich über Jahrzehnte hinziehen, an seinem Ende steht in den meisten Fällen die vollständige Ersetzung der zuvor staatsrechtlichen Elemente durch rein völkerrechtliche Beziehungen zwischen souveränen Staaten. In einer ganz anderen Richtung können wir bei der Entwicklung der Europäischen Gemeinschaften sehen, wie das Gemeinschaftsrecht nach verbreiteter Ansicht weder dem Völkerrecht angehört noch die Qualität staatlichen Rechts (sei es der Mitgliedstaaten, sei es eines europäischen Bundesstaates) hat ${ }^{42}$. Die historischen und die aktuellen Beispiele zeigen, daß die gängigen Vorstellungen einer sauberen Scheidung des zwischenstaatlichen Rechts vom innerstaatlichen Recht nicht immer eine angemessene Erfassung der Phänomene ermöglichen.

Läßt sich derartiges Anschauungsmaterial für das heutige „Deutschland" mit Gewinn auswerten? Gibt es auch bei uns und insbesondere im Verhältnis zwischen der Bundesrepublik und der DDR eine Gemengelage aus Staats- und Völkerrecht? Diese Frage ließe sich relativ einfach beantworten, wenn beide deutsche Staaten übereinstimmende Auffassungen verträten, aber der Dissens ist unverkennbar und in der vorhersehbaren Zukunft in vielen Punkten unauflösbar.

Angesichts dieses Dissenses könnte es angebracht erscheinen, durch eine Bestandsaufnahme der maßgeblichen Rechtsnormen und eine Realanalyse der tatsächlichen Gegebenheiten mehr Klarheit darüber zu schaffen, ob zwischen den beiden Staaten neben dem Völkerrecht auch noch Staatsrecht erkennbar ist und praktiziert wird. Eine solche Detailprüfung führt jedoch nicht zu sicheren Ergebnissen, da bestehende Besonderheiten

42 Vgl. nur H. P. Ipsen, Europäisches Gemeinschafitsrecht, 1972, $6 \mathrm{ff}$., $182 \mathrm{ff}$; L.-J. Constantinesco, Das Recht ider Europäischen Gemeinschaften, Bd. I, 1977, $654 \mathrm{ff}$. 
im ,innerdeutschen“ Verhältnis wohl durchweg auch völkerrechtlich erklärt werden können ${ }^{43}$. Die Existenz von Besonderheiten sagt ja nichts darüber aus, daß es sich deshalb um staatsrechtliche Bindungen oder Regeln handeln müsse, denn auch zwischen Völkerrechtssubjekten können exzeptionelle Regeln und Praktiken bestehen oder vereinbart werden. Die Frage lautet: Gibt es zwischen der Bundesrepublik und der DDR Rechtsbeziehungen, die bei Anlegung anerkannter Maßstäbe nur als staatsrechtlich qualifiziert werden können? Diese Frage ist $\mathrm{m}$. E. eher zu verneinen als zu bejahen ${ }^{44}$.

So komme ich angesichts einer unbefriedigenden Situation zu dem unbefriedigenden Ergebnis, daß die denkbare Gemengelage von Staats- und Völkerrecht diskutabel, aber nicht mit Sicherheit nachweisbar ist. Wir befinden uns in einem historischen Prozeß, und unser derzeitiger Standort in diesem Prozeß wie sein weiterer Verlauf sind unklar und umstritten. Aber es spricht viel dafür, daß wir das Stadium staatsrechtlicher Bindungen zwischen den beiden Staaten in Deutschland hinter uns gelassen haben. Besonderes gilt für Berlin, dazu später.

\section{Hauptprobleme im Uberblick}

\section{Das Wiedervereinigungsgebot}

Es kann kein Zweifel daran bestehen, daß eine auf Wiedervereinigung gerichtete deutsche Politik völkerrechtlich zulässig ist. $\mathrm{Zu}$ dieser Feststellung bedarf es keiner subtilen Untersuchung der rechtlichen Bedeutung und Auslegung der sogenannten Briefe zur deutschen Einheit ${ }^{45}$ oder der "Gemein-

${ }^{43}$ Das gilt m. E. u. a. auch für die Einrichtung ,Ständiger Vertretungen" anstelle von Botschaften. Vgl. hierzu insibes. D. Blumenwitz, Die Errichtung Ständiger Vertretungen im Lichte des Staatsund Völkernechts, $1975 ; H$. H. Mahnke, Die Ständigen Vertretungen der beiden Staaten in Deutschland, JIR Bd. 17 (1974), 36 ff.

44 Natürlich gibt es Regeln und Praktiken, die auch rund vielleicht besser staatsrechtlich, als dem Staatsnecht zugehörig, gedeutete werden können, aber es ist zweifelhaft, ob sie nur staatsrechtlich oder micht auch völkernechtlich erklärt wenden können. Und selbst wenn das ider Fall wäne, könnte auf einzelne staatsnechtliche Elemente nicht unbedingt ein fortbestehendes Reichsdiach gesetzt werden.

45 Brief des Außenministers der Bundesrepublik an den sowjetischen Außenminister vom 12. 8. 1972 zum Moskauer Vertrag, Brief des Bundesministens für besondere Aufgaben an den Staatssekretär bøim Ministernat der DDR vom 21. 12. 1972 zum Grundlagenvertrag; dazu D. Blumenwitz in: Finis Germaniae (oben Anm. 1), $47 \mathrm{ff}$. 
samen Entschließung" des Bundestages vom 17. Mai $1972^{46}$. Es genügen vielmehr die folgenden Hinweise: Bei Abschluß der Ostverträge war den Partnern der Bundesrepublik deren Ziel, auf friedliche Weise zur Wiederherstellung gesamtdeutscher Staatlichkeit zu gelangen, eindeutig bekannt. Zur „Geschäftsgrundlage“ der Verträge gehört es, daß alle Beteiligten ihre politischen Grundpositionen und Zielsetzungen aufrechterhalten haben ${ }^{47}$; das hat u. a. in der Präambel des Grundvertrages einen Niederschlag gefunden. Schließlich sind die Verträge unter Berücksichtigung des allgemeinen Völkerrechts zu interpretieren ${ }^{48}$, und dieses läßt sicher eine Politik zu, die auf Wiederherstellung früherer staatlicher Einheit unter Berücksichtigung des Selbstbestimmungsrechts gerichtet ist. $\mathrm{DaB}$ sich auch die Mittel einer Wiedervereinigungspolitik im Rahmen des Völkerrechts halten müssen und damit jede Gewaltanwendung oder Drohung mit Gewalt ausgeschlossen ist, ist ebenfalls zweifelsfrei. So wäre $z$. B. die staatliche Unterstützung von Umsturzbewegungen im jeweils anderen deutschen Staat nicht mit dem völkerrechtlichen Interventionsverbot zu vereinbaren.

Während eine Wiedervereinigungspolitik völkerrechtlich nur zulässig, aber nicht notwendig ist, ist sie verfassungsrechtlich geboten. So das Bundesverfassungsgericht ${ }^{49}$. Hier liegen schwierige Probleme. Die grundsätzliche Aussage des Gerichts, daB es ein verfassungsrechtliches Wiedervereinigungsgebot gebe, läßt sich mit guten Gründen vertreten und aus den einschlägigen, viel zitierten Bestimmungen des Grundgesetzes ableiten. Schwierig wird es, wenn die Grenze zwischen dem politischen Gestaltungsspielraum der Bundesorgane und den verfassungsrechtlichen Beschränkungen gezogen werden soll. Im Urteil über den Grundlagenvertrag hat das Bundesverfassungsgericht erneut betont, es müsse ,den zu politischem Handeln berufenen Organen der Bundesrepublik überlassen bleiben zu entscheiden, welche Wege sie zur Herbeiführung

${ }^{46}$ Bundestags-Protokoll 10960 f., Bull. Nr. 72/1972; auch abgedruckt bei Cieslar-Hampel-Zeitler, a. a. O. (oben Anm. 21), $351 \mathrm{f}$. sowie bei Dolzer u. Papadimitriu, Völkerrechtliche Praxis der Bundesrepublik in den Jahren 1971 und 1972, ZaöRV 34 (1974), 503 ff., $546 \mathrm{ff}$.

${ }^{47}$ Grundlegend zur Auslegung des Moskauer Vertrages $H$. Steinberger, Völkerrechtliche Aspekte des deutsch-sowjetischen Vertragswerkes vom 12. August 1970, ZaöRV 31 (1971), $63 \mathrm{ff}$.

${ }^{48}$ Hierzu R. Bernhardt, Die Auslegung völkernechtlicher Verträge, $1963,136 \mathrm{ff}$.

${ }^{48}$ BVerfGE 5, 85 (126 ff.); 12, 45 (51 f.); 36, 1 (17 ff.). 
der Wiedervereinigung als politisch richtig und zweckmäßig ansehen"50. Diese richtige Maxime wird jedoch $\mathrm{m}$. E. in derselben Entscheidung mißachtet. Ich zitiere einige Passagen aus der Entscheidung:

„Die klare Rechtposition jeder Regierung der Bundesrepublik Deutschland ist: Wir haben von der im Grundgesetz vorausgesetzten, in ihm ,verankerten Existenz Gesamtdeutschlands mit einem deutschen (Gesamt-)Staatsvolk und einer (gesamt-)deutschen Staatsgewalt auszugenen."

„Wenn heute von der ,deutschen Nation' gesprochen wird, die eine Klammer für Gesamtdeutschland sei, so ist dagegen nichts einzuwenden, wenn darunter auch ein Synonym für das ,deutsche Staatsvolk' verstanden wird, an jener Rechtsposition also festgehalten wird und nur aus politischen Rücksichten eine andere Formel verwandt wird.“

Weiter heißt es:

Verfassungsgemäß sei nur die Annahme, daß die Viermächte-Verantwortung für Gesamtdeutschland „eine weitere Rechtsgrundlage für das Bemühen der Bundesregierung um Wiedervereinigung bildet, nämlich eine ,völkerrechtliche" neben der staatsrechtlichen".

U. a. dürfe der „Handel zwischen der Bundesrepublik Deutschland und der Deutschen Demokratischen Republik... im Zuge der Fortentwicklung kein Außenhandel werden; $d . h$. es darf in diesem Bereich keine Zollgrenze vereinbart werden" ${ }^{\prime 51}$.

Dies und einiges mehr hat das Bundesverfassungsgericht zu den tragenden Gründen seiner Entscheidung und damit für verbindlich erklärt ${ }^{52}$. Es hat damals, im Jahre 1973, zweifellos zur politischen Befriedung in der Bundesrepublik beigetragen. Trotzdem verdient die Entscheidung die überwiegend vorgebrachte herbe Kritik. Die Entscheidung zwingt, wenn man ihre Bindungswirkung ganz ernst und streng nimmt, zur Negierung des völkerrechtlichen Befundes. Nach ihr muß auch dann von einer fortbestehenden gesamtdeutschen Staatlichkeit ausgegangen werden, wenn nichts mehr davon erkennbar ist. Der Gebrauch des Begriffs ",deutsche Nation" darf nur dann aus politischen Rücksichten und als Formel verwandt werden,

50 BVierfGE 36, 1 (17).

51 Ibid. S. 19, 33.

52 Ibid. S. 36. 
wenn damit in Wahrheit (wenn auch verdeckt) das deutsche Staatsvolk gemeint ist. Und wenn alle politische Vernunft und internationale Bindungen, etwa Gründe europäischer Integration, in Zukunft dafür sprechen sollten, zwischen den beiden deutschen Staaten eine Zollgrenze zu ziehen ${ }^{53}$, dürfte das nach dem Spruch des Bundesverfassungsgerichts nicht geschehen. Schließlich ist die Aussage des Gerichts, es dürfe auf keinen Rechtstitel aus dem Grundgesetz verzichtet werden, der mit dem Ziel der Wiedervereinigung eingesetzt werden könnte, sowohl unklar als auch gefährlich. Ich meine, daß weder die Art, in der die Regierung damals das Bundesverfassungsgericht zeitlich unter Druck gesetzt hat, noch seine Reaktion Beifall verdient ${ }^{54}$. Vielmehr ist festzustellen, daß damals sowohl die Verfassungsgerichtsbarkeit als auch die Notwendigkeiten langfristiger Deutschlandpolitik im Rahmen der Verfassung eine Schlappe erlitten haben.

Im Ergebnis gibt es, wenn man das Wiedervereinigungsgebot als rechtlich bindendes Verfassungsgebot ansieht ${ }^{55}$, drei Möglichkeiten, dieses Gebot auszulegen. Erstens können Regierung und Parlament einer Vielzahl von Einzelbindungen unterliegen, die ihre Deutschlandpolitik drastisch beschränken. Zweitens könnte angenommen werden, daß nur wenige und drastische $\mathrm{Maßnahmen,} \mathrm{insbesondere} \mathrm{eine} \mathrm{ausdrückliche} \mathrm{völkerrechtliche}$ Anerkennung der DDR und ihrer Auslandseigenschaft durch die Bundesrepublik, ausgeschlossen seien. Drittens könnte selbst eine solche Anerkennung zulässig sein, wenn nämlich die politisch verantwortlichen Kräfte mit vertretbaren Gründen zu dem Ergebnis kommen, daß die angestrebte Wiedervereinigung allenfalls über eine zeitweilige volle Trennung $\mathrm{zu}$ erreichen $\operatorname{se}^{56}$. Die dritte Interpretation des Wiedervereinigungsgebots

${ }^{53}$ Für die Europäischen Gemeinschaften ist das Protokoll über den innerdeutschen Handel maßgeblich. Dazu etwa C.-D. Ehlermann u. a., Handelspartner DDR - Innerdeutsche Wirtschaftsbeziehungen, 1975, $205 \mathrm{ff}$.; R. Biskup, Deutschlands offene Handelsgrenze, 1976. Nach dem Urteil des Gerichtshofs der Europäischen Gemeinschiaften vom 27. 9. 1979 (Rechtssache 23/79) ist der Begriff "Ausfuhr" in gemeinschaftsrechtlichen Bestimmungen ,dainin auszulegen, daß er Handelsgeschäfte nicht enfaßt, die zum irineideutschen Handel im Sinne des Protokolls über iden innendeutschen Handel und die damit zusammenhängenden Fragen vom 25. März 1957 gehönen".

${ }^{54}$ Hierzu E. Friesenhahn, Hüter der Verfassung?, ZRP 1973, $188 \mathrm{ff}$.

35 Dazu jetat G. Ress, Das Wiedervereinligungsgebat des Grundgesetzes, in: Fünf Jahre Grundvertragsurteil (oben Anm. 13), 265 ff.

${ }^{50}$ D. Murswiek, Die verfassunggebende Gewalt nach dem Grundgesetz für die Bundesrepublik Deutschland, 1978, 113, stellt zutref- 
erscheint mir nach 30 Jahren Grundgesetz zutreffend, auch wenn es zu ihren Konsequenzen gehört, daß die verfassungsgerichtliche Kontrolle weitgehend ausfällt.

\section{Die Deutschen und ihre Staatsangehörigkeit}

Die Frage nach der Staatsangehörigkeit oder den Staatsangehörigkeiten der heute auf dem Gebiet des (ehemaligen?) Deutschen Reiches nach dem Stande vom 31. Dezember 1937 wohnenden Deutschen gehört zu den zentralen Themen sowohl der politischen Auseinandersetzung zwischen Ost und West als auch der wissenschaftlichen Diskussion ${ }^{57}$. Fassen wir kurz zusammen:

Schon vor der Ersetzung der DDR-Verfassung von 1949, die "nur eine deutsche Staatsangehörigkeit" zuließ, durch die Verfassung von 1968 setzte sich in der DDR die These durch, mit der Staatsgründung im Jahre 1949 sei ein neuer Staat mit einer eigenen Staatsangehörigkeit entstanden, die weder mit der Staatsangehörigkeit in der Bundesrepublik noch mit einer nicht mehr existierenden gesamtdeutschen Staatsangehörigkeit zusammenfalle. Diese These hat im Staatsbürgerschaftsgesetz der DDR von 1967 ihren amtlichen Niederschlag gefunden. Hand in Hand mit dieser These geht der Vorwurf an die Adresse der Bundesrepublik, sie handele völkerrechtswidrig, indem sie fremde Staatsbürger - eben die der DDR - als eigene Staatsangehörige in Anspruch nehme und sich dadurch u. a. in die inneren Angelegenheiten eines anderen Staates einmische ${ }^{58}$.

fend fest, daß Art. 146 GG auch dann noch sinnvoll und anwendbar ist, wenn es derzeit ein gesamtdeutsches Staatsvolk nicht mehr gebien sollite.

57 Vgl. neuerdings etwa $K$. Doehring, Das Staatsrecht der Bundesrepublik, 1976, 93 ff.; G. Zieger, Die Staatsangehörigkeit im geteilten Deutschland, 1971; ders., Deutsche Staatsangehörigkeit und Drittstaaten, in: Internationales Recht und Wirtschaftsordnung, Festschrift für F. A. Mann, 1977, 505 ff.; ders., Das Problem der deutschen Staatsangehörigkeit, in: Fünf Jahre Grundvertragsurteil des Bundesverfiassungsgerichts (oben Anm. 13), $189 \mathrm{ff}$. (mit Diskussion S. $223 \mathrm{ff}$.); H. $v$. Morr, Der Bestand der deutschen Staatsangehörigkeit nach dem Grundvertrag, 1977 (Schriften zum Offentlichen Recht. Bd. 330); W. Seiffert, „Deutsche" und „DDR-Bürger", Zur Problematik der Staatsangehönigkeit in den Beziehungen zwischen den beiden Ideutschen Stalaten, Deutschland Archiv 11. Jg. (1978), $1271 \mathrm{ff}$. Zahlneiche weitere Nachweise in diesen Publikationen.

58 Vor allem G. Riege hat mehrfach zu den Staatsangehörigkeitsfragen aus der Sicht der DDR S.tellung genommen (Nachweise bei H. v. Morr, a. a. O. - Anm. 57 - 119 f.), vgl, zuletzt G. Riege, Staat- 
Ein ähnlicher Vorwurf wird von polnischer Seite erhoben ${ }^{59}$. Nach ihr sind die Gebiete östlich der Oder und Neiße in vollem Umfang und ohne rechtliche Beschränkungen polnisches Staatsgebiet, und die dort wohnenden Personen sind - im Rahmen des polnischen Rechts - polnische Staatsangehörige. Ehemalige Deutsche in diesen Gebieten dürften, jedenfalls soweit sie die polnische Staatsbürgerschaft besäßen, nicht von der Bundesrepublik in Anspruch genommen werden. Bei der gegenteiligen westdeutschen Praxis und der Aufrechterhaltung von Art. 116 Abs. 1 des Grundgesetzes handele es sich um ,juristische Aggression". Dem Ausdruck ,juristische Aggression" begegnen wir in der östlichen Polemik neuerdings nicht selten ${ }^{60}$; dabei dürfte kein ernsthafter Völkerrechtler bestreiten können, daß der Begriff der Aggression hier in einem maßlos übersteigerten und völkerrechtlich unhaltbaren Sinn gebraucht wird. Mit dem Vorwurf wird dem sogenannten juristischen Aggressor absichtlich eine besonders verwerfliche Haltung attestiert.

So einfach wie die östliche Seite können wir es uns in der Bundesrepublik nicht machen. Einmal und vor allem haben wir außer den allgemeinen Überlegungen zur Rechtslage Deutschlands Art. 16 und Art. 116 GG zu beachten. Weiter haben wir die Fortgeltung des Reichs- und Staatsangehörigkeitsgesetzes von $1913 \mathrm{zu}$ berücksichtigen. Andererseits ist auch bei uns ein Unbehagen an einer rigorosen und konsequenten Inanspruchnahme aller Deutschen als Angehörige der Bundesrepublik unverkennbar. Es gibt verschiedene Vorschläge zur Änderung der geltenden Vorschriften, die den derzeitigen Zustand überwinden wollen ${ }^{61}$.

liche Souveränität und Staatsbürgerschaftsrecht, Neue Justiz 1978, $98 \mathrm{ff}$., sowie G. Riege und H.-J. Kulke, Nationalität: deutsch Staatsbürgerschaft: DDR, 1979.

59 Vgl. L. Janicki, Legal Problems Involved in the Realization by the Federal Republic of Germany of the Treaty with Poland Dated 7th December 1970, Polish Western Affairs 18 (1977), $76 \mathrm{ff} ., 88 \mathrm{ff}$. (Die Interpretation oder gar der Text von Art. 116 Abs. 1 GG müsse geändert werden, um mit dem Warschauer Vertrag übereinzustimmen.)

${ }^{60}$ Z. B. im Lehrbuch Staatsrecht der DDR, 1977, 158; vgl. weiter etwa L. Janicki, Die Problematik des Staatsgebiets und der Staatsangehörigkeit im Rechtssystem der BRD, in: Volksrepublik Polen - Bundesrepublik Deutschiland, Probleme der Normalisierung gegenseitiiger Beziehungen, 1972, $136 \mathrm{ff}$., $146 \mathrm{ff}$.

${ }_{61}$ Vigl. vitwa K. M. Meessen, Verfassungsrechtliche Grenzen viner Neuregelung der Staatsangehörigkeit im geteilten Deutschland, JZ 72, 637 ff. (s. auch JZ 73, 117 f.); ders., Das Problem der deutschen Staatsangehörigkeit nach dem Grundvertrag, Europa Archiv 1973, 
Die Diskussion wird durch zwei Faktoren erschwert: Durch die politische und ideologische Aufladung des Staatsangehörigkeitsbegriffs und durch die internationalen Auswirkungen des primär innerdeutschen Streits. $\mathrm{Zu}$ beiden Faktoren nur einige Anmerkungen:

Natürlich kann es keinen Staat ohne Staatsangehörige geben. Aber der Gehalt der Staatsangehörigkeit kann unterschiedlich gesehen und bestimmt werden. Wenn man etwa in der Staatsangehörigkeit primär den Anknüpfungspunkt für weitere Rechte und Pflichten sieht, die konkret aus der jeweiligen Rechtsordnung abgeleitet werden müssen, sind diese konkreten Rechte und Pflichten wichtiger als die formale Staatsangehörigkeit. Viel stärker als in der Bundesrepublik wird aber in der DDR und bei ihren Verbündeten die Staatsbürgerschaft nicht nur als konstitutives Element der Staatlichkeit, sondern als ein besonderer Status mit allgemeinen Rechten und Pflichten im Sinne sozialistischer Einbindung des Einzelnen in die Gemeinschaft gesehen ${ }^{62}$. Die Verneinung einer eigenen Staatsbürgerschaft der DDR oder auch nur die zusätzliche Inanspruchnahme der DDR-Bürger durch die Bundesrepublik verletzt hiernach die Eigenständigkeit des dortigen Staates.

Der internationale Faktor, der in unserem Zusammenhang eine Rolle spielt, ist die unbestrittene Abhängigkeit des diplomatischen Schutzes von der Staatsangehörigkeit. Jeder Staat kann sich international, gegenüber anderen Völkerrechtssubjekten, grundsätzlich und mit Aussicht auf Erfolg nur für seine eigenen Staatsangehörigen einsetzen und nur ihre Rechte im Wege des diplomatischen Schutzes verteidigen. Wer ist nun gegenüber einem dritten Staat für den diplomatischen Schutz eines Dresdners, eines Leipzigers oder eines Magdeburgers zuständig? Nur die DDR, nur die Bundesrepublik, oder beide? Bekanntlich haben Konsularverträge der DDR mit verschiedenen Staaten zu Kontroversen geführt ${ }^{63}$; ein Konsularvertrag zwi-

515 ff.; J. Isensee, Die deutsche Staatsangehörigkeit (Art. 116 GG), in: Finis Germaniae (Anm. 1), 99 ff., vgl. auch H. v. Morr, a.a. O. (Anm. 57), bei dem aber unklar bleibt, welche Anderungen des geltenden Rechts ohne Verfassungsänderung möglich sind (vgl. S. 37), und dessen Vorschlag, die Staatsangehörigkeit in den Bundesiändern zwecks Vermittlung der deutschen Staatsangehörigkeit zu beleben, wenig übrerzeugend ist.

${ }^{62}$ Vgl. Staatsrecht der DDR (Anm. 60), $149 \mathrm{ff}$.

${ }^{63}$ Vigl. J. A. Frowein, Das Individuum als Rechtssubjekt im Konsularnecht; G. Zieger, Deutsche Staatsangehörigkeit und Drittstaaben, beides in: Internationales Recht und Wirtschaftsordnung, Festschrift für F. A. Mann, 1977, 367 ff., 505 ff. (519 ff.); K. Hailbronner, 
schen Frankreich und der DDR scheint vorerst an diesen Schwierigkeiten gescheitert zu sein.

Eine gesetzliche oder vertragliche Lösung der Divergenzen könnte zwar wünschenswert sein, doch halte ich sie in absehbarer Zeit sowohl wegen des emotionalen Gehalts als auch wegen der sachlichen Schwierigkeiten für unwahrscheinlich. Daher ist die Frage zu beantworten, ob der von östlicher Seite behauptete Versto $B$ der westdeutschen Gesetze und der staatlichen Praxis gegen das Völkerrecht wirklich besteht. Das setzt eine Klärung der Rechtslage nach unserem Recht voraus. M. E. sind Lösungen möglich und angezeigt, die dem Verfassungsrecht der Bundesrepublik und dem Völkerrecht gleichermaßen gerecht werden.

Es wäre weder mit dem allgemeinen Völkerrecht noch mit dem Grundlagenvertrag vereinbar, wenn die Bundesrepublik die Existenz einer eigenen Staatsbürgerschaft der DDR und ihr Recht bestreiten würde, sich für ihre Staatsbürger einzuset$z^{6}{ }^{64}$. Man kann nicht einem anderen Staat versprechen, ihn als Staat und seine Unabhängigkeit und Selbständigkeit ,in seinen inneren und äußeren Angelegenheiten" zu respektieren, man kann nicht vertraglich versichern, keiner der beiden deutschen Staaten könne den anderen international vertreten (so der Grundlagenvertrag zwischen der Bundesrepublik und der DDR), und zugleich dem Vertragspartner das Recht absprechen, eigene Staatsangehörige zu haben und sie diplomatisch zu vertreten. Diesen Befund kann man nicht durch Hinweise auf die laut Präambel des Grundvertrages fortbestehenden Meinungsverschiedenheiten über die nationale Frage oder auf den westdeutschen Protokollvermerk zur Staatsangehörigkeit ausräumen, denn zu eindeutig sind die Aussagen über die Staatlichkeit der DDR und ihre Respektierung.

Die Frage kann nur lauten: Haben die Bewohner der DDR (und Deutsche jenseits der Oder und Neiße) auch einen gesicherten Status nach dem in der Bundesrepublik geltenden Recht und ist ein derartiger Status mit dem Völkerrecht vereinbar? Beide Fragen sind zu bejahen.

Eine genauere Betrachtung des geltenden Rechts der Bundesrepublik ergibt $m$. E., daß es die Deutschen mit Wohnsitz auBerhalb der Bundesrepublik gar nicht in dem Sinne als Staats-

Deutsche Staatsangehörigkeit und diplomatischer Schutz durch die BRD, JZ 1975, 596 ff. - Zuletzt wurde Anfang September 1979 ein Konsularvertrag der USA mit der DDR unterzeichnet, vgl. Neue Zürcher Zeitung vom 6.9.1979, S.2, sowie Archiv der Gegenwart 1979, S. 22854.

4 Vgl. auch G. Ress, a. a. O. (Anm. 1), $209 \mathrm{ff}$. 
angehörige in Anspruch nimmt, daß sie Träger der normalen staatsbürgerlichen Rechte und Pflichten sind. Darauf hat zuletzt Ulrich Scheuner aufmerksam gemacht ${ }^{65}$. Wehrpflicht, Steuerpflicht und andere Grundpflichten der Staatsangehörigen treffen die Deutschen jenseits der Grenze nicht. Selbst wenn Gesetze ihren Geltungsbereich nicht ausdrücklich auf das Bundesgebiet beschränken, sind sie in vielen Fällen in diesem Sinne zu interpretieren.

Deutsche im Sinne von Art. 116 Abs. 1 GG sind fast alle Bewohner der DDR und eine nicht exakt feststellbare Zahl von Bewohnern jenseits der Oder und Neiße. Sie haben ein verfassungsmäßiges Recht darauf, von den Organen der Bundesrepublik als Deutsche behandelt zu werden. Die Ausübung dieses Rechts ist in der Regel von der Anwesenheit in der Bundesrepublik abhängig ${ }^{66}$. Hier genießen alle Deutschen im Sinne des Grundgesetzes dessen Schutz, sie können alle Grundrechte in Anspruch nehmen. Das ist völkerrechtlich unbedenklich. Wir haben es mit einem besonderen Inländerstatus zu tun, der legitimerweise sowohl an geschichtliche Entwicklungen als auch an die fortbestehende gesamtdeutsche Problematik anknüpft. Im Grundvertragsurteil findet sich im übrigen ein wichtiger Hinweis auf die Möglichkeiten eines individuellen Verzichts auf gewisse Rechtspositionen ${ }^{67}$. Diesen Gesichtspunkt sollte man weiter verfolgen und dabei die individuelle Entscheidung und Selbstbestimmung im Einklang mit den Menschenrechten betonen. Das heißt, daß nur der als Deutscher im Sinne des Grundgesetzes angesehen werden muß, der diesen Status in Anspruch nehmen will.

${ }^{65} U$. Scheuner, Die deutsche einheitliche Staatsangehörigkeit: ein fortdauerndes Problem der deutschen Teilung, Europa Archiv 1979, 345. Vgl. auch $R$. Bernhardt, Der Begriff des Deutschen und die deutsche IStaatsangehörigkeit nach dem Recht der Bundesrepublik, in: Staatsiangehörigkeit - Soziale Grundrechte - Wirtschaftliche Zusammenarbeit, 1976, 16 ff., 24 ff.; W. Seiffert, a. a. O. (Anm. 57), 1275.

66 In der DDR wohnende Deutsche können sich zwar gegenüber den Organen der Bundesrepublik grundsätzlich auf die Grundrechte bemufen, aber der Wohnsitz außerhalb des Bundesgebietes läßt doch gewisse Sonderregieln zum Nachteil der Betroffenen zu; vgl. hinsichtlich der Verfügung über Guthaben in der Bundesrepublik Urteil des BVerwG vom 27. 10. 1978, BVerwGE 57,40.

${ }^{67}$ BVerfGE 36,1 (30): „Dazu gehört insbesondere, daß ein Deutscher, wann immer er in den Schutzbereich der staatlichen Ordnung der Bundesrepublik gelangt - solange er nicht darauf verzichtet -, einen Anspruch darauf hat, nach dem Recht der Bundesrepublik Deutschland vor den Gerichten sein Recht zu suchen." 
Das internationale Problem des diplomatischen Schutzes läßt sich ebenfalls lösen. Wenn man davon ausgeht, daß die DDR eigene Staatsbürger hat und ihnen diplomatischen Schutz angedeihen lassen kann, kommt ein Schutz durch die Bundesrepublik solange nicht in Betracht, wie der Betroffene nicht ausdrücklich um den Schutz der Bundesrepublik nachsucht, etwa indem er die diplomatische Vertretung der Bundesrepublik in einem dritten Staat aufsucht. Wenn er um diesen Schutz nachsucht, müssen sich die Organe der Bundesrepublik im Rahmen des völkerrechtlich Zulässigen (und des politisch Möglichen oder Vertretbaren) für ihn einsetzen ${ }^{68}$. Dritte Staaten sind berechtigt, in dem Bekenntnis zur Bundesrepublik das "genuine link" zu sehen, das nach heute herrschender Auffassung ${ }^{68}$ für die Ausübung des diplomatischen Schutzes von Bedeutung ist ${ }^{70}$, und ein etwaiger Widerspruch der DDR ist insoweit unbegründet. Wieweit jedoch dritte Staaten verpflichtet sind, den diplomatischen Schutz bisheriger DDR-Bewohner durch die Bundesrepublik anzuerkennen, ist eine schwierige völkerrechtliche Frage, auf die hier nicht einzugehen ist.

Diese Skizze der staatsangehörigkeitsrechtlichen Probleme ${ }^{71}$ weist zweifellos noch Unklarheiten und Schwierigkeiten auf. Eine davon betrifft den Inlandsbegriff in § 25 RuStAG. Darauf und auf einige andere Probleme ist später kurz zurückzukommen. Im übrigen kann es nicht die Aufgabe dieses Berichts sein, vollständige Lösungsvorschläge zu machen.

68 Vgl. zu der Frage, ob es einen (verfassungsnechtlichen?) Anspruch auf diplomatischen Schutz gibt, W. K. Geck, Der Anspruch des Staatsbüngens auf Schutz gegenüber dem Ausliand nach deutschem Recht, ZaöRV 17 (1956/57), 476 ff.; K. Doehring, Die Pflicht des Staates zur Gewährung dijplomatischen Schutzes, 1959; E. Klein, Grundrechtliche Schutzpflicht und Auslandsschutz, in: Bundesverfassungsgericht und Ostverträge, 1977, $9 \mathrm{ff}$.

99 Vgl. die Nattebohm-Entscheidung des Internationalen Gerichtshofs, I. C. J. Reports 1955, $44 \mathrm{ff}$. Diese Entscheidung war und ist insoweit umstritten, als damals auch hinsichtlich der allein für den Betroffenen in Betracht kommenden Staatsangehörigkeit ein "genuine link" gefordert wunde; bei konkurrierenden Staatsangehörigkeiten dürfte die Relevanz des "genuine link" kaum zweifelhaft sein.

${ }^{70}$ Vgl. zur Bedeutung des Willens des Einzelnen bei der konsularischen Betreuung J. A. Frowein, a. a. O. (Anm. 63), $368 \mathrm{ff}$.

71 Zum Kollisionisrecht hat $A$. Heldrich, Innerdeutsches Kollisionsrecht und Staatsangehörigkeitsfrage, NJW 78, 2169, neuerdings dazu aufgefordert, die Staatsbürgerschaft der DDR - soweit sie die effektivere ist - zu respektieren. 


\section{Deutschlands Grenzen}

(a) Zur Grenze zwischen der Bundesrepublik und der DDR findet sich im Grundvertragsurteil des Bundesverfassungsgerichts die Feststellung, „daß es sich ... um eine staatsrechtliche Grenze handelt ähnlich denen, die zwischen den Ländern der Bundesrepublik Deutschland verlaufen"72. Diese Äußerung ist besonders viel gescholten worden, andererseits ist beschwichtigend bemerkt worden, das Bundesverfassungsgericht habe ja nur ,ähnlich" gesprochen. Mit Nachdruck ist zu sagen, daß die Aussagen des Bundesverfassungsgerichts in diesem Punkt nicht haltbar sind. Abgesehen davon, daB rechtliche Aussagen sich nach Möglichkeit nicht völlig von der Realität lösen sollten, ist die getroffene rechtliche Aussage als solche nicht zutreffend. Man bedenke u. a., daß Bundeswehr und Bundesgrenzsschutz sich innerhalb des Bundesgebietes ohne wesentliche Rücksichtnahme auf die Ländergrenzen frei bewegen können, Ähnliches dagegen im Verhältnis zur DDR völkerrechtlich und verfassungsrechtlich gleichermaßen unzulässig und zudem faktisch unmöglich wäre. Die Hoheitsrechte beider Staaten und ihrer Organe enden an der gemeinsamen Grenze. Die Grenze zwischen der Bundesrepublik und der DDR ist - so schmerzlich das auch ist - eine völkerrechtliche Grenze. Wenn man am Fortbestehen eines gesamtdeutschen staatlichen Daches über den beiden Staaten festhalten will, mag man die Grenze auch als eine staatsrechtliche bezeichnen, das ist $\mathrm{m}$. E. weder sonderlich nützlich noch bedenklich, wenn man sich darüber klar ist, daß mit dieser Qualifizierung keine nennenswerten Rechtsfolgen verbunden sind ${ }^{73}$.

$\mathrm{Zu}$ den Arbeiten und Ergebnissen der Grenzkommission, insbesondere zu dem Regierungsprotokoll vom 29. November $1978^{74}$ und zu dem weiterhin umstrittenen Grenzverlauf im Bereich der Elbe, ist hier nichts weiter zu sagen. Die Kommission hat kein Mandat zur Änderung, sondern nur zur Feststellung und Markierung der von den Alliierten gezogenen und

72 BVerfGE 36, 1 (26). Vgl. zuletzt E. Klein, Die rechtliche Qualifizierung der innerdeutschen Grenze, in: Fünf Jahne Grundvertragsunteil (Anm. 13), $95 \mathrm{ff}$.

${ }^{73}$ So auch W. A. Kewenig, Auf der Suche nach einer neuen Deutschland-Theorie, DOV 1973, $797 \mathrm{ff}$.

$74 \mathrm{Vgl}$. dazu die Dakumentationen des Bundesministeriums des Innern ,6 Jahre Grenzkommission mit der DDR“ und des Bundesmimisteriums für tinnerdeutsche Beziehungen ,Die Grenzkommission", beide 1979 . 
praktizierten Grenze ${ }^{75}$. Eine Änderung würde in den Vorbehaltsbereich der Siegermächte fallen.

(b) Nun noch kurz zur Oder-Neiße-Grenze ${ }^{76}$. Der Moskauer Vertrag, der Warschauer Vertrag und der Vertrag mit der Tschechoslowakei enthalten sachlich übereinstimmend, nur mit z. T. etwas unterschiedlichen Formulierungen die Verpflichtung der Vertragspartner zur gegenseitigen Respektierung ihrer territorialen Integrität innerhalb der heutigen Grenzen ${ }^{77}$. Die Partner erklären, „daß sie gegeneinander - im Moskauer Vertrag heißt es: ,gegen irgend jemand' - keinerlei Gebietsansprüche haben und solche auch in Zukunft nicht erheben werden". Zugleich hat aber die Bundesrepublik keinen Zweifel daran gelassen, daß die Verträge keine neue Rechtsgrundlage für den derzeitigen Grenzverlauf schaffen.

Hieran schließen sich die folgenden Utberlegungen und Feststellungen an: Die Bundesrepublik Deutschland und alle ihre Organe sind verpflichtet, jetzt und in Zukunft keine Ansprüche auf die Gebiete jenseits der Oder und Neiße zu erheben. Es darf also staatlicherseits nicht behauptet und geltend gemacht werden, es gebe rechtlich oder politisch eine Rückgabepflicht Polens oder der Sowjet-Union oder die dort effektiv ausgeübte Staatsgewalt sei illegal. Das gilt aber entgegen der östlichen Auffassung ${ }^{78}$ nicht für den Fall einer echten friedensvertraglichen Regelung und/oder für den Fall einer gesamtdeutschen Lösung; insoweit greifen die alliierten Vorbehaltsrechte ein, an denen die Bundesrepublik - für alle Vertragspartner erkennbar - nicht rütteln konnte und wollte. Es handelt sich bei realistischer Betrachtung um einen rechtlichen Merkposten im Hauptbuch der europäischen Geschichte; er kann durchaus einmal wieder Bedeutung erlangen, so unwahrscheinlich das im Augenblick auch erscheint.

75 Das hindert natürlich nicht, getroffene Vereinbarungen als völkerrechtliche Abkommen anzusehen; das ist in der Tat von der hier vertretenen Position aus für das Protokoll vom 29. 11. 1978 anzunehmen.

${ }_{76}$ Zur Bewentung der Rechtslage vor Abschiluß der Ostverträge S. Krülle, Die völkerrechtlichen Aspekte des Oder-Nieiße-Probliems, 1970 (Schniften zum Völkerrecht, Bd. 10), mit umfassenden Literaturangaben.

77 Vgl. zu 'den Verträgen BVerfGE 40, 141; 43, 203.

78 Vgl. L. Janicki (oben Anm. 59), 82 ff.; s. auch K. Skubiszewski, Die Westgrenze Polens aus der Sicht der Verträge vom Jahre 1970, in: Volksrepublik Polen - Bundesrepublik Deutschlland. Probleme der Normalisierung gegenseitiger Beziehungen, 1972, $59 \mathrm{ff}$.; ders., Poliand's Western Frontier and the 1970 Treaties, A. J. I. L. 67 (1973), $23 \mathrm{ff}$. 


\section{Berlin}

Bei unserem Thema und an diesem Ort muß selbstverständlich auch etwas über Berlin gesagt werden. Zugleich ist es nahezu unmöglich, in wenigen Minuten Substantielles zur Rechtslage Berlins zu äußern. Ich beschränke mich erneut auf wenige Bemerkungen und verweise im übrigen auf die umfassenden Arbeiten zur Rechtslage Berlins ${ }^{79}$ und auf die meisterhaften Skizzen, die Dieter Schröder und Klaus Stern 1975 zum Kasseler Herbert-Krüger-Symposion beigetragen haben ${ }^{80}$.

Vor 35 Jahren, im September 1944, wurde im Londoner Protokoll niedergelegt, daß außer den Besatzungszonen ,ein besonderes Berliner Gebiet" geschaffen und von den Alliierten gemeinsam besetzt werden solle. Das ist zusammen mit den nachfolgenden Absprachen die heute noch fortwirkende Basis der Vier-Mächte-Rechte in Berlin. Inzwischen ist eine Vielzahl rechtlicher, politischer und tatsächlicher Akte hinzugekommen: Die Blockade der Jahre 1948/49; die Verabschiedung des Grundgesetzes mit der Bezeichnung Berlins als Land der Bundesrepublik und dem hierzu erklärten Vorbehalt im Genehmigungsschreiben der Militärgouverneure; die Erklärung Berlins zur Hauptstadt der DDR in deren Verfassung vom Oktober 1949; der Berlin-Vorbehalt im Deutschlandvertrag von 1955; das sowjetische Ultimatum vom November 1958, das die Beendigung des Besatzungsregimes und die Umwandlung West-Berlins ,in eine selbständige politische Einheit — eine Freie Stadt _ . ..“ forderte; der Mauerbau von 1961; das Vier-Mächte-Abkommen von 197181; schließlich die jüngst sich abzeichnende Entscheidung der DDR, die Ostberliner Abgeordneten der Volkskammer direkt wählen zu lassen ${ }^{82}$.

${ }^{79}$ D. Mahncke, Benlin im geteilten Deutschland, 1973; H. Schiedermair, Die völkerrechtliche Stellung Berlins nach dem VierMächte-Abkommen vom 3. September 1971, 1975; E. R. Zivier, Der Rechtsstatus des Landes Berlin, 3. Aufl. 1977; vgl. jetzt auch $H$. $H$. Mahnke, Das Hauptstadtproblem, in: Drei Jahrzehnte Außenpolitik der DDR (oben Anm. 18), 109 ff.

${ }^{80}$ D. Schröder, Monstro simile - Zum heurtigen Status von Berlin; K. Stern, Perspektiven des Berlin-Status seit $1971 \ldots$, beides in: Finis Germaniae (Anm. 1), $27 \mathrm{ff} ., 33 \mathrm{ff}$.

${ }^{81}$ Zur Vorgeschichte und zum Verlauf der Verhandlungen jetzt G. Wettig, Die Bindungen West-Berlin's als Verhandlungs- und Vertragsgegenstand der vier Mächte 1970/71, Deutsichland Archiv 12. Jg. (1979), 278 ff.; ders., Die Entwicklung der Bindungen WestBerlins vor dem Vier-Mächte-Abkommen von 1971, Europa Archiv 1978, $1182 \mathrm{ff}$.

${ }^{82}$ Dazu J. Seiffert, Anmerkungen zur Anderung des Gesetzes über die Wahlen zu den Volksvertretungen der DDR, Deutschland Ar- 
Diese und zahlreiche andere Vorgänge haben zu einer undurchdringlichen Gemengelage verschiedenartiger Rechtsnormen und „Praktiken" geführt.

Zum Status von Ost-Berlin kann ich nur anmerken, daß nach den allgemeinen Regeln des Völkerrechts bindende Vereinbarungen grundsätzlich nicht einseitig gelöst werden können und daher keine der alliierten Mächte berechtigt war und ist, ihren Sektor einseitig der Vier-Mächte-Verantwortung zu entziehen, diese ist daher auch für Ost-Berlin noch in Geltung. Das ist in dem Vier-Mächte-Abkommen von 1971 erkennbar zum Ausdruck gekommen ${ }^{83}$. Auch die tägliche Praxis in Berlin bietet etliche Anhaltspunkte dafür, daß Ost-Berlin die besatzungsrechtlichen Bindungen keineswegs vollständig abgestreift hat.

Geht man vom Grundgesetz und von der Berliner Verfassung aus, so beansprucht das deutsche Verfassungsrecht Geltung in und für West-Berlin als Land der Bundesrepublik; dies hat das Bundesverfassungsgericht mehrfach nachdrücklich betont ${ }^{84}$. Aber das deutsche Verfassungsrecht hat niemals seine Wirkung voll entfalten können, es wurde zumindest partiell von Besatzungsrecht und alliierten Vorbehalten suspendiert oder überlagert. Diesen Zustand hat das Vier-Mächte-Abkommen von 1971 verfestigt und zum Teil neu geordnet. Dissense und Streitpunkte sind bestehen geblieben oder neu geschaffen worden. Verfassungsrechtlich läßt das Grundgesetz nur die Feststellung zu, daß es einen Anspruch auf Einbeziehung Berlins in unsere Verfassungsordnung erhebt und daß dieser Anspruch von den Organen der Bundesrepublik insoweit zu beachten und zu erfüllen ist, wie die alliierten Vorbehaltsrechte das zulassen.

chiv 12. Jg. (1979), 792 f., und K. W. Fricke, Die 9. Tagung der Volkskammer, ibid., $787 \mathrm{f}$.

\& Wenn in der Präambel und in Teil I von dem ,betreffienden Grebiet" ("the relevrant area"), in Teil II dagegen von Vorschriften speziell für die West-Sektoren von Berlin die Rede ist, sprechen allgemeine Auslegungsregeln für eine unterschiedliche Bedieutung der gebrauchten Ausdrücke. Sicher ist, daß der unkllare Ausdruck "relevant area" einen Fonmelkompromiß zur Viendeckung gegensätzlicher Meinungen und Ziele darstellt, aber das hindert nicht den Rückgriff auf allgemeine Rechtsregeln.

${ }^{84}$ BVenfGE 7, 1; 19, 377 (384 f.); 36, 1 (32 f.); 37, 57 (62); vgl. auch BVerfGE 49, 329 (335 f.), wo das Gericht unter Hinweis auf BVerfGE 37, 57 (60 f.) bemerkt, es übe ,seine Gerichtsbarkeit über solche [d. h. Berliner] Akte" derzeit nicht aus. Vigl. näher P. Lerche, Die Rechtsprechung des Bundesverfassungsgerichts in Berliner Fragen, in: Bundsverfassungsgericht und Grundgesetz, Bid. I, 1976, $715 \mathrm{ff}$. 
Mit der rechtlichen Gemengelage und ihren zahlreichen Schwierigkeiten im Grundsätzlichen wie im Alltag müssen Berlin und Deutschland leben. Man kann einen Schritt weitergehen und sagen, daß West-Berlin erst durch die Gemengelage leben kann, denn ohne die Rechte der Westlichen Alliierten und die damit verbundenen Sicherheiten wäre es ebensowenig lebensfähig wie ohne die Bindungen an die Bundesrepublik. Die Grenze zwischen den Rechten der Alliierten und der Einbindung Berlins in die westdeutsche Rechts- und Verfassungsordnung läßt sich weniger abstrakt umschreiben als jeweils punktuell festlegen.

Es ist verschiedentlich gesagt worden, daß im Interesse Berlins an der These festgehalten werden müsse, Gesamtdeutschland bestehe als Völkerrechtssubjekt fort. Nur so könne der Status der Stadt und der Bewohner Berlins ${ }^{85}$ rechtlich erklärt und gesichert werden. Ich bin nicht dieser Ansicht. Bei Annahme der Identität zwischen dem Deutschen Reich und der Bundesrepublik und der weiteren m. E. zulässigen Annahme, daß Berlin in den Grenzen der alliierten Rechte und Verantwortlichkeiten zur Bundesrepublik gehört, lassen sich die Probleme ebenso gut oder ebenso schlecht lösen wie bei der Annahme eines fortbestehenden Reichsdachs.

\section{Einzelfragen in Auswahl}

\section{Auseinandersetzungen um Deutschland im rechtlichen Alltag}

Das politische Ringen um Deutschland und die grundsätzlichen Auseinandersetzungen über Deutschlands Rechtslage finden ihren Niederschlag im rechtlichen Alltag. Ist jemand, der in Dresden nach dortigem Recht eingebürgert wurde, Deutscher im Sinne des Grundgesetzes? Verliert derjenige, der 1979 in Breslau ausdrücklich die polnische Staatsbürgerschaft beantragt und sie erhält, seinen bisherigen Status als Deutscher? Ist Inland im Sinne der Gesetze der Bundesrepublik das Gebiet eben dieser Bundesrepublik oder kann bzw. muß darunter das Gebiet des Deutschen Reiches in den Grenzen von 1937 verstanden werden ${ }^{86}$ ? Wie und wo sind die Grenzen Rußlands und Po-

85 Zur Staatsangehönigkeit der Berliner $R$. Grawert, Die Staatsangehörigkeit der Berliner, Der Staat 12, 1973, 289 ff.; K. Ipsen, Die Staatsangehörigkeit der Bünger West-Berlins, JIR 16 (1973), 233 ff.; Landesarbeitsgericht Berlin, Uriteil vom 16. 1. 1978, DOD 1978, 79.

${ }^{86}$ Vgl. H. Rumpf, Inland und Ausland als Rechtsbegriffe in ihrer Bedeutung für Deutschland, Der Staat 1970, $289 \mathrm{ff}$. 
lens und die deutschen Grenzen von 1937 auf amtlichen Karten zu markieren?

Dies sind einige der Rechtsfragen des Alltags. Dabei treffen wir nicht selten auf eine paradoxe Situation: Ein und dieselbe Antwort wird in der Bundesrepublik für verfassungsrechtlich geboten und notwendig, von den östlichen Nachbarn für völkerrechtswidrig gehalten. Für den einen muß unter Inland das gesamte Gebiet des Deutschen Reiches verstanden werden, der andere hält eben dies für völkerrechtswidrig.

Nach meiner Ansicht haben in den meisten Fällen beide unrecht. Aus dem, was zuvor zur Existenz zweier Staaten in Deutschland ausgeführt wurde, folgt, daß keiner von ihnen Hoheitsrechte im Gebiet des anderen Staates in Anspruch nehmen darf. Etwas anderes ist es aber, wenn für die Anwendung des jeweiligen staatlichen Rechts durch die staatlichen Organe Anknüpfungspunkte jenseits der Grenzen herangezogen werden. Die moderne Entwicklung des Völkerrechts läßt das weitgehend zu, zumindest dann, wenn für die Anknüpfung legitime Gründe geltend gemacht werden können. Der allergrößte Teil der von östlicher Seite erhobenen Vorwürfe völkerrechtswidriger Bundesgesetze und Praktiken fällt aus diesem Grund in sich zusammen. Andererseits sollte das hohe verfassungsrechtliche Gebot der Wiedervereinigung nicht unbedingt in die Münze des Umsatzsteuerrechts und seines Inlandbegriffs umgewechselt werden.

Es wäre daher angezeigt, auf Pauschalurteile und auf den Streit um die generell richtigen Begriffe und Bezeichnungen zu verzichten und für jedes Gesetz und jede Rechtsfrage die sachlich angemessene, verfassungsrechtlich und völkerrechtlich gleichermaßen akzeptable Lösung zu finden. Dabei kann sich im Einzelfall auch ergeben, daß eine bestimmte Norm oder Maßnahme völkerrechtlich bedenklich oder unzulässig ist, weil tatsächlich Hoheitsrechte im anderen Staat in Anspruch genommen werden. Gegenüber den Vorwürfen von östlicher Seite, eine beträchtliche Zahl von Vorschriften der Bundesrepublik sei völkerrechtswidrig, könnte in diesem Zusammenhang eine Gegenrechnung aufgemacht werden. Wenn etwa eine DDRVerordnung von $1978^{87}$ Kulturbesitz in der Bundesrepublik und in Berlin ${ }^{88}$ kurzerhand zum Eigentum der DDR erklärt, weil er

${ }^{87}$ Verardnung über den Staatlichen Museumsfonds der Deutschen Demoknatischen Republik vom 12. April 1978, GBl. DDR 1978 I, S. 165 ( $\$ 1$ Abs. 2 S. 2:u. 3).

88 Vgl. hierzu R. Mussgnug, Wem gehört die Nofretete? Schriftenreihe der Juristischen Gesellschaft Berlin, Heft 52, 1977; Klaus Vogel, Wem gehört die Nofretete?, in: Finis Germaniae (Anm. 1), $106 \mathrm{ff}$. 
sich lange vor der Gründung der DDR einmal auf ihrem heutigen Gebiet befunden hat, so ist die Völkerrechtsgemäßheit dieses Dekrets in hohem Maße zweifelhaft.

Ich plädiere also insgesamt dafür, den Streit weniger grundsätzlich zu führen und statt dessen nach den jeweils sachgerechten Lösungen zu suchen. Diese Position soll an einigen Beispielen verdeutlicht werden.

\section{Der Inlandsbegriff des $\S 25$ Abs. 1 RuStAG}

$\S 25$ Abs. 1 RuStAG sieht bekanntlich den Verlust der deutschen Staatsangehörigkeit für den Fall vor, daß ein Deutscher ohne Wohnsitz im Inland und ohne vorherige Genehmigung auf Antrag eine ausländische Staatsangehörigkeit erwirbt. Die offizielle Auffassung in der Bundesrepublik geht dahin, daß die Gebiete jenseits der Oder und Neiße bis zum Inkrafttreten des Warschauer Vertrages als Inland, seitdem als Ausland anzusehen sind ${ }^{80}$. Dem wird entgegengehalten, auch heute umfasse das Inland im Sinne dieser Vorschrift das gesamte Reichsgebiet ${ }^{\text {o0 }}$.

Völkerrechtlich bestehen gegen keine der vertretenen Auffassungen durchgreifende Bedenken, da jeder Staat autonom darüber entscheidet, wann der Verlust seiner Staatsangehörigkeit eintritt. Das gilt entsprechend für den Status des Deutschen ohne Wohnsitz in der Bundesrepublik. Verfassungsrechtlich ist es von der hier vertretenen Grundposition aus zulässig, die Gebiete jenseits von Oder und Neiße als Ausland anzusehen und zu bezeichnen. Damit ist die Frage nach einfachem Recht unter Berücksichtigung des Normzwecks zu beantworten. Und da spricht einiges dafür, daß der, der 1979 in Breslau freiwillig die polnische Staatsangehörigkeit beantragt, die deutsche ebenso verliert wie sein Landsmann, der einen gleichen Antrag in Posen stellt, das 1937 ja nicht zum Deutschen Reich gehörte.

\section{Ein- und Ausbürgerungen in der DDR}

Ist der, der auf Antrag in der DDR eingebürgert wird, damit auch Deutscher im Sinne des Grundgesetzes? Die bisher vorherrschende Auffassung ${ }^{91}$, die auch ich früher vertreten habe ${ }^{92}$,

Vgl. u. a. Bundestags-Drucks. VI/3176; auch BVerfGE 40, 155.

90 Vgl. E. Klein, Deutsche Staatsangehönigkeit und Inlandbegriff, DVB1. 1978, $876 \mathrm{ff}$., $878 \mathrm{f}$.

91 Vgl. B. Tiemann, Zur Rechtsverbindlichkeit von Staatsangehörigkeitsakten der DDR für die Bundesrepublik, DOV 72, 73 ff.; zu- 
bejaht diese Frage mit der Einschränkung, daß Korrekturen durch Anwendung des ordre public erfolgen können. Diese Ansicht erscheint mir heute zweifelhaft, sie ist wohl auch vom Wortlaut des Art. 116 Abs. 1 GG her nicht geboten. Die Vorschrift will überkommene nationale Zugehörigkeiten erhalten und sie auf Familienangehörige erstrecken; sie muß nicht besagen, daß Hoheitsakte fremdstaatlicher Gewalt den Status des Deutschen im Sinne des Grundgesetzes begründen können. Aber auch hier sind beide Auffassungen weder verfassungsrechtlich noch völkerrechtlich zu beanstanden.

$\mathrm{DaB}$ Entziehungen und Aberkennungen der Staatsbürgerschaft durch Organe der DDR, etwa bei mißliebigen Künstlern, bei uns nicht wirksam sind, da sie in eklatanter Weise den Wertungen unserer Staatsordnung widersprechen, ist zweifelsfrei. Schwieriger steht es bei der freiwillig beantragten Entlassung aus der DDR-Staatsbürgerschaft. Hier neige ich dazu, den Verlust auch für die Bundesrepublik als wirksam anzusehen, und zwar im Hinblick auf die individuelle Entscheidung ${ }^{93}$. Wiederum handelt es sich m. E. nicht um eine Frage der Verfassung, sondern um die Auslegung des einfachen Rechts.

\section{Der Inlandsbegriff in anderen einfachen Gesetzen}

Im Strafrecht, im Steuerrecht, im Sozialrecht spielt der Inlandsbegriff eine Rolle. Völkerrechtlich wäre es kaum zulässig, wenn der deutsche Gesetzgeber von dem Dresdner Fabrikarbeiter Lohnsteuer und von dem Leipziger Betrieb für Umsätze in der DDR Umsatzsteuer verlangen würde, ebenso unzulässig wäre die Heranziehung von Breslauer Unternehmen und Arbeitern zu Beitragszahlungen im Rahmen der westdeutschen Sozialversicherung. Wenn ich richtig sehe, werden derartige Ansprüche von keiner Seite erhoben.

Es geht vielmehr um Anknüpfungen an Vorgänge im anderen deutschen Staat und in Polen bei der Anwendung der west-

letzt OVG Münster, Urteil vom 5.9.1978, JZ 79, $136=$ DVBl. 79, 429 (mit Literaturangaben).

${ }^{92}$ R. Bernhardt, Das Staatsbürgenschaftsgesetz der DDR, Mitteilungsblatt des Königsteinier Kreises 1968, 25 ff.

93 Konsequenter wäre es zugegebenermaßen, wenn man allen Akten der DDR-Organe in Staatsangehörigkeitsfragen keine unmittelbaren Wirkungen für das Recht der Bundesrepublik beimißt. Mit der Entlassung aus der DDR-Staatsbüngerschaft wind wohl in den meisten Fällen der Erwerb einer fremđen Staatsangehörigkeit Hand in Hand gehen, so daß für das Recht der Bundesrepublik § 25 RuStAG reingreift. 
deutschen Gesetze, etwa um die Behandlung von Umsätzen westdeutscher Unternehmen mit und in der DDR oder um Sozialversicherungsansprüche von Bewohnern der Oder-NeißeGebiete, aber auch um die Strafbarkeit von in der DDR und östlich der Oder und Neiße begangenen Taten. Wiederum lautet die hier vertretene Auffassung, daß es insoweit bei der Annahme von Inland und Ausland in aller Regel nicht um völkerrechtliche oder verfassungsrechtliche Gebote, sondern um Zweck und Funktion der jeweiligen Norm geht ${ }^{94}$. Von Gesetz zu Gesetz sind unterschiedliche Resultate möglich.

Sehen wir uns einige Vorschriften etwas näher an.

(a) Nach $\S 3$ des Strafgesetzbuches gilt das deutsche Strafrecht für die Taten, die im Inland begangen werden. In der Begründung des Bundestagsausschusses für die Strafrechtsreform findet sich hierzu die bemerkenswerte Äußerung, die Auslegung des Inlandbegriffs solle der Rechtsprechung überlassen bleiben $^{95}$. Diese hat in neuerer Zeit noch nicht viel Gelegenheit gehabt, sich mit dem uns interessierenden Problem zu befassen; immerhin wird in einzelnen Entscheidungen zumindest die entsprechende Anwendung des internationalen Strafrechts im Verhältnis zur DDR bejaht ${ }^{96}$; das heißt, daß die in der DDR begangene Tat jedenfalls nicht im Inland $i$. S. von $\S 3$ begangen worden ist.

In der strafrechtlichen Literatur hat sich in neuerer Zeit ein bemerkenswerter Wandel vollzogen. Während früher weitgehend das sogenannte interlokale Strafrecht bei in der DDR begangenen Taten für anwendbar erklärt wurde und damit das Strafrecht des Tatorts gelten sollte, haben sich seit Ende der 60er Jahre die Ansichten gewandelt. Der Inlandsbegriff des $\S 3 \mathrm{StGB}$ wird überwiegend funktional verstanden ${ }^{97} \mathrm{mit}$ dem

${ }^{94}$ Ein Blick auf andere Staaten ist auch hier lehrreich. Ohne irgendwelche Skrupel hat der britische Ireland Act von 1949 erklärt: "The Republic of Ireland is not a foneign country for the purposes of any law in force in any pant of the United Kingdom..." (zitiert nach Ress, obren Anm. 1, 177). Dies beweist, daB es weniger auf die Begriffe als auf den jeweiligen Regelungsgehalt ankommt.

${ }^{95}$ Bundestags-Drucks. V/4095, S. 4.

98 LG Berlin, Urteil vom 20. 7. 1974, JZ 1976, 98; BGH, Unt. v. 9. 9. 1977, NJW 1978, 113; OLG Düisseldorf, Beschil. v. 21. 8. 1978, NJW 1979, 59 (mit eingehenden Literaturnachweisen). Vgl. auch F.-C. Schroeder, Strafrechtliche Probleme im Verhältnis zwischen der Bundesrepublik Deutschland und der DDR, Deutschlland Archiv 1978, 854 ff., 859.

${ }^{27}$ Schönke-Schröder, Strafgesetzbuch, Kommentar (19. Aufl. 1978), Rn. 29 vor § 3; K. Lackner, Strafgesetzbuch mit Erläutenungen (12. Aufll. 1978), Vorbem. 4 a vor $\S 3 ; H .-H$. Jescheck, Lehrbuch des Straf- 
Ergebnis, daß nur die Bundesrepublik einschließlich Berlin darunter fällt ${ }^{28}$. Für Taten in den früheren deutschen Ostgebieten scheint sich ziemlich unwidersprochen die Ansicht durchgesetzt zu haben, diese Gebiete seien kein Inland. Für die DDR gibt es noch einzelne abweichende Äußerungen ${ }^{99}$, aber in der Literatur herrscht doch die Auffassung vor, daß die DDR nicht Inland im Sinne des $\S 3$ StGB ist. Dem ist zuzustimmen.

Damit gelten auch im Verhältnis zur DDR die Regeln des internationalen Strafrechts (unmittelbar oder entsprechend). Nach unserem Strafrecht sind nur die Auslandstaten strafbar, für die das ausdrücklich angeordnet ist. Insoweit können sich auch in Zukunft noch schwierige Rechtsfragen stellen, etwa beim Schußwaffengebrauch an der Grenze. Darüber ist im Zusammenhang mit dem Hanke-Fall in den 60er Jahren und auch später viel und kontrovers diskutiert worden ${ }^{100}$. Das zentrale Problem ist (neben der Frage nach dem Kreis der „Deutschen“ i. S. des StGB) folgendes: Kann oder muß in der Bundesrepublik eine Tat bestraft werden, die nach dem Recht des Tatortes

rechts, Allgemeiner Teil (3. Aufl. 1978), § 20 III 3 S. 153 f.; H. Blei, Strafnecht I, Allgiemeiner Teil (17. Aufl. 1977), $\$ 12$ III 1a S. 40 f.; J. Baumann, Strafrecht, Allgemeiner Teil (8. Aufl. 1977), § 6 II 2b S. 75 f.; R. Maurach - H. Zipf, Strafrecht, Allgemeiner Teil, Teilband I (5. Aufl. 1977), § 11 II a 1b S. $147 \mathrm{ff}$.

${ }^{88}$ Bei der Strafrechtsanwendung spielt nicht nur der Inlandsbegriff, sondern auch der Begriff des Deutschen (\$ 7 StGB) eine Rolle, insoweit besteht hinsichtlich der Bewohner der DDR noch weitgehende Unklarheit und Streit. Dazu etwa H. Roggemann, Grenzübertritt und Strafnechtsanwendung zwischen beiden deutschen Staaten, Anmerkungen zum Fall Weinhold, ZRP 1976, $243 \mathrm{ff}$., m. w. N.

${ }^{90}$ Dreher/Tröndle, Strafgesetzbuch und Nebengesetze (38. Aufl. 1978), Anm. 3 und 11 zu $\$ 3 ; D$. Oehler, Internationales Strafrecht (1973), 277 ff. (278); E. Heimeshoff, Aktuelle innendeutsche Strafrechtsprobleme, DRiz 1977, 19 ff. (21).

100 Aus der früheren Diskussion: $K$. Doehring, Die Teilung Deutschilands als Problem der Strafrechtsanwendung, Der Staat (1965), 259 ff.; G. Grünwald, Ist der Schußwaffengebrauch an der Zonengrenze strafbar? JZ 1966, $633 \mathrm{ff}$; $E$. W. Böckenförde, Die Rechtsauffassung im ikommunistischen Staat, 1967, 94 ff.; W. Rosenthal, Zur Stnafbarkeit des Schußwaffengebrauchs an der Zonengrenze, Recht in Ost und West, 1967, $7 \mathrm{ff}$; aus :der Sicht ider DDR: F. K. Kaul u. B. Graefrath, Völkerrechtiswidrige Initervention in Form der Rechtsprechung. Aus einer gutachtlichen Stellungnahme zum Urteil des Schwurgerichts Stuttgart im Fall Hanke, Neue Justiz (1964), $272 \mathrm{ff} ., 277$; zur jetzigen Rechtslage H. Roggemann, a. a. O. Anm. 98), 246 f. einerseits, und $H$. Woesner, Deutsch-deutsche Strafrechtskonflikte, ZRP 1976, $248 \mathrm{ff}$. sowie F.-C. Schroeder, Notwehr bei der Flucht aus der DDR, NJW 78, $2577 \mathrm{ff}$., andererseits: 
erlaubt oder gar geboten war ${ }^{101}$ ? Dazu kann ich hier nicht Stellung nehmen, jedenfalls ist der Inlandsbegriff nicht relevant ${ }^{102}$.

(b) Das nächste Beispiel kommt aus dem Umsatzsteuerrecht ${ }^{103}$. Dort hat sich in jüngster Zeit zwischen Regierung und Opposition ein heftiger Streit im Zusammenhang mit der Neuordnung der Mehrwertsteuer im Rahmen der Europäischen Gemeinschaft abgespielt ${ }^{104}$. Zur Zeit - d. h. im Herbst 1979 definiert $\S 1$ Abs. 2 des Umsatzsteuergesetzes den Inlandsbegriff als das Gebiet des Deutschen Reiches in den Grenzen vom 31. Dezember 1937. Die Regierung will das ändern, die Opposition widerspricht unter Hinweis auf Deutschlands Rechtslage. Der Inlandsbegriff ist im 1979 geltenden Umsatzsteuergesetz klar definiert, es bleibt insoweit kein Raum für die Auslegung. In der Praxis wird aber nicht das Unternehmen in der DDR zur Umsatzsteuer herangezogen, sondern für die Umsätze des westdeutschen Unternehmers mit Partnern aus der DDR gelten dieselben Regeln wie für Umsätze in der Bundesrepublik. Hier kann man darüber streiten, ob die geltende Regelung sinnvoll

101 G. Hoffmann, Die deutsche Teilung, Staats- und völkerrechtliche Aspekte, 1969, S. 56, hält es für völkerrechtswidrig, wenn ein Starat, die in Ausübung der Souveränität ihres Staates - scil. eines fremden Staates - handelnden Organe für deren Handeln strafrechtlich zur Verantwortung" ziehen will.

102 Das Strafrecht der DDR stellt Ausliandistaten von Ausländern in völkerrechtlich bedenklichem Umfang unter Strafe, vgl. $\$ 80$ Abs. 3 Ziff. 3 StGB i. d. F. vom 1. 8. 1979 (GBl. I 140 ff.): „... wenn ... sie durch ein Verbrechen die Rechte und Interessen der Deutschen Demokratischen Republik oder ihrer Bürger erheblich breeinträchtigt haben." Die Vorschrift ist im Zusammenhang mit den z. T. außerordentlich weit und unpräzise gefaßten Straftatbeständen zu sehen, vgl. etwa § 106 über "Staatsfeindliche Hetze“.

103 Vgl. K.-M. Wilke, Die staatsrechtliche Stellung der DDR im Steuerrecht der Bundesrepublik Deutschland, ROW 1979, $17 \mathrm{ff}$.

104 Der Regienungsentwurf des Umsatzsteuengesetzes vom 5. Mai 1978 (Bundestags-Drucks. 8/1779) sah in § 1 Abs. 2 vor: „Unter Inland im Sinne dieses Gesetzes ist der Geltungsbereich des Gesetzes mit Ausnahme der Zollausschlüsse und der Zollfreigebiete zu verstehen. Ausland im Sinne dieses Gesetzes ist das Gebiet, das nicht Inland ist und nicht zur Deutschen Demokratischen Republik und Berlin (Ost) gehört. ..." Vgl. ıdazu auch die Begründung ebenda S. 29. Dem hatte der Bundestag zugestimmt (vgl. BT-Drucks. 8/2827). Die Bundesnatsmehrheit wollte die bisherige Fassung ides Gesetzes beibehialten (BT-Drucks. 8/3012), bestätigte laber in der Begründung: „Die Beibehaltung des bisherigen Inlandsbegriffes beinhaltet nicht die Ausübung von Hoheitsgewalt außerhalb des Geltungsbereichs des Grundgesetzes." Der Streit wunde nach Abschluß des Manuskripts durch einen Kompromiß beigelegt. 
ist, aber die Handhabung ist jedenfalls völkerrechtlich unbedenklich. Anders, nämlich völkerrechtlich unzulässig wäre die Erstreckung des westdeutschen Steuerrechts allgemein auf Vorgänge in der DDR; aber selbst das bedürfte noch einer näheren Untersuchung, die hier nicht angestellt werden kann.

(c) Schließlich ist in den $\S \S 1315$ ff. RVO sowohl vom Geltungsbereich dieses Gesetzes als auch vom Ausland und von ausländischen Staaten die Rede. Nach einem komplizierten System werden Renten und Beitragserstattungen für Personen außerhalb der Bundesrepublik teils gezahit, teils verweigert, teils muß nicht gezahlt werden, aber es kann gezahlt werden. Die Ansicht des Bundessozialgerichts, die früheren deutschen Ostgebiete seien auch nach Abschluß des Warschauer Vertrages nicht Ausland im Sinne der RVO ${ }^{105}$, hat Beachtung und Widerspruch gefunden. Wiederum meine ich, daß es auf eine funktionsgerechte Auslegung des einfachen Rechts ankommt und weder das Verfassungsrecht noch das Völkerrecht eine bestimmte Lösung zwingend gebieten.

\section{Die Grenzen auf amtlichen Karten}

Wie sind schließlich auf amtlichen Karten und in Schulatlanten $^{108}$ die Grenzen im Osten einzuzeichnen? Völkerrechtlich bedenklich wäre es, wenn trotz der Ostverträge die gegenwärtigen tatsächlichen Grenzen in amtlichen Karten überhaupt nicht vermerkt würden, denn das könnte den Eindruck erwecken, daß amtliche Stellen in der Bundesrepublik nicht bereit sind, den Grenzverlauf $\mathrm{zu}$ respektieren. Im Hinblick auf den Vorbehalt späterer gesamtdeutscher und friedensvertraglicher Regelung bestehen andererseits keine völkerrechtlichen Bedenken, wenn die alten Grenzen des Deutschen Reiches auf amtlichen Karten auch eingezeichnet werden. Verfassungsrechtlich kann man fragen, ob die Kenntlichmachung der alten Grenzen geboten ist; das ist nach den Urteilen des Bundesverfassungsgerichts wohl zu bejahen. Frowein und $v$. Münch haben konkrete Vorschläge gemacht ${ }^{107}$, wie dem Völkerrecht und dem Verfassungsrecht gleichermaßen Rechnung getragen werden kann. Ich würde den zulässigen Spielraum wohl noch etwas weiter ziehen. Im übri-

105 BSGE 42, 249; 43, 164 (hier wurde die Frage letztlich offen gelassen); 46, 293.

${ }^{108}$ Dazu jetzt: Informationen über Bildungsmedien in der Bundesrepublik Deutschland VIII, Grenzdarstellungen in Schulatlanten, 1979, mit Beiträgen von I. v. Münch, J. A. Frowein, und D. Blumenwitz. Vgl. auch Frankfurter Allgemeine Zeitung vom 8 .2. 1979, S. 9. ${ }^{107}$ A. a. O., S. 24. 
gen meine ich auch hier, daß die Auseinandersetzungen nüchterner und mit weniger verfassungsrechtlichen Grundsatzbetrachtungen geführt werden sollten.

\section{Ausblick}

Gibt es nach 30 Jahren Grundgesetz und Bundesrepublik noch ein Deutschland? Die Frage ist zu bejahen, wenn man unter Deutschland eine geschichtlich zusammengehörende $\mathrm{Na}-$ tion versteht mit dem Willen zur Selbstbestimmung und wohl auch zur Wiedervereinigung. $\mathrm{Da}$ es diese Nation und ihren Einheitswillen heute noch gibt, läßt sich nicht exakt beweisen oder belegen. Weder die Versuche des DDR-Regimes, den dortigen Staat als Repräsentanten des wahren Volkswillens und zugleich als Produkt der geschichtlichen Notwendigkeit auszugeben, noch demoskopische Umfragen in der Bundesrepublik über den Willen zur Einheit oder eine etwaige Entfremdung der Menschen diesseits und jenseits von Werra und Elbe sind beweiskräftig. Das Wesentliche ist, da $B$ dem ganzen deutschen Volk noch keine Gelegenheit gegeben wurde, in freier Entscheidung kundzutun, ob es Einheit oder Teilung will.

Dies darf nicht darüber hinwegtäuschen, daß die Bundesrepublik Deutschland und die Deutsche Demokratische Republik in dreißig Jahren ihre je eigene Staatlichkeit errichtet und gefestigt haben. Beide Staaten sind vor 30 Jahren mit dem Anspruch angetreten, das ganze und wahre Deutschland zu repräsentieren und die Einheit herzustellen. Die Entwicklung ist anders verlaufen. Aus dem Provisorium oder Transitorium der Bundesrepublik und ihres Grundgesetzes ist eine demokratisch legitimierte Staatsordnung geworden. Ihre völkerrechtliche Identität mit dem Deutschen Reich läßt sich mit guten Gründen annehmen. Eine solche Identifikation würde international und innerstaatlich leichter verständlich sein als das Festhalten an einem besonderen Völkerrechtssubjekt Gesamtdeutschland.

Zugleich hat die DDR zwar nicht durch demokratische Konsensbildung, wohl aber durch effektive, von ihrem Hauptverbündeten gestützte Machtausübung Staatlichkeit geschaffen und erlangt. Die Staatengemeinschaft unter Einschluß der Bundesrepublik hat die Entwicklung der DDR zu einem eigenständigen Völkerrechtssubjekt nach längerem Widerstand letztlich akzeptiert.

Es ist möglich und notwendig, das Grundgesetz im Einklang mit dem internationalen Befund zu interpretieren. Dabei muß zwar hier und da etwas von den bisher verteidigten Positionen 
preisgegeben werden, aber die zentralen Anliegen der Verfassung können und müssen gewahrt werden. Das gilt für das Wiedervereinigungsgebot als verbindliche Leitlinie der Deutschlandpolitik (mit einem weiten Ermessensspielraum von Regierung und Parlamentsmehrheit), es gilt für den Schutz aller Deutschen durch unsere Grundrechte und unsere staatlichen Organe sobald und soweit rechtlich und faktisch dieser Schutz in Anspruch genommen wird, es gilt auch für die Bindungen Berlins an die Bundesrepublik.

Bei dem Blick auf Deutschland nach 30 Jahren Grundgesetz darf schließlich nicht übersehen werden, da $B$ die „,deutsche Frage" heute und auf absehbare Zeit unlösbar mit der weltpolitischen Entwicklung verbunden ist. Deutschland ist der geographische Ort, an dem sich die Machtblöcke ideologisch, politisch, militärisch und wirtschaftlich unmittelbar begegnen und berühren. Dabei sind weder die Weltmächte noch die europäischen Freunde zur Zeit einer Wiedervereinigung sonderlich wohl gesonnen.

In Europa ist die Integration der beiden deutschen Staaten in die jeweiligen Wirtschaftssysteme auch für die staatliche Entwicklung relevant. Die weitere Stärkung der Europäischen Gemeinschaft mag politisch berechtigt und notwendig sein, für Deutschland als Ganzes kann sie hinderlich sein. Ob verfassungsrechtlich die Eingliederung der Bundesrepublik in einen europäischen Bundesstaat wegen des Wiedervereinigungsgebotes ohne Änderung des Grundgesetzes unzulässig wäre ${ }^{108}$, muß hier dahingestellt bleiben ${ }^{109}$.

Deutschland ist nach 30 Jahren Grundgesetz in erster Linie eine politische Aufgabe und nur noch sehr begrenzt ein rechtlicher Befund.

108 So $K$. Doehring, Die Wiedervereinigung Deutschlands und die europäische Integration als Inhalte der Präiambel des Grundgesetzes, DVBl. 1979, $633 \mathrm{ff}$.

100 Dasselbe gillt für andere Fragen der europäischen Integration, etwa die Erstreckung der Rechite des EWG-Vertrages auf alle Deutschen i. S. des Grumdgesetzes, dazu A. Bleckmann, German Nationality within the Meaning of the EEC Treaty, Common Market Law Review 15 (1978), 435 ff. 
Leitsätze des Berichterstatters über:

\section{Deutschland nach 30 Jahren Grundgesetz}

\section{Anmerkungen zur Verfassungsauslegung}

1. Das Grundgesetz ist grundsätzlich im Einklang mit dem Völkerrecht und unter Berücksichtigung der internationalen Ordnung zu interpretieren.

2. Bei weit gefaßten Verfassungsnormen für politisch besonders sensible Bereiche steht den zur politischen Gestaltung berufenen staatlichen Organen ein beträchtlicher Spielraum zu, den Rechtsprechung und Rechtswissenschaft zu respektieren haben. Das gilt vor allem bei internationalen Sachverhalten und damit bei der Deutschland-Frage.

3. Die Verfassungsauslegung kann und muß sich ändern, soweit veränderte Umstände und Anschauungen dies zwingend nahelegen und weder die tragenden Verfassungsprinzipien noch der Verfassungstext entgegenstehen. Auch das ist für „Deutschland nach 30 Jahren Grundgesetz" von Bedeutung.

4. Die Rechtsprechung des Bundesverfassungsgerichts zur Deutschland-Frage, insbesondere das Urteil zum Grundlagenvertrag, steht weder außerhalb der Kritik noch darf durch sie das Verfassungsrecht auf Dauer festgeschrieben werden.

\section{Der völkerrechtliche Befund}

5. Es gibt heute zwei Staaten und Völkerrechtssubjekte in Deutschland: Die Bundesrepublik Deutschland und die Deutsche Demokratische Republik. Nicht demokratische Legitimation und Nationalbewußtsein, sondern die effektive staatliche Ordnung sind für diesen Befund ausschlaggebend.

6. Nicht nur im Verhältnis der beiden deutschen Staaten zu dritten Staaten, sondern auch zwischen der Bundesrepublik und der DDR gilt (zumindest auch) Völkerrecht.

7. Die Annahme eines Völkerrechtssubjekts „Gesamtdeutschland" neben oder über den real existierenden beiden deutschen Staaten ist völkerrechtlich kaum noch begründbar, da es seit Jahrzehnten an einer staatlichen Ordnung fehlt und keine Anhaltspunkte für eine Wiederherstellung in absehbarer Zeit vorliegen. 
8. Völkerrechtlich begründbar und naheliegend ist nach wie vor die Annahme rechtlicher Identität zwischen dem Deutschen Reich und der Bundesrepublik Deutschland. Dabei ist jedoch die Verselbständigung der DDR zu einem eigenen Staat zu respektieren. Die Identitätsthese verstößt in dieser Beschränkung weder gegen die "souveräne Gleichheit" der beiden deutschen Staaten noch gegen bestehende Verträge.

9. Die alliierten Vorbehaltsrechte „in bezug auf Berlin und auf Deutschland als Ganzes einschließlich der Wiedervereinigung Deutschlands und einer friedensvertraglichen Regelung" (Art. 2 des Deutschlandvertrages) gelten fort und beschränken jede deutsche Staatsgewalt in der Weise, daß sie über diese Gegenstände nicht (allein) verfügen kann. Die dadurch bewirkte rechtliche Offenhaltung der deutschen Frage birgt Chancen und Gefahren zugleich.

10. Das Selbstbestimmungsrecht ist zwar grundsätzlich im heutigen Völkerrecht anerkannt, doch verschwimmen seine Konturen. Völkerrechtlich zulässig ist es, wenn die Organe der Bundesrepublik weiterhin nachdrücklich fordern, dem ganzen deutschen Volk Gelegenheit zur freien Selbstbestimmung zu geben.

\section{Gemengelagen von Staats- und Völkerrecht}

11. Gemengelagen von Staats- und Völkerrecht sind in der geschichtlichen Entwicklung sowohl im Vorfeld neuer Staatsbildungen als auch beim Verfall bisheriger staatlicher Ordnungen anzutreffen und deshalb keinesfalls a limine für das heutige Deutschland auszuschließen.

12. Es spricht jedoch viel dafür, daß der geschichtliche Pro$z e \beta$ ein Stadium erreicht hat, in dem eine derartige Gemengelage im Verhältnis der beiden deutschen Staaten zueinander nicht mehr existiert. Besonderes gilt für Berlin.

\section{Hauptprobleme im Überblick}

13. Das Wiedervereinigungsgebot wird zutreffend als Verfassungsgebot des Grundgesetzes angesehen, doch ist der politische Gestaltungsspielraum weiter als vom Bundesverfassungsgericht angenommen.

14. Die $D D R$ ist als Staat und Völkerrechtssubjekt berechtigt, eigene Staatsangehörige zu haben, international für sie einzutreten und ihre Staatsangehörigkeit rechtlich zu regeln.

15. Wenn die Bundesrepublik auch die in der DDR und in den Ostgebieten wohnenden Deutschen in vollem Umfang als ei- 
gene Staatsangehörige in Anspruch und in Pficht nähme, wäre das völkerrechtlich bedenklich. Unsere Rechtsordnung erhebt einen solchen Anspruch nicht.

16. Alle Deutschen im Sinne des Grundgesetzes (Art. 116 Abs. 1) haben in der Bundesrepublik und gegenüber ihren Organen ein Recht darauf, als Deutsche behandelt zu werden, insbesondere können sie sich auf die Grundrechte berufen.

17. Gegenüber dritten Staaten sind die Organe der Bundesrepublik nach dem Recht der Bundesrepublik gehalten, sich dann für nicht in der Bundesrepublik ansässige Deutsche einzusetzen, wenn diese ausdrücklich um Schutz nachsuchen. Dritte Staaten sind völkerrechtlich befugt, diesen Schutz auch dann anzuerkennen, wenn die DDR widerspricht.

18. Da das Recht der Bundesrepublik in der skizzierten Weise völkerrechts- und verfassungsgemäß ausgelegt und gehandhabt werden kann, gibt es insoweit keine zwingenden Gründe für gesetzliche Änderungen des Staatsangehörigkeitsrechts.

19. Die Grenze zwischen der Bundesrepublik und der DDR ist eine völkerrechtlich relevante und anerkannte Grenze. Die Annahme des Bundesverfassungsgerichts, es handele sich (auch) um eine staatsrechtliche Grenze, ist problematisch.

20. Hinsichtlich der Gebiete des Deutschen Reiches jenseits der Oder und Neiße kann die Bundesrepublik nach Abschluß der Ostverträge nicht mehr geltend machen, es gebe rechtlich oder politisch einen Anspruch auf Rückgabe oder die effektiv ausgeübte polnische bzw. russische Staatsgewalt sei illegal.

21. Die alliierten Vorbehaltsrechte und der erkennbare Wille der Bundesrepublik bei Abschluß der Ostverträge verbieten die Annahme, auch bei etwaigen Verhandlungen über eine abschließende Friedensregelung und/oder eine Wiedervereinigung Deutschlands dürften die Grenzen rechtlich und politisch nicht erneut zur Diskussion gestellt werden.

22. Die Rechte und Verantwortlichkeiten der Vier Mächte in und für Berlin gelten nach wie vor für ganz Berlin. Sie überlagern (mit unterschiedlicher Intensität) die verfassungsrechtlichen Ansprüche beider deutschen Staaten auf volle Einbeziehung der beiden Teile Berlins in die jeweiligen staatlichen Ordnungen. In West-Berlin ist eine vorerst unauflösliche Gemengelage von Staats- und Völkerrecht unverkennbar.

\section{Einzelfragen in Auswahl}

23. Die Auseinandersetzungen um Deutschland finden im rechtlichen Alltag ihren Niederschlag im Streit um die Begriffe 
„Inland" und „Ausland" in deutschen Gesetzen, bei der Einzeichnung der Grenzen auf amtlichen Karten, etc. Es spricht viel dafür, den Streit herabzustufen: Es handelt sich überwiegend weniger um völkerrechtliche und verfassungsrechtliche Ge- oder Verbote als um die funktionsgerechte Ausgestaltung und Auslegung einfachen Rechts.

24. Unzulässig ist die Inanspruchnahme hoheitlicher Befugnisse im jeweils anderen deutschen Staat. In weitem Umfang zulässig ist dagegen die Anknüpfung an Sachverhalte im anderen Staat bei der Anwendung des eigenen Rechts. Bei jedem einzelnen Gesetz und bei jeder Rechtsfrage ist unter Verzicht auf generelle Aussagen festzustellen, welche Lösung verfassungsrechtlich, völkerrechtlich und vom Wortlaut und Zweck der Norm geboten ist.

VI. Ausblick

25. „Deutschland" ist nach 30 Jahren Grundgesetz in erster Linie eine politische Aufgabe und nur noch sehr begrenzt ein rechtlicher Befund.

\section{Anhang: Einige Zitate}

Nihil ergo aliud restat, quam ut dicamus, Germaniam esse irregulare aliquod corpus et monstro simile...

Severinus de Monzambano (= Samuel von Pufendorf), 1667.

Deutschland ist kein Staat mehr.

Georg Wilhelm Friedrich Hegel, 1802.

Die Begebenheiten der drei letzten Kriege, welche Deutschland beinahe ohnunterbrochen beunruhigt haben, und die politischen Veränderungen, welche daraus entsprungen sind, haben die traurige Wahrheit in das hellste Licht gesetzt, daß das Band, welches bisher die verschiedenen Glieder des deutschen Staatskörpers mit einander vereinigen sollte, für diesen $Z$ weck nicht mehr hinreiche, oder vielmehr, daß es in der That schon aufgelöst sey...

.... vergeblich suchte man Deutschland mitten im deutschen Reichskörper.

Austrittserklärung der Rheinbundstaaten vom 1. August 1806.

Da nach der Erfahrung eines ganzen Menschenalters der Mangel an Einheit in dem Deutschen Staatsleben innere Zerrüttung und Herabwürdigung der Volksfreiheit, gepaart mit 
Ohnmacht nach Außen hin, über die Deutsche Nation gebracht hat, so soll nunmehr an die Stelle des bisherigen Deutschen Bundes eine auf Nationaleinheit gebaute Verfassung treten.

Siebzehner-Entwurf der Reichsverfassung, der Deutschen Bundesversammlung am 26. April 1848 überreicht.

[Die deutschen Fürsten und freien Städte] ... schließen einen ewigen Bund zum Schutze des Bundesgebietes und des innerhalb desselben gültigen Rechtes, sowie zur Pflege der Wohlfahrt des Deutschen Volkes.

Vorspruch der Verfassung des Norddeutschen Bundes und der Verfassung des Deutschen Reiches, 1867/71.

Das Deutsche Volk, einig in seinen Stämmen und von dem Willen beseelt, sein Reich in Freiheit und Gerechtigkeit zu erneuern und zu festigen, dem inneren und dem äußeren Frieden zu dienen und den gesellschaftlichen Fortschritt zu fördern, hat sich diese Verfassung gegeben.

Vorspruch der Verfassung des Deutschen Reichs vom 11. August 1919.

Ich würde bitten, in die Diskussion hereinzunehmen, daß wir uns heute einfach „Bundesrepublik Deutschland" nennen... Mit dem Wort „Deutschland“ geben wir dem Ganzen ein gewisses Pathos...

Theodor Heuss in den Beratungen des Parlamentarischen Rates, 1948.

...von dem Willen beseelt, seine nationale und staatliche Einheit zu wahren..., hat das Deutsche Volk in den Ländern..., um dem staatlichen Leben für eine Utbergangszeit eine neue Ordnung zu geben, kraft seiner verfassungsgebenden Gewalt dieses Grundgesetz der Bundesrepublik Deutschland beschlossen.

Präambel des Grundgesetzes, 1949.

Deutschland ist eine unteilbare demokratische Republik... ...

Es gibt nur eine deutsche Staatsangehörigkeit.

Art. 1 der Verfassung der Deutschen Demokratischen Republik von 1949.

Deutschland ist gegenwärtig bloß ein geographischer, vielleicht auch ein völkerrechtlicher, aber kein staatsrechtlicher Begriff.

Friedrich Giese im ersten Kommentar zum Grundgesetz, 1949. 
Das eigentliche Problem des „Deutschen Staates" entstand nicht mit dem Zusammenbruch im Jahre 1945, sondern mit der Schaffung der Bundesrepublik und der DDR 1948/49. Kern dieses Problems ist nicht die Frage nach dem Fortbestand des Deutschen Staates, sondern die nach der Stellung der Bundesrepublik und der DDR zu diesem Deutschen Staat - d.h. die Frage, wer die fortbestehende Deutsche Staatsgewalt von Rechts wegen ausübt und repräsentiert.

Beide als Antwort auf diese Frage denkbaren rechtlichen Deutungen - sowohl die Identitätstheorie als auch die Teilordnungstheorie - sind rechtlich vertretbar. Es ist Sache des Politikers, hier die Entscheidung zu treffen.

Beide Thesen bieten nur Utbergangslösungen, rechtliche Deutungen eines vorübergehenden außergewöhnlichen Zustandes. Sie dürfen nicht in endgültige Lösungen verfälscht werden.

Friedrich August Freiherr von der Heydte auf der Staatsrechtslehrertagung 1954.

Da eine besatzungsrechtliche Fremdbestimmung über das Kontinuum der Einheit Deutschlands nicht erfolgt ist, insbesondere auch nicht in der völkerrechtlichen Behandlung der beiden Teilordnungen gesehen werden kann, entscheidet nach wie vor das deutsche Selbstverständnis über das Weiterbestehen des gesamtdeutschen Staates. In dieser Situation aber hat die als Staatselement aufgefaßte „objektive geistige Tradition“, sofern sie ständig erneuert wird, die Kraft, einen Staat trotz Suspendierung im Organisatorischen als Staat überdauern zu lassen, so daß er ohne Neugründung wieder institutionell-organisatorisch perfektioniert werden kann.

Günter Dürig, ebenda.

Unsere Republik und die BRD verhalten sich zueinander wie jeder von ihnen zu einem anderen dritten Staat. Die BRD ist somit Ausland, und noch mehr: sie ist imperialistisches Ausland.

Erich Honecker am 6. Januar 1972.

Das Deutsche Reich existiert fort..., besitzt nach wie vor Rechtsfähigkeit, ist allerdings als Gesamtstaat mangels Organisation ... selbst nicht handlungsfähig ...

Die Bundesrepublik Deutschland ist... als Staat identisch mit dem Staat „Deutsches Reich", - in bezug auf seine räumliche Ausdehnung allerdings ,teilidentisch“, so daß insoweit die Identität keine Ausschließlichkeit beansprucht.

Das Bundesverfassungsgericht im Urteil vom 31 . Juli 1973 zum Grundlagenvertrag. 
Was die nationale Frage auf deutschem Boden betrifft, so hat hierüber die Geschichte längst entschieden. Das Volk der Deutschen Demokratischen Republik hat in freier Ausübung seines Selbstbestimmungsrechtes ein für allemal die sozialistische Gesellschaftsordnung gewählt. Heute existieren auf deutschem Boden ein sozialistischer Staat, die Deutsche Demokratische Republik, in dem sich die sozialistische Nation entwickelt, und die kapitalistische Bundesrepublik Deutschland, in der die kapitalistische Nation besteht.

DDR-Außenminister Oskar Fischer am 25. September 1974 vor der Generalversammlung der Vereinten Nationen.

Das gesamte Deutsche Volk bleibt aufgefordert, in freier Selbstbestimmung die Einheit und Freiheit Deutschlands zu vollenden.

Präambel des Grundgesetzes, letzter Satz. 
2. Mitbericht von Professor Dr. Norbert Achterberg, Münster Deutschland nach 30 Jahren Grundgesetz

Inhalt

Finleitung Seite

............. 56

II. Die Rechtslage Deutschlands in rechts- und staatstheoretischer Sicht . . . . . . . . . . . . . . . . . . 61

1. Vombemerkung: Verfassungstheorie als Desiderat . . . 61

2. Rechtstheoretische Deutung . . . . . . . . . . . 65

3. Staatstheoretische Deutung . . . . . . . . . . . . 67

4. Konsequenzen . . . . . . . . . . . . . . . . . 73

III. Die Stabilität der staatlichen Binnenstruktur als Integrationsfaktor . . . . . . . . . . . . . . . . . . 76

1. Die Bedeutung des Bundesverfassungsgerichts für die Festigung der Verfassungslage in der Bundesrepublik

Deutschland . . . . . . . . . . . . . . . . . . 76

2. Die Ausgestaltung der verfassunggestaltenden Grundentscheidungen . . . . . . . . . . . . . . . . . 81

3. Die Konkretisierung der Grundrechte . . . . . . . . 92

4. Die Entwicklung im organisatorischen Bereich des Grundgesetzes . . . . . . . . . . . . . . . . 95

IV. Engebnis . . . . . . . . . . . . . . . . 104 


\section{Einleitung}

Irgendwo zwischen „Ursprung und Ziel der Geschichte" liegen auch jene dreißig Jahre seit Inkrafttreten des Grundgesetzes, denen unsere Aufmerksamkeit in diesen Stunden gilt. Dem Beziehungsreichtum geschichtlicher Epochen ist kaum ein anderer deutscher Philosoph so wie Karl Jaspers nachgegangen: In der Tat gilt für jede, auch noch so geringe Teilstrecke innerhalb des unabsehbar, wenn auch vielleicht nicht unendlich währenden menschlichen Daseins seine Aussage, daß sie nach keiner Seite abschließbar und damit nicht als ein sich selbst tragendes Gesamtbild zu gewinnen ist, sondern vielmehr einerseits die Gegenwart sich durch den geschichtlichen Grund erfüllt, den wir in uns zur Wirksamkeit bringen und andererseits diese von der ihr verborgenen Zukunft bestimmt wird, deren Tendenzen wir in Zustimmung oder Abwehr zu den unseren machen ${ }^{1}$.

Damit angesprochen ist das metazeitliche, das metastaatliche und das metakonstitutionelle Umfeld der staatsrechtlichen Entwicklung unter dem Grundgesetz ${ }^{2}$ : Als Beleg für die metazeit-

${ }^{1} K$. Jaspers, Vom Unsprung und Ziel der Geschichte, 1952, S. 5.

2 Die verschiedenen Jubiläen waren vielfältiger Anlaß zur Befassung mit der Rechtslage Deutschlands und der Entwicklung des Verfassungsrechts. Vgl, nach 10 Jahren: H. Schäfer, Zehn Jahre Grundgesetz, DVBI. 59, 341; nach 20 Jahren: U. Scheuner, Das Grundgesetz in der Entwicklung zweier Jahrzehnte, AöR (1970), 353; W. Strauß, 20 Jahre Grundgesetz, DOV 69, 297; W. Weber, Die Bundesrepublik und ihre Verfassung an der Schwelle des dritten Jahrzehnts, DVBl. 69, 413; nach 25 Jahren: H.P. Ipsen, Utber das Grundgesetz - nach 25 Jahren, DOV 74, 289; K. Löw (Hrsg.), 25 Jahre Grundgesetz. Ein Zwischenzeugnis, 1974; nach 30 Jahren: E. Benda, Bundesverfassungsgericht und Gesetzgeber im dritten Jahrzehnt des Grundgesetzes, DOV 79, 465; K. Doehring, Die Wiedervereinigung Deutschlands und die europäische Integration als Inhalte der Präambel des Grundgesetzes, DVB1. 79, 633; G. Hartkopf, Zur Lage der Bundesverwaltung nach 30 Jahren Grundgesetz, DÖV 79, 349; W. Leisner, Demokratie. Selbstzerstörung einer Staatsform?, 1979; ders., Flexibilität als Bewährungsprobe, BayVBl. 79, 518; Th. Maunz, Die gegenwärtige Gestalt des Grundgesetzes, BayVB1. 79, 513; M. Rommel, Zur Lage der Kommunalverwaltung nach 30 Jahren Grundgesetz, DOV 79, 362; H. Schnoor, Zur Lage der Länderverwaltung nach 30 Jahren Grundgesetz, DOV 79, 355; H. Weichmann, Dreißig Jahre Grundgesetz, DVB1. 79, 365. - Des dreißigjährigen Bestehens des Grundgesetzes wurde auch in Ringveranstaltungen von Hochschulen und Vereinigungen gedacht, so auf der 47. Staatswissenschaftlichen Fortbildungstagung der Hochschule für Verwaltungswissenschaften, Speyer, 28. bis 30. 3. 1979, mit Referaten von H. Buchheim, R. Herzog, H. Schambeck, Th. Maunz, E. Benda, K. Doehring, K. D. Bnacher (Bericht hierüber bei H. Stern, 30 Jlahre Grundgesetz, JZ 79, 
liche Verhaftung unserer Verfassung genügt hinsichtlich derjenigen mit der Vergangenheit der Hinweis auf die Fortentwicklung der Verfassungsrechtslage unter der Weimarer Reichsverfassung - in Abkehr und Abwehr von Fehlentwicklungen, die in der Weimarer Republik zu beobachten waren (einem überzogenen Wertrelativismus und zugleich einer Labilität des politischen Kräftefeldes) ${ }^{3}$ und die letztlich $\mathrm{zu}$ ihrem Scheitern führten: dies eine schmerzliche Erkenntnis in einem Jahr, in dem wir nicht nur des dreißigjährigen Bestehens des Grundgesetzes, sondern - was hierüber nach meiner Auffassung zu kurz gekommen ist - zugleich des sechzigjährigen Jubiläums des Inkrafttretens der ersten demokratischen Reichsverfassung gedenken können. Die Zurückdrängung der plebiszitären Komponente der parlamentarischen Demokratie, die Stabilisierung der Parteienlandschaft, aber auch die Beschränkung der Ministerverantwortlichkeit gegenüber dem Parlament sind Konsequenzen dieser Entwicklung. Hinsichtlich derjenigen mit der Zukunft läßt sich die metazeitliche Verhaftung unserer Verfassung durch das bleibende Erfordernis der Bewältigung neuer Staatsaufgaben sowie kurzfristig dasjenige der Integration der Bürgerinitiativen in die Staatsgrundordnung belegen ${ }^{4}$ - diese

507), sowie auf dem Forum der Deutschen Vereinigung für Politische Wissenschaft, München, 2. 2. 1979, mit Referaten von $H$. Maier, $H$. Ridder, U. Matz, A. Grosser (abgedr. PVS 20 [1979], 153). - Speziell zur Geschichte des Bundestags: 30 Jahre Deutscher Bundestag. Dokumentation, Statistik, Daten, bearb. Schindler, 1979. - Schließlich aber wurden nach $A$. Grosser, Deutschlandbilanz, 6. Aufl., 1977, auch gegenwärtig politische Bestandsaufnahmen vorgelegt, vgl. $M$. u. S. Greiffenhagen, Ein schwieriges Vaterland. Zur politischen Kultur Deutschlands, 1979; W. Scheel (Hrsg.), Nach Dreißig Jahren. Die Bundesrepublik Deutschland - Vengangenheit, Gegenwart, Zukunft, 1979.

${ }^{3}$ Dazu K. D. Bracher, Der parlamentarische Parteienstaat zwischen Anfechtung und Bewährung, in: W. Scheel (Hrsg.), Nach DreiBig Jahren, S. $28(36,42)$.

4 Zu diesen Staatsaufgaben zählt gegenwärtigg vor allem der zweite Beratungsgegenstand ,Staatsaufgabe Umweltschutz". — ,Integration" der Büngerinitiativen meint nicht Ubernahme ihrer Anliegen in staatlicher Regie, sondern Offenheit der staatlichen Organe für sachbezogene Diskussion. Der (vereinzelt gebliebene) Versuch; Staatsongane als "Anlaufstellen" für Bürgerinitiativen einzurichten (durch den „Ausschuß für Büngerinitiativen und andere Eingaben“ des Landtags von Schleswig-Holstein [§ 9 Abs. $1 \mathrm{Nr} .11$ LTGO]) reicht nicht aus (kritisch dazu $P$. Hübner, Landtagsausschuß für Bürgerinitiativen. Parlamentarische Omnikompetenz für einen neuen Ausschuß?, ZParl. 3 [1972], 199). „Regelungsidefizite“ (Gesetzgebungs- und/oder Vollzugsdefizite) sowie "Transparenzdefizite" 
über die metazeitliche sogar in die metastaatliche Dimension hineinragend, weil sie mangelnde Offenheit nicht nur staatlicher Organe, sondern auch politischer Parteien für ihre Anliegen anzeigen - sowie die Verwirklichung von Vorschlägen zur Verfassungsreform ${ }^{5}$. Der metastaatliche Aspekt betrifft die Stellung der Bundesrepublik Deutschland als „kooperativer Verfassungsstaat" 8 im Geflecht der internationalen Beziehungen - auch dies eines der Themen früherer Tagungen dieser

sind für die Ausbreitung der Bürgeninitiativen ursächlich, ihhre Beseitigung durch einen entsprechenden Stil politischen Handelns stellt das Verhältnis des parlamentarischen Regierungssystems zu den Bürgerinitiativen weniger als rechtliches, denn als politisches Problem dar. Im einzelnen dazu $N$. Achterberg, Die Parlamentarische Demokratie als Entfaltungsraum für Büngerinitiativen, NJW 78, 1993 (1995 ff.).

5 Diejenigen der Enquête-Kommission Verfassungsreform in ihrem Schlußbericht BT-Dr. 7/5924 sind zwar auf beachtliches Interesse der Rechtswissenschaft gestoßen - zusammenfassend $\boldsymbol{H}$. $\boldsymbol{P}$. Ipsen, Zum Schlußbericht der Enquête-Kommission Verfassungsreform, DOV 77, 537; R. Grawert, Zur Verfassungsreform, Staat 18 (1979), 229; $R$. Wahl, Empfehlungen zur Verfassungsreform, AöR 103 (1978), 477; zu Einzelfragen N. Achterberg, Parlamentarische Kontrollrechte, DOV 77, 548; W. Fiedler, Die Verteilung der Gesetzgebungskompetenzen, DOV 77, 580; J. Frowein, Rechtsetzungsbefugnisse der Exekutive, DOV 77, 555; W. Knies, Der Bundesnat: Zusammensetzung und Aufgaben, DOVV 77, 575; W. Schmitt Glaeser, Stärkung der politischen Mitwirkungsrechte der Bünger, DOV 77, 544; sowie beispielsweise das 14. Cappenbenger Gespräch der Freiherr-vom-Stein-Gesellschaft, Stuttgart, 22. 4. 1977, mit Referaten von E.-W. Böckenförde und $K$. Stern (Bericht hlierüber bei W. Berg, Zur verfassungsrechtlichen Fortentwicklung der Bundesrepublik Deutschland, DOV 77, 556) - bisher jedoch lediglich durch Einfühmung des Art. 45 c GG durch das Zweiunddreißigste Gesetz zur Anderung des Grundgesetzes (Artikel 45 c) v. 15. 7. 1975 (BGBl. I 1901) sowie die Anderung des Art. 39 GG durch das Dreiunddreißigste Gesetz zur Änderung des Grundgesetzes (Artikel 29 und 39) v. 23.8. 1976 (BGBl. I 2381) verwirklicht wonden.

- $P$. Häberle, Verfassungsinterpretation und Verfassunggebung, in: Verfassung als öffentlicher Prozeß. Materialien zu einer Verfassungstheorie der offenen Gesellschaft, 1978, S. 182 (189); ders., Der koopenative Verfassungsstaat, in: Recht und Gesellschaft, Festschrift für Helmut Schelsky, hrsg. Kaulbach/Knawietz, 1978, S. 141 (144: „Der kooperative Verfassungsstaat betreibt aktiv die Sache der andenen Staaten, der internationalen und supranationalen Einrichtungen und der ,fremden' Bürger: Seine ,Umweltoffenheit' ist ,Weltoffenheit" ".) 
Vereinigung ${ }^{7}$-, insbesondere das Hineinwachsen unseres Staa-

${ }^{7}$ C. Tomuschat/R. Schmidt, Der Verfassungsstaat im Geflecht der internationalen Beziehungen, VVDStRL 36, 7, 65. - Nachdem die Rechtslage Deutschlands Beratungsgegenstand der Staatsrechtslehrertagung 1954 gewesen war - vgl. F. A.Frh. v.d. Heydte/G. Dürig, Der deutsche Staat im Jahre 1945 und seither, VVDStRL 13, 6, $27-$ spiegeln die Beratungsgegenstände der Tagungen die staatsrechtliche Entwicklung unter dem Grundgesetz wider, so insbesondere: W. Jellinek/H. Schneider, Kabinettsfrage und Gesetzgebungsnotstand nach dem Bonner Grundgesetz, VVDStRL 8 (1949); E. Kaufmann/M. Drath, Die Grenzen der'Verfassungsgenichtibarkeit, VVDStRL 9 (1950); H. P. Ipsen/H. Ridder, Enteignung und Sozialisierung, VVDStRL 10 (1951); W. Weber/H. Peters, Die Gegenwartslage des Staatskirchenrechts, VVDStRL 11 (1952); E. Forsthoff / O. Bachof, Begriff und Wesen des sozialen Rechtsstrates, VVDStRL 12 (1953); W. Grewe/E. Menzel, Dive auswärtige Gewalt der Bundesnepublik, VVDStRL 12 (1953); K. M. Hettlage/Th. Maunz, Die Finanzverwaltung im Rahmen der Staatsverfassung, VVDStRL 14 (1955); E. Friesenhahn/K. J. Partsch, Parlament und Regierung im modernen Staat, VVDStRL 16 (1957); K. Hesse/G. Kafka, Die verfassungsrechtliche Stellung der politischen Parteien im madernen Staat, VVDStRL 17 (1958); G. Erler/W. Thieme, Das Grundgesetz und die öffentliche Gewalt internationaler Staatengemeinschaften, VVDStRL 18 (1959); H. Bülck/P. Lerche, Födenalismus als nationales und internationales Ondnungsprinzip, VVDStRL 21 (1962); U. Scheuner/R. Schnur, Pressefreiheit, VVDStRL 22 (1963); G. Leibholz/G. Winkler, Staat und Verbände, VVDStRL 24 (1965); O. Kimminich/P. Pernthaler, Das Staatsoberhaupt in der parlamentarischen Demokratie, VVDStRL 25 (1966); $M$. Heckel/A. Hollerbach, Die Kirchen unter dem Grundgesetz, VVDStRL 26 (1967); G. C. v. Unruh/H. Quaritsch, Führung und Organisation der Streitkräfte im demokratisch-parlamentarischen Staat, VVDStRL 26 (1967); K. H. Friauf/H. Wagner, Offentlicher Haushailt und Wirtschaft, VVDStRL 27 (1968); R. Bäumlin/E.-W. Böckenförde, Das Grundrecht der Gewissensfneiheit, VVDStRL 28 (1969); W. v. Simson/M. Kriele, Das demokratische Prinzip im Grundgesetz, VVDStRL 29 (1970); W. Martens/P. Häberle, Grundrechte im Leistungsstaat, VVDStRL 30 (1971); J. Frowein/I. v. Münch, Gemeinschaftsaufgaben im Bundesstaat, VVDStRL 31 (1972); K. Doehring/J. Isensee, Die staatsrechtliche Stellung der Ausländer in der Bundesrepublik Deutschliand, VVDStRL 32 (1973); Th. Oppermann/H. Meyer, Das parlamentarische Regiemungssystem des Grundgesetzes, VVDSitRL 33 (1974); P. Saladin/H.-J. Papier, Untemehmen und Unternehmer in der verfassungsnechtlichen Ordnung der Wirtschaft, VVDStRL 35 (1976); E. Denninger/H. H. Klein, Verfassungstreue und Schutz der Verfassung, VVDStRL 37 (1978). Utber die Entwicklung berichtet nach Schwerpunkten geordnet $H$. P. Ipsen, 50 Jahre deutsche Staatsrechtswissenschaft im Spiegel der Verhandlungen der Vereinigung der Deutschen Staatsnechtslehrer. II. Die Verhandlungen von 1949 (Heidelberg) bis 1971 (Regensburg), AöR 97 (1972), 375. 
tes in die Europäische Gemeinschaft mit allen ihren Konsequenzen, aber auch die Beziehungen zur Deutschen Demokratischen Republik. Die metakonstitutionelle Komponente schließlich beruht auf dem Umstand, daß sich die staatsrechtliche Entwicklung unter dem Grundgesetz nicht nur auf der formellverfassungsgesetzlichen Ebene vollzogen hat, sondern auch auf einer innerhalb des Normstufenbaus höherrangigen sowie tieferrangigen - insbesondere derjenigen der Verfassungsgerichtsbarkeit.

$\mathrm{Da} \beta$ das Grundgesetz bei alledem "seinen Inhalt wie ein Grundbuch wandelt", in welchem sich "variables Situationsrecht" in einer Weise verändere, daß unsere Verfassung ,kaum noch als einheitlicher Willensausdruck eines prinzipiell widerspruchsfreien Staatsgestaltungskonzepts gedeutet werden kann" - wie das Urteil in einem unserer Grundgesetz-Kommentare lautet ${ }^{8}$ - vermag ich indessen nicht zu sehen. Sicherlich darf nicht verkannt werden, daß innerhalb der dreißig Jahre seit Inkrafttreten des Grundgesetzes im Durchschnitt jährlich etwas mehr als ein verfassungsänderndes Gesetz ergangen ist und von der Verfassungsänderung ungefähr ein Drittel des grundgesetzlichen Normenbestands betroffen war, wobei noch unberücksichtigt bleibt, daß hiervon Normen mitunter insgesamt, mitunter teilweise berührt wurden, sowie daß neue Normen geschaffen wurden, die in dem ursprünglichen Normenbestand nicht enthalten waren, und daß schließlich verschiedene Normen mehrfachen Änderungen unterworfen waren. Hinzukommt das Richterrecht des Bundesverfassungsgerichts, durch das die von diesem angewandten Rechtsnormen konkretisiert wurden und das nicht nur Rechtsanwendung, sondern zugleich Rechtsetzung bedeutet. Der scheinbar allzuschnelle Wandel des grundgesetzlichen Normenbestands spricht gleichwohl nicht gegen die Verfassungskonzeption. Denn jede freiheitliche Verfassung enthält in diesem Zusammenhang nicht zu übersehende innere Antinomien: Je weiter Freiheitsräume sind, um so eher gibt es Identifikationsdefizite, je offener eine Verfassung ist ${ }^{9}$,

8 A. Hamann/H. Lenz, Das Grundgesetz für die Bundesrepublik Deutschland vom 23. Mai 1949, 3. Aufl., 1970, S. V.

${ }^{9}$ Der zu Beginn der Geltung des Grundgesetzes rentstandene Streit, ob dieses eher dem Typ „offener" oder "starrer" Verfassungen sowie demjenigen der ,Teilverfassungen" oder der "Vollverfassungen" zuzurechnen ist (i. S. "Teilverfassung“ z. B. W. Schätzel, Zweites Rechtsgutachten betreffend Rechtsfragen einer Wiederaufrüstung Deutschlands, in: Der Kampf um den Wiehrbeitrag, o. J., Bd. II, S. 620 [629]; i. S. „Vollverfassung“ z. B. E. Menzel, Gutachten 
um so eher gibt es Konkretisierungsbedürfnisse, je länger eine Verfassung andauert, um so größer ist das Erfordernis, Prävisionsinsuffizienzen des Verfassunggebers $\mathrm{zu}$ heilen ${ }^{10}$. Aus allem folgt das Erfordernis, sich auf eine der Verfassung eigene Dynamik einzustellen, die der Fortschreibung bedarf, um Grundkonsens und auf ihm beruhende Verfassungseffektivität zu erhalten ${ }^{11}$.

\section{Die Rechtslage Deutschlands in rechts- und staatstheoreti- scher Sicht}

\section{Vorbemerkung: Verfassungstheorie als Desiderat}

a) Die Anleitung des Verfassungsrechts und der Verfassungspraxis durch eine Verfassungstheorie fehlt uns freilich $\mathrm{zu}$

über die Notwendigkeit eines verfassungsändernden Gesetzes zur Errichtung deutscher bewaffneter Streitkräfte im Rahmen der Europäischen Verteidigungsgemeinschaft, ebda., Bd. I, S. 280 [302 f.]), wird gegenwärtig nicht weitergeführt. Die Schnelligkeit, mit der das Grundgesetz beraten wunde, spricht - wie auch die nachträgliche Erweiterung des Normenbestandes (insbesondere um denjenigen zur Vorsonge für den Verteidigungsfall) - für die Natur als Teilverfassung, die enge Begrenzung des unantastbaren Normenbereichs für eine "offene Verfassung", wie sie im übrigen durch die Anforderungen der plunalistischen Gesellschaftsordnung auch geboten ist. Zur sachgemäßen Zuordnung starrer und beweglicher Verfassungselemente im Interesse "relativer Elastizität" und „nelativer Stabilität" der Verfassung $K$. Hesse, Grundzüge des Verfassungsrechts der Bundesrepublik Deutschland, 11. Aufl., 1978, \& 1 III 4, S. 16 f.

10 Zur Problematik der Prognose $P$. Noll, Gesetzgebungslehre, 1973, S. 95. Er bezeichnet sie als die „größte Schwienigkeit, mit der sich die Gesetzgebung im Zusammenhang mit den Tatsachengrundlagen ihner Entscheidungen konfrontiert sieht" und hebt mit Recht hervor, daß diese Schwierigkeiten bei der Gesetzgebung erheblich größer sind als bei der Rechtsprechung. Hinzuzufügen ist dem nur, $\mathrm{daB}$ sie bei der Verfassunggebung - wegen deren erstrebter Geltungsdauer und erschwerter Abänderbarkeit - noch stärker sind als bei der ,einfachen" Gesetzgebung.

11 Zur Bedeutung des Konsenses im Verfassungsrecht $U$. Scheuner, Konsens und Pluralismus als verfassungsrechtliches Problem, in: Rechtsgeltung und Konsens (hrsg. Jakob), 1976, 33 (34 f., 38 ff., $55 \mathrm{ff}$ ). Zum Verhältnis von "Grundkonsens" und "Einzelkonsens" A. Podlech, Wententscheidungen und Konsens, ebda., S. 9 (24 f.). Zur Aufgabe, die dem Bundesverfassungsgericht bei der Fortschreibung der Verfassung zukommt, W. Fiedler, Fortbildung der Verfassung durch das Bundesverfassungsgericht, JZ 79, 417. 
einem guten Stück noch immer ${ }^{12}$, abgesehen etwa von „Materialien $\mathrm{zu}$ einer Verfassungstheorie der offenen Gesellschaft", wie sie Peter Häberle vorgelegt hat ${ }^{13}$. Man kann die Frage nach dem Erfordernis einer Verfassungstheorie nicht damit ausräumen, da $\beta$ auf bestehendes Verfassungsrecht verwiesen wird und darauf, daß Verfassungstheorie Verfassungsrecht vorauszugehen, aber nicht nachzufolgen hat. Denn immerhin befindet sich auch Verfassungsrecht in einer fortwährenden Wandlung - wie schon allein die Gegenüberstellung von Verfassungsrecht und Verfassungswirklichkeit sowie die erfolgten Verfassungsänderungen erweisen -, und eben auch für diese bedarf es der Vergewisserung, soll solche Entwicklung nicht im Ozean der Zeiten richtungslos dahintreiben. Verfassungstheorie hat dabei spezieller zu sein als Rechtstheorie, weil sie die Verfassungsebene betrifft, zugleich aber genereller, weil sie Rechtstheorie und Metarechtstheorie zugleich sein muß, die Verfassung eben nicht nur im rechtlichen, sondern auch in dem sie umwölbenden gesellschaftlichen Raum angesiedelt ist, so daß nicht ihre monistisch-juristische, sondern ihre dualistisch-juristische und -metajuristische Betrachtung angezeigt ist ${ }^{14}$.

12 Dies ist so bemerkenswert, daß es genade bei Behandlung dieses Themas in den Vordergrund gestellt werdien muß. Zur staatstheoretischen Unterbillanz der Staatsrechtslehrertagungen $H$. $P$. Ipsen, AöR 97 (1972), 377: „Darin“ [sc. in der Sicht des ganzen Staats, in seiner Rechtsgestalt, seiner historischen Lage, seinen sozialwissenschaftlich begreifbaren Sitrukturen und seinen wirtschafts- und sozialpolitischen Aufgaben und Verantwortlichkeiten] „liegt ... ein Ansatz zur . . F Fundienung einer Staatsrechtswissenschafit, die ihren Primat in der Stalstheorie behaupten will. Ob die Tagungen der Vereinigung insoweit genug geleistet haben, zur Methodik und zur Sache Grundfragen aufzuwerfen und sich der Fundamentalkritik $z u$ stellen, bleibt selbstkritisch $z u$ bedenken. Insbesondere sollte das auch pro futuro geschehen ..." (Hervorheb. von mir).

${ }^{13} P$. Häberle (s. o. Anm. 6). Vig1. aber lauch K. Stern, Das Staatsrecht der Bundesrepublik Deutschland, Bd. I, 1977, § 3 , S. 45 ff., § 5 , S. $115 \mathrm{ff}$.

14 Im Streit um den mon'istischen und den dualistischen oder sogar trialistischen Staatsbegriff - der erste vertreten insb. von $H$. Kelsen, Allgemeine Staatslehre, 1925, S. 19 ff.; ders., Der soziologische und der juristische Staatsbegriff, 1928, S. $105 \mathrm{ff}$.; ders., Reine Rechtslehre, 2. Aufl., 1960, S. 288, der zweite aus juristischer Sicht knon G. Jellinek, Allgemeine Stalatslehre, 3. Aufl., 7. Neudruck, 1960, S. $174 \mathrm{ff}$., aus soziologischer Sicht von Th. Kistiakowski, Gesellschaft und Einzelwesen, 1899, S. $60 \mathrm{ff}$., der dritte von H. Nawiasky, Allgemeine Staatslehre, 1. T., 1945, $\S 3$ ff., S. 29 ff. - ist der erste inzwischen eindeutig unterlegen. 
Bei allem darf nicht außer acht bleiben, daß auf Teilgebieten Ansätze einer Verfassungstheorie vorliegen: so im Bereich der Verfassungshermeneutik durch die Erkenntnisse der Freiburger Schule ${ }^{15}$, so im Bereich der Grundrechtsdogmatik ${ }^{16}$, so für die Institutionen- und die Funktionenlehre - dies unter Berücksichtigung sowohl zunächst staatsrechtlicher Bereiche wie des Parlaments, als auch der den Staat transzendierenden Beziehungen $z u$ organisierten Interessen ${ }^{17}$. Dennoch: Eine Verfassungstheorie aus einem Guß, die alle diese Denkansätze einbezieht, steht noch aus und stellt ein dringendes Desiderat dar. Sie hätte den Staat als Subsystem der Gesellschaft unter anderen Subsystemen, aber auch seine Überlegungen gegenüber diesen anderen Subsystemen, sie hätte das Verhältnis des Indivi-

15 Kennzeichnend $H$. Ehmke, Prinzipien der Verfassungsinterpretation, VVISSRL 20,53 (unter Hervorhebung der aus der Offenheit der Struktur der Vierfassungsordnung resultierendien Bedeutung topischer Interpretation bei gleichzeitiger Berücksichtigung der Einheit der Verfassung); K. Hesse, a. a. O., § 2, S. 20 ff. (unter Betonung der Natur der Verfassungsinterpretation als Konkretisierung sowie der Herausarbeitung von Interpretationstopoi, wie insbesondere des Prinzips der pnaktischen Konkordanz); F. Müller, Die Einheit der Verfassung, 1979, S. 85 ff. (unter Aufzeiging der Einsatzmöglichkeiten dieses Arguments).

18 So vornehmlich dunch die Hervorhebung der Gnundrechte als Wertsystem durch G. Dïrig bei Th. Maunz/G. Dürig/R. Herzog/R. Scholz, Grundgesetz, 1978, Art. 1 Abs. I RdNr. 1 ff., Art. 2 Abs. I RdNr. 1 ff., Art. 3 Abs. I RdNr. 1 ff., 156 ff., durch die Nutzung des systemtheoretischen Ansatzes für die Grundrechtsdeutung durch $N$. Luhmann, Grundnechte als Institution, 1965; ders., Rechtssoziologie, 1972, S. 281 f., 329; H. Willke, Stand und Kritik der neueren Grundrechtstheorie, Schritte zu einer normativen Systemtheorie, 1975, passim, insb. S. $157 \mathrm{ff}$, durch die Erarbeitung einer allgemeinen Grundrechtstheorie durch A. Bleckmann, Allgiemeine Grundrechtslehren, 1979; H. v. Mangoldt/F. Klein, Das Bonner Grundgesetz, Bd. I, 1966, Vorbem. Die Grundnechte, S. $51 \mathrm{ff}$.

${ }_{17}$ Vgl. zur Institutionenlehre z. B. M. Drath, Die Entwicklung der Volksrepräsentation, 1954; E. Fraenkel, Die repräsentative und die plebiszitäne Komponente im deutschen Verfassungsstaat, 1958; $M$. Hättich, Demokratie als Herrschaftsordnung, 1967, S. 176 ff.; J. H. Kaiser, Die Repräsentation organisienter Intenessen, 1956; G. Leibholz, Parteienstaat und Repräsentative Demokratie, DVBl. 51, 1; U. Scheuner, Das nepräsentative Prinzip in der Demokratie, in: Verfassungsrecht und Verfassungswirklichkeit, Festschrifit für Hans Hubler, 1961, S. 222; Zur Funktionenlehre N. Achterberg, Probleme der Funktionenlehre, 1970; G. Zimmer, Funktion - Kompetenz Legitimation, 1979. 
duums und der Transindividuen ${ }^{18}$ zum Staat unter Berücksichtigung personfunktionaler ${ }^{19}$ wie systemfunktionaler Ansätze ${ }^{20}$, sie hätte die Grundrechte in ihrer petitionellen, institutionellen und funktionellen Seite, sie hätte die Institutionen und Funktionen des Staats und die Prozesse im Staat miteinzubeziehen.

b) Mehr als das: Utber Verfassungstheorie muß - unter Berücksichtigung ihrer Erkenntnisse - in die Rechts- und Staatstheorie ausgegriffen werden, wenn die Rechtslage Deutschlands gedeutet werden soll - ein Unternehmen, das sich in den dreiBig Jahren nach, ebenso wie in den vier Jahren vor dem Grundgesetz keineswegs allgemeinen Konsenses rühmen kann ${ }^{21}$. Je-

18 Dieser Begriff soll (abkürzend) organisierte und nicht-organisierte Personenverbindungen jeglicher Art bezeichnen. „Verband“ billdet reinen seiner Unterbegriffe, erschöpft ihn jedoch - jedenfalls mit seinem herkömmlichen Inhalt (zu diesem J. H. Kaiser, a. a. O., passim; K. P. und J. Tudyka, Verbände. Geschichte, Theorie, Funktion, 1973, passim; H. J. Varain, Verbände, in: Evangelisches Staatslexikon, hrsg. Kunst-Herzog-Schneemelcher, 2. Aufl., 1975, Sp. 2682) - nicht. Er könnte durch „Kollektiv“ ersetzt werden, wäre nicht auch dieser Begriff mit Vorständnissen belastet (dem Begriff ,transindividuell" vergleichbar ist der Begriff "transsubjektiv" [J. Hoffmeister, Wörterbuch der philosophischen Begriffe, 2. Aufl., 1955, S. 617]).

${ }^{19} \mathrm{H}$. Schelsky, Systemfunktionaler, anthropologischer und personfunktionaler Ansatz der Rechtssoziologie, in: Jahrbuch für Rechtssoziologie und Rechtstheorie 1 (1970), S. 41; dazu F. Rotter, Der personfunktionale Ansatz in der Rechtssoziologie. Eine Auseinandersetzung mit dem Ansatz von Helmut Schelsky, in: Recht und Gesellschaft (s. o. Anm. 6), S. 481.

20 Vig1. z. B. N. Luhmann, Funktion und Kausalität, in: Soziologische Aufklärung. Aufsätze zur Theorie sozialer Systeme, Bd. 1, 4. Aufl., 1974, S. 9 ff. (im Anschluß an die analytische Systemtheorie von T. Parsons, Das System moderner Gesellschaften, 2. Aufl., 1976, S. 12 ff.); ders., Funktionale Methode und Systemtheorie, ebda., S. 31; ders., Moderne Systemtheorien als Form gesamtgesellschaftlicher Analyse, in: J. Habermas/N. Luhmann, Theorie der Gesellschaft oder Sozialtechnologie - Was leistet die Systemtheorie?, 1974 , S. 7. Zum Recht als Systemstruktur überhaupt ders., Rechtssoziologie, S. 8 f., 105, 124, 134, 251 f., auch $R$.-P. Callies, Rechtstheorie als Systemtheorie, in: Rechtstheorie. Beiträge zur Grundlagendiskussion, hrsg. Jahr/Maihofer, 1971, S. 142.

21 Zwischen dem als Anfangspunkt und als gegenwärtig vorläufigen Endpunkt der theoretischen Diskussion zu bezeichnenden Beiträgen von $R$. Stödter, Deutschlands Rechtslage, 1948, und G. Ress, Die Rechtslage Deutschlands nach dem Grundlagenvertrag vom 21 . Dezember 1972, 1978, liegt eine nahezu unübrersehbare Literatur, innerhalb deren die Herausarbeitung der unterschiedlichen Denkan- 
der Versuch, diese Frage anzugehen, muß von vornherein und dies geschieht nicht immer mit der erforderlichen Deutlichkeit - einige Prämissen berücksichtigen:

$\mathrm{Zu}$ ihnen zählt zunächst, daß sich die Rechtslage Deutschlands aus der Sicht der Rechts- und Staatstheorie anders darstellen kann, als aus derjenigen des Völkerrechts oder gar des Staatsrechts. Hieraus folgen sowohl der Zwang, die Aussagezuständigkeit der jeweiligen Disziplin zu beachten, als auch das Erfordernis der Vermeidung eines Disziplinensynkretismus.

Dies bleibt unberücksichtigt, wenn in einer gewissen Beliebigkeit mit Instituten wie "Nation" - einem soziologischen -, "Staatsvolk" - einem staatstheoretischen -, „Staatsangehörige" - einem staatsrechtlichen Begriff - operiert und hierbei der Anschein ihrer Austauschbarkeit erweckt wird ${ }^{22}$.

$\mathrm{Zu}$ beachten ist weiterhin, daß die Deutung der Rechtsnatur Deutschlands unter keinem nur möglichen Blickwinkel mit Sicherheit auf allgemeine Zustimmung rechnen kann. Jedem nur denkbaren rechts- und staatstheoretischen Erklärungsversuch fehlt normative Verbindlichkeit - nicht Normativität, sondern Plausibilität vermag ihm eine tragfähige Grundlage zu verschaffen ${ }^{23}$.

Von der zweiten dieser beiden Prämissen aus kann die Vermutung geäußert werden, daß das Konsensziel um so eher erreicht wird, je höher das Abstraktionsniveau der Deutung ist, je weiter diese der tagespolitischen Situation entrückt ist.

\section{Rechtstheoretische Deutung}

Das verweist darauf, die Rechtslage der Bundesrepublik Deutschland, insbesondere ihr Verhältnis zur Deutschen Demokratischen Republik, in erster Annäherung aus der Sicht der

sätze durch $R$. Schuster, Deutschlands staatliche Existenz im Widerstreit politischer und rechtlicher Gesichtspunkte 1945-1963, 1963, einen Höhepunkt darstellt.

22 Kennzeichnend hierfür beispielsweise $H$. Rumpf, Vom Niemandsland zum deutschen Kernstaat, 1979, S. 107.

${ }^{23}$ In diesem Sinne ist $J$. Esser, Juristisches Argumentieren im Wandel des Rechtsfindungskonzepts unseres Jahrhunderts (= Sitzungsberichte der Heidelbenger Akademie der Wissenschaften, Phil.hist. Klasse), 1979, S. 24, zuzustimmen: „Plausibilität ist das Prädikart, das der diskursiv gefundene Lösungsvorschlag verdient, weil er nicht als unvermeidliche Konsequenz, sondern als optimales Ergebnis aus der Berücksichtigung aller relevanten Gesichtspunkte hervorgeht. Diese Optimierung ist im praktischen Diskurs das Ergebnis einer Abwägung des Beachtenswerten unter Berücksichtigung der Tragweite der Konsense." 
Rechtstheorie zu versuchen, die sich unter diesem Aspekt als praxisnäher erweist als die Rechtsdogmatik: Vergegenwärtigt man sich die Komplexität der Rechtsordnung insgesamt, ihre Natur als Beziehungsgefüge von Rechtsverhältnissen ${ }^{24}$, deren Gemeinsamkeit darin besteht, daß sie rechtsnormgestaltete Beziehungen zwischen Subjekten darstellen, die aber im übrigen - insbesondere, was Art und Ausmaß ihrer Determination angeht - mannigfache Unterschiede aufweisen, so zwingt nichts dazu, alle völkerrechtlichen und staatsrechtlichen Verhältnisse für sich oder auch unter sich nach denselben Kriterien zu beurteilen. Im Gegenteil läßt die polytome Natur der Rechtsordnung ${ }^{25} \mathrm{zu}$, auch das Rechtsverhältnis zwischen der Bundesrepublik Deutschland und der Deutschen Demokratischen Republik als ein eigengeartetes $\mathrm{zu}$ verstehen, das sich von sonstigen völkerrechtlichen und staatsrechtlichen Verhältnissen unterscheidet; für Besonderheiten im Verhältnis zu Berlin gilt sinngemäß dasselbe. Für diesen Unterschied ist erheblich, daß nicht nur - wie die Lehre vom Normstufenbau annimmt - jede Rechtserzeugungsstufe, sondern auch jedes Rechtsverhältnis eine autonome Determinante aufweist ${ }^{26}$, auf der nicht nur juristische, sondern auch metajuristische Elemente einzufließen vermögen. Für das Rechtsverhältnis zwischen Bundesrepublik Deutschland und Deutscher Demokratischer Republik ergibt sich hieraus, daß dies zwar zwischen zwei Staaten als Endsubjekten besteht - die demgemäß auch den Grundlagenvertrag miteinander abschließen konnten -, daß die metajuristische Determinante dieses Rechtsverhältnisses aber die beide umwölbende Nation darstellt, die jedes Rechtsverhältnis zwischen beiden Staaten mitbestimmt. Hier — als metajuristische Deter-

${ }^{24}$ N. Achterberg, Rechtsverhältnisse als Strukturelemente der Rechtsordnung. Prolegomena zu einer Rechtsverhältnistheonie, Rechtstheorie 9 (1978), 385; ders., Grundzüge einer Rechtsverhältnistheorie, Vortrag auf dem 9. Weltkongreß ,Zeitgenössische Rechtskonzeptionen" der Internationalen Vereinigung für Rechts- und Sozialphilosophie, Basel, 1979 (erscheint demnächst in den dem Kongreß gewidmeten Sonderbänden des ARSP). Zur Anwendbarkeit der Rechtsverhältnistheorie im Sozialnecht F. E. Schnapp, Sozialrecht und Verwaltungsrecht, SGb 79, 200 (202 ff.).

${ }^{25} N$. Achterberg, Rechtstheorie 9 (1978), $398 \mathrm{ff}$.

26 Zur autonomen Determinante der Rechtserzeugungsstufen $H$. Kelsen, Allgemeine Staatslehre, S. 243; zustimmend H. Nawiasky, Kritische Bemerkungen zur Lehre vam Stufenbau des Rechts, ZOffR VI, 488 (488). Ausführlich hierzu insb. J. Behrend, Untersuchungen zur Stufenbaulehre Adolf Merkls und Hans Kelsens, 1977, S. $82 \mathrm{ff}$. - $\mathrm{Zu}$ autonomen Determinante der Rechtsverhältnisse N. Achterberg, Rechtstheorie 9 (1978), 406. 
minante der rechtlichen Beziehungen zwischen beiden Staaten - gewinnt die Nation Bedeutung, nicht aber dadurch, daß sie in Fortführung der These von Mancini27 als Rechtssubjekt begriffen und damit als Reichssurrogat verwandt wird ${ }^{28}$. Aus rechtstheoretischer - genauer gesagt: rechtsverhältnistheoretischer - Sicht läßt sich die Beziehung zwischen der Bundesrepublik Deutschland und der Deutschen Demokratischen Republik mithin als intranationales interstaatliches Rechtsverhältnis bestimmen.

\section{Staatstheoretische Deutung}

Mag das Abstraktionsniveau dieser Deutung auf breiteren Konsens hoffen lassen, so ist indessen auch die Leistungsgrenze der rechtstheoretischen Aussage sichtbar: Mit ihr läßt sich keine Klarheit über den Fortbestand des Deutschen Reiches, auch nicht über die brennend gewordene Frage der deutschen Staatsangehörigkeit ${ }^{20}$ erzielen. In einer zweiten Annäherung ist daher die Einnahme eines staatstheoretischen und staatsrechtlichen Blickwinkels unerläßlich.

a) Der Fortbestand des Reiches über die Kapitulation hinaus ist schon bald zur herrschenden Meinung geworden ${ }^{30}$, so daß hierzu - obwohl als metazeitlicher Einstieg in die Thematik unverzichtbar - nur weniges gesagt $z u$ werden braucht: Aus der Sicht der Wiener Schule war die abweichende These vom Untergang des Reiches konsequent. Kelsens eigene Prämisse für diese Annahme deutet zwar vordergründig darauf hin, daß

${ }^{27}$ P. St. Mancini, Della Nazionalità come Fondamento del Diritto delle Genti (Vortrag 1851, abgedr. in: Diritto Internazionale, 1873, S. 1). Vgl. hierzu auch H. Rumpf, a. a. O., S. 34, 36 (welcher der Nation geradezu Rechtssubjektivität zuerkennt).

28 Wie dies bei $H$. Rumpf, a. a. O., S. 36 f., geschieht.

20 Dies insbesondere, seitdem die von den Regierungen der beiden deutschen Staaten vertretenen unterschiedlichen Positionen nach dem einschlägigen Protokollvermerk beim Abschluß des Grundlagenvertrags nicht mehr verdeckt werden konnten (vgl. Verträge, Abkommen und Vereinbarungen zwischen der Bundesrepublik Deutschland und der Deutschen Demokratischen Republik, hrsg. vom Presse- und Informationsamt der Bundesregierung, 1973, S. 27).

30 Auf ihr beruhen alle unterschiedlichen, im Schrifttum mitunter terminolagisch modifizierten Fortbestandistheorien (so die Dachtheorie, die Identitätstheorie, aber auch die Varianten der Zwei-Staaten-Lehre). Besonders übersichtlich hierzu R. Schuster, a. a. O., S. $77 \mathrm{ff}$., sowie neuestens I. v. Münch, Grundbegriffe des Staatsrechts I, 1979 , S. $33 \mathrm{ff}$. 
er hierbei völkerrechtlich und staatsrechtlich argumentiert und auf den Wegfall von Staatsorganen abgestellt hat ${ }^{31}$. In Wirklichkeit aber ergibt sich auf der Grundlage der Identifizierung von Staat und Recht schon staatstheoretisch nichts anderes: Dann führt nämlich ein durch Unterbrechung des Delegationszusammenhangs bewirkter Zusammenbruch der Rechtsordnung zugleich zum Untergang des Staats. Ber Einwand, faktische Situationen könnten nach der Reinen Rechtslehre diesen nicht zur Folge haben ${ }^{32}$, greift deshalb nicht durch, weil diese die Effektivität der Rechtsordnung als deren Geltungsbedingung anerkennt ${ }^{38}$. Indessen hat sich die Kelsensche Staatslehre in Deutschland immer nur einer geringeren Zustimmung erfreut als die Jellineksche ${ }^{84}$ - so evident deren Mängel auch sind ${ }^{35}$ : Sie beruhen weniger auf der Unvergleichbarkeit der Staatselemente als vielmehr auf der petitio principii, die in der Bezugnahme auf „Staats"gewalt, ,Staats"volk, ,Staats“gebiet als Konstitutitven des Staats liegt und die zumindest zu einer Korrektur der Staatsdefinition in der Richtung Anlaß geben $\mathrm{muß}, \mathrm{da} \beta$ der Staat als persönlicher und räumlicher Geltungsbereich einer von ursprünglicher Verbandsgewalt gesetzten Rechtsordnung zu verstehen ist.

Wie dem aber auch sei: Die Unsicherheit über den Fortbestand der Staatsgewalt zeigt sich darin, daß durch Verdoppelung von Argumenten eine Argumentationsinsuffizienz herbei-

${ }^{31} \mathrm{H}$. Kelsen, The legal Status of Germany acconding to the Declanation of Berlin, AJIL 39 (1945), 518 (519): ,The existence of an independent government is an essential element of a state in the eyes of international law. By abolishing the last Government of Germany the victorious powers have destroyed the existence of Germany as a sovereign state. Since her unconditional surrender, at least since the abolishment of the Dönitz Government, Germany has ceased to exist as a state in the sense of international law ...".

${ }^{32}$ So aber G. Dürig, VVDStRL 13, 28 f. S. demgegenüber den Diskussionsbeitrag von $H$. Nawiasky, VVDStRL 13, 65, sowie H. Rumpf, a. a. O., S. 175 .

${ }^{33}$ H. Kelsen, Reine Rechtslehre, 2. Aufl., 1960, S. $212 \mathrm{ff} ., 339 \mathrm{f}$.

${ }^{34}$ Die Staatselemente werden bei $G$. Jellinek, Allgemeine Staatslehre, S. $394 \mathrm{ff}$. dargestellt.

${ }^{35}$ Die neuere deutsche Staatstheorie steht der Drei-ElementeLehre überwiegend kritisch gegenüber, ohne sich jedoch von ihr $\mathrm{zu}$ lösen. Vgl. z. B. R. Herzog, Allgemeine Staatslehre, 1971, S. $85 \mathrm{ff}$; M. Kriele, Einführung in die Stalatslehre, 1975, S. 85 ff.; H. Krüger, Allgemeine Staatslehre, 2. Aufl., 1966, S. $145 \mathrm{f}$; $R$. Zippelius, Allgemeine Staatslehre, 6. Aufl., 1978, §§ 9-11, S. $41 \mathrm{ff}$. 
geführt wurde: indem nämlich zum einen angenommen wurde, die Besatzungsmächte hätten die Staatsgewalt treuhänderisch für die Reichsorgane ausgeübt, zum anderen darauf abgehoben wurde, daß die Staatsgewalt auf unterster Ebene fortbestanden hätte und durch deutsche Organe wahrgenommen worden wäre ${ }^{36}$. In der Tat läßt sich annehmen, daß die Reichsgewalt von den Besatzungsmächten ohne Auftrag ausgeführt wurde, und zwar außer im eigenen auch im Interesse des Deutschen Reiches ${ }^{37}$. Daß dies zutraf, wird dadurch indiziert, daß das Reich als Vertragspartner für einen zukünftigen Friedensvertrag sowie als Schuldner für Reparationslasten und damit als fortdauerndes Rechtssubjekt begriffen wurde.

b) Fanden das Grundgesetz und die Verfassung der Deutschen Demokratischen Republik im Jahre 1949 diese Rechtslage vor, so entsteht allerdings die Frage, welche Konsequenzen die Etablierung beider Verfassungsordnungen auf sie ausübte eine Problematik, die in der Geschichte der Bundesrepublik Deutschland von der strengen Identitätstheorie mit dem Alleinvertretungsanspruch und der Hallstein-Doktrin ${ }^{38}$ als ihren Konsequenzen bis $\mathrm{zu}$ der vom Bundesverfassungsgericht angenommenen Teilidentitätslehre ${ }^{39}$ ein wechselvolles Schicksal durchlebt hat. In der Tat haben alle Deutungsversuche ${ }^{40}$ beachtliche Mängel:

36 Vgl. dazu Th. Maunz, Deutsches Staatsrecht, 22. Aufl., 1978, $\S 2$ I, S. 9; ferner I. v. Münch, a. a. O., S. 29; H. Rumpf, a. a O., S. $178 \mathrm{f}$.

${ }^{37}$ Kritisch hierzu K. Doehring, Das Staatsrecht der Bundesrepublik Deutschland, 1976, S. 50 (mit der Begründung, daß das Besatzungsnecht auch nicht teilweise als deutsches Recht deklariert worden sei; hiergegen spricht indessen, daB Kontrollnatsgesetze und Militärregierungsverordnungen durchaus für Deutsche verbindlich waren); H. Rumpf, a. a. O., S. 23, 36 f., 179.

${ }^{38}$ Zur Hallstein-Doktrin R. Schuster, a. a. O., S. 272 ff. Zur Abkehr von Alleinvertretungsanspruch und Hallstein-Doktrin durch den Grundlagenvertrag zutreffend G. Ress, a. a. O., S. 272 ff., 303.

39 BVerfGE 36, 1 (16).

40 Die Terminologie ist vielfältig. Beispielsweise unterscheidet R. Schuster, a. a. O., S. $77 \mathrm{ff}$., $114 \mathrm{ff} .:$ 1. Identitätstheonien (Staatskern-, Schrumpfstaats-, Kongruenz-, Teilidentitätstheorie), 2. Neustaats- oder Irredentatheorie, 3. Zwei-Staaten-Theorien (als echte: Äquivalenz-, Sezessionstheorie, als unechte: Kernstaatstheorie), 4. Drei-Staaten-Theorien (Dachtheorie, dualistische Gestaltungstheorie). S. dazu A. Bleckmann, Grundgesetz und Völkerrecht, 1975, S. 79 ff.; I. v. Münch, a. a. O., S. $23 \mathrm{ff}$; G. Ress, a. a. O., S. 199 ff.; $H$. Rumpf, a. a. O., S. $183 \mathrm{ff}$. 
Die Dachtheorie ${ }^{41}$ setzt die Annahme eines dritten Staats eben des Deutschen Reiches - voraus, der die bereits erwähnten Kriterien des Staats erfüllen muB. Von ihnen aber fehlt eine eigenständige Rechtsordnung, als deren Geltungsbereich dieser dritte Staat umschrieben werden könnte. Es gibt keine bis zum Eintritt der Handlungsfähigkeit von Reichsorganen gewissermaßen ruhende Reichsrechtsordnung mehr, nachdem das ehemalige Reichsrecht auf Bund und Länder übergeleitet worden ist ${ }^{42}$. Die Identitätstheorie in der Variante der Staatskerntheorie ${ }^{43}$ läßt die Gründung der Deutschen Demokratischen Republik als separatistisch und illegal erscheinen. Dies braucht noch nicht die Folge eines Eingliederungsanspruchs auszulösen, läßt es aber doch als schwer begreiflich erscheinen, daß die Bundesrepublik Deutschland zu der Deutschen Demokratischen Republik durch den Grundlagenvertrag in ein Rechtsverhältnis getreten ist, welches auf der Grundlage der Gleichberechtigung der Entwicklung „normaler gutnachbarlicher Beziehungen" 44 dienen soll. Damit bleibt lediglich die „Schrumpfstaatstheorie ${ }^{\text {"455, }}$, wobei diese allerdings eine überaus desintegrierende Wirkung auslöste, falls aus ihr die Konsequenz gezogen werden müßte, daß sich die Deutsche Demokratische Republik als Ausland erweist und ihre Bürger im Verhältnis zur Bundesrepublik Deutschland als Ausländer darstellen.

c) Nun könnte man sich angesichts dieser Situation mit der vorgenommenen rechtstheoretischen Deutung zufrieden geben

${ }^{41}$ Vertreten linsb. von G. Dürig, VVDStRL 13, 51; ders., Deutsches Reich VII, in: Evangelisches Staatslexilkon, Sp. $464 \mathrm{f}$.

42 Ant. $123 \mathrm{ff}$. GG. Die mit der Identitätstheonie in Zusammenhang gebrachte Frage, ob diese Vorschriften hiernach nur deklaratorische Natur besitzen (BK-Holtkotten, Art. 123 I, Erl. II 1; W. Grewe, Das Grundgesetz, DRZ 49, 313 [315]; Th. Maunz/G. Dürig/R. Herzog/ R. Scholz, Grundgesetz, 1978, Art. 123 RdNr. 1), mag hier auf sich beruhen.

${ }^{43}$ Begniff bei R. Schuster, a. a. O., S. 84. Die Staatskemtheorie umschließt im übrigen die These, daß die durch die Bundesrepublik Deutschland auszuübende Hoheitsgewalt des Reiches sich auch auf das Gebiet der Deutschen Demokratischen Republik erstreckt und dort nur derzeit nicht ausübbar ist, M. Kriele, a. a. O., S. 77.

44 Ant. 1 Vertrag über die Grundlagen der Beziehungen zwischen der Bundesrepublik Deutschland und der Deutschen Demokratischen Republik (BGBl. 1973 II 423). Dazu G. Ress, a. a. O., S. 229 ff.

${ }_{45}$ Begriff bei R. Schuster, a. a. O., S. 89. Im Unterschied zur Staatskerntheorie enthält die Schrumpfstaatstheorie nicht die These der auch auf das Gebiet der Deutschen Demokratischen Republik erstreckten, aber nur derzeit nicht ausübbaren Hoheitsgewalt, $M$. Kriele, a. a. O., S. 77. 
und sich dabei auf die These zurückziehen, daß diese eher international plausibel gemacht $\mathrm{zu}$ werden vermag als rechtsdogmatische Erkenntnisse und aus ihnen abgeleitete Konsequenzen, wobei ein Verzicht auf die These vom Fortbestand des Reiches entgegen der Ansicht des Bundesverfassungsgerichts $^{46}$ keineswegs mit einem solchen auf Wiedervereinigung verbunden zu sein braucht, die Nation sich vielmehr durchaus als Determinante des Ausbaus der rechtlichen Beziehungen zwischen Bundesrepublik Deutschland und Deutscher Demokratischer Republik eignet. Indessen bliebe die theoretische Selbstgenügsamkeit, die allein in der Konsenserzielung läge, nicht nur politisch unbefriedigend, sondern sie mißachtete vor allem, daß das Grundgesetz den Begriff „Deutschland“ im Sinne des „Staats“, nicht nur in demjenigen der „Nation" gebraucht ${ }^{47}$. Dem Bundesverfassungsgericht ist mit seiner These, daß die Bundesrepublik Deutschland in ihren räumlichen und persönlichen Grenzen das Deutsche Reich - von dem unlogischen, daher unhaltbaren, aber auch überflüssigen Begriff ,teilidentisch" sowie einigen anderen Argumentationsschwächen abgesehen $^{48}$ - fortsetzt, eine plausible Deutung gelungen ${ }^{49}$, die lediglich als solche noch nicht schlüssig erscheinen läßt, daß die Deutsche Demokratische Republik der Bundesrepublik Deutschland gegenüber kein Ausland darstellt. Denn über die Identi-

46 BVerfGE 36, 19.

47 In der Präambel, den Vorschriften über die Bürgerrechte sowie in Art. 16, 23, 116, 146 GG. Ebenso BVerfGE 36, 15 f., 19.

${ }^{48}$ BVerfGE 36, 16. - Kritisch dazu auch BK-Kimminich, Anhang: Grundvertrag, RdNr. 178.

${ }^{49}$ Der Entscheidung wird im Grundsatz weithin gefolgt (nach Th. Maunz/G. Dürig/R. Herzog/R. Scholz, a. a. O., Präambel RdNr. 22, ist sie zur ,amtlichen Lehre bei der Auslegung der Präambel des Grundigesetzes geworden"), wenn auch an Details Kritik geübt worden ist, so an ider These von den inter-se-Beziehungen (dazu $G$. Ress, a.a. O., S. 188 ff.) oder an der Vermengung der Identitätslehre mit Elementen der Dachtheorie (dazu insb. U. Scheuner, Die staatsrechtliche Stellung der Bundesrepublik, DOV 73, 581 [583]; $\boldsymbol{H}$. $\boldsymbol{P}$. Ipsen, DOV 74, $301 \mathrm{f}$; W. Kewenig, Auf der Suche nach einer neuen Deutschland-Theorie, DOV 73, 797; O. Kimminich, Das Urteil über die Grundlagen der staatsrechtlichen Konstruktion der Bundesrepublik, DVBl. 73, 661; Th. Oppermann, Anmerkung zu BVerfG, JZ 73, 588, JZ 73, 594 [596 f.]; C. Tomuschat, Auswärtige Gewalt und verfiassungsrechtliche Kontrolle, DOVV 73, 801). Zusammenfassung der Kritik bei H. v. Morr, Der Bestand der deutschen Staatsangehörigkeit nach dem Grundlagenvertnag, 1977, S. 41 ff. - Positiver urteilt $A$. Bleckmann, a. a. O., S. 97 f., wenn er das Schwanken des Bundesverfassungsgerichts zwischen Dach- und Identitätstheorie 
tät auch der Deutschen Demokratischen Republik mit dem Deutschen Reich können sich im Bereich des Staatsrechts nicht die Staatsorgane der Bundesrepublik, sondern lediglich diejenigen der Deutschen Demokratischen Republik verhalten.

Das aber zwingt dazu, die Lösung auch dieser Frage in der Staatstheorie zu suchen. Ihr Ausgangspunkt muß die Erkenntnis sein, daß die Begriffe "Staat" und „Staatsvolk“ - dieses abbreviierend für den persönlichen Geltungsbereich der von einer ursprünglichen Herrschaftsmacht gesetzten Rechtsordnung verstanden -, aber auch die Begriffe "Staatsvolk" und "Staatsangehörigkeit" und infolgedessen schließlich auch die Begriffe „Staat" und „Staatsangehörigkeit" keine vollständige Korrelation besitzen. Staat gibt es nicht ohne Staatsvolk, wohl aber Staatsvolk ohne Staat ${ }^{50}$ - dann nämlich, wenn eines der anderen Staatsmerkmale fehlt, anderenfalls bliebe deren Addition ohne Sinn. Ebenso gibt es Staatsangehörigkeit nicht ohne Staatsvolk, wohl aber - wie die Gliedstaaten im Bundesstaat belegen - Staatsvolk ohne Staatsangehörigkeit. Auch nachdem die Reichsrechtsordnung auf die Bundesrepublik Deutschland übergeleitet worden war, vermochte daher außer der deutschen Nation auch das deutsche Staatsvolk fortzubestehen. Verhält es sich im übrigen so, daß die Staatsangehörigen keineswegs mit dem Kreis der einer Staatsgewalt Unterworfenen identisch sind ${ }^{51}$ - dieser kann größer, aber auch kleiner sein -, so erweist sich nicht der Staat, sondern das Fortbestehen des Staatsvolks als Anknüpfungspunkt für die Staatsangehörigkeit. Man mag daher zum Fortbestand des Deutschen Reiches stehen, wie immer man will: Bereits das Fortbestehen des Staatsvolks führt zur Aufrechterhaltung einer gemeinsamen deutschen Staatsangehörigkeit ${ }^{52}$.

während einer „Ubergangslage“ - als die sich die gegenwärtige Rechtslage Deutschlands darstelle - hinnehmbar bezeichnet.

50 In diesem Sinne schon $A$. Arndt, in: Deutschland als Wahrheit und Wagnis, Die Zeit Nr. 9, vam 4. 3. 1954: „Das Volk setzt seinen Staat fort, nicht kann der Staat ein Volk fontsetzen"; ders., Teilstaat oder Staatsteil?, SPD-Pressedienst v. 23. 9. 1959, S. 1: „es gibt kein Volk, das zwei Staaten hat." iS .dazu auch $R$.Schuster, a. a. O., S. $31 \mathrm{ff}$.

51 So besonders deutlich $M$. Kriele, a.a. O., S. 99; R. Zippelinus, a. a. O., § $10 \mathrm{IV}$, S. 55.

52 Die zuvor genannite These umschließt einen doppelten - im folgenden noch näher auszuführenden - Aspekt: 1) dive Zuord- 


\section{Konsequenzen}

Für die Weiterentwicklung der Beziehungen zwischen der Bundesrepublik Deutschland und der Deutschen Demokratischen Republik wird indessen - wenn nicht alles trügt - die Nation eine größere Bedeutung erlangen und ihre Eignung als metajuristische Determinante der rechtlichen Beziehungen zwischen beiden Staaten erweisen müssen ${ }^{53}$. Von dieser Prämisse

nung der Staatsangehörigkeit zum Staatsvolk, 2) die Annahme der Möglichkeit eines Fortbestehens des Staatsvolks auch nach Untergang des Staats. Im einzelnen ergibt sich dazu folgendes: $Z u$ 1): Unbeschadet des Umistands, daß die Staatsangehörigkeitsnormen im staatsrechtlichen Sinne ein Rechtsverhältnis der Staatsangehörigen zum Staat begründen, bedeutet dies im staatstheoretischen Sinne keine Abhängigkeit der Staatsangehörigkeit vom Starat. Wenn in einem Rechtsverhältnis das eine Endsubjekt entfällt (hier möglicherweise der Staat), hat dies auf die Existenz des anderen Endsubjekts (der Staatsangehörigen) keinen Einfluß. Von den nach der Drei-Elemente-Lehre anerkannten Staatselementen kommt „staatsangehörig“ als Eigenschaft weder der Staatsgewalt, noch des Staatsgebiets, sondern allein der Mitglieder des Staatsvolks in Betracht; „staatsangehörig" ist kein sachliches, sondern ein persönliches Merkmal. Von der hier vertretenen Auffassung aus, daß die Bundesrepublik Deutschland mit dem Deutschen Reich nicht nur in ihnem Gebiets-, sondern auch in ihrem Volksumfang identisch ist, ergibt sich schon hiernach die Fortdauer der deutschen Staatsangehörigkeit. $\mathbf{Z u ~ 2 ) : ~ D i e ~ m i t u n t e r ~ a n z u t r e f f e n d e ~ A u f f a s s u n g , ~ S t a a t s v o l k ~ k o ̈ n n e ~}$ nicht ohne Staat fortbestehen, ist falsch. Ihre Ursache mag die bereits erwähnte, in der Drei-Elemente-Lehre liegende petitio principii sein, die zu dem Fehlschluß einer Abhängigkeit des Staatsvolkbegriffs vom Staatsbegriff verleiten mag - ein Mißverständnis, idas sich schon bei G. Jellinek, a. a. O., S. 426 f., findet, nach dem sich die Staatselemente ,gegenseitig bedingen“, so daß es nur (aber immerhin) „hypothetisch möglich [sei], eines von ihnen zu isolieren, da jedes das andere zur Voraussetzung hat" (ähnlich gegenwärtig z. B. H. Rumpf, a.a. O., S. 96, 156). Wäre dem wirklich so, dann wäre die gesamte Drei-Elemente-Lehre eine Tautologie. Richtigerweise wird man vielmehr anzunehmen haben, daß der Staat zwar bereits mit einem seiner drei Elemente entfällt, daß der Wegfall eines von ihnen aber noch nichts über das Schicksal der beiden anderen aussagt, sondern dieses gesondert zu prüfen ist. Staatsvolk entfällt hiernach, wenn sich dieses einem anderen Staat unterstellt oder von ihm einverleibt wird; daß dies bezüglich des Volks des Deutschen Reiches igeschehen wäre, ist jedoch nicht erkennbar.

53 Mit Recht bemerkt R. Herzog, a. a. O., S. 45, Anm. 15: „Je weiter die Hoffnung auf eine deutsche Wiedervereinigung hinausrückt, desto deutlicher wird sich zeigen, daß hier [sc. in der Nation und dem aus ihr folgenden, Willen zur Staatlichkeit'] wenigstens der 
aus sind die sich hieraus ergebenden Konsequenzen zu entwikkeln. Sie stellen sich folgendermaßen dar:

Nation läßt sich nicht, wie dies mitunter geschieht, auf kulturelle Gemeinsamkeit reduzieren. Sie bedeutet vielmehr gemeinsame Abstammung, gemeinsame Sprache, gemeinsame Geschichte, gemeinsame Kultur, gemeinsame Gesellschaftordnung mit allen ihren Subsystemen ${ }^{54}$ - wobei freilich festzuhalten ist, daß die Nation (wie übrigens auch Rechtsstaatlichkeit oder Sozialstaatlichkeit) einen relativen Begriff darstellt ${ }^{55}$. Man wird von Nation also auch dann noch sprechen können, wenn eines oder einige der zuvor genannten Merkmale - die gemeinsame Gesellschaftsordnung beispielsweise - fehlen oder nur unvollkommen entwickelt sind.

Alle zuvor genannten Kriterien haben die Gemeinsamkeit als gemeinsamen Nenner. Daraus folgt das Erfordernis, Gemeinsamkeit $\mathrm{zu}$ erhalten und möglichst $\mathrm{zu}$ vergrößern. Hier - in der Nationerhaltung - gewinnt die Integrationstheorie eine neue und - berücksichtigt man Smends ausdrückliche Bezugnahme auf Renan ${ }^{56}$ - sogar wieder ihre ursprüngliche Bedeutung ${ }^{57}$. Sie legt für die weitere Ausgestaltung des Verhältnisses zwischen Bundesrepublik Deutschland und Deutscher Demokratischer Republik die Katalogisierung aller integrieren-

begriffliche Ansatz zu einem Verständnis der deutschen Situation liegt." - Zur Bedeutung der Nation für die DDR U. Scheuner, Das Problem der Nation und des Verhältnisses zur Bundesrepublik Deutschland, in: Drei Jahrzehnte Außenpolitik der DDR, hrsg. Jacobsen/Leptin/Scheuner/Schulz, 1979, S. 85 (101 ff.).

${ }^{54}$ Zum Begriff der Nation und zu ihrer Bedeutung auch in der Staatstheorie F. Ermacora, Allgemeine Staatslehre, 1. Teilbd., 1970, S. $58 \mathrm{ff}$; $H$. Heller, Staatslehre, hrsg. Niemeyer, 3. Aufl., 1963, S. $161 \mathrm{f}$; R. Herzog, a. a. O., S. $43 \mathrm{ff}$.; M. Kriele, a. a. O., S. $101 \mathrm{ff}$; ders., Die Bedeutung der Verträge für den Erhalt der Nation, in: Zur deutschen Frage, 1972, S. 15 (15 ff.); G. Leibholz, in: Evangelisches Staatslexikon, Sp. 1589; H. Rumpf, a. a. O., S. 107 ff.; M. Weber, Wirtschaft und Gesellschaft, 4. Aufl., hrsg. Winckelmann, 2. Halbbd., 1956, Kap. VIII, § 5, S. $527 \mathrm{ff}$.

s5 Von der „Relativität" der Staatlichkeit (beispielsweise der Rechtsstaatlichkeit) gesprochen wird z. B. von W. Apelt, Diskussionsbeitrag, VVDStRL 12, 107; W. Kägi, Rechtsstaat und Demokratie (Antinomie und Synthese), in: Demokratie und Rechtsstaat, Festgabe für Zaccaria Giacometti, 1953, S. 107 (135); A. Vodopivec, Die Balkanisierung Österreichs, 1966, S. $313 \mathrm{ff}$. Vgl. auch N. Achterberg, Antinomien verfassunggestaltender Grundentscheidungen, Staat 8 (1969), 159 (162 f.).

${ }^{58}$ E. Renan, Qu'est-ce qu'une nation?, 1882.

${ }^{57}$ R. Smend, Staatsrechtliche Abhandlungen und andere Aufsätze, 2. Aufl., 1968, S. 136, 475. 
den und desintegrierenden Vektoren nahe mit dem Ziel, die integrierenden $\mathrm{zu}$ aktivieren, die desintegrierenden $\mathrm{zu}$ inaktivieren und auf dieser Grundlage die interstaatlichen Rechtsverhältnisse zwischen den beiden Staaten zu determinieren ${ }^{58}$.

Sowohl die integrierenden als auch die desintegrierenden Wirkkräfte sind juristischer und metajuristischer Natur. Eine Auflistung muß in diesem Zusammenhang aus Zeitgründen unterbleiben, so daß es bei einigen Anmerkungen hierzu bewenden muß: Als einer der wichtigsten desintegrierenden Vektoren erweist sich der Zeitablauf, der von gemeinsamer Geschichte, gemeinsamer Gesellschafts- und gemeinsamer Wirtschaftsordnung immer weiter weg führt und damit auch die Kenntnis über den jeweiligen anderen Staat vermindert. Wer Tilsit in die Schweiz verlegt - wie das selbst bei heutigen Examenskandidaten vorkommt -, beweist kein hohes Nationbewußtsein. Die Integrierung der Bundesrepublik Deutschland in die Europäische Gemeinschaft läßt sich demgegenüber im Verhältnis zur Deutschen Demokratischen Republik noch nicht ohne weiteres als desintegrierender Vorgang bewerten. Rechtssubjekte gehören in der komplexen Rechtsverhältnisordnung in aller Regel mehreren Rechtsverhältnissen an und sie können dies auch, solange die Rechtsverhältnisse nicht alternative $\mathrm{Zu}$ ordnungen erzwingen, sondern kumulative erlauben, was von ihrer jeweiligen Außen-Innen-Differenzierung abhängt. Die gegenwärtige Konzeption der Europäischen Gemeinschaft zumindest steht dem Ausbau der intranationalen interstaatlichen Beziehungen zwischen der Bundesrepublik Deutschland und Deutscher Demokratischer Republik nicht entgegen ${ }^{59}$.

58 Dabei ist hervorzuheben, daß die herkömmlicherweise durch das fortdauernde Plebiszit (R. Smend, a. a. O., S. 136, 138 [,der Staat ist, weil und sofern er sich dauernd integriert..."]) sich gleichsam von selbst vollziehende Integration um so schwächer wird, je stärker sich desintegrierende Vektoren bemerkbar machen. Dies bewirkt, daß an die Stelle des Plebiszits gezielte integrierende Maßnahmen - wie vertragliche Vereinbarungen - treten müssen, um einheitswahrend und -stiftend zu wirken (mit Recht formuliert G. Ress, a. a. O., S. 221: „Die Nation vermittelt nicht zwingend staatliche Einheit"; ähnlich W. Fiedler, Staats- und völkerrechtliche Probleme des Staatsuntergangs, ZfP XX [1973], 150 [174]). Integration erfolgt dann nicht mehr „intransitiv", sondern „transitiv", doch steht dies dem Integrationsbegriff nicht entgegen (vgl. $R$. Smend, a. a. O., S. $241 \mathrm{f}$. [zum Verfassungsrecht als Integrationssystem S. 476]).

59 Ebenso K. Doehring, DVB1. 79, $636 \mathrm{ff}$., der aber auch hervorhebt, daß dies nicht so zu bleiben braucht. 
Als ein besonders wichtiger Integrationsfaktor stellt sich - und dies ist nun staatsrechtlich von besonderer Bedeutung die Stabilität der staatlichen Binnenstruktur dar. Sie ist Voraussetzung für Integrationserfolge. Damit wird der Blick auf die staatliche Entwicklung der Bundesrepublik Deutschland unter dem Grundgesetz gelenkt mit dem Ziel, zu einer Aussage darüber zu gelangen, ob ihre Binnenstruktur sich als labil oder als stabil und damit als ungeeigneter oder geeigneter Integrationsfaktor erweist.

\section{Die Stabilität der staatlichen Binnenstruktur als Integrationsfaktor}

1. Die Bedeutung des Bundesverfassungsgerichts für die Festigung der Verfassungslage in der Bundesrepublik Deutschland

a) Die Betrachtung der staatsrechtlichen Entwicklung unter dem Grundgesetz darf sich dabei nicht allein am verfassungsgesetzlichen Normenbestand orientieren, sondern muß insbesondere Rechtsstellung und Rechtsprechung des Bundesverfassungsgerichts einbeziehen, das diese wesentlich mitgeprägt hat. Diese Mitprägung wird von den Kritikern des Bundesverfassungsgerichts gern als Usurpation von Gesetzgebung oder Uberschreitung des judicial self-restraints bezeichnet ${ }^{60}$, zu dem sich das Bundesverfassungsgericht indessen selbst ausdrücklich bekennt $^{61}$. Zu seinen Kritikern zählen dabei merkwürdigerweise auch diejenigen, die entweder jedem oder zumindest dem vom

${ }^{60}$ Vgl. hierzu insb. $M$. Kriele, Recht und Politik in der Verfassungsrechtsprechung, NJW 76, 77; C. Müller, Das Bundesverfassungsgericht: Gesetzgeber des Gesetzgebers?, Vortrag vor der TheodorHeuss-Akademie Gummersbach, 23. 5. 1976; C. Tomuschat, DOV 73, $808 \mathrm{f}$; P. Wittig, Politische Rücksichten in der Rechtsprechung des Bundesverfassungsgerichts?, Staat 8 (1969), 137. - Einschlägige Entscheidungen des Bundesverfassungsgerichts, hinsichtlich deren dem Gericht mitunter zuwenig judicial self-restraint unterstellt wird, sind BVerfGE 36,$1 ; 37,271 ; 39,1 ; 40,296$. Umgekehrt wird dem Bundesverfassungsgericht aber auch zuviel judicial self-restraint vorgeworfen hinsichtlich BVerfGE 30, 1 (so durch $P$. Häberle, Kommentierte Verfassungsrechtsprechung, 1979, S. 91 [der im übrigen ein Wechselspiel zwischen „judicial restraint" und ,judicial activism" befürwortet, S. 417, 430, 442]), Angemessenen self-restraint im Mitbestimmungsurteil bescheinigt dem Bundesverfassungsgericht $K$. $M$. Meessen, Das Mitbestimmungsurteil des Bundesverfassungsgerichts, NJW 79, $833(833,837)$.

61 BVerfGE 36, 1 (LS 2). 
Bundesverfassungsgericht gefundenen Recht den Charakter des „Politischen" beilegen ${ }^{62}$, obwohl gerade von dieser Position aus dem Bundesverfassungsgericht nun wirklich überhaupt kein Hinübergreifen in die politische Sphäre vorgeworfen werden kann. Die eine These ist im übrigen so falsch wie die andere:

Abgesehen von der begrifflichen Unschärfe des „Politischen"68, besagt die Annahme politischer Natur des Rechts nichts anderes, als daB jede Rechtsetzung - und solche stellt wegen der Ambivalenz von Rechtsanwendung und Rechtsetzung auch der Richterspruch dar ${ }^{64}$ - wegen der Einbettung der Rechtsordnung in die sie umwölbende Gesellschaftsordnung zugleich ein Stück Sozialgestaltung ist ${ }^{66}$. Die Sonderstellung, die das Bundesverfassungsgericht hierbei einnimmt, liegt nur - wenn auch immerhin - darin, daß der rückkoppelnde Strang richterlicher Kontrolle in seinem Fall auf der Verfassungsebene induziert wird und infolgedessen eine wesentlich größere soziale Breiten- und Tiefenwirkung entfaltet als vergleichbare Entscheidungen anderer Gerichte ${ }^{68}$.

${ }^{62}$ Zum politischen Charakter des Verfassungsrechts schon $H$. Triepel, Staatsrecht und Politik, 1927. Vgl. neuerdings z. B. W.-R. Schenke, Der Umfang der bundesverfassungsgerichtlichen Uberprüfung, NJW 79,1322 (1322).

6s Versuche seiner Bestimmung sind allerdings vielfältig, s. z. B. W. Besson, Politik (I), in: Evangelisches Staatslexikon, Sp. 1855; O. H. v. d. Gablentz, Politik als Wissenschaft, ZfP I (1954), 2; P. Häberle, a. a. O., S. 433 ff., 443; $M$. Hättich, Lehrbuch der Politikwissenschaft, 1. Bd., 1967, S. 21 ff.; U. Scheuner, Staatstheorie und Staatsrecht, hrsg. Listl/Rüfner, 1978, S. 472; F. Schuppert, Die verfassungsgerichtliche Kontrolle der Auswärtigen Gewalt, 1973, S. $117 \mathrm{ff}$; K. Sontheimer, Politische Wissenschaft und Staatsrechtslehre, in: Politik, hrsg. Bergstraesser, 1963, S. 7; K. Stern, a. a. O., § 1 V 2, S. $14 \mathrm{ff}$.; D. Sternberger, Begriff der Politik als Wissenschaft, in: Synopsis, Festgabe für Adolf Weber, 1948, S. 687; M. Weber, Politik als Beruf, in: Gesammelte politische Schriften, hrsg. Winckelmann, 2. Aufl., 1958, S. 493 (494).

*4 Spätestens seit der Merkl-Kelsenschen Stufenlehre (A. Merkl, Prolegomena zu einer Theorie des rechtlichen Stufenbaues, in: Gesellschaft, Staat und Recht, Untersuchungen zur Reinen Rechtslehre [Festschrift Hans Kelsen], 1931, S. 252; ders., Allgemeines Verwaltungsrecht, 1927, S. 15, 173; H. Kelsen, Reine Rechtslehre, 1. Aufl., 1934, S. 62 ff., 2. Aufl., 1960, S. 240) dürfte sich diese Erkenntnis allgemein durchgesetzt haben.

${ }_{65}$ Ausführlicher hierzu N. Achterberg, Bundesverfassungsgericht und Zurückhaltungsgebote - Judicial, political, processual, theoretical self-restraints, DÖV 77, 649 (650 f.).

${ }^{66}$ Dazu näher $N$. Achterberg, Rechtstheoretische Grundlagen einer Kontrolle der Gesetzgebung durch die Wissenschaft, Rechtstheorie 1 (1970), 147 (153); ders., DOV 77, $651 \mathrm{f}$. 
Unrichtig ist aber auch der Vorwurf eines unter Mißachtung des judicial self-restraints erfolgten Übergreifens in die metarechtliche Sphäre des Politischen oder in die metajudizielle der Legislative $^{67}$. Die deutsche Rechtsordnung kennt keine politicalquestion-doctrine $e^{68}$, so daß das Bundesverfassungsgericht seine Entscheidung nicht verweigern kann, weil die ihm vorgelegte Frage politischen Charakter trägt, zum anderen kann keine wie auch immer geartete Verfassungsorgantreue ${ }^{69}$ das Bundesverfassungsgericht daran hindern, seine ihm verfassungsgesetzlich zuerkannten Kompetenzen wahrzunehmen und auszuschöp$f^{70}{ }^{70}$. Nehmen die Verfassungsnormen an einer geringen Rechtsdetermination und zugleich hohen Sozialdetermination teil, so bewirken die Entscheidungen des Bundesverfassungsgerichts im übrigen eine Verstärkung eben jener rechtlichen Determinanten der Verfassung, was eher den rechtlichen, als den meta-

67 Umgekehrt wird man vielmehr eine hinreichende Zurückhaltung attestieren können, wenn das Bundesverfassungsgericht dem Gesetzgeber eine Einschätzungsprärogative beim Gesetzesbeschluß zuspricht, ihm einen weiten Gestaltungsspielraum zuerkennt, sich selbst dagegen nur eine beschränkte Kontrollkompetenz zumißt (mit einer Beurteilungsskala von „Evidenzkontrolle“ über „Vertretbarkeitskontrolle" bis zu „intensivierter inhaltlicher Kontrolle", wobei der jeweils anzuwendende Maßstab sich nach dem materiell-rechtlichen Problemzusammenhang richte). Vgl. dazu K. M. Meessen, NJW 79, 836.

68 Zur political-question-doctrine des US-Verfassungsrechts $R$. Dolzer, Die staatstheoretische und staatsrechtliche Stellung des Bundesverfassungsgerichts, 1972, S. $100 \mathrm{ff}$; $B$. Eisenblätter, Die Uberparteilichkeit des Bundesverfassungsgerichts, 1976, S. 86 ff.; F. W. Scharpf, Grenzen der richterlichen Verantwortung, 1975, passim; W.-R. Schenke, NJW 79, 1325; R. Zuck, Political-Question-Doktrin, Judicial-self-restraint und das Bundesverfassungsgericht, JZ 74, 361.

${ }^{60} \mathrm{Zu}$ diesem Thema gerade im Hinblick auf das Bundesverfassungsgericht ausführlich W.-R. Schenke, Die Verfassungsorgantreue, 1977, S. 115 ff., der mit Recht auf die Uberlagerung der (von ihm [S. 26] auf den „Gedanke[n] der Gewinnung staatlicher Einheit durch Integration" zurückgeführten) Verfassungsorgantreue durch andere verfassungsrechtliche Prinzipien, insbesondere dasjenige der „Gewaltentrennung“" verweist (S. 116); ders., NJW 79, 1325.

${ }_{70}$ Damit wird nicht in Abrede gestellt, daß dem Bundesverfassungsgericht im Rahmen seiner verfassungsrechtlichen Zuständigkeiten Beschränkungen auferlegt sein können, wie beispielsweise Zurückhaltung bei obiter dicta (so auch W.-R. Schenke, Verfassungsorgantreue, S. $122 \mathrm{ff}$.; ders., NJW 79, $1328 \mathrm{f}$.). Ob dies freilich eine Folge von Verfassungsorgantreue ist und sich nicht nur aus einfachen prozeßrechtlichen Erwägungen ergibt, mag hier auf sich beruhen. 
rechtlichen (,politischen“) Charakter der Rechtsprechung des Bundesverfassungsgerichts unterstreicht.

b) In der Rechtsprechung des Bundesverfassungsgerichts von größter Bedeutung sind seine hermeneutischen, insbesondere interpretationstheoretischen Erkenntnisse ${ }^{71}$. $\mathrm{Zu}$ ihnen zählt die Absage an die Unterstellung der Möglichkeit, verfassungswidriger Verfassungsnormen": Indem das Gericht die Verfassung als Einheit begreift und die Existenz aneinander meßbarer ranghöherer und rangniederer Vorschriften auf Verfassungsebene prinzipiell verneint ${ }^{72}$, stimmt es mit dem in der Rechtswissenschaft anzutreffenden Theorem von der Konkordanz der Verfassungsnormen ${ }^{73}$ überein - und zwar im Sinne sowohl internormativer, als auch - wie gerade das Mitbestimmungsurteil durch das Postulat optimaler Verwirklichung von Bestandsgarantie, Inhalts- und Schrankenbestimmung sowie Sozialpflichtigkeit des Eigentums bestätigt hat ${ }^{74}$ — „intranormativer Konkordanz".

Nur so läßt sich auch begründen, daß die verfassunggestaltenden Grundentscheidungen als Auslegungsmaximen für alles andere Recht herangezogen werden dürfen ${ }^{75}$ : Ihre formelle Gleichrangigkeit mit anderen Verfassungsnormen darf nicht darüber hinwegtäuschen, daß ihnen eine materielle Höherwertigkeit zukommt, die sie im Wege der Verfassungskonkordanz in der Tat als Auslegungsrichtlinien geeignet macht. Allein aus der Bindung an Gesetz ,und Recht", allein aus dem Bekenntnis auch des Bundesverfassungsgerichts zur Existenz überpositiven Rechts im Sinne einer der positiven Rechtsordnung vorgeordneten Idee der Gerechtigkeit ${ }^{76}$ läßt sich dies nämlich des-

71 Insbesondere deshalb, weil eben gerade die Auslegungsarbeit am Grundgesetz, die vor allem das Bundesverfassungsgericht leistet, von erheblicher Bedeutung für die Verfassungsentwicklung ist (überzogen allerdings W. Hennis, Alternativen ohne Spielraum - Möglichkeiten und Unmöglichkeiten des politischen Systems, in: W. Scheel [Hrsg.], Nach dreißig Jahren, S. 58 [58: „Das Grundgesetz gilt heute so, wie es in Karlsruhe ausgelegt wird"]).

${ }_{72}$ BVerfGE 3, 225 (231 ff.); 4, 294 (296). - Das Bundesverfassungsgericht hat in seiner bisherigen Rechtsprechung noch niemals Veranlassung gehabt, die Verfassungswidrigkeit einer Verfassungsnorm anzunehmen. In größerem Umfang wandte sich dem Problem, soweit ersichtlich, erstmals $O$. Bachof, Verfassungswidrige Verfassungsnormen?, 1951, S. 32 ff., zu, der die Möglichkeit solcher Normen prinzipiell bejahte.

${ }^{73}$ K. Hesse, a. a. O., $\$ 2$ III 2 c, S. 28 f.; F. Müller, a. a. O., S. 85 ff.

74 BVerfGE 50, 290 (340).

75 BVerfGE 1, 14 (32 f.); 30, 1 (19).

76 BVerfGE 1, 14 (18 LS 27, 32), wo das Bundesverfassungsgericht 
halb nicht begründen, weil keineswegs ausgemacht ist, daß die verfassunggestaltenden Grundentscheidungen deren Bestandteil sind. Zumal hinsichtlich der Staatsformvorschriften ist schwerlich begründbar, daß sie einer der Rechtsordnung vorausliegenden Gerechtigkeit angehören ${ }^{77}$.

$\mathrm{DaB}$ das Bundesverfassungsgericht in seiner Rechtsprechung trotz Herausarbeitung wichtiger hermeneutischer Richtlinien die lex artis nicht gefunden hat, kann nicht verwundern. Als in seiner Tragweite nicht zu unterschätzender hermeneutischer Fortschritt ist indessen die Lehre von der verfassungskonformen Auslegung zu werten ${ }^{78}$, die im Hinblick auf den Normstufenbau und das Prinzip von der Einheit und Effektivität der Rechtsordnung einer Erweiterung dahin bedarf, daß insgesamt ein Gebot "normkonformer Norminterpretation" anzuerkennen ist.

Trotz der hiernach beträchtlichen Bedeutung des Bundesverfassungsgerichts in der Staatsgrundordnung unter dem Grundgesetz $^{79}$ würde man der Funktion der anderen Staatsorgane nicht gerecht, wollte man ausschließlich dieses Gericht mit dem „Hüter der Verfassung"80 identifizieren oder in seiner Tätig-

Verfassungssätze anerkennt, die so elementar und so sehr Ausdruck eines auch der Verfassung vorausliegenden Rechts sind, daß sie den Verfassungsgesetzgeber selbst binden und zur Nichtigkeit gegen sie verstoßender Verfassungsnormen führen.

${ }^{77}$ In der modernen Gerechtigkeitstheorie - vgl. etwa Ch. Perelman, Uber die Gerechtigkeit, 1967; J. Rawls, Gerechtigkeit als Fairneß, hrsg. Höffe, 1977; I. Tammelo, Theorie der Gerechtigkeit, 1977 - wird die Gerechtigkeit zur Staatsform nicht in Beziehung gesetzt.

${ }^{78} \mathrm{Vgl}$. aus der Rspr. des Bundesverfassungsgerichts insb. BVerfGE 2, 266 (282 f.); 8, 210 (221); 12, 45 (60 f.), 151 (166 ff.); 17, 155 (164 ff.); 18, 18 (33 f.); 22, 180 (215 ff.); 26, 186 (195 ff.); 32, 199 (224 ff.); 35, 263 (277 ff.); 36, 1 (31), 126 (135 f.).

${ }^{79}$ Die "Aufbauleistungen" des Bundesverfassungsgerichts sind insb. von P. Häberle, a. a. O., S. 431 ff., gewürdigt worden, wobei er als übergeordnete Gesichtspunkte wesentlicher Judikate des Bundesverfassungsgerichts Grundrechts- und Rechtsstaats-, Föderalismus- und Gewaltenteilungs-, Oppositions- und Minderheitenschutzentscheidungen sowie die "Toleranzrechtsprechung" im Staatskirchenrecht erwähnt. - Die Liste ist erweiterungsfähig (zumindest um hermeneutisch bedeutsame Entscheidungen [s. o. Anm. 78], staatspolitisch wichtige Urteile [BVerfGE 2,$1 ; 5,85]$; wirtschaftspolitisch erhebliche Judikate [BVerfGE 44, 322; 50, 290]; staatsorganisatorisch wesentliche Entscheidungen [BVerfGE 40, 296; 44, 308]).

${ }^{80}$ Die Apostrophierung des Bundesverfassungsgerichts mit diesem bereits zur Weimarer Zeit gebrauchten Begriff (C. Schmitt, Hüter der Verfassung, AöR 55 [1929], 161; ders., Der Hüter der Verfassung, 1931, mit der These, Hüter der Verfassung sei das Staatsoberhaupt 
keit René Marcics Diagnose der Entwicklung „Vom Gesetzesstaat zum Richterstaat"81 bestätigt finden. Die verfassungsrechtliche Lage, die in Deutschland nach dreißig Jahren Grundgesetz besteht, stellt sich als Resultat vielfacher juristischer und metajuristischer Faktoren dar.

\section{Die Ausgestaltung der verfassunggestaltenden Grundent- scheidungen}

Vor allem hinsichtlich der verfassunggestaltenden Grundentscheidungen ist erkennbar, daß diese in den vergangenen dreiBig Jahren einen beachtlichen Rationalitätszuwachs erfahren haben.

a) Bezüglich der Rechtsstaatlichkeit ist niemals in Zweifel gezogen worden, daß sie die Verwirklichung der Gerechtigkeit und der Rechtssicherheit als ihrer materiellen Komponenten bezweckt ${ }^{82}$, wobei die zwischen diesen mögliche Spannungslage schon frühzeitig herausgearbeitet wurde ${ }^{83}$ und auch gegenwärtig bewußt ist, ohne daß das Bundesverfassungsgericht ihr allerdings eine praktikable Abgrenzung zu geben vermochte ${ }^{84}$.

und hieran geübter scharfer Kritik von $H$. Kelsen, Wer soll Hüter der Verfassung sein?, Die Justiz 31, 5, abgedr. auch in: Die Wiener rechtstheoretische Schule, hrsg. Klecatsky/Marcic/Schambeck, 1968, S. 1873) ist allenfalls im Hinblick auf seine Verwerfungskompetenz sowie seine Entscheidungsbefugnis über Verfassungsbeschwerden schlüssig; im übrigen kommt dasselbe Prädikat allen Staatsorganen gleichermaßen zu. Mit Recht hebt $K$. Stern, a. a. O., \$6 II 5 ff., S. 154 ff., demgegenüber auch die anderen Instrumente der Verfassung zu ihrer Sicherung hervor, dies im Ergebnis übereinstimmend mit $H$. Kelsens, a. a. O., S. 1914, Definition des Hüters der Verfassung als „des Organes, das die Verfassungsmäßigkeit gewisser Staatsakte zu sichern, indem es in irgendeiner Weise gegen Verfassungsverletzungen zu reagieren hat." In diesem Sinne sind auch die Parlamente, Regierungen, Verwaltungsbehörden und Gerichte Verfassungshüter. Zutreffend W. Fiedler, JZ 79, 420.

${ }^{81}$ R. Marcic, Vom Gesetzesstaat zum Richterstaat, 1957, passim, insb. S. 241, 248, 278.

82 BVerfGE 7, 89 (82); 20, 323 (331); 22, 322 (329); 25, 269 (290); 35, 41 (47).

${ }^{83}$ BVerfGE 2, 280 (403 ff.); 22, 329; 25, 290 f.; 35, 47; G. Radbruch, Rechtsphilosophie, 8. Aufl. hrsg. Wolf-Schneider, 1973, § 9, S. $164 \mathrm{ff}$. S. auch N. Achterberg, Staat 8 (1969), $163 \mathrm{ff}$.

84 Insb. dadurch, daß es die Entscheidung über die Bevorzugung des einen oder des anderen Prinzips dem Gesetzgeber zuweist, der diesen Widerstreit nach der einen wie nach der anderen Seite lösen solle (BVerfGE 22, 329; 25, 290 f.; 35, 47), und vor allem der These, im Regelfall habe die Rechtssicherheit den Vorrang, sofern nicht 
Trägt die Rechtsstaatlichkeit - wie jede andere verfassunggestaltende Grundentscheidung - einen relativen Charakter in sich $^{85}$, so ermöglicht dieser im übrigen eine gewisse Schwankungsbreite ihrer Ausformung, ohne daß sie zugleich ins Mark getroffen oder - im Sprachgebrauch des Staatsrechts - in ihrem Wesensgehalt berührt wäre. Das aber relativiert die Aussagekraft jener Kassandrarufe, mit denen hin und wieder die Demontage der Rechtsstaatlichkeit beklagt wird ${ }^{86}$ - sei es bei Einführung der Verfassungsvorsorge für den Verteidigungsfall, sei es bei Maßnahmen zur Abwehr von drohenden Gefahren für die freiheitliche demokratische Grundordnung. Hierin liegt nicht nur kein Verlust an Rechtsstaatlichkeit, sondern im Gegenteil läßt sich in mannigfacher Hinsicht eine zunehmend bessere Erfüllung des rechtsstaatlichen Programms erkennen.

Dies gilt beispielsweise für die Ausweitung des Gesetzesbegriffs und des Gesetzesvorbehalts dadurch, daß die gesetzliche Regelung für alle wichtigen - insbesondere grundrechtsrelevanten - Angelegenheiten gefordert wird ${ }^{87}$, wodurch die in der Reduzierung des Gesetzesbegriffs auf die abstrakt-generelle Regelung noch immer enthaltene Beschränkung parlamentarischer Regelungsprärogative im Bereich der Rechtsetzung überwunden wird ${ }^{88}$. Rechtsstaatlich nicht minder bedeutsam ist die

\footnotetext{
„besonders zwingende und schwerwiegende, den Erwägungen der Rechtssicherheit übergeordnete Gründe dazu Anlaß geben“, BVerfGE 2, 380 (405). Abgesehen von der Anhäufung unbestimmter Rechtsbegriffe liegt hierin nur eine Leerformel (die Rechtssicherheit ist übergeordnet, sofern es nicht die Gerechtigkeit ist).

85 S. o. Anm. 55.

B8 Vgl. z. B. M. u. S. Greiffenhagen, a. a. O., S. $86 \mathrm{ff}$.

${ }^{87}$ BVerfGE 41, 241 (259 ff.); 49, 89 (126 f.); BVerwG, NJW 75, 1180, 1182; BayVerfGH, BayVBl. 75, 298; HessStGH, DOV 71, 201; OVG Berlin, DVBl. 73, 723, DOV 75, 570; OVG Lüneburg, DVB1. 73, 280; OVG Münster, DVBl. 75, 445; D. Grimm, Aktuelle Tendenzen in der Aufteilung gesetzgeberischer Funktionen zwischen Parlament und Regierung, ZParl. 1 (1970), 448 (463 ff., in Würdigung zahlreicher anderer, von ihm Anm. 84 genannter Autoren); G. Kisker, Neue Aspekte im Streit um den Vorbehalt des Gesetzes, NJW 77, 1313 (1314); ders., Zuständigkeit des Parlaments für politische Leitentscheidungen, ZParl. 9 (1978), 53; K. M. Meessen, Maßnahmegesetze, Individualgesetze und Vollziehungsgesetze, DŐV 70, 314 (319).

${ }^{88}$ Dazu N. Achterberg, Kriterien des Gesetzesbegriffs unter dem Grundgesetz, DOV 73, 289 (297). Man braucht deswegen nicht sogleich die Organsouveränität des Parlaments anzunehmen, wie D. Jesch, Gesetz und Verwaltung, 1961, S. 99 ff., m. Anm. 115. Zutreffend $J$. Linck, Zum Vorrang des Parlaments gegenüber anderen Gewalten, DOV 79, 165.
} 
zunehmende normative Auffüllung solcher Rechtsverhältnisse, die ehedem als sogenannte besondere Gewaltverhältnisse ein verfassungsrechtlich fossilienhaftes Dasein fristeten ${ }^{80}$. Aber auch die Einführung neuer Kontrollorgane ${ }^{80}$ sowie mancherlei institutioneller und prozeduraler Verbesserungen ${ }^{91}$ haben $\mathrm{zu}-$ sammen mit der Festigung der Rechtsprechung zu einem beachtlichen Zuwachs an Rechtsstaatlichkeit geführt, der zwar in Einzelheiten - wie hinsichtlich der Verminderung der Normenflut oder der Verkürzung der Verfahrensdauer - noch Wünsche offenlassen mag, an einem positiven Urteil jedoch nichts zu ändern vermag.

b) Bezüglich der Sozialstaatlichkeit fällt die Diagnose weniger günstig aus. Kann schon von ihrer theoretischen Bewältigung kaum die Rede sein - wofür auch die seinerseits mit Verve vorgebrachte Skepsis Ernst Forsthoffs gegenüber dem verfassungsrechtlichen Gehalt dieses Prinzips mitverantwortlich sein mag ${ }^{92}$ - , so spielt es auch in der Praxis eine bescheidenere Rolle als das Rechtsstaatsprinzip. Indiz hierfür ist, daß die Rechtsprechung des Bundesverfassungsgerichts zum Rechtsstaatsprinzip von Leibholz und Rinck auf fünfzig, diejenige zum Sozialstaatsprinzip auf fünf Seiten dargestellt wird ${ }^{93}$. Aussage-

80 Eingeleitet für das Strafgefangenenverhältnis durch BVerfGE 33, 1 (9 ff.), differenzierend fortgesetzt für das Schulverhältnis durch BVerwG, DOV 75, $347 \mathrm{~m}$. Anm. W. Bosse, DOV 75, 349. S. auch $E$.-W. $F u \beta$, Personale Kontaktverhältnisse zwischen Verwaltung und Bürger. Zum Abschied vom besonderen Gewaltverhältnis. DOV 72, 765; B. Löhning, Der Vorbehalt des Gesetzes im Schulverhältnis, 1974, S. 19 ff.; Th. Oppermann, Bildung, in: Besonderes Verwaltungsrecht, hrsg. v. Münch, 5. Aufl., 1979, S. 615 (633); N. Niehues, Schul- und Prüfungsrecht, 1976, RdNr. 64 ff.; $H$. Sellschopp, Das Schulverhältnis und der Gesetzesvorbehalt, DÖV 71, 413 (414 ff.).

00 So den Wehrbeauftragten durch (7.) Gesetz zur Engänzung des Grundgesetzes v. 19. 3. 1956 (BGBl. I 111) und die Datenschutzbeauftragten des Bundes und der Länder.

91 Vgl. dazu des näheren $u$. III 4.

${ }^{92} E$. Forsthoff, Begriff und Wesen des sozialen Rechtsstaates, VVDStRL 12, 8 (19, 23 f., 29, 33); vgl. demgegenüber aber O. Bachof, ebda., S. 43 ff., 80 LS 5, sowie die Diskussionsbeiträge von $H$. C. Nipperdey, ebda., 92; W. Merk, ebda., 100, H. Krüger, ebda., 79 f. Daß Adressat der Sozialstaatsklausel ,in erster Linie“ der Gesetzgeber ist (F. E. Schnapp, in: Grundgesetz-Kommentar, hrsg. v. Münch, 1975, Art. 20 RdNr. 19), wird damit nicht in Abrede gestellt.

is G. Leibholz/H. J. Rinck, Grundgesetz, 5. Aufl., 1975, Art. 20, einerseits S. 483 bis 533, andererseits S. 467 bis 472 . Der naheliegende Einwand, die Bedeutung des Sozialstaatsprinzips zeige sich eher in der Rechtsprechung der Sozialgerichtsbarkeit, greift deshalb 
kräftig ist dies deshalb, weil kaum zu erwarten ist, daß die judizielle Abstinenz unseres höchsten Gerichts auf einen ungetrübten Konsens über Inhalt und Tragweite des Sozialstaatsprinzips zurückführbar ist.

Kaum Dissens wird bezüglich der materiellen Komponenten der Sozialstaatlichkeit, sozialer Gerechtigkeit und Leistungseffizienz - Wirksamkeit staatlicher Maßnahmen in zeitlicher, inhaltlicher und umfänglicher Hinsicht - bestehen ${ }^{94}$. Hinsichtlich der formellen Merkmale der Sozialstaatlichkeit ist zu konstatieren, daß die Entwicklung des Systems der sozialen Sicherung, das zu seinen tragenden Säulen zählt, zu einem gewissen Abschluß gekommen ist. Die wahrhaft „enormen" Aufgaben der Vertriebenenhilfe und des Lastenausgleichs sind zu einem groBen Teil bewältigt ${ }^{95}$ - die soziale Sicherung im übrigen ist gleichfalls als angemessen $\mathrm{zu}$ betrachten -, Veränderungen in Richtung auf eine Volksfürsorge sind in absehbarer Zeit nicht zu erwarten; ob sie trotz der Flexibilität der Verfassung zulässig sind, ist überdies zweifelhaft ${ }^{96}$. Im Grunde Einverständnis dürfte auch darüber bestehen, daß die sozialstaatlichen Aufgaben im Schutz nicht nur des ökonomischen, sondern auch des ökologischen Existenzminimums bestehen ${ }^{97}$, sowie daß sich aus ihnen das Erfordernis maßvoller staatlicher Einflußnahmen auf die Wirtschaft ergibt ${ }^{98}$.

Wenn darüber hinaus vor einigen Jahren die Disgruenz von Sozialstaatlichkeit und Wohlfahrtsstaatlichkeit angezweifelt

nicht durch, weil dann auch die Bedeutung des Rechtsstaatsprinzips in der Instanzgerichtsbarkeit berücksichtigt werden müßte. Ob und inwieweit sich das Bild dann verschiebt, muß hier auf sich beruhen; auf der Ebene der Bundesverfassungsgerichtsbarkeit jedenfalls zeigt sich eine bemerkenswerte Diskrepanz.

94 Näher N. Achterberg, Staat 8 (1969), 168.

85 Zahlreiche Angaben hierzu bei F. Pirkl, Gedanken zum Sozialstaat, in: 25 Jahre Grundgesetz, hrsg. Löw, 1974, 143 (147 f.).

${ }_{96}$ Bejahend W. Leisner, BayVB1. 79, 522. Indessen ist insoweit $\mathrm{zu}$ berücksichtigen, daß das Subsidiaritätsprinzip - auch wenn es kein durchgehend die geltende Staatsgrundordnung durchziehender Grundsatz ist, dazu BVerwGE 23, 304 (306 f.); H. P. Bull, Die Staatsaufgaben nach dem Grundgesetz, 2. Aufl., 1977, S. 196 ff.; R. Herzog, in: Evangelisches Staatslexikon, Sp. 2592; J. Isensee, Subsidiaritätsprinzip und Verfassungsrecht, 1968, S. $264 \mathrm{ff}$. - zur Auslegung des Sozialstaatsprinzips herangezogen werden kann.

${ }^{97}$ In diesem Sinne $M$. Bullinger, Das Verursachungsprinzip und seine Instrumente, 1974, S. 78; J. Kölble, Staat und Umwelt, DOV 77,1 (1); K. Stern, a. a. O., \$21 II 3 i, S. 708.

88 Ubersicht über entsprechende unterverfassungsrechtliche Regelungen bei K. Stern, a. a. O., \$21 II 3 f, S. $700 \mathrm{ff}$. 
wurde ${ }^{99}$, so ist demgegenüber hervorzuheben, daß präventive Reglementierung der gesellschaftlichen Evolution nicht sozialstaatliche Aufgabe sein kann, weil sie systemimmanente Spielräume verengt und damit die gesellschaftliche Entwicklung in eine bestimmte Richtung drängt, die sie ohne eine solche möglicherweise nicht nehmen würde. Die Evolutionsaufgabe kann demgemäß nur in der Vorbeugung gegen absehbare Fehlentwicklungen, nicht dagegen in der Einleitung erkennbarer oder nicht erkennbarer Entwicklungen liegen; solche bleiben der Selbstregulierung der Gesellschaft vorbehalten. Nicht in Abrede gestellt wird damit die zentrale Bedeutung, welche die Wachstumsvorsorge ${ }^{\mathbf{1 0 0}}$ innerhalb des Sozialstaatsprinzips besitzt: Können die Aufgaben des Sozialstaats nur durch Wachstum bewältigt werden, so hat dieser die Verpflichtung, auch hierfür zu sorgen. Bevölkerungsexpansion einerseits, Ressourcenverknappung andererseits müssen berücksichtigt werden, um die optimale Input-Output-Relation auch für die Zukunft zu erzielen.

c) Im Grundsatz unbezweifelt blieb seit Inkrafttreten des Grundgesetzes die Bedeutung der Demokratie als Staatsformbestimmung. Die Modifizierung ihrer Ausgestaltung als parlamentarische in Richtung auf ein Rätesystem ${ }^{101}$, wie sie Ende der sechziger Jahre von der Fundamentalkritik am parlamentarischen Regierungssystem vorgeschlagen wurde, stieß schnell auf die Erkenntnis, daß sich das parlamentarische System unter den gegenwärtigen Bedingungen als alternativenlos er-

${ }^{08}$ S. dazu F. Pirkl, a. a. O., S. 155 f. Auch U. Scheuner, Staatstheorie und Staatsrecht, S. 242, liest aus den im Grundgesetz formulierten Staatszielen wenigstens die Tendenz zur Wohlfahrtsstaatlichkeit heraus.

100 So insb. H. P. Ipsen, Diskussionsbeitnag, VVDStRL 24, 221, (222).

101 Diskutiert beispielsweise auf der Tagung der Deutschen Vereinigung für Politische Wissenschaft, Berlin 1969 (= PVS Sonderheft $2 / 1970 \mathrm{~m}$. Beiträgen z. B. von $U$. Bermbach, Rätesysteme als Alternative?, S. 110; J. Fijalkowski, Bemerkungen zu Sinn und Grenzen der Rätediskussion, S. 139). Gerade diese Tagung trug wesentlich zur Ernüchterung der Diskussion bei (vgl. demgegenüber aber insb. W. Gottschalch, Parlamentarismus und Rätedemokratie, 1970). Einen wesentlichen Beitrag bilden auch die Abhandlungen in: Theorie und Praxis der direkten Demokratie, hrsg. Bermbach, 1973, insb. von U. Bermbach, Rätegedanken versus Parlamentarismus? Uberlegungen zur aktuellen Diskussion der Neuen Linken, S. 154 ; P. v. Oertzen, Freiheitliche demokratische Grundordnung und Rätesystem, S. 173. 
weist ${ }^{102}$. Denn keines der in diesem Zusammenhang vorgebrachten Argumente hat sich als tragfähig erwiesen: Das gilt sowohl für die Behauptung, das Parlament sei einem überkommenen Gesellschaftsmodell verhaftet, das einen bereits bestehenden Grundkonsens über das Gemeinwohl und damit zugleich eine homogene Binnenstruktur des Parlaments erfordere, wie für die These von der Entmachtung des Parlaments durch wirtschaftliche Konzentration wie schließlich für die Unterstellung, das Parlament hindere durch von ihm ausgehende Disziplinierungseffekte die gesellschaftliche Entwicklung überhaupt, indem es repressiv-manipulativ Antagonismus auf Pluralismus reduziere ${ }^{\mathbf{1 0 3}}$. Hierbei wird weithin ein spezifisch marxistisches Blickfeld eingenommen, bei dem anstelle sozialen Ausgleichs totale Herrschaft einer bestimmten Klasse und damit gewaltsame Durchsetzung dieses Anspruchs angestrebt wird. Insgesamt hat die Scheinalternative des Rätesystems schnell an Anziehungskraft verloren.

In der Zielsetzung weniger weitreichend, in der Substanz jedoch ernster zu nehmen, sind die seit derselben Zeit anzutreffenden Partizipationsforderungen ${ }^{104}$, als deren eine unter ande-

${ }^{102}$ N. Achterberg, Das Parlament im modernen Staat, DVB1. 74, 693 (699 f.); Th. Oppermann, Das parlamentarische Regierungssystem des Grundgesetzes, VVDStRL 33, 8 (12).

${ }^{103}$ So vor allem J. Agnoli, Die Transformation der Demokratie, in: Die Transformation der Demokratie, hrsg. Agnoli/Brückner, 1968, S. 7 (insb. 10, 24 ff., 28 f., 54, 68, 82); J. Habermas, Strukturwandel der Offentlichkeit, 4. Aufl., 1969, S. 155; U. Jaeggi, Macht und Herrschaft in der Bundesrepublik, 1969, insb. S. 43, 97, $99 \mathrm{ff}$., $128 \mathrm{ff} ., 141 \mathrm{ff} . ;$ R. Kühnl, Das liberale Modell öffentlicher Herrschaft, in: Einführung in die politische Wissenschaft, hrsg. Abendroth/ Lenk, 1968, S. 57, $64 \mathrm{ff} ., 79 \mathrm{ff}$.

104 Hierzu besonders ausführlich P. Dagtoglou, Partizipation Privater an Verwaltungsentscheidungen, DVBI. 72, 712; G. Kisker, Gruppenmitbestimmung an der öffentlichen Verwaltung, DÖV 72, 520; P. Oberndorfer, Partizipation an Verwaltungsentscheidungen in Österreich, DOV 72, 529; R. Walter/W. Schmitt Glaeser, Partizipation an Verwaltungsentscheidungen, VVDStRL, 31, 145, 179. Das Thema wird - vor allem unter speziellen Fragestellungen gegenwärtig weiterbehandelt, so durch den 52 . Deutschen Juristentag, Wiesbaden 1978, mit Gutachten von C. H. Ule/H.-W. Laubinger, Empfehlen sich unter dem Gesichtspunkt der Gewährleistung notwendigen Umweltschutzes ergänzende Regelungen im Verwaltungsverfahrens- und Verwaltungsprozeßrecht?, 1978. Das Abstimmungsergebnis der Abteilung (79: 24: 4), nach dem für alle auf Verwirklichung umweltbedeutsamer Vorhaben gerichteten Verfahren eine Bürgerbeteiligung vorzusehen sei, zeigt das noch immer wache Partizipationsinteresse. 
ren Folgeerscheinungen sich gegenwärtig die Bürgerinitiativen darbieten ${ }^{105}$. Auch die Partizipationseuphorie wich alsbald einer nüchternen Betrachtung aufgrund der Erkenntnis, daß Partizipation nicht nur Motivation erfordert - an der es, wie fehlgeschlagene Volksbegehren zeigen, oftmals fehlt -, sondern daß weiterhin Information, Kommunikation und Diskussion notwendig sind, womit sehr schnell an die Rahmenbedingungen einer arbeitsteilig verfaßten Massengesellschaft gestoßen wird, da $B$ überdies jegliche Partizipation sich den Schranken normativer Determination konfrontiert sieht ${ }^{106}$ und es in einem parlamentarischen Regierungssystem weder systemadäquat, noch auch nur erstrebenswert ist, die Präzision der Normgestaltung durch eine partizipationsfreundliche Elastizität zu ersetzen. Damit wird nicht in Abrede gestellt, daß das vorhandene Arsenal von Partizipationsinstrumenten ausbaufähig sein mag ${ }^{107}$; gleichwohl bleiben die Ausbaumöglichkeiten räumlich gesehen vor allem im Lokalen - nicht nur zufällig betrifft über die Hälfte aller Anliegen von Bürgerinitiativen den kommunalen Bereich ${ }^{108}-$, sachlich gesehen eher im Marginalen.

Was indessen unter dem demokratischen Aspekt bis an die Grundlagen unseres Staats rührt, ist das Ausmaß seiner Verhaftung mit einem Wertrelativismus ${ }^{109}$, der in dem Pluralismus

${ }^{105}$ N. Achterberg, Die Parlamentarische Demokratie als Entfaltungsraum für Bürgerinitiativen, NJW 78, 1993; P. C. Mayer-Tasch, Die Bürgerinitiativbewegung, 1976; U. Thaysen, Bürgerinitiativen, Parlamente und Parteien in der Bundesrepublik. Eine Zwischenbilanz (1977), ZParl. 9 (1978), 87.

${ }_{100}$ Kritisch gegenüber einer Uberdehnung des Partizipationsprinzips insb. die Diskussionsbeiträge von $K$. A. Bettermann, VVDStRL 34, 275; G. Kisker, ebda., 275; G. Püttner, ebda., 273.

107 In Betracht kommen insb. Offenlegungspflichten, Einsichtsrechte, Einwendungsbefugnisse, Anhörungsrechte, Erörterungstermine, dazu C. H. Ule/H.-W. Laubinger, a. a. O., S. $75 \mathrm{ff}$.

108 Nach einer Mitteilung von Staatssekretär Dr. Hartkopf, in: Bürgerinitiativen - Wege oder Irrwege der parlamentarischen Demokratie? (= Schriftenreihe des Deutschen Städte- und Gemeindebundes, Heft 30), 1978, S. 24, haben $60 \%$ aller Bürgerinitiativen ein kommunales, $30 \%$ ein landes-, $10 \%$ ein bundespolitisches Ziel, wobei allerdings gerade letztere Vorhaben besonders im Blickfeld der Offentlichkeit stehen.

${ }^{109}$ S. dazu H. Kelsen, Sozialismus und Staat, 2. Aufl, 1923, S. $191 \mathrm{ff}$; ders., Vom Wesen und Wert der Demokratie, 2. Aufl., 1929, S. 101 ff.; ders., Zur Soziologie der Demokratie, in: Der österreichische Volkswirt 19 (1926), 209, 239 (abgedr. in: Die Wiener rechtstheoretische Schule, S. 1729); ders., Demokratie, in: Schriften der Deutschen Gesellschaft für Soziologie, I. Serie, V. Bd., Verhandlungen des Fünften Deutschen Soziologentages, 1927, S. 37, 113 (ab- 
der Gesellschaftsordnung seine soziologische Entsprechung besitzt. Unübersehbar ist nämlich, daß diesem Wertrelativismus durch die freiheitliche demokratische Grundordnung, zu der sich das Grundgesetz bekennt, eine wertabsolutistische Grenze gezogen ist. Sie steht mit jenem Wertrelativismus auch keineswegs in Widerspruch, sondern bildet den Bedingungsrahmen zur Gewährleistung und Erhaltung von Relativismus und Pluralismus, dessen Relativierung zu einer Verdichtung der Handlungsspielräume und damit zum Abbau von Demokratie führen müßte: ${ }^{110}$ Entsprechend ist vor allem die staatliche Intoleranz gegenber Verfassungsfeinden $\mathrm{zu}$ beurteilen. Das Grundgesetz gibt nicht nur das Recht, Gegner der freiheitlichen demokratischen Grundordnung vom öffentlichen Dienst fernzuhalten; es begründet sogar eine solche Pflicht. Ist die Verfassungstreue Bestandteil der Eignung, nach welcher der $\mathrm{Zu}$ gang zu einem öffentlichen Amt eröffnet wird ${ }^{111}$, und stellt diese Vorschrift zugleich eine Ausprägung des Gleichheitssatzes dar, der eben nicht nur das Gebot zur Gleichbehandlung gleicher Voraussetzungen, sondern als dessen begriffsnotwendiges Korrelat auch dasjenige zur Ungleichbehandlung ungleicher

gedr. auch ebda. S. 1743); R. Marcic, Hegel und das Rechtsdenken, 1970, S. 45, unter Bezugnahme auf $H$. Ryffel, Rechts- und Staatsphilosophie, 1969, S. $262 \mathrm{ff}$.

${ }_{110}$ N. Achterberg, Kelsen und Marx. Zur Verwendbarkeit der Reinen Rechtslehre in relativistischen und dogmatistischen Rechtssystemen ( $=$ Vortrag vor den Wissenschaftlichen Arbeitskreisen des Kuratoriums Unteilbares Deutschland, Berlin 1. 11. 1974), Politik und Kultur 2/1975, S. 40 (53 ff.); ders. Das rahmengebundene Mandat (= Vortrag vor der Juristischen Gesellschaft Berlin, 27. 1. 1975), 1975, S. 35; ähnlich E. Fraenkel, Der Pluralismus als Strukturelement der freiheitlich-rechtsstaatlichen Demokratie (= Festvortrag auf dem 45. Deutschen Juristentag, Karlsruhe 1964), 1964, S. B 8, 17; $K$. Sontheimer, Der Pluralismus und seine Kritiker, in: Klassenjustiz und Pluralismus, Festschrift für Ernst Fraenkel, 1973, S. 425 (429).

11 Auf die „Eignung“ i. S. Art. 33 Abs. 2 GG heben auch BVerfGE 39, 334 (351); BVerwGE 47, 330 (337); BAG, NJW 78, 71, ab. Ebenso K. Stern, Zur Verfassungstreue der Beamten, 1974, S. 25; ders., Staatsrecht, \$11 IV 3 a, S. 282. Angesichts dieser Verankerung erscheint es unerheblich, ob die (auch politische) Treuepflicht überdies noch zu den hergebrachten Grundsätzen des Berufsbeamtentums i.S. Art. 33 Abs. 5 GG gezählt wird (so BVerfGE 39, 334); bedenklich erscheint dies deshalb, weil hierdurch scheinbar der Weg eröffnet wird, stattdessen ein - diesen Grundsätzen nicht unterliegendes - Angestelltenverhältnis vorzusehen. 
Voraussetzungen umfaßt, so folgt hieraus unabweisbar der Satz: Keiner hat bei Nichteignung - und dazu gehört nun eben einmal die mangelnde Verfassungstreue - Zugang zu einem öffentlichen Amt und dies deshalb, weil nur bei Verfassungstreue auch mit einer getreulichen Beachtung jener die Verfassung konkretisierenden unterrangigen Normen zu rechnen ist, die das Beamtenverhältnis determinieren. Für die Einstellung von Verfassungsgegnern der Begründung von Angestelltenverhältnissen statt Beamtenverhältnissen das Wort zu reden, erscheint von dieser Prämisse aus bestenfalls als geradezu groteske Zuflucht zur Rechtsunkenntnis: Der Funktionsvorbehalt hindert die Austauschbarkeit der Rechtsverhältnisse, und wenn zur Wahrnehmung hoheitlicher Funktionen auch lediglich „,in der Regel“ die Begründung des Beamtenverhältnisses vorgeschrieben ist, so wird man der Verfassung schwerlich unterstellen können, sie wolle die Verfassungsfeindlichkeit mit der Zubilligung der Ausnahme honorieren. Im übrigen aber fordert auch das Angestelltenverhältnis die Treue zum Dienstherrn ${ }^{112}$, und niemand wird plausibel nachweisen können, daß sie in einem solchen einen anderen Inhalt als im Beamtenverhältnis haben sollte, in ihm vielleicht gar noch die Verfassungsfeindlichkeit umschließen darf. Man wird auch nicht der Auffassung zustimmen können, daß die Rechtsunsicherheit, welche eine dezisionistische Beurteilung der Verfassungsfeindlichkeit durch die Gerichte heraufbeschwört, einer schematischen Rechtssicherheit vorzuziehen ist. Die hierin umschlossene These vom Wert kasuistischer Differenzierungen und hierdurch bewirkter gerechterer Entscheidungen trifft nicht zu. Differenzierungen allein verbürgen noch keine $\mathrm{Ge}-$ rechtigkeit, sondern sind als solche gerechtigkeitsneutral, können gerecht oder ungerecht sein - dies eine Kehrseite der Gleichheitsneutralität der Gerechtigkeit.

d) Bezüglich der Bundesstaatlichkeit haben sich in der Bundesrepublik die dieser Staatsform eigenen zentripetalen Tendenzen gezeigt ${ }^{113}$. Staatsaufgaben wurden in den vergangenen

$112 \S 8$ Abs. 1 BAT. Zutreffend BVerfGE 39, 334 (LS 7; Sondervotum W. Seuffert, S. 378).

11 Ausführlich dazu K. Hesse, Der unitarische Bundesstaat, 1962, insb. S. $12 \mathrm{ff}$. Dieselbe Tendenz zeigte sich bereits im Deutschen Reich nach der RV 71 (vgl. R. Thoma, Das Staatsrecht des Reiches, in: Handbuch des Deutschen Staatsrechts, hnsg. Anschütz-Thoma, 1. Bd., 1930, S. 69 [71]; H. Triepel, Unitarismus und Föderalismus im Deutschen Reiche, 1907, S. $53 \mathrm{ff}$.) wie auch im Deutschen Reich nach der RV 19 (s. $R$. Thoma, Das Reich als Bundesstaat, Handbuch des Deutschen Staatsrechts, 1. Bd., S. 169 [180, 182 f.]). 
Jahrzehnten zunehmend auf die Zentralstaatsebene emporgezogen. Neu hinzugekommene Aufgaben drängten nach überregionaler Bewältigung, Erfordernisse der Gleichbehandlung und der Sozialstaatlichkeit geboten einheitliche Lösungen. Die gerade von dieser ausgehende Unitarisierung wurde denn auch frühzeitig erkannt. Konrad Hesse insbesondere sah es bereits vor über fünfzehn Jahren nicht nur als Zufall oder Auswirkung antiföderalistischer Tendenzen an, sondern als ,untrügerisches Kennzeichen jenes Wandels, daß sich das Schwergewicht der staatlichen Aufgaben zunehmend beim Bunde konzentriert hat, daß sich im Aufgabenbereich der Länder eine ständig fortschreitende Selbstkoordinierung vollzieht und daß sich die spezifisch politische Wirksamkeit der Länder zunehmend auf ihre Beteiligung an den Angelegenheiten des Bundes in einem Bundesorgan verlagert hat." 114

Nachweisbar ist dies in der Tat zum einen an dem Ausbau der Bundeskompetenzen im Bereich der Legislative ${ }^{115}$ unter Einschluß der weiten Ausschöpfung der konkurrierenden Bundesgesetzgebung, wobei die Deutung der Bedürfnisklausel als Ermessensvorschrift erkennen läßt, daß selbst das Bundesverfassungsgericht solchen Tendenzen zumindest nicht prinzipiell ablehnend gegenübersteht ${ }^{116}$. Schließlich zeigt sich dasselbe

114 K. Hesse, a. a. O., S. 14.

115 Vgl. die Einfügung der Art. 74 Nr. 11 a durch Gesetz zur Ergänzung des Grundgesetzes v. 23. 12.1959 (BGBl. I 813), die Änderung des Art. $74 \mathrm{Nr}$. 10 und die Ergänzung des Art. $74 \mathrm{Nr}$. 10 a durch Dreizehntes Gesetz zur Änderung des Grundgesetzes v. 16. 6. 1965 (BGBl. I 513), die Änderung des Art. $73 \mathrm{Nr} .1$ durch Siebzehntes Gesetz zur Ergänzung des Grundgesetzes v. 24. 6. 1968 (BGBl. I 709), die Änderung des Art. 74 Nr. 13 und die Einfügung des Art. 74 Nr. 19 a sowie Art. 75 Abs. 1 Nr. 1 a, Abs. 2 und Abs. 3 durch Zweiundzwanzigstes Gesetz zur Änderung des Grundgesetzes vom 12. 5. 1969 (BGBl. I 363), die Einfügung des Art. 74 a und die Änderung des Art. 75 durch Achtundzwanzigstes Gesetz zur Anderung des Grundgesetzes vom 18. 3. 1971 (BGBl. I 206), die Ånderung des Art. $74 \mathrm{Nr} .20$ durch Neunundzwanzigstes Gesetz zur Änderung des Grundgesetzes vom 18. 3. 1971 (BGBl. I 207), die Einfügung des Art. 74 Nr. 24 durch Dreißigstes Gesetz zur Änderung des Grundgesetzes v. 12. 4. 1972 (BGB1. I 593), die Einfügung des Art. $74 \mathrm{Nr}$. 4 a durch Einunddreißigstes Gesetz zur Änderung des Grundgesetzes vom 28. 7. 1972 (BGBl. I 1305) und die Anderung dieser Bestimmung durch Vierunddreißigstes Gesetz zur Änderung des Grundgesetzes vom 23. 8. 1976 (BGBl. I 2383).

116 BVerfGE 2, 213 (224); 4, 115 (127); 10, 234 (245); 13, 230 (234 f.). Kritisch dazu $N$. Achterberg, Die Entscheidung über das Bedürfnis für die Bundesgesetzgebung (Art. 72 Abs. 2 GG), DVB1. 67, 213; M. Gruson, Die Bedürfniskompetenz, 1967, S. $88 \mathrm{ff}$; W. Leisner, 
bei der Zunahme von Verwaltungskompetenzen des Bundes ${ }^{117}$, der Ausschöpfung zentralstaatlicher Ingerenzmöglichkeiten bei der Ausführung von Bundesgesetzen durch die Länder auf dem Wege über Verwaltungsvorschriften des Bundes sowie der Etablierung einer „dritten Ebene" des Bundesstaats in solchen Bereichen der Landeshoheit, die man geradezu als ihre klassischen bezeichnen kann, wie im Kultuswesen und im Polizeiwesen ${ }^{118}$. Verwaltungsabkommen, einheitliche Richtlinien und Musterentwürfe für landesrechtliche Regelungen führen quasizentralstaatliche Lösungen herbei. Kaum an einer anderen Stelle zeigt sich dies derartig schlaglichtartig wie bei der Revisionsfähigkeit der Verletzung von Bestimmungen des Landesverwaltungsverfahrensrechts ${ }^{119}$, die mit denen des Bundesverwaltungsverfahrensrechts übereinstimmen. Das in der neueren Rechtsprechung des Bundesverfassungsgerichts nur noch zurückhaltend benutzte Institut der Bundestreue hat dagegen nicht die ursprünglich vermutete Bedeutung erlangt ${ }^{120}$.

BayVB1. 79, 522. Die Enquête-Kommission Verfassungsreform empfiehlt die Uberprüfbarkeit durch das Bundesverfassungsgericht (BTDr. $7 / 5924$, S. 123).

117 Vgl. die Einfügung des Art. 120 a durch Gesetz zur Einfügung des Art. 120 a GG in das Grundgesetz v. 14. 8. 1952 (BGBl. I 445), die Einfügung der Art. $87 \mathrm{a}, 87 \mathrm{~b}$ durch Gesetz zur Ergänzung des Grundgesetzes v. 19. 3. 1956 (BGBl. I 111), die Einfügung des Art. $87 \mathrm{c}$ durch Gesetz zur Ergänzung des Grundgesetzes v. 23. 12.1959 (BGBl. I 813), die Einfügung des Art. $87 \mathrm{~d}$ durch Gesetz zur Einfügung eines Artikels über die Luftverkehnsverwaltung in das Grundgesetz (11. Änderung des Grundgesetzes) v. 6. 2. 1961 (BGBl. I 65), die Änderung des Art. 87 a durch Siebzehntes Gesetz zur Ergänzung des Grundgesetzes v. 24. 6. 1968 (BGBl. I 709), die Einfügung der Art. 91 a, 91 b, 104 a durch Einundzwanzigstes Gesetz zur Anderung des Grundgesetzes (Finanzreformgesetz) v. 12. 5. 1969 (BGBl. I 1359), die Änderung des Art. 87 Abs. 1 durch EinunddreiBigstes Gesetz zur Ånderung des Grundgesetzes v. 28. 7. 1972 (BGBl. I 1305).

${ }_{118}$ Dazu G. Hartkopf, DƠv 59, 353 f.; G. Kisker, Kooperation im Bundesstaat, 1971, S. 280 ff.; $H$. Schnoor, DÖV 79, $355 \mathrm{ff}$.

$118 \S 137$ Abs. 1 Nr. 2 VwGO. Die Regelung dient der Wahrung der Einheitlichkeit der Auslegung und Anwendung der Verwaltungsverfahrensgesetze des Bundes und der Länder (h. M., vgl. nur F. O. Kopp, Verwaltungsgerichtsordnung, 4. Aufl., 1979, §137 RdNr. 15). Dasselbe läßt sich auch für andere Landesgesetze denken, wodurch weitere Einbrüche in den Föderalismus ermöglicht würden.

120 Vgl. dazu BVerfGE 1, 299 (315); 3, 52 (57); 4, 115 (141 f.); 6, 309 (361); 8, 122 (138); 12, 205 (254 ff.); 13, 54 (75 f.); 32, 199 (218); 34, 216 (232); 42, 103 (117); 43, 291 (348 f.). - S. demgegenüber aber auch BVerfGE 34, 9 (44); 45, 400 (421). Kritisch gegenüber der Bundestreue auch K. Hesse, a. a. O., S. 7 ff.; ders., Grundzüge des Ver- 


\section{Die Konkretisierung der Grundrechte}

Bezüglich der Grundrechte ist der Normenbestand des Grundgesetzes seit seinem Inkrafttreten nur verhältnismäßig geringfügig geändert worden. Von erheblich größerem Ausmaß ist demgegenüber der Rationalitätszuwachs, den sie durch die Rechtsprechung des Bundesverfassungsgerichts erhalten haben. Hierzu zählen die Betonung des Grundrechtssystems als ein die gesamte Rechtsordnung durchziehendes Wertsystem ${ }^{121}$, die Deutung der freien Entfaltung der Persönlichkeit als Auffanggrundrecht ${ }^{122}$, die Übertragung der Schranken dieses Grundrechts in funktionsdifferenzierter Reduktion auf die spezielleren Freiheitsrechte ${ }^{123}$ sowie die, freilich mancherlei hermeneutische Probleme aufwerfende Deutung der Beziehung zwischen Meinungsfreiheit und sie einschränkenden allgemeinen Gesetzen als solche einer Wechselwirkung ${ }^{124}$. Mit der späteren Konkretisierung dahingehend, daß ein unter Androhung

fassungsrechts, $\$ 7$ II 3, S. 108 ff.; warnend vor einer Uberdehnung $M$. Bullinger, Zum Verhältnis von Bundesaufsicht und Bundestreue, AöR 87 (1962), 488 (494 f.); H. Ehmke VVDStRL 20, 73; U. Scheuner, Rezension zu Hesse, Der unitarische Bundesstaat, DÖV 63, 197 (197). Weitere Hinweise bei $K$. Stern, a. a. O., §19 III 4, S. 545, Anm. 379, der S. 544 ff. - ebenso wie seinerzeit H.-W. Bayer, Die Bundestreue, 1961, passim - dem Prinzip positiver gegenübersteht. - Nicht in Abrede gestellt wird, daß sich einige ausdrückliche Verfassungsnormen - insbesondere diejenigen über Rechts- und Amtshilfe (Art. 35 Abs. 1 GG), Finanzausgleich (Art. 107 Abs. 2 GG) und Verpflichtung zur Wahrung des gesamtwirtschaftlichen Gleichgewichts (Art. 109 Abs. 2 GG) - auf den Gedanken der Bundestreue als gemeinsamen Nenner zurückführen lassen.

121 BVerfGE 7, 198 (205); 10, 59 (81); 12, 205 (259); 24, 367 (389); 25,256 (263); 30, 173 (188 ff.); 35, 77 (114); 37, 57 (65); zahlreiche weitere Hinweise bei G. Leibholz/H. J. Rinck, a. a. O., Anm. 2 vor Art. 1-19.

${ }^{122}$ BVerfG st. Rispr., vgl. z. B. BVerfGE 4, 52 (57); 9, 73 (77); 10, 55 (58), 185 (199); 11, 234 (238); 19, 206 (225); 21, 227 (234); 23, 50 (55 f.); 25,44 (62).

${ }^{123}$ BVerfGE 6, 32 (38). Vgl. dazu N. Achterberg, Die Gesellschaftsbezogenheit der Grundrechte, in: Festschrift für Helmut Schelsky, 1978, S. 1 (25); Th. Maunz/G. Dürig/R. Herzog/R. Scholz, a. a. O., Art. 2 Abs. I RdNr. 69 ff.; F. Müller, Juristische Methodik, 2. Aufl., 1976, S. $157 \mathrm{f}$.

${ }_{124}$ BVerfG st. Rspr., so insb. BVerfGE 7, 198 (207 ff.); 12, 113 (124 f.); 20, 162 (176 f.); 25, 44 (55); 34, 384 (401); 42, 163 (169). Weitere Hinweise bei G. Leibholz/H. J. Rinck, a. a. O., Art. 5 Anm. 12. Vgl. dazu auch $H$. Schneider, Die Güterabwägung des Bundesverfassungsgerichts bei Grundrechtskonflikten, 1979, S. $25 \mathrm{ff}$., $69 \mathrm{ff}$., $153 \mathrm{ff}$., $219 \mathrm{ff}$. 
schwerer Nachteile ausgelöster wirtschaftlicher Druck die Chancengleichheit bei der Meinungsbildung zu verletzen vermag ${ }^{125}$, mit der durch metainterpretative Rechtsgewinnung abgeleiteten Schrankensystematik der Berufsfreiheit ${ }^{126}$, mit der Hervorhebung der Bedeutung der Pressefreiheit als Bestandteil einer freiheitlichen demokratischen Grundordnung ${ }^{127}$, mit der Betonung der Natur der Eigentumsgarantie als grundlegendes Freiheitsrecht im vermögensrechtlichen Bereich und damit als Konkretisierung des allgemeinen Freiheitsrechts sowie zugleich seinem Verständnis als Gewährleistung von Eigentum in der überkommenen privatrechtlichen Form ${ }^{128}$ hat das Bundesverfassungsgericht wesentliche Konkretisierungen im Grundrechtsbereich vorgenommen.

Nicht zu unterschätzen ist dabei die Einstellung des Bundesverfassungsgerichts zur Natur der Grundrechte auch als solcher eines status positivus: Mit der These, daß im Verhältnis zwischen Bürger und Staat neben das ursprüngliche Postulat der Freiheitssicherung um so mehr die komplementäre Forderung nach Teilhabeverbürgung tritt, je stärker der Staat sich der sozialen Sicherung und kulturellen Förderung seiner Bürger zuwendet ${ }^{129}$, werden Abwehrrechte und Teilhaberechte nicht nur als alternativ, sondern als kumulativ begriffen. Ähnliches zeigt sich in der Mitbestimmungsentscheidung, wenn das Bundesverfassungsgericht ausführt, daß die Sozialpflichtigkeit des Eigentums sich in dem Maße ausweitet, wie Sozialbereiche hiervon betroffen werden ${ }^{130}$. Die hieran zu orientierende Gestaltung durch den Gesetzgeber rückt im übrigen die funktionelle Seite der Grundrechte in das Blickfeld. Sie zeigt sich auch bei der These des Bundesverfassungsgerichts, noch stärker

125 BVerfGE 25, 256 (265).

${ }_{126}$ BVerfGE 7, 377 (405 ff.). Zum metainterpretativen, rechtsschöpferischen Charakter dieser Entscheidung Th. Maunz/G. Dürig/ R. Herzog/R. Scholz, a. a. O., Art. 12 RdNr. 34.

${ }_{127}$ BVerfGE 20, 162 (174f.); 36, 321 (340).

${ }^{128}$ BVerfGE 1, 264 (278); 14, 263 (277f.); 24, 367 (389); 31, 229 (239 f.); 37, $132(140) ; 42,64$ (76).

129 BVerfGE 33, 303 (330). Dazu P. Häberle, a. a. O., S. 57 ff. (59 ff.), wo allerdings zutreffend auf den „Vorbehalt des Möglichen" (62) hingewiesen wird, der das Verständnis der Grundrechte als Leistungsrechte von vornherein begrenzt. Dabei kann kein Zweifel bestehen, daß sich der Leistungscharakter von Grundrechten nicht nur über deren petitionelle Seite („den Individualanspruch“), sondern auch über die funktionelle Komponente (den Verfassungsauftrag an den Gesetzgeber) erschließt, so auch $P$. Häberle, a. a. O., S. $67 \mathrm{ff}$.

130 BVerfGE 21, 73 (83); 31, 229 (242); 36, 281 (292); 37, 132 (140); 42,263 (294); 50, $290(340)$. 
als die Vereinigungsfreiheit bedürfe die Koalitionsfreiheit gesetzlicher Ausformung durch Schaffung der erforderlichen Rechtsinstitute und Normenkomplexe, aber auch durch Errichtung von Schranken, die sich an dem Ausmaß der Abhängigkeit des Regelungsgegenstands von den sich verändernden wirtschaftlichen und sozialen Bedingungen zu orientieren hätten ${ }^{131}$. In allen diesen Fällen kommt es zu einem subsystemdifferenzierten Grundrechtsverständnis und zugleich zur Schaffung eines Kriterienarsenals für die künftige Rechtsentwicklung, das sich im Mitbestimmungsrecht zunächst so darstellt, daß nunmehr nicht nur die Sozialpflichtigkeit schärfer konturiert ist, sondern auch der mit anderen Formen der Vergesellschaftung in Aufstufung zu sehenden, selbst dem Übermaßverbot unterworfenen Sozialisierung weithin der Boden entzogen sein dürfte ${ }^{132}$.

Insgesamt läßt sich hiernach feststellen, daß die petitionelle, wie die institutionelle Seite der Grundrechte in den vergangenen Jahren wesentlich konkretisiert worden ist. Aber auch ihre theoretisch bisher etwas im Hintergrund gebliebene funktionelle Komponente ${ }^{133}$ ist zumindest dort zutage getreten, wo

131 BVerfGE 4, 96 (107 f.); 20, 312 (317 f.); 28, 295 (306); 38, 386 (393); 44, 322 (341 f.).

${ }^{132}$ Unbeschadet des Umstands, daß die Mitbestimmung der Sozialisierung gegenüber insofern ein aliud darstellt, als sie nicht aus Art. 15 GG ableitbar ist (Th. Maunz/G. Dürig/R. Herzog/R. Scholz, a. a. O., Art. 15 RdNr. 9), folgt die Rechtslage, daß Sozialisierung unter dem Aspekt des Übermaßverbots ausgeschlossen ist, solange Mitbestimmung ausreicht, um die Einflußnahme auf Unternehmen zu gewährleisten, aus dem in Art. 15 GG stillschweigend mitgeschriebenen Erfordernis der Sozialisierungseignung (zu diesem BKKimminich, Art. $15 \mathrm{RdNr}$. 34; E. R. Huber, Wirtschaftsverwaltungsrecht, 2. Bd., 1954, \$77 III 4, S. $152 \mathrm{ff}$.; H. v. Mangoldt/F. Klein, Das Bonner Grundgesetz, 2. Aufl., 1966, Art. 15 Anm. VI; Th. Maunzl G. Dürig/R. Herzog/R. Scholz, a. a. O., Art. 15 RdNr. 23).

133 Sie wieder in das Blickfeld gerückt $\mathrm{zu}$ haben, ist vor allem das Verdienst von $N$. Luhmann, Grundrechte als Institution, 1965, S. $11 \mathrm{ff}$., 17, 25, $199 \mathrm{f}$. (funktionaler Sinn der Grundrechte: soziale Differenzierung) - zu ihm ausführlich $H$. Willke, a. a. O., S. $157 \mathrm{ff}$. -, nachdem das diese Komponente umschließende Institutionenverständnis von $\boldsymbol{M}$. Hauriou, Die Theorie der Institution und der Gründung (Essay über den sozialen Vitalismus), abgedr. in: Die Theorie der Institution und zwei andere Aufsätze von Maurice Hauriou, hrsg. Schnur, 1965, S. 27 ff., durch C. Schmitt, Verfassungslehre, 3. Aufl., 1957, S. 170 ff., auf die Bestandsgarantie von Rechtseinrichtungen verkürzt worden war. S. hierzu auch $N$. Achterberg, in: Festschrift für Helmut Schelsky, S. 14 f., sowie A. Bleckmann, Allgemeine Grundrechtslehren, 1979, S. $204 \mathrm{ff}$. 
ein grundrechtlicher Funktionswandel vom Programmsatz zu aktuellem Recht anerkannt worden ist ${ }^{134}$ oder wo das Bundesverfassungsgericht den grundrechtlich begründeten Regelungsauftrag an den Gesetzgeber durch eine - und sei es mitunter auch nur: bedingte - Appellentscheidung betont hat ${ }^{135}$.

\section{Die Entwicklung im organisatorischen Bereich des Grundgesetzes}

Hinsichtlich der Entwicklung des organisatorischen Teils des Staatsrechts können nur einige besonders bedeutsame Punkte dargestellt werden.

a) Zunächst kann konstatiert werden, daß sich das parlamentarische System uneingeschränkt bewährt hat. Reformvorschläge, die zur sogenannten „Kleinen Parlamentsreform“ geführt haben ${ }^{136}$ und denen weitere Reformmaßnahmen auf Verfassungs-, Gesetzes- und insbesondere Geschäftsordnungsebene vorausgegangen oder nachgefolgt ${ }^{137}$ oder die von der Enquête-

${ }^{134}$ Hierzu A. Bleckmann, a. a. O., S. 45 f.; H. v. Mangoldt/F. Klein, a. a. O., Vorbem. Die Grundrechte, Anm. A VI 1, S. 79 f., B VII, S. $102 \mathrm{f}$. In der Rechtsprechung des Bundesverfassungsgerichts sind vor allem einschlägig die Entscheidungen zur Art. 3 Abs. 2 i. V.m. 117 Abs. 1 GG sowie Art. 6 Abs. 5 GG (vgl. dazu BVerfGE 3, 225 [239]; 25, 167 [179 ff.]).

135 Beispiele für die unbedingte Appellentscheidung: BVerfGE 33, 1 (13); 40, 169 (191 ff.); für die bedingte: BVerfGE 50, 290 (335). Hierzu auch $N$. Achterberg, DÖV 77, 655; P. Häberle, a. a. O., S. 443; W. Rupp-v. Brünneck, Darf das Bundesverfassungsgericht an den Gesetzgeber appellieren?, in: Festschrift für Gebhard Müller, hrsg. Ritterspach/Geiger, 1970, S. 355 (mit dem Hinweis, daß auch die Nichtigerklärung eines Gesetzes einen Appell an den Gesetzgeber zu Folgeregelungen umschließt [366]).

136 Unter dem Begriff „Kleine Parlamentsreform" werden die im Jahre 1969 beschlossenen Reformmaßnahmen zusammengefaßt. Dazu H.-H. Giesing, "Kleine Reform" im Deutschen Bundestag, DOV 70, 124; U. Thaysen, Parlamentsreform in Theorie und Praxis, 1972, S. $182 \mathrm{ff}$.; $U$. Thaysen/P. Schindler, Bundestagsreform 1969. Die Ånderungen der Geschäftsordnung, ZParl. 1 (1969/70), 20 (1969).

187 Ubersicht über die Gesetzgebung zum Parlamentsrecht sowie über die Änderungen der Geschäftsordnung in den ersten dreißig Jahren der Arbeit des Bundestags in: 30 Jahre Deutscher Bundestag (s. o. Anm. 2), S. 306 ff., 311 ff. Dazu auch N. Achterberg, Parlamentsreform - Themen und Thesen, DठัV 75, 833; $H$. Donner, Parlamentsreform durch einen Bundeswirtschafts- und -sozialrat?, DVBl. 74, 183; Th. Ellwein, Vier Thesen über Parlamentsreform, ZParl. 1 (1969/70), 76 (1969); M. Hereth, Die Reform des Deutschen Bundestages, 1971; J. Kölble, Vorschläge zur Parlamentsreform, 
Kommission Verfassungsreform angeraten worden sind ${ }^{138}$, betreffen mehr die technische Ausgestaltung des Verfahrens als eine zielorientierte Standortbestimmung und möglicherweise Neukonzeption des Parlamentarismus: Insoweit pflegt man sich mit dem Hinweis zu begnügen, daß an die Stelle der Kontrolle des Parlaments diejenige der Opposition über die Koalition getreten ist ${ }^{139}$, und im übrigen damit, die beständige Arbeitsüberlastung des Parlaments zu beklagen, ohne aber der Flut von Gesetzen wirksam zu steuern. Im Gegenteil: Alle bisher diskutierten, wenn auch teilweise verworfenen Vorschläge, wie die Utberführung der Gesetzgebungskompetenz auf Ausschüsse ${ }^{140}$

DOUV 69, 189; H. K. J. Liesegang, Parlamentsreform in der Bundesrepublik, 1974; Th. Oppermann/H. Meyer, VVDStRL 33, 8, 69; U. Thaysen, a. a.O. Hinzukommt vor allem die Reformdiskussion über Stellung und Verfahren der Untersuchungsausschüsse (z. B. Empfiehlt es sich, Funktion, Struktur und Verfahren der parlamentarischen Untersuchungsausschüsse grundlegend zu ändern?, Verhandlungen des 45. Deutschen Juristentages 1964, 1965 [mit Gutachten von K. J. Partsch]).

${ }^{138}$ Hierzu BT-Dr. 7/5924, Kap. 2 (Zum parlamentarischen Mandat), S. 22 ff., Kap. 3 (Allgemeine Stellung des Bundestages, Dauer und vorzeitige Beendigung der Wahlperiode...), S. 32 ff., Kap. 4 (Parlamentarische Kontrollrechte), S. 49 ff.; Kap. 5 (Gestaltung der Gesetzesberatung), S. $80 \mathrm{ff}$. Dazu N. Achterberg, Parlamentarische Kontrollrechte. Zum Schlußbericht der Enquête-Kommission Verfassungsreform, DÖV 77, 548.

${ }^{139} M$. Friedrich, Parlamentarische Opposition in der Bundesrepublik Deutschland. Wandel und Konstanz, in: Parlamentarische Opposition, hrsg. Oberreuter, 1975, S. $230 \mathrm{ff}$; N. Gehrig, Gewaltenteilung zwischen Regierung und parlamentarischer Opposition, DVBl. 71,633 ; H. Oberreuter, Die Opposition im parlamentarischen Regierungssystem, 1971, S. 27 ff.; F. Schäfer, Der Bundestag, 2. Aufl., 1975, S. 25 f.; H.-P. Schneider, Die parlamentarische Opposition im Verfassungsrecht der Bundesrepublik Deutschland, Bd. I, 1974, S. 6 ff., 232 ff., 258 ff.; W. Steffani, Parlamentarische und präsidentielle Demokratie. Strukturelle Aspekte westlicher Demokratien, 1979, S. 239 ff.; K. Stern, a. a. O., § 23 I 3 a, S. 813.

${ }_{140} \mathrm{~S}$. dazu N. Achterberg, DVBl. 74, 705 f.; H. Dichgans, Vom Grundgesetz zur Verfassung, 1970, S. 75 ff.; Th. Ellwein/A. Görlitz, Parlament und Verwaltung, Bd. II, 1. T., 1967, S. 258 ff.; M. Hereth, a.ı. O., S. 65; K.-U. v. Hassel, Parlamentarische Erfahrungen im ersten Jahr der 7. Wahlperiode, DUD 28 (1974), Nr, 3, S. 1 (3); W. Kewenig, Bericht über Möglichkeiten einer Entlastung des Plenums im Bereich der Gesetzgebung, in: Zur Sache 1/73, S. 134 (abgedr. auch bei H. K. J. Liesegang, a. a. O., S. 98); R. v. Lucius, Gesetzgebung durch Parlamentsausschüsse?, AöR 97 (1972), 568; K. J. Partsch, Verlagerung des Gesetzesbeschlusses an Ausschüsse in den beiden Häusern des italienischen Parlaments, in: Zur Sache 1/73, 
oder die Verkürzung der Gesetzesberatung von drei auf zwei Lesungen ${ }^{141}$ lassen vermuten, $\mathrm{da} B$ auch bei ihrer Realisierung die Zahl der Gesetze nicht geringer, sondern umgekehrt möglicherweise noch größer wird.

Vor allem die parlamentarische hat zugleich zu einer beträchtlichen politischen Stabilität der Bundesrepublik Deutschland geführt. Institute wie die Sperrklausel142 oder das konstruktive Mißtrauensvotum haben die in sie gesetzten Erwartungen voll erfüllt; daß die Vertrauensfrage zwischendurch einmal dazu denaturiert wurde, Neuwahlen zu ermöglichen ${ }^{143}$,

S. 136; F. Rietdorf, Vorschlag zur Frage der Delegation der rechtsetzenden Gewalt, insbesondere zur Neufassung des Art. 80 GG nebist thesenartiger Begründung, in: Zur Sache 1/73, S. 128 (130 f.); Zusammenfassung des Gutachtens von Staatssekretär a.D. Dr. Loschelder, Uber Fragen der Gesetzgebung, ebda., S. 131 (133); $H$. H. Rupp, Zweikammersystem und Bundesverfassungsgericht, Ordo 30 (1979), 95, der einen Vorschlag von $F$. A. v. Hayek aufgreift, die Legislative in eine Kammer zur Behandlung der auf Dauer und Beständigkeit angelegten allgemeinen Rechtsregeln und eine weitere zur Erledigung der laufenden legislatorischen und sonstigen parlamentarischen Tagesgeschäfte aufzuteilen.

141 Hinsichtlich des Bundestags für den Regelfall (ausgenommen verfassungsändernde Gesetze, Haushaltsgesetze und andere Gesetze bei entsprechendem Minderheitenantrag eines Viertels der Mitglieder des Bundestags) angeraten im Schlußbericht der EnquêteKommission Verfassungsreform, BT-Dr. 7/5924, S. $81 \mathrm{f}$. Nur zwei Beratungen sind bereits gegenwärtig vorgesehen in den Parlamenten von Bayern, Berlin, Bremen, Hamburg, Hessen, NordrheinWestfalen, Rheinland-Pfalz und Schleswig-Holstein.

142 Da die Sperrklausel einem unbeschränkten Pluralismus nicht entspricht (wie dieser aber auch die durch die Sperrklausel geförderte Funktionsfähigkeit des Parlaments zu den Anforderungen der Demokratie zählt), ist gerade in diesem Zusammenhang der Eindruck von Interesse, der hierüber im Ausland besteht: $A$. Grosser (s. o. Anm. 2), S. 220, zieht eine Parallele zwischen der FünfProzent-Klausel und der Bemessung der Zuschüsse nach der Zahl der Wähler und folgert aus der Sicht dieser (freilich ganz heterogenen) Faktoren die Begünstigung der großen Parteien und die Erschwerung des Aufstiegs der kleineren, ohne hiergegen jedoch Vorbehalte zu erheben.

149 Am 20. 9. 1972 durch Bundeskanzler Brandt. Die Abstimmung ergab bei einer Teilnahme von 482 Stimmberechtigten und 22 Berliner Abgeordneten die Ja-Stimmen von 233 Stimmberechtigten zuzüglich 12 Berliner Abgeordneten, die Nein-Stimmen von 248 Stimmberechtigten und 10 Berliner Abgeordneten sowie die Enthaltung eines stimmberechtigten Abgeordneten. $\mathrm{Zu}$ diesem Vorgang des näheren $W$. Blischke, Verfahrensfragen des Bundestages im Jahre 1972, Staat 12 (1973), 65; R. Lange/G. Richter, Erste vor- 
liegt nicht an ihr, sondern an der mangelnden vorzeitigen Beendbarkeit der Wahlperiode des Bundestags ${ }^{144}$. Zwischen Parteienstaat und Parlamentarismus bestehende Spannungen sind im übrigen vor allem von Gerhard Leibholz so oft und deutlich herausgestellt worden ${ }^{145}$, daß dem hier wenig hinzuzufügen ist. Sicherlich besitzen die politischen Parteien eine Formierungsfunktion, durch die der Volkswille kanalisiert wird. Doch nehmen sie auch an Phänomenen teil, die sich auf der Seite der Parlamente und Abgeordneten zeigen: Denn auch wie diese, sind die Parteien während der Wahlperiode vom Wähler relativ unabhängig, ist ihr politisches Schicksal während dieser Zeit selbst dann nicht in Frage gestellt, wenn sie sich vom Willen der Wähler entfernen. Demgegenüber - auch dies spiegelt sich übrigens in dem neuen Diätenverständnis wider - ist das Abgeordnetenmandat weniger von staatlicher Seite bedroht als ehedem $^{146}$. Die weitaus größere Gefährdung der Unabhängig-

zeitige Auflösung des Bundestages. Stationen vom konstruktiven Mißtrauensvotum bis zur Vereidigung der zweiten Regierung Brandt/Scheel, ZParl. 4 (1973), 38; 30 Jahre Deutscher Bundestag (s. o. Anm. 2), S. 202 ff.

144 Nunmehr vorgeschlagen von der Enquête-Kommission Verfassungsreform, BT-Dr. 7/5924, S. 39 ff. (auf Minderheitenantrag eines Viertels der Mitglieder des Bundestags).

145 G. Leibholz, Verfassungsrechtliche Stellung und innere Ordnung der Parteien, Referat auf dem 38. Deutschen Juristentag, Frankfurt/Main 1950, 1951, S. C 2 (15); ders., Parteienstaat und Repräsentative Demokratie, DVBl. 51, 1; ders., Der Strukturwandel der modernen Demokratie, in: Strukturprobleme der modernen Demokratie, 1974, S. 78 (94 ff.). Vgl. demgegenüber aber auch $U$. Scheuner, Das repräsentative Prinzip in der modernen Demokratie, in: Verfassungsrecht und Verfassungswirklichkeit, Festschrift für Hans Huber, 1961, S. 222 (222, 225, 239 ff.).

146 Nur so läßt sich die Bereitschaft erklären, durch ein gehaltsähnliches Diätenverständnis die Abgeordnetentätigkeit als durch „full-time-job" (BVerfGE 40, 296 [314]) erbrachte Erledigung von Staatsaufgaben zu honorieren. Vgl. hierzu insb. H. H. v. Arnim, Die Steuerfreiheit der Abgeordnetendiäten ist verfassungswidrig, Betrieb 72, 898; $P$. Conradi, Parlamentarier in privilegienfeindlicher Demokratie - Anmerkungen eines Bundestagsabgeordneten zum „Diäten-Urteil“" des Bundesverfassungsgerichts, ZParl. 7 (1976), 113; M. Friedrich, Der Landtag als Berufsparlament?, 1977; W. Geiger, Der Abgeordnete und sein Beruf. Eine kritische Auseinandersetzung mit folgenreichen Mißdeutungen eines Urteils, ZParl. 9 (1978), 522; R. Hanauer, Der Abgeordnete und seine Bezüge - Fragen zu einer Antwort von Willi Geiger, ZParl. 10 (1979), 115; K. Schlaich/H. J. Schreiner, Die Entschädigung der Abgeordneten, NJW 79, 673; $H$. Schneider, Diäten und Rechtsstellung der Bundes- und Landtags- 
keit des Abgeordneten eriolgt durch Interessengruppen und durch die politischen Parteien. Durch die denkbare, nach meiner Auffassung verfassungsrechtlich auch nicht ausgeschlossene, Einführung einer rahmenhaften Bindung des Abgeordneten an das Parteiprogramm und die Wahlplattform ${ }^{147}$ ließe sich die Harmonisierung beider Prinzipien möglicherweise im Sinne einer praktischen Konkordanz vergrößern; gleichwohl erscheint es zumindest für absehbare Zeit nicht so, daß dieser Weg beschritten werden würde. Bundesrat und Vermittlungsausschuß schließlich haben unabhängig von der jeweiligen politischen Konstellation ihre Aufgabe als „Integrationsorgane par excellence" erfüllt"148.

b) Bezüglich der vollziehenden Funktion ist zunächst erkennbar, daß die gegenüber dem Weimarer Staat veränderte Konzeption des Bundespräsidentenamts sich bewährt hat. Die mittelbare Wahl des Staatsoberhaupts bewirkt eine „distanzierte" Legitimation, die der Bedeutung des Amtes angemessen ist. Entgegen einer mitunter verbreiteten Auffassung korrelieren seine Legitimationsform und sein Kompetenzbereich zwar keineswegs ${ }^{149}$ - denn es ist nicht erkennbar, warum nicht

abgeordneten, ZParl. 9 (1978), 452; ders., Teil- oder Vollzeitabgeordnete in den Landtagen? Ist das ,Stuttgarter Modell“ verallgemeinerungsfähig?, ZParl. 9 (1978), 456; U. Thaysen, Die Volksvertretungen der Bundesrepublik und das Bundesverfassungsgericht: uneins in ihrem Demokratie- und Parlamentsverständnis, ZParl. 7 (1976), 3.

147 N. Achterberg, Das rahmengebundene Mandlat, 1975; ähnlich das Plädoyer von Th. Oppermann, VVDStRL 33, 53, für das „generelle Mandat". - Kritisch demgegenüber $K$. Stern, a. a. O., § 24 IV $4 \mathrm{c}, \mathrm{S} .848 \mathrm{f}$.

148 Als Beleg für die erfolgreiche Tätigkeit des Bundesrats ist es zu werten, daß sich seine Gesetzgebungsinitiative von $0,8 \%$ aller Gesetzentwürfe in der 1. Wahlperiode des Bundestags bis auf $10,9 \%$ sämtlicher Gesetzentwürfe in der 7. Wahlperiode des Bundestags gesteigert hat, $\mathrm{daB}$ er beispielsweise in der 7. Wahlperiode $63,6 \%$ aller Gesetze zugestimmt und nur 2,1\% der Gesetze die Zustimmung verweigert hat, bei $32,9 \%$ der Gesetze keinen Einspruch, bei $1,2 \%$ Einspruch eingelegt hat, daB in den ersten sieben Wahlperioden von 404 Anrufungen des Vermittlungsausschusses 370 durch den Bundesrat erfolgten und es nach erfolgtem Vermittlungsverfahren (6 Verfahren wurden wegen Zurücknahme der Anrufung, anderweitiger Erledigung des Anrufungsbegehrens oder lediglich vorsorglicher Anrufung nicht durchgeführt) in 349 Fällen zum Gesetzeserlaß kam (statistische Angaben in: 30 Jahre Deutscher Bundestag [s. o. Anm. 2], S. 268, 273, 276).

140 So aber die Enquête-Kommission Verfassungsreform, BT-Dr. 7/5924, S. 21; R. Wahl, Staat 18 (1979), 236. 
auch ein mit schmaleren Kompetenzen ausgestattetes Staatsoberhaupt sich auf breiteste Legitimation sollte stützen können - aber auch ohnedies läßt sich die verminderte Zuständigkeit des Staatsoberhaupts nicht bemängeln. Die Inhaber des höchsten Staatsamtes in der Bundesrepublik Deutschland haben sich durchwegs an die ihnen von der Verfassung zugeteilten Kompetenzen gehalten und dabei dem Parlament und der Regierung das belassen, was deren Amtes ist. Von dem Stil des jeweiligen Organwalters zumindest ebenso deutlich geprägt wurde das Amt des Bundeskanzlers, wobei die Richtlinienkompetenz mitunter stärker, mitunter schwächer wahrgenommen wurde ${ }^{150}$. Immerhin war das Vertrauen des Parlaments in den jeweiligen Bundeskanzler so groß, daß es kein einziges Mal zu einem erfolgreichen konstruktiven Mißtrauensvotum gekommen ist - auch dies ein Beweis für die politische Stabilität der Bundesrepublik Deutschland.

Nur gestreift werden können in diesem Zusammenhang jene besonderen Zweige unserer Rechtsordnung, die auch verfassungsrechtlich geregelt sind:

Das gilt zunächst für das öffentliche Dienstrecht. Die Entscheidung des Verfassunggebers für die Beibehaltung des Berufsbeamtentums war nicht selbstverständlich. Begreiflich ist es denn auch, daß es immer wieder Bestrebungen zur vollen oder teilweisen Vereinheitlichung des Dienstrechts gegeben hat, obwohl diese ohne Erfolg geblieben sind und auch das Aktionsprogramm des Bundesministers des Innern ihnen nicht nachgegeben hat ${ }^{151}$. Hinsichtlich der Arbeits- und Wirtschaftsverfassung hat die Wahrung der Koalitions- und Tariffreiheit dazu

150 Das Utbergangsphänomen des Kressbronner Kreises war dabei (ohne verfassungswidrig zu sein) eher ein Zeichen schwächerer Wahrnehmung der Richtlinienkompetenz, ähnlich auch $A$. Grosser, (s. o. Anm. 2), S. 184 f. (der S. 169 ff. ausführlich die Handlungsstile aller ersten vier Bundeskanzler untersucht).

151 Vgl. dazu Aktionsprogramm Tz. 5, nachdem die Studienkommission für die Reform des öffentlichen Dienstrechts (Bericht der Kommission 1973) mit 10 von ihren 19 Mitgliedern vorgeschlagen hatte, das öffentliche Dienstrecht durch Gesetz zu regeln, während die übrigen eine Regelung teils durch Gesetz, teils durch Tarifvertrag befürwortet hatten. Für differenzierende Lösungen auch der DGB in seinem nach Status- und Folgerecht gegliederten Modell, vgl. Grundsätze des Deutschen Gewerkschaftsbundes zur Neuordnung des Beamtenrechts - Gliederung in Statusrecht und Folgerecht (1970), während der Vorschlag des DBB zur Reform des öffentlichen Dienstrechts (1972) an den Prinzipien des Beamtenrechts festhielt. Auch verschiedene Landesregierungen, politische Parteien und kommunale Spitzenverbände haben in die Diskussion eingegriffen 
beigetragen, daß der Bundesrepublik Deutschland die Volkswirtschaft fundamental erschütternde Arbeitskämpfe bisher erspart geblieben sind. Nicht nur das Bundesverfassungsgericht, sondern auch das Bundesarbeitsgericht hat hierzu wesentlich beigetragen, wobei die gebotene Neutralität gegenüber den Sozialpartnern konstatiert werden kann. Ist die Zulässigkeit des Streiks für Angestellte und Arbeiter, seine Unzulässigkeit für Beamte - die begrenzte Einführung auch nur für solche nicht versorgungsnotwendiger Organe geriete schnell an die Grenze des Gleichheitssatzes - im wesentlichen unumstritten ${ }^{152}$, so kann dasselbe für die Aussperrung freilich nicht festgestellt werden ${ }^{153}$. Indessen erscheint diese Frage unmittelbarer rechtlicher Lösung überhaupt nicht zugänglich, weil sie von der jeweils eingenommenen sozio-ökonomischen Sicht abhängt. Im übrigen hat das Bundesverfassungsgericht zwar zutreffend festgestellt, da $B$ das Grundgesetz sich einer wirtschaftspolitischen Grundentscheidung enthalten hat ${ }^{154}$, dennoch wird die bisher

und ihre Vorstellungen in Erklärungen konkretisiert, Ubbersicht im Aktionsprogramm, Tz. 2, sowie bei $N$. Achterberg, Das Leistungsprinzip im öffentlichen Dienstrecht, DVBl. 77, 541 (543, Anm. 14).

${ }_{152}$ So BVerfGE 8, 1 (15 ff.); 19, 303 (322); 44, 249 (264), sowie das Aktionsprogramm, S. 12, entsprechend der Rechtsauffassung der Gutachter E. Forsthoff, W. Schick, C. H. Ule, F. Mayer, Verfassungsrechtliche Grenzen einer Reform des öffentlichen Dienstrechts, in: Studienkommission für die Reform des öffentlichen Dienstrechts, Bd. 5, S. 17 (50 ff.), 171 (252 ff.), 441 (481 ff.), 557 (663 ff.). Dazu auch J. Isensee, Beamtenstreik, 1971, S. 33 ff.; $F$. Mayer, Verfassungsrechtliche Probleme einer Reform des öffentlichen Dienstes, in: Offentliches Recht und Politik, Festschrift für Hans Ulrich Scupin, hrsg. Achterberg, 1973, S. 249 (256, 276 ff.); I. v. Münch, Beamtenstreik und Sozialstaatsprinzip, ZBR 70, 371; K. Stern, a. a. O., § 11 IV 3 a, S. 283, m. zahlreichen Hinweisen Anm. 136. - A. M. insb. W. Däubler, Der Streik im öffentlichen Dienst, 1970, S. 66 ff.; T. Ramm, Das Koalitions- und Streikrecht der Beamten, 1970, passim.

${ }^{153}$ Nach in der Rechtsprechung vertretener Auffassung sind Streik und Aussperrung durch das Grundgesetz weder gewährleistet noch verboten, BAG, NJW 55, 882 (883); BSG, NJW 63, 2189 (2190). Ebenso auch Th. Maunz, Staatsrecht, \$20 II 1, S. 176; zur Aussperrung kritisch insb. A. Hamann/H. Lenz, Das Grundgesetz für die Bundesrepublik Deutschland vom 23. Mai 1949, 3. Aufl., 1970, Art. 9, Anm. B 8 b bb, S. 237 f., m. zahlreichen Hinweisen.

154 BVerfGE 4, 7 (17 f.); 7, 377 (400); 12, 354 (363 f.); 14, 263 (275); 30, 292 (315, wo die wirtschaftspolitische Neutralität bedenklicherweise in einer Art Umkehrung der Werte sogar zum Auslegungskriterium für Grundrechte gemacht wird); 40, 290 (338). - Gleicher Ansicht $R$. Schmidt, Wirtschaftspolitik und Verfassung, 1971, S. $130 \mathrm{f}$. Vgl. zum Thema neuestens $K$. M. Meessen, NJW 79, 834. 
nicht verwirklichte Möglichkeit partieller Sozialisierung in ihrer Bedeutung jedenfalls weit übertroffen von den verfassungsrechtlichen Instrumenten sozialer Marktwirtschaft - wie Vertragsfreiheit, Berufs- und Gewerbefreiheit, Vereinigungsfreiheit und Eigentumsfreiheit -, wenn auch vor allem durch verstärktes Planungsbewußtsein staatliche Ingerenzen auf die Wirtschaft insgesamt zugenommen haben ${ }^{155}$. Von beachtlicher Bedeutung sind ferner die Änderungen, die sich seit Inkrafttreten des Grundgesetzes im Rahmen der Finanzverfassung ergeben haben. Zugleich mit der Einführung der Gemeinschaftsaufgaben ${ }^{156}$ ist durch die Neufassung der haushalts- und finanz-

155 Die Entwicklung hat insoweit verschiedene Stadien durchlaufen: Nach einer Phase der Zurückhaltung bei der Planung hat sich - nicht zuletzt unter dem Eindruck der französischen planification - in den sechziger Jahren ein verstärktes Planungsbewußtsein gezeigt, das sich zunächst in planerischer Tätigkeit der Exekutive auswirkte, während zu Beginn der siebziger Jahre eine Parlamentarisierung der Planung in Erscheinung trat; davon unabhängig verlief die Entwicklung von der (baurechtlichen, bildungsrechtlichen, finanzrechtlichen, kommunalrechtlichen) Fachplanung zur ressortübergreifenden integrierten Entwicklungsplanung. Dazu insb. $E .-W$. Böckenförde, Planung zwischen Regierung und Parlament, Staat 11 (1972), 429; H. Harnischfeger, Planung in der sozialstaatlichen Demokratie, 1969; R. Herzog/R. Pietzner/F. Wagener/W. Blümel, Planung, in: Evangelisches Staatslexikon, Sp. 1818; H. J. Hoenisch, Planifikation, 1974; J. H. Kaiser (Hrsg.) Planung, Bd. I ff., 1965 ff.; F. Ossenbühl, Welche normativen Anforderungen stellt der Verfassungsgrundsatz des demokratischen Rechtsstaats an die staatliche planende Tätigkeit, dargestellt am Beispiel der Entwicklungsplanung? Gutachten zum 50. Deutschen Juristentag, 1974; W. Graf Vitzthum, Parlament und Planung, 1978; R. Wahl, Notwendigkeit und Grenzen langfristiger Aufgabenplanung, Staat 11 (1972), 459.

156 Durch Einundzwanzigstes Gesetz zur Änderung des Grundgesetzes (Finanzreformgesetz) v. 12. 5. 1969 (BGBl. I 359). Der umstrittenen Natur der Gemeinschaftsaufgaben wurde durch die Erörterung in der Vereinigung der Deutschen Staatsrechtslehrer Rechnung getragen, vgl. J. Frowein/I. v. Münch, Gemeinschaftsaufgaben im Bundesstaat, VVDStRL 31, 13, 51, die sich übereinstimmend (S. 50 LS 17, S. 86 LS 9) für eine „Chance der Bewährung“ ausgesprochen haben (während es inzwischen - wie R. Wahl, Staat 18 [1979] 251, zutreffend bemerkt - um den Ausbau des parlamentarischen Regierungssystems und des Bundesstaatsprinzips zum Zwecke koordinativer Gesamtsteuerung geht). Auch die Enquête-Kommission Verfassungsreform, BT-Dr. 7/5924, S. 151, schlägt im Grundsatz - wenn auch in der Ausgestaltung modifizierend - die Beibehaltung gemeinsamer Aufgabenplanung vor. Die Finanzverfassungsreform wurde von W. Strau $\beta$, DOV 69, 298, als „wichtigste Reformaufgabe des GG überhaupt" angesprochen. 
bezogenen Vorschriften des Grundgesetzes dem Erfordernis Rechnung getragen worden, daß mannigfache Staatsaufgaben die Zusammenarbeit von Bund und Ländern erfordern und die Neuverteilung der Aufgaben auch diejenige der Ausgaben sowie Einnahmen verlangt. Wie der Bericht des Rechtsausschusses erkennen läßt, stand hierfür die UUberlegung Pate, daß die „bundesstaatliche Ordnung der Zukunft... aus dem Geist eines kooperativen Föderalismus verstanden und weiterentwickelt werden $(\mathrm{mu})^{\prime \prime 157}$ - dies eine über den konkreten Anlaß hinausweisende Maxime. Die auch finanzverfassungsrechtlich relevante Neugliederung des Bundesgebiets scheint jedoch bis auf weiteres keine Verwirklichungschance zu besitzen ${ }^{158}$.

c) Damit verbleibt schließlich noch der Blick auf die Rechtsprechung, die sich formell-rechtlich auf Verfassungsebene als am wenigsten der Veränderung unterworfene Staatsfunktion erwiesen hat. Die Ersetzung der Absicht zur Errichtung eines Obersten Bundesgerichts durch die Bildung des Gemeinsamen Senats der obersten Gerichtshöfe des Bundes ${ }^{159}$, die Vereinheitlichung der beiden Klassen der Richter am Bundesverfassungsgericht ${ }^{180}$ sowie die Einführung des Sondervotums ${ }^{161}$ an diesem

${ }^{157}$ Vgl. Schriftlicher Bericht des Abgeordneten Dr. Bayerl zu BT-Dr. V/3605, S. 3.

${ }^{158}$ Ausdruck hierfür ist die Änderung des Art. 29 GG durch Fünfundzwanzigstes Gesetz zur Änderung des Grundgesetzes v. 19.8. 1969 (BGBl. I 1241), durch das die vormalige Muß- durch eine KannVorschrift ersetzt wurde. Die Anregung von H. P. Ipsen, DÖV 74, 300 ; Th. Maunz, Das Verhältnis von Bund und Ländern in verfassungsrechtlicher Sicht, in: 25 Jahre Grundgesetz, hrsg. Löw, S. 123 (138), Art. 29 GG ersatzlos zu streichen, bleibt aktuell.

${ }_{159}$ Durch Sechzehntes Gesetz zur Änderung des Grundgesetzes v. 18. 6. 1968 (BGBl. I 657). Dazu insb. K. Miebach, Der Gemeinsame Senat der obersten Gerichtshöfe des Bundes, 1971; W. Späth, Zur Stellung des Gemeinsamen Senats der Obersten Gerichtshöfe des Bundes und seiner Anrufung, Der Steuerberater 72, 21.

${ }^{100}$ Bis zum Vierten Gesetz zur Änderung des Gesetzes über das Bundesverfassungsgericht v. 21. 12 . 1970 (BGB1. I 1765) wurden die Richter jedes Senats des Bundesverfassungsgerichts aus der Zahl der Richter an den oberen Genichtshöfen des Bundes für die Dauer ihres Amtes an diesen Gerichten, im allgemeinen also bis zum Erreichen der Altersgrenze, die übrigen Richter auf die Dauer von acht Jahren ohne Rücksicht auf die Altersgrenze mit der Möglichkeit der Wiederwahl gewählt, seitdem sieht $\S 4$ Abs. 1, 2 BVerfGG die einheitliche Amtszeit von 12 Jahren spätestens bis zur Altersgrenze, ohne Möglichkeit der Wiederwahl vor. Damit ist der Kritik insb. von $H$. Laufer, Verfassungsgerichtsbarkeit und politischer Prozeß, 1968, S. 215 ff., Rechnung getragen.

161 § 30 Abs. 2 BVerfGG (eingefügt durch das Vierte Änderungs- 
Gericht haben materiell-rechtlich Verfassungsänderungen gebracht - letztere übrigens in einem Akzentwandel von der überwiegend subjektiven zur objektiven Rechtsschutzkomponente, weil das Sondervotum im Interesse subjektiven Rechtsschutzes weitaus besser bei den Instanzgerichten angesiedelt worden wäre als bei dem Bundesverfassungsgericht, wo es allenfalls der Rechtsfortbildung zu dienen vermag. $\mathrm{DaB}$ das Bundesverfassungsgericht im übrigen politische Folgewirkungen durchaus zulässigerweise und sachgerecht mitreflektiert, beweisen die Grundlagenvertrags-, die Schleyer- und die Mitbestimmungsentscheidung ${ }^{162}$.

\section{Ergebnis}

Evolution bedarf der Evaluation. In diesem Sinne ist auch die Zwischenbilanz zur Verfassungsgeschichte der Bundesrepublik Deutschland zu verstehen. Sie führt insgesamt zu einem positiven Urteil über die Verfassung, die seit nunmehr dreißig Jahren die rechtliche Grundordnung unseres Staats darstellt und stabilisierende und korrigierende Elemente in einem ausgewogenen, kontinuierliche Evolution ermöglichenden Verhältnis enthält.

Die mitunter gestellte Frage nach der Identität des Grundgesetzes nach dreißig Jahren ${ }^{163}$ erscheint mir dabei allerdings

gesetz, s. Anm. 160) führte das Sondervotum ein, nachdem sich der 47. Deutsche Juristentag bereits mit dieser Frage befaßt hatte, vgl. vor allem das Gutachten von $K$. Zweigert, Empfiehlt es sich, die Bekanntgabe der abweichenden Meinung des überstimmten Richters (Dissenting Opinion) in den deutschen Verfahrensordnungen zuzulassen?, 1968 (befürwortend für alle Gerichte).

162 S. BVerfGE 36, 1 (17 ff., 20 ff.); 46, 160 (165); 50, 290 (328 f., 333, $373 \mathrm{ff}$.). Zur Zuläissigkeit der Einbeziehung von (auch politischen) Konsequenzen N. Achterberg, DOV 77, $652 \mathrm{~m}$. weit. Hinweisen, Anm. 21 ; O. Bachof, Der Verfassungsrichter zwischen Recht und Politik, in: Summum ius - summa iniuria, 1963, S. 41 (45 f., 47 f.); $P$. $H \ddot{a}-$ berle, Offentliches Interesse als juristisches Problem, 1970, S. 711; ders., Kommentierte Verfassungsrechtsprechung, S. 91; H. H. Klein, Bundesverfassungsgericht und Staatsraison, 1968, S. $31 \mathrm{ff}$.

${ }_{103} H$. Vorländer, Identität des Grundgesetzes nach 30 Jahren?, JuS 79, 313. Dies ist nicht weiter erstaunlich: F. Wieacker, Privatrechtsgeschichte der Neuzeit, 1952, S. 307 f., meint sogar, das heute geltende Privatrecht könne nicht mehr aus dem Gesetzbuch abgelesen werden. Auch dadurch wind die Kongruenzidentität des Privatrechts nicht ausgeschlossen. Im Ergebnis wie hier Th. Maunz, BayVB1. $79,514$. 
schon im Ansatz verfehlt. Daß weder der Normtext als Ganzer, noch die gesellschaftliche Lage nach dieser Zeit übereinstimmt, ist eine Binsenweisheit, die keiner näheren Behandlung bedarf. Indessen ist auch nicht dies, sondern vielmehr die Kongruenzidentität entscheidend: ob nämlich die Uereinstimmung zwischen Verfassungstext und Verfassungswirklichkeit auch nach den erfolgten Fortschreibungen noch immer dasselbe AusmaB aufweist wie zuvor. Das aber wird man mit gutem Gewissen bejahen können, und auch die eingangs erwähnten, relativ häufigen Ergänzungen und Änderungen des Grundgesetzes sind weniger der ursprünglichen Verfassungskonzeption anzulasten, sondern Konsequenzen von Wandlungen einer sich immer schneller bewegenden Welt.

Die positive Bilanz der Untersuchung der staatlichen Binnenstruktur der Bundesrepublik Deutschland führt schlieBlich zu folgenden weiteren Ergebnissen:

Zum ersten läßt sie eine Aussage über die mitunter diskutierte fortdauernde „Regierbarkeit“ der Bundesrepublik Deutschland zu. Versteht man unter einer solchen die Möglichkeit, die verfassungsrechtlich umrissenen Staatsziele mit der gleichfalls verfassungsgesetzlich hierfür zur Verfügung gestellten Staatsform unter Wahrung eines optimalen Verhältnisses von Freiheit und Gleichheit zu erreichen, so besteht zumindest für einen überschaubaren Zeitraum an dieser fortdauernden Regierbarkeit kein Zweifel ${ }^{164}$.

Zum zweiten ergibt sich aus den zuvor angestellten Utberlegungen die Konsequenz, da $B$ der in der Stabilität der Binnenstruktur der Bundesrepublik Deutschland liegende Integrationsfaktor für den Ausbau ihrer rechtlichen Beziehungen mit der Deutschen Demokratischen Republik vorhanden ist. Der Grundlagenvertrag ist ein Schritt in Richtung zu jener Einigkeit, die nach der Präambel des Grundgesetzes und - hier zeigt sich nochmals der Bezug zur Nation - nach der National-

${ }^{104} \mathrm{Zu}$ demselben Ergebnis kommt $H$. Meyer, Zur Regierbarkeit der parlamentarischen Demokratie, in: 15. Cappenberger Gespräch der Freiherr-vom-Stein-Gesellschaft, 1979 , S. $48(63,68)$ - allerdings von einem modifizierten Begriffsverständnis der Regierbarkeit aus (S. 55: nach seiner Auffassung ist ein System hinreichend regierungsfähig, „wenn es bei ausreichender Kontinuität Regenerationsund Lernfähigkeit besitzt, wenn es belastbar ist und wenn es über ein ausreichendes $\mathrm{Maß}$ an autonomer Steuerungsfähigkeit verfügt".). Die Skepsis z. B. W. Webers, DVB1. 69, 414, hinsichtlich der politischen Stabilität der Bundesrepublik Deutschland hat sich nicht bewahrheitet, dasselbe bleibt gegenüber derjenigen von $W$. Leisner, BayVBl. 79, 521 f., zu hoffen. 
hymne ${ }^{185}$ ein zentrales Ziel unserer staatlichen Entwicklung bildet, aber auch nach dreißig Jahren Deutschland unter dem Grundgesetz noch nicht erreicht ist. Einigkeit und Recht und Freiheit haben wir für uns - das Verfassungsprogramm indessen geht über uns hinaus. In diesem Sinne, im Sinne der über den Staat hinausreichenden Nation - und wie könnte das deutlicher ins Bewußtsein gerückt werden als durch Geschichte und Lage dieses Hauses, in dem wir uns befinden bleibt die Forderung zu verwirklichen: „Einigkeit und Recht und Freiheit für das deutsche Vaterland."

165 Die Bezugnahme auf die Nationalhymne liegt wegen der politischen Vergleichbarkeit nahe: Hoffmann $v$. Fallerslebens Anliegen spiegelt das Streben nach einem über den völkerrechtlichen Verband des Deutschen Bundes hinausgehenden, die Territorien umfassenden deutschen (Bundes-)Staat wider. Die Ähnlichkeit der Beziehungen beider deutscher Staaten mit den im Deutschen Bund vertraglich verbundenen Staaten (ohne daß diese freilich zusätzliche Erkenntnisse über diejenigen beider deutscher Staaten zueinander erbringt: G. Ress, a. a. O., S. 159 ff., insb. S. 162 f.), wird zumindest derjenige sehen, der die Beziehungen zwischen der Bundesrepublik Deutschland und der Deutschen Demokratischen Republik (auch) als solche völkerrechtlicher Art versteht; nichts anderes ergibt sich auf der Grundlage der zuvor vertretenen These von der Natur dieser Beziehungen als solcher eines „intranationalen interstaatlichen Rechtsverhältnisses". 
Leitsätze des Mitberichterstatters über:

\section{Deutschland nach 30 Jahren Grundgesetz}

\section{Einleitung}

1. Trotz 34 verfassungsändernden Gesetzen ist das Grundgesetz während der 30 Jahre seines Bestehens in seinem Grundgehalt unverändert geblieben. Der.Wandel des Normenbestands spricht nicht gegen die Verfassungskonzeption.

2. Je weiter verfassungsgesetzlich eröffnete Freiheitsräume sind, um so eher besteht die Gefahr von Identifikationsdefiziten, je offener eine Verfassung ist, um so eher gibt es Konkretisierungsbedürfnisse, je länger eine Verfassung andauert, um so erforderlicher ist es, Prävisionsinsuffizienzen des Verfassunggebers zu heilen. Aus allem ergibt sich die Notwendigkeit der Verfassungsfortschreibung.

II. Die Rechtslage Deutschlands in rechts- und staatstheoretischer Sicht

3. Von Ansätzen abgesehen, fehlt der Bundesrepublik Deutschland noch immer eine Verfassungstheorie als Anleitung für die Verfassungspraxis. Eine solche muß Rechtstheorie und Metarechtstheorie sein, weil der Staat nur dualistisch juristisch und metajuristisch gedeutet werden kann.

4. Gegenstände einer Verfassungstheorie müssen der Staat als Subsystem neben anderen Subsystemen der Gesellschaft, aber auch seine Überlegenheit diesen gegenüber, das Verhältnis von Individuen und Transindividuen zum Staat, die Grundrechte in ihrer petitionellen, institutionellen und funktionellen Seite sowie Institutionen, Funktionen und Prozesse im Staat sein.

5. Uber die Verfassungstheorie muß in die Rechts- und Staatstheorie ausgegriffen und ebenso müssen das Völkerrecht und das Staatsrecht berücksichtigt werden, wenn die Rechtslage Deutschlands gedeutet werden soll. Dabei ist es unerläßlich, die Aussagekompetenz der jeweiligen Disziplin zu beachten und einen Disziplinensynkretismus zu vermeiden.

6. Konsens über die Rechtslage Deutschlands ist um so eher zu erwarten, je höher das Abstraktionsniveau ihrer Deutung 
ist. In erster Annäherung kommt eine solche aus der Sicht der Rechtstheorie in Betracht.

7. Die Natur der Rechtsordnung als Beziehungsgefüge von Rechtsverhältnissen - als Rechtsverhältnisordnung - bewirkt, daß es Rechtsverhältnisse verschiedenster Art gibt, die unterschiedlichen rechtlichen und metarechttichen Determinanten unterliegen.

8. Auf das Rechtsverhältnis zwischen der Bundesrepublik Deutschland und der Deutschen Demokratischen Republik wirkt sich vor allem deren gemeinsame Überwölbung durch die $\mathrm{Na}-$ tion aus. Sie läßt diese Beziehung als intranationales interstaatliches Rechtsverhältnis erscheinen.

9. Die rechtstheoretische Aussage über die Beziehung zwischen der Bundesrepublik Deutschland und der Deutschen Demokratischen Republik ergibt allerdings nichts für das Schicksal des Deutschen Reiches.

10. Aus der Sicht der Wiener Schule war die Untergangsthese konsequent; sie hat sich jedoch nicht durchgesetzt. Statt ihrer ist davon auszugehen, daß das Deutsche Reich auch nach dem Jahre 1945 fortbestanden hat und die Reichsgewalt von den Besatzungsmächten ohne Auftrag treuhänderisch ausgeübt worden ist.

11. Sämtliche nach der Etablierung der beiden deutschen Verfassungsordnungen vertretenen Deutschlandtheorien sind unbefriedigend. Die Dachtheorie insbesondere ist deswegen unhaltbar, weil es keine von der Rechtsordnung der Bundesrepublik Deutschland unabhängige Reichsrechtsordnung gibt, als deren Geltungsbereich das Deutsche Reich begriffen werden könnte. Am plausibelsten erscheint die These des Bundesverfassungsgerichts von der Identität des Deutschen Reiches mit der Bundesrepublik Deutschland in deren Gebietsumfang.

12. Der Fortbestand einer gemeinsamen deutschen Staatsangehörigkeit folgt - welche Auffassung man auch zu demjenigen des Deutschen Reiches vertritt - aus demjenigen des Staatsvolks.

13. Ist die Nation die metajuristische Determinante des Rechtsverhältnisses zwischen der Bundesrepublik Deutschland und der Deutschen Demokratischen Republik, so hängt dessen Ausgestaltung von der Aktivierung integrierender und der Inaktivierung desintegrierender Vektoren $a b . Z u$ den integrierenden zählt die Stabilität der staatlichen Binnenstruktur. 


\section{Die Stabilität der staatlichen Binnenstruktur als Integrationsfaktor}

14. Die staatsrechtliche Entwicklung unter dem Grundgesetz ist wesentlich von der Rechtsprechung des Bundesverfassungsgerichts geprägt.

15. Die Kritik, das Bundesverfassungsgericht greife in seinen Entscheidungen mitunter von der rechtlichen und die politische Ebene hinüber, verkennt die Institutionsimmanenz der seinen Entscheidungen zukommenden sozialen Breiten- und Tiefenwirkung. Im Verhältnis zu den übrigen Funktionsträgern, insbesondere den Organen der Legislative, ist das Bundesverfassungsgericht nicht gehindert, seine ihm verfassungsrechtlich zustehende Kompetenz voll auszuschöpfen.

16. Besondere Bedeutung hat die bundesverfassungsgerichtliche Fortentwicklung der Hermeneutik erlangt. Hierzu zählen die Verwendung des Theorems von der Konkordanz der Verfassungsnormen, die Anerkennung überpositiver als Leitmaximen für die Setzung und Anwendung positiver Normen sowie die Lehre von der verfassungskonformen Auslegung, die im übrigen zu einer solchen von der, ,normkonformen Norminterpretation" überhaupt zu erweitern ist.

17. Die verfassunggestaltenden Grundentscheidungen haben in den vergangenen dreißig Jahren einen beachtlichen Rationalitätszuwachs erfahren.

18. Ausgebaut worden ist insbesondere die Rechtsstaatlichkeit durch die Erweiterung des Gesetzesbegriffs und des Gesetzesvorbehalts, durch die normative Auffüllung von „Innenrechts"-Verhältnissen, durch die Verbesserung des verwaltungsgerichtlichen Rechtsschutzes sowie durch die Schaffung zusätzlicher Kontrollorgane.

19. Demgegenüber ist die Sozialstaatlichkeit theoretisch weniger bewältigt; sie spielt auch in der Verfassungsrechtsprechung eine geringere Rolle. Die umstrittene Frage, ob Evolution zu ihren Bestandteilen zählt, ist differenzierend $z u$ beantworten. Präventive Reglementierung gesellschaftlicher Entwicklung ist keine sozialstaatliche Aufgabe, wohl aber gehört $z u$ dieser die Vorbeugung gegen absehbare Fehlentwicklungen. Unter diesem Aspekt zählt auch die Wachstumsvorsorge zur Sozialstaatlichkeit.

20. Die Demokratie hat sich in ihrer Ausformung als parlamentarische als alternativenlos erwiesen. Die Rätedemokratie stellt für sie keinen Ersatz dar. Partizipationsausweitungen sind nicht nur juristische, sondern auch sozio-ökonomische 
Grenzen gesetzt. Der mit der Demokratie verhaftete Wertrelativismus ist durch die freiheitliche demokratische Grundordnung beschränkt. Der Staat hat nicht nur das Recht, sondern auch die Pficht, Verfassungsgegner vom öffentlichen Dienst fernzuhalten.

21. Als Bundesstaat hat die Bundesrepublik Deutschland von Anbeginn einen Unitarisierungstrend gezeigt (Ausbau der Bundeskompetenzen; Deutung der Bedürfnisklausel als Ermessensvorschrift; kooperatives Handeln im Bereich der Landeskompetenzen; Einführung der Gemeinschaftsaufgaben). Die Bundestreue besitzt über die das Verhältnis zwischen Bund und Ländern betreffenden ausdrücklichen Verfassungsnormen hinaus einen allenfalls geringen Erkenntniswert.

22. Die Grundrechte sind insbesondere durch die Rechtsprechung des Bundesverfassungsgerichts konkretisiert worden.

23. Bedeutsam sind dabei vor allem das Verständnis des Grundrechtssystems als Wertordnung, der Ausbau der Schrankensystematik, die Anerkennung einer beschränkten „Drittwirkung", die behutsame Deutung von Grundrechten als Teilhaberechte sowie neuerdings ein subsystemdifferenziertes Grundrechtsverständnis gewesen.

24. Die neben der petitionellen und der institutionellen sichtbar werdende funktionelle Seite der Grundrechte ist zutage getreten, wo deren Strukturwandel von Programmsätzen zu aktuellem Recht anerkannt wurde und wo Appellentscheidungen des Bundesverfassungsgerichts auf Grundrechte gestützt wurden.

25. Im ganzen stabil hat sich auch der organisatorische Teil des Grundgesetzes erwiesen. Größere Veränderungen hat es lediglich im Bereich der Finanzverwaltung sowie durch Einfügung der Vorschriften zur Vorsorge für den Verteidigungsfall gegeben.

26. Im Bereich des Parlamentsrechts haben sich Reformmaßnahmen auf Randkorrekturen beschränkt. Diskussionen über Spannungen zwischen Parteienstaatlichkeit und Parlamentarismus haben an der allgemeinen Zustimmung zum repräsentativen Mandat nichts geändert. Die Einführung eines rahmengebundenen Mandats zur Verbesserung der praktischen Konkordanz zwischen beiden Prinzipien ist zumindest in absehbarer Zeit nicht zu erwarten. Vorschläge zur Entlastung des Parlaments harren noch der Verwirklichung. - Auch der Bundesrat und der Vermittlungsausschuß haben ihre Aufgaben als ,Integrationsorgane par excellence" unabhängig von der jeweiligen politischen Kräftekonstellation sachgerecht erfüllt. 
27. Das Recht der Exekutive hat - von den erwähnten Ausnahmen abgesehen - keine durchgreifende Änderung erfordert und erfahren. Die Ämter des Bundespräsidenten und der Regierungsmitglieder haben sich sowohl hinsichtlich der Legitimationsbreite als auch hinsichtlich des Kompetenzbereichs als funktionsgerecht erwiesen. Dem entspricht die Stabilität des öffentlichen Dienstrechts.

28. Im Bereich der Arbeitsverfassung hat der Staat seine Neutralität gegenüber den Tarifpartnern gewahrt, in demjenigen der Wirtschaftsverfassung haben durch verstärktes Planungsbewußtsein staatliche Ingerenzen allerdings zugenommen; im Bereich der Finanzverfassung sind Verbesserungen durch die gestiegene Erkenntnis des Erfordernisses der Kooperation zwischen Bund und Ländern zur Wahrung des gesamtwirtschaftlichen Gleichgewichts eingetreten. Die auch finanzverfassungsrechtlich relevante Neugliederung des Bundesgebiets scheint jedoch bis auf weiteres keine Verwirklichungschance $z u$ besitzen.

29. Im Bereich des Rechtsprechungsrechts haben sich Änderungen vor allem auf der Ebene der Prozeßordnungen als „konkretisierten Verfassungsrechts" vollzogen; auf derjenigen des Verfassungsrechts selbst sind sie Ausnahme geblieben.

\section{Ergebnis}

30. An der fortdauernden „Regierbarkeit" der Bundesrepublik Deutschland besteht nach den Erfahrungen der vergangenen dreißig Jahre zumindest für einen überschaubaren Zeitraum kein Zweifel. Die Stabilität ihrer Binnenstruktur bildet einen Integrationsvektor, der zur Erfüllung des Verfassungsauftrags zu dienen vermag, die beiden Teile der Nation wieder zusammenzuführen. 


\section{Aussprache und Schlußworte}

\section{Deutschland nach 30 Jahren Grundgesetz}

Vorsitzender (Oppermann): Verehrte gnädige Frau, verehrte Kollegen! Die Aussprache über unseren ersten Beratungsgegenstand, zu der ich Sie willkommen heiße, dürfte sich im wesentlichen aus den beiden Referaten ergeben. Die mehr völkerrechtliche Außenseite einerseits und die innerverfassungsrechtliche Betrachtung andererseits dürften die beiden Hauptkomplexe sein. Wir sollten in der Reihenfolge der Referate zunächst mit der Rechtslage Deutschlands 1979 beginnen. Dabei bietet sich an, als Erstes mehr allgemein zum heutigen Grundstatus des deutschen Raumes zu sprechen. Hierher mag auch manches Grundsätzliche aus dem Referat Achterberg gehören. Ein zweiter Abschnitt des ersten Diskussionsteiles könnten wichtige Einzelprobleme des deutschen Rechtsstatus wie Staatsangehörigkeit, Ostgebiete, Inland/Ausland u. ä. sein. Alsdann könnten wir im zweiten Hauptteil zur verfassungsrechtlichen Binnenentwicklung übergehen.

Vor Eintritt in die Sachdiskussion möchte ich jedoch noch einmal seitens des Vorstandes dem Dank gegenüber dem Präsidium des Deutschen Bundestages Ausdruck geben, daß wir das Thema gerade dieses ersten Beratungsgegenstandes hier im Reichstagsgebäude verhandeln können. Es gibt wohl - das ist heute morgen bereits etwas angeklungen, ich möchte es aber noch einmal betonen - kaum einen anderen Ort in ganz Deutschland, wo der geschichtliche Hintergrund unseres Themas so mit Händen greifbar wäre wie hier im alten Reichstag. Im zweiten Kaiserreich und ganz besonders in der Weimarer Republik verkörperte der Reichstag die beiden wichtigsten Elemente unseres Themas: Er war sichtbarer politischer Ausdruck für die Einheit des Deutschen Reiches. In ihm vollzog sich aber auch ein wesentlicher Teil der Parlamentarisierung und Demokratisierung in Deutschland seit 1871 und 1919. Das Bonner Grundgesetz hat bekanntlich vor 30 Jahren wichtige Entscheidungen unseres heutigen Staatswesens bekräftigt und erneuert, die hier in Berlin und in Weimar vor 60 Jahren gefallen sind. Andererseits haben der Brand des Reichstages 1933 und seine Erstürmung durch die Rote Armee 1945 in düsterer Weise symbolisiert, wieviel von diesen verfassungsmäßigen Errungenschaften in der Hitlerzeit vorübergehend oder auch längerfri- 
stig verspielt worden ist. Wir können aus den Fenstern dieses Fraktionsraumes mit dem Blick auf die Mauer die Teilung Deutschlands unmittelbar beobachten, die einen der Kernpunkte unseres Themas darstellt. Wir sind hier also für die Diskussion atmosphärisch in einmaliger Weise eingestimmt eine Diskussion, zu der ich als Erstem Herrn Mosler das Wort erteilen darf.

Mosler: Der Vorstand der Vereinigung hat mich gebeten, die Diskussion zu eröffnen. Beide Referate - damit hoffe ich, die Grundstimmung der Kollegen wiederzugeben - entsprechen den besten Traditionen unserer Vereinigung, so da $\beta$ beiden Rednern unser Dank gebührt.

Nun zum ersten Diskussionsthema, das das Referat von Herrn Bernhardt betrifft. Ich stimme mit ihm in so vielen Punkten überein, daß es schwer ist, etwas hinzuzufügen. Eine Nuancierung der letzen These (Nr. 25) möchte ich aber zur Diskussion stellen, indem ich ihr ein halbes Wort hinzufüge: „Deutschland ist nach 30 Jahren Grundgesetz in erster Linie eine politische Aufgabe und nur noch sehr begrenzt ein staatsrechtlicher Befund." Wir leben in einem historischen ProzeB, der sich rechtlich und politisch - der Rangordnung nach umgekehrt - immer mehr von den Ausgangspositionen von 1945: oberste Gewalt der Alliierten, und 1949: Beginn der staatlichen Teilung, entfernt. Die beiden deutschen Staaten haben sich in der Weise, wie es der Referent geschildert hat, nebeneinander entwickelt. Utbrig bleiben die alliierten Vorbehalte, die auf die Viermächtebasis von 1945 zurückgehen. Sie haben - daran kann man nicht zweifeln, den Bezugspunkt „Deutschland“ aufrechterhalten, , und zwar nicht nur als „Raum", wie es in der Formulierung des Diskussionsthemas heißt, sondern als rechtlichen Bezugspunkt. Damit ist nicht mehr ohne weiteres - auch darin stimme ich Herrn Bernhardt zu - eine Völkerrechtsfähigkeit Deutschlands ohne Handlungsfähigkeit gegeben. Diese These war aber für die Jahre nach 1945 bis 1949 und teilweise noch eine Zeitlang danach richtig - soweit die Westzonen in Frage kommen, bis zur endgültigen Ablösung des Besatzungsstatuts.

Einem Bezugspunkt muß, wie ich glaube, ein rechtlicher Status entsprechen. Mit diesem Begriff sind viele Assoziationen verbunden. Im Völkerrecht wächst die Diskussion um Statuspositionen, von denen man eine gewisse Drittwirkung annimmt, nämlich unter der Voraussetzung, daß sie 1 . auf eine gewisse Dauer angelegt sind, mag diese auch nur vorübergehend intendiert sein, und 2. daß sie eine Befriedungswirkung haben. 
Beides ist bezüglich des Status Deutschlands der Fall. Damit ist eine Außenwirkung verbunden, die man näher definieren kann. Die Ostverträge und das Berlin-Abkommen zeigen, daß die Vorbehalte erhalten geblieben sind; das Bezugssystem ist also noch da.

Es gibt staatsrechtliche Elemente, die von diesem völkerrechtlichen Statusbefund abhängen. Das war sicherlich 1945-1949 der Fall, als man noch von der treuhänderischen Wahrnehmung der Staatsgewalt sprechen konnte; es sind Kollegen im Saal, die diese rechtliche Situation damals eingehend beschrieben haben. Gegenwärtig hängen die staatsrechtlichen Beziehungen der Bundesrepublik Deutschland und Berlins mit den völkerrechtlichen Vorbehalten der Westalliierten, dem Deutschland- und dem Berlin-Vorbehalt, zusammen. Das ist ein Rest deutschen Staatsrechts in Verkoppelung mit Völkerrecht.

Ich stimme Herrn Bernhardt $\mathrm{zu}$, daß es gegenwärtig keine staatsrechtliche Beziehung zwischen den beiden deutschen Staaten gibt. Dazu bedürfte es beider Partner.

Der Referent hat über den Status Berlins gesprochen. Ich glaube, man kann ihn nur im Zusammenhang mit dem Deutschland-Status sehen. Der besondere Berlin-Status steht im engsten Zusammenhang mit der Viermächtebasis und dem Deutschland-Vorbehalt des Generalvertrags. Sobald wir ihn als isolierten Vorbehalt sehen, isolieren wir Berlin.

Ausgehend von dem Zusammenhang zwischen dem völkerrechtlichen Status Deutschlands und den damit verknüpften staatsrechtlichen Ansätzen, die wir im Verhältnis Bundesrepublik - Berlin konkretisiert sehen, könnte man vielleicht etwas weitergehen. Die folgende These versehe ich mit einem Fragezeichen, weil ich sie noch nicht genügend durchdacht habe: Könnte nicht dieser fortbestehende völkerrechtliche Status Deutschlands die Basis für künftige staatsrechtliche Anknüpfungen werden? Das könnte allerdings im Verhältnis zur DDR nur dann der Fall sein, wenn sie zustimmt, und dazu besteht zur Zeit keine Aussicht. Die Entwicklung entfernt sich immer mehr von der gemeinsamen Grundlage. Aber dennoch, der historische ProzeB bleibt noch anhängig, wenn auch nicht vor einem Richter, so doch vor der internationalen Rechtsgemeinschaft.

Häberle: Ich kann an die Ausführungen von Herrn Mosler und Herrn Bernhardt anknüpfen. Zwei Wege schlage ich vor, um über das rein rechtliche, wie wir gehört haben sehr rudimentäre Gehäuse hinaus, das für uns als Juristen von „Deutsch- 
land" übrig geblieben ist, einen Deutschland-Begriff und ein Deutschland-Bild zu erarbeiten. Das erste Stichwort lautet: Wie können und sollen wir im Wege einer kulturwissenschaftlichen Arbeitsweise und Methode, kulturgeschichtlich und kulturpolitisch das Deutschland-Bild näher konturieren, um auf lange Sicht ein ideelles Substrat für die Identität und Einheit von Deutschland und uns Deutschen zu gewinnen? Das zweite Stichwort heißt: Müssen wir nicht das Verhältnis von Grundgesetz und Ostverträgen in einer Art „Wechselwirkung“ bestimmen, also das Grundgesetz auch von den Ostverträgen her auslegen, so schmerzlich dies im Ergebnis zum Teil sein mag?

Zum ersten Punkt: der kulturwissenschaftlichen Erfassung und Umfassung, langfristig vielleicht auch dem „Verfassen“ von "Deutschland“. Mir scheint, daß nur eine Selbstvergewisserung über die Jahrhunderte, also die Erfahrungen, und über die Zukunft, also die Hoffnungen, über das, was die Identität von uns Deutschen als Kulturnation, als kulturelle Nation ausmacht, bei der Gewinnung des Deutschland-Bildes weiterhilft. Was muß ich über das rein Juristische hinaus alles berücksichtigen? Angesichts der begrenzten Leistungsfähigkeit bloß juristischer Texte und Konstruktionen ist tiefer anzusetzen: Wir sollten nach nichtjuristischen (Klassiker-)Texten, ihren Kontexten, ihrer Wirklichkeit und ihren Möglichkeiten suchen. Große Texte dieser Art haben ihren eigenen Geltungsgrund. Darum war ich so begeistert, daß Herr Bernhardt in seinem "Anhang“ Texte von Pufendorf bis Hegel und Dürig vorgeführt hat. Diese Texte können heute „nur" kulturwissenschaftlich und nur sehr vermittelt juristische Relevanz gewinnen - wir können heute nur noch Dürig als juristischen Text gelten lassen! Darum mein Vorschlag, diese Tradition des Problems der deutschen Frage in dem Kontinuum der kulturellen Identität Deutschlands mit all ihren Fragwürdigkeiten und Brechungen aufzunehmen. Erweiternd hinzugenommen werden sollten Äußerungen von Literaten, Intellektuellen, Künstlern, auch der Musik. Denken Sie an Walter Jens' Frage nach der ,, anderen Republik" (1978 bzw. 1979), an die „Briefe zur Verteidigung der Republik“ aus dem Jahre 1977, auch wenn uns manches daran nicht gefällt. Wir müssen die Distanziertheit vieler Vertreter der "schönen Literatur" gegenüber unserem Grundgesetz als dem Modell einer Republik abzubauen suchen. Günter Grass hat laut FAZ von vorgestern (vom 2. 10. 1979) jüngst in Peking erklärt, die nach 1945 in beiden deutschen Staaten wiedererstandene Literatur sei mit „das letzte Gesamtdeutsche, was wir haben". Das sollten wir aufgreifen. Ebenso die Texte einer Sarah Kirsch, die ich besonders liebe - als große Lyrikerin -, eines Reiner 
Kunze, in dessen Ubersiedlung von Deutschland nach Deutschland ebenso ein Stück Gesamtdeutschland liegt wie in seinen dichterischen Texten.

Hier in Kürze weitere Stichworte für ein kulturwissenschaftliches Arbeiten, das „Deutschland“ durch das Kulturell-Ideelle lebendig halten und "aufheben" will, nachdem der rechtliche Deutschlandbegriff heute ohne eine effektive Staatlichkeit ist: Wir sollten aus der Geschichte lernen, auf welche Weise eine kulturelle Nation wie die polnische drei gewaltsame Teilungen überlebt hat; wir sollten fragen, welche Kräfte hier "Träger" der nationalen Kulturtradition und so Elemente der Kontinuität waren: neben der Sprache vor allem die katholische Kirche. Heute müßten wir nach dem gesamtdeutschen Bewußtsein i. S. der politischen Kulturforschung fragen und es z. B. kulturpolitisch, deutschlandpolitisch in Schulbüchern von "unten her" und in Nationalstiftungen pflegen und erneuern. Mit anderen Worten: über die von Herrn Bernhardt ebenso nüchtern-realistisch wie eindrucksvoll vorgeführten rechtlichen Rudimente von Deutschland hinaus müssen wir unseren Gesichtskreis erweitern, als Juristen auch auf die Nicht-Juristen zugehen, um etwas von der Einheit Deutschlands als Kulturnation bzw. Kulturbegriff zu retten: aus gemeinsam erlittener - aktualisierbarer - Geschichte, aus Objektivationen von Erfahrungen und Hoffnungen im Spiegel unserer Gegenwart. So können wir Klassikertexte eines Friedrich Schiller zur Gedankenfreiheit und Gewaltenteilung einbeziehen, auch Texte eines Georg Büchner in seinem Kampf gegen die „Paläste“. Schon und auch damals war Deutschland eine geistige, kaum eine juristische Einheit. Die Tradition der oft zuwenig aktualisierten Paulskirchentexte von 1848/49 und ihr Problem der Verbindung von Freiheit und Einheit jenseits von 1871 wird relevant. Wenn wir heute aus diesem Saal des Berliner Reichstagsgebäudes hinüberblicken, so erinnern wir uns bestimmt des "Serenissimus" Karl Eugen, gegen den Schiller im Namen der Freiheit anrannte, und erkennen andere Duodezfürsten und Tyrannen in Deutschland. Damals wie heute war und ist die deutsche Frage als Frage von Einheit und Freiheit nicht gelöst. Auch das begründet eine Art von Kontinuität.

Zweitens: ein Wort zum Verhältnis völkerrechtliche Verträge und Grundgesetz. Viel diskutiert ist derzeit die "Alternative“ Auslegung der Ostverträge vom Grundgesetz oder umgekehrt: Auslegung der Verfassung von den Ostverträgen. Ich erinnere an das heute früh gebrauchte Bild von der "Gemengelage" zwischen Völkerrecht und Staatsrecht. Meines Erachtens wird das juristische Deutschland-Bild langfristig in einem offenen 
Proze $\beta$ von den Aussagen des ins materielle Verfassungsrecht hineinwachsenden "Grundlagenvertrags" von 1972 als solchen her mitbeeinflußt im Sinne einer Wechselwirkung von ,völkerrechtlichem" Text und Verfassungstext, ganz im Sinne des „kooperativen Verfassungsstaates". Wir kennen die - bewährte - „Wechselwirkung" von den Grundrechten und ihren Grenzen und sollten sie jetzt in einem neuen Zusammenhang fruchtbar machen. Das hat Auswirkungen auf "Deutschland nach 30 Jahren Grundgesetz". - Hier möchte ich meine erste und zweite These verklammern: Können wir wirklich die polnischen Gebiete jenseits der Oder/Neiße noch zu „Deutschland“ rechnen, wie dies manche im derzeitigen Streit um den umsatzsteuerrechtlichen Inlandsbegriff „Deutschland in den Grenzen von 1937" tun? Jener Raum ist doch nicht mehr von lebendiger deutscher Kultur der Deutschen „erfüllt" und gestaltet, in ihr geschehen doch keine Objektivationen der deutschen Nation als Kulturbegriff mehr. Das folgt aus meinem kulturwissenschaftlichen, (nicht bloß sozialwissenschaftlichen!) Ansatz, dessen Vermittlung mit dem rechtlichen im einzelnen freilich noch zu leisten wäre, gerade auch dort, wo Deutschland als Bezugssystem und Einheit in Zukunft fortdauern und -leben soll.

Geck: Ich stimme mit Herrn Häberle darin überein, daß wir mit den Fragen nach Volk und Kulturnation so tiefgehend ansetzen sollen, wie er dies mit einigen Beispielen skizziert hat. Die Fragestellung von Herrn Bernhardt war aber eine Fragestellung auf völkerrechtlicher und staatsrechtlicher Ebene, speziell auf völkerrechtlicher Ebene. Das Völkerrecht hat, wie Sie wissen, mit den Völkern als Kulturnationen nicht viel im Sinne; der soziologische Nationen- und Völkerbegriff findet im Völkerrecht keinen wesentlichen Platz, wie die internationale Praxis immer wieder zeigt.

Ich komme zurück auf die Ausführungen von Herrn Bernhardt und stimme mit ihm und Herrn Achterberg darin überein, da $\beta$ es sichere Lösungen nicht gibt. Jede Lösung, jede Theorie über die Rechtslage Deutschlands bietet Möglichkeiten, aber zugleich Kritikmöglichkeiten mannigfacher Art. Meine grundsätzliche Einstellung in der wesentlichen Frage Herrn Bernhardts entspricht weitgehend seinen Ergebnissen. Ich bin mit ihm insbesondere darin einig, daß man in der gegenwärtigen Situation mit der Dachtheorie nicht mehr viel anfangen kann. Ich glaube, daß die Identitätstheorie im Sinne von Ls. 8 mit allen ihren Schwächen uns heute eher weiterhilft. Ich stimme mit Herrn Bernhardt auch in der Kritik an einzelnen völkerrechtlichen Ausführungen des Bundesverfassungsgerich- 
tes überein, einer Kritik, die großenteils zusammenfaßt, was in verschiedenen wissenschaftlichen Äußerungen zu dem Grundlagenvertragsurteil bereits gesagt ist.

Bei dieser grundsätzlichen Utbereinstimmung möchte ich nun eine Frage stellen, Herr Bernhardt, die auch an etwas anknüpft, was Herr Mosler eben ausgeführt hat: Wenn man in Ls. 9 und 22 von den alliierten Vorbehaltsrechten und der ViermächteVerantwortung ausgeht a) für Deutschland als Ganzes, b) für Berlin, dann kann man diese unter zwei verschiedenen Gesichtspunkten sehen. Man kann einmal sagen, hier liegen ganz gewöhnliche völkerrechtliche Verträge vor, die nach den Rechtsnormen des Völkerrechts gehalten werden müssen, die aber nach den Erfahrungen der internationalen Praxis auch gebrochen werden können; völkerrechtliche Verträge, die dann Deliktsfolgen nach sich ziehen, aber eben auch nicht mehr. Man kann die Vorbehaltsrechte und die Vier-Mächte-Verantwortung aber auch anders sehen und fragen: Haben diese Verträge nicht einen besonderen internationalen Status begründet, einen Status, der nicht durch das einseitige Ausscheren eines Vertragspartners geändert werden kann, sondern der auch dann bleibt, wenn von irgendeiner Seite ein Vertragsbruch erfolgt? Diese Frage kann man möglicherweise gleich, möglicherweise unterschiedlich beantworten, a) für den Vier-Mächte-Vorbehalt über Deutschland als Ganzes, b) für Berlin. Die praktischen Folgen liegen auf der Hand. Ich wäre Ihnen dankbar, Herr Bernhardt, wenn Sie etwa in Ihren Schlußworten auf diesen Punkt noch eingehen könnten.

Böckenförde: Meine Dame, meine Herren! Ich bin nur Randgänger im Völkerrecht und äußere mich daher nur mit Zurückhaltung und einem nicht ganz guten Gewissen zu diesen Fragen. Wenn ich einen allgemeinen Eindruck formulieren darf, den ich beim Anhören des Referats von Herrn Bernhardt hatte, dann ist es der, ob hier nicht das Völkerrecht zu sehr wie eine staatsrechtliche Normenordnung vorausgesetzt und angewandt worden ist; man hat versucht, aus einem anerkannten Normenund Grundsatzsystem Folgerungen für die Beurteilung der Situation zu ziehen, die sich nach 1945 und bis zum heutigen Tag in Deutschland entwickelt hat. Früher wurde das Völkerrecht als die Courtoisie der Könige bezeichnet - und vielleicht war sie gar nicht so schlecht, diese Bezeichnung. Das Völkerrecht entwickelt sich, wenn ich das richtig sehe, auf einer Woge von Präzedenzfällen; was in ihm an normativem Gerüst und „System" entsteht, stellt sich als normative Verarbeitung von Präzedenzfällen dar. Der Rechtsbildungsvorgang im Völkerrecht 
ist doch weithin so, daß aufgrund von Rechtsbehauptungen, die allmählich Resonanz und Anerkennung finden, die auch durchgehalten werden durch lange Zeit, sich ein Konsens zu bilden beginnt und dieser dann für die Beurteilung weiterer Lagen maßgeblich wird.

Nun haben wir es bei dem, was sich seit 1945 in Deutschland vollzogen hat, mit einem völlig präzedenzlosen Vorgang zu tun und dies in vielerlei Hinsicht: Die Art, wie die Alliierten die oberste Gewalt übernommen haben, eine Annexion abgelehnt haben, sich aber vorbehalten haben, die Grenzen Deutschlands festzulegen; die Weise, wie dann die von ihnen innegehabte Gewalt stückweise rückübertragen worden ist, mit der interessanten Formulierung „authorizise“, also Autorisierung - was Ermächtigung und Verpflichtung zugleich enthält, und vieles andere mehr. Meine Frage ist nun, was eigentlich geschieht und geschehen muß, wenn man versucht, diesen präzendenzlosen Vorgang von einem rechtlichen System her einzuordnen und zu beurteilen, das auf ganz anderen Präzedenzfällen beruht und daraus abgeleitet ist. Kann es nicht gerade sinnvoll sein, bei der Art, wie sich Rechtsbildung im Völkerrecht vollzieht, neue Positionen zu entwickeln, auch Rechtsbehauptungen aufzustellen, für die man versucht, Anerkennung zu gewinnen und die es dann ermöglichen, daß eine bestimmte, zunächst nur politische Position vielleicht auch zu einer rechtlichen wird. Dabei besteht natürlich das Problem, daß solche Positionen oder Rechtsbehauptungen sich nicht völlig von der Realität entfernen dürfen, denn dann kann man nicht damit rechnen, dafür allmählich Anerkennung zu finden, zu erreichen, $\mathrm{da} B$ eine solche Position sich als Rechtsmeinung verfestigt.

Dies vorausgeschickt, habe ich persönlich starke Bedenken, die staatsrechtlich-völkerrechtliche Gemengelage, was die rechtliche Lage Deutschlands und der beiden deutschen Staaten angeht, nicht anzuerkennen. Wenn wir davon abgehen, daß dies eine Gemengelage ist und versuchen, sie im Sinne der Eindeutigkeit aufzulösen, dann bleibt, da die Lage Deutschlands als ein staatsrechtliches Verhältnis schlechterdings nicht mehr betrachtet werden kann, nur der Übergang zum rein völkerrechtlichen Verhältnis. Das mag zwar im Sinne einer konsequenten Unterscheidung von Staatsrecht und Völkerrecht folgerichtig sein, und wenn man davon ausgeht, daß die Sache dem einen oder anderen Rechtskreis zuzuordnen ist und es dazwischen juristisch nichts gibt, dann steht man in der Tat vor dieser Alternative. Aber ich möchte mich eben hiergegen wenden und umgekehrt formulieren: Es kommt gerade darauf an, diese Gemengelage als Rechtsbehauptung vorzutragen und zu begrün- 
den, um unsere Position und den Versuch aufrechtzuerhalten, daß Deutschland nicht völlig auseinandertritt und das Verhältnis der Staaten in Deutschland sich nicht in ein solches entwickelt, wie es zwischen Deutschland und Frankreich besteht, einmal von der EG hier abgesehen.

Ich habe dann noch eine Frage, und damit möchte ich schlieBen: Wie Herr Bernhardt die Identitätstheorie in der Weise, wie er sie als völkerrechtlich akzeptabel angesehen hat, eigentlich versteht? Meine Schwierigkeit, auch mit dem Urteil des Bundesverfassungsgerichts, ist immer die, da $B$ dann, wenn ich davon ausgehe, daß es sich zwischen Deutschem Reich und Bundesrepublik um eine Identität handelt, die aber begrenzt ist auf den Bereich und die Grenzen der Bundesrepublik Deutschland - also nicht mehr den Anspruch der alten, sog. vollen Identitätstheorie, der die DDR ja letztlich als aufständisches Gebiet qualifizierte -, daß dann nichts anderes übrig bleibt, als daß die DDR draußen ist. Dann ist das Deutsche Reich, so wie es fortbesteht - deshalb auch die Bezeichnung Schrumpfoder Kernstaatstheorie -, mit der Bundesrepublik identisch; in dieser Weise besteht es fort, das andere, die DDR, ist dann draußen, ein Staat außerhalb Deutschlands. Es kann sein, daß das Ihrer Position entspricht; Sie haben ja auch das Staatsangehörigkeitsproblem nicht als eine Option, die aus einem staatrechtlichen Restbestand hervorgeht, offengehalten, sondern aus völkerrechtlichen Gründen so zu lösen versucht. Wenn man diese Konsequenzen zu ziehen bereit ist, ist das in sich folgerichtig. Ich würde freilich aus den vorher genannten Gründen mich nicht dazu verstehen wollen, das Verhältnis Deutschland - Bundesrepublik als Teilidentität - wir wollen da über den logischen Widerspruch nicht streiten -, als Identität, beschränkt auf das Gebiet der Bundesrepublik zu definieren. - Ich danke Ihnen!

Meessen: Eine Gemengelage von Völkerrecht und Staatsrecht in dem Sinne, daß auf dieselbe Frage sowohl staatsrechtliche als auch völkerrechtliche Antworten zu geben sind, besteht sicherlich und wird, wenn ich Herrn Bernhardt richtig verstanden habe, auch von ihm nicht abgestritten. Die eigentliche Frage lautet, ob aus der völkerrechtlichen Regelung der Beziehungen zwischen der Bundesrepublik und der DDR einzelne Teile staatsrechtlich ausgeklammert sind. Prinzipiell würde ich diese Frage ebenso wie Herr Bernhardt verneinen. Dies schließt nicht aus, daß sich für den Einzelfall eine völkerrechtlich, z. B. besatzungsrechtlich, fundierte Sonderregelung nachweisen läßt. 
Auch in den Utberlegungen zum Fortbestand des Deutschen Reiches - unter Anerkennung der Teilidentität der Bundesrepublik -, zur Anerkennung der DDR-Staatsangehörigkeit und zur Qualifizierung der Grenzen folge ich Herrn Bernhardt. Ich glaube sogar, Herr Böckenförde, daß die völkerrechtliche Beurteilung in diesem Zusammenhang ein größeres $\mathrm{Maß}$ an Sicherheit aufweist als die staatsrechtliche, gerade weil sie eingebettet ist in Präzedenzfälle. Die Art und Weise, wie sich die gegenwärtige faktische Lage in Deutschland seit 1945 entwikkelt hat, mag ohne Präzedenzfall sein. Das Ergebnis aber, das Bestehen zweier befriedeter Staaten nebeneinander, ist jedoch für den Völkerrechtler, der einen weltweiten Vergleich zieht, kein so unbekanntes Phänomen. Er kann mit den Regeln seiner Kunst zu relativ sicheren Antworten kommen. Der Verfassungsrechtler hingegen geht vom Text des Grundgesetzes aus, der 1949 von politischen Erwartungen erfüllt wurde, die in keiner Weise realisiert werden konnten. Der Text selbst ist höchst unklar. Die Gefahr, einem illusionären Wunschdenken zu verfallen, ist hier besonders groß.

Ich meine, daß die völkerrechtliche Beurteilung - Sie werden sagen, hier spricht der Völkerrechtler - die verfassungsrechtliche letztlich mitbestimmen muß: Ich sehe keinen Grund, der Verfassung auf der Linie des Grundvertragsurteils eine Rechtspflicht zur Einnahme fiktiver völkerrechtlicher Positionen $\mathrm{zu}$ entnehmen. Im Gegenteil sollte hier die völkerrechtsfreundliche Grundhaltung, die in Art. 25 Grundgesetz niedergelegt ist, zum Tragen kommen. Im übrigen meine ich, daß normative Fakten geschaffen worden sind. Diese Fakten liegen dies ist im Grundvertragsurteil nicht genügend berücksichtigt worden - eher außerhalb des Grundvertrages als im Vertrag selbst, denn der Vertrag hat, und das ist das Wesentliche, die Voraussetzung zur weltweiten Anerkennung der DDR geschaffen. Von diesem Faktum müssen wir auch in unserer verfassungsrechtlichen Beurteilung ausgehen, so daß ich die Diskrepanz in der Beurteilung der deutschen Rechtslage - wenn ich das vereinfachend sagen darf - zwischen dem Referat Bernhardt auf der einen Seite und dem Grundvertragsurteil auf der anderen Seite auch verfassungsrechtlich im Sinne des Referates von Herrn Bernhardt lösen würde.

Vorsitzender: Vielen Dank, Herr Meessen! - Es ist bisher sehr viel Zustimmung zu dem Referat Bernhardt zu hören. Ich schlage vor, daß wir im Sinne des Diskussionsplanes noch zwei völkerrechtliche Stellungnahmen von Herrn Ress und Herrn Schiedermair hören und dann zwischendurch beiden Referenten 
Gelegenheit geben, das, was bisher gesagt worden ist, aufzuarbeiten. - Herr Ress, bitte!

Ress: Vom methodischen Vorgehen her habe ich es begrüßt, daß Herr Bernhardt den Begriff der "Gemengelage" von Staats- und Völkerrecht zur Deutung der Rechtslage Deutschlands herangezogen hat, weil ich meine, daß wir diesen Prozeß der Desintegration Deutschlands ohne eine solche Gemengelage rechtlich nicht adäquat erklären können, im übrigen schon gar nicht die Rechtsstellung Berlins.

Wir haben für derartige Gemengelagen eine Reihe von Präzedenzfällen, Herr Böckenförde, die dem Völkerrechtler eine Einordnung derartiger Fälle erleichtern, auch wenn derartige "Vorlagen" stets Eigenarten aufweisen und bei der Úbertragung der dabei entwickelten Rechtssätze und -prinzipien auf das Phänomen "Deutschland seit 1945" Vorsicht sicher angebracht ist. Herr Bernhardt hat in seinem Referat als Beispiele für derartige Gemengelagen die Dekolonialisierungsvorgänge, die in anderer Hinsicht sicher mit der Rechtslage Deutschlands nicht vergleichbar sind, angeführt, und es gibt eine Reihe von ähnlichen Vorgängen - ich nenne nur das Stichwort Irland/Großbritannien -, in denen diese Frage eine Rolle spielt. Herr Bernhardt hat nun in seinen Thesen unter III, 12 gesagt: „Es spricht viel dafür, daß der geschichtliche Proze $\beta$ ein Stadium erreicht hat, in dem eine solche Gemengelage im Verhältnis zwischen den beiden deutschen Staaten nicht mehr existiert." Das Problem besteht jedoch darin, exakt anhand rechtlicher Kriterien $\mathrm{zu}$ bestimmen, wann eine derartige Gemengelage endet bzw. wann die Deutung dieser Lage im Sinne von noch staatsrechtlichen Restbindungen nicht mehr vertretbar erscheint. Ein Hinweis auf den vagen Begriff des „geschichtlichen Prozesses" scheint mir dafür allein nicht ausreichend. Wir haben als Ansatz für die Fortexistenz derartiger staatsrechtlicher Elemente immer auch die Viermächte-Rechte und Verantwortlichkeiten herangezogen. Ich brauche hier nicht die zahlreichen Vorgänge näher anzuführen, die beim $\mathrm{Ab}-$ schluß der Ostverträge, des Grundlagenvertrages und des Viermächte-Abkommens über Berlin zur Bestätigung - oder gar Verstärkung - dieser Rechte und Verantwortlichkeiten geführt haben. Ich weise nur darauf hin, daß erst am 9. November 1972 bei der Aufnahme der beiden deutschen Staaten in die Vereinten Nationen die Fortexistenz dieser ViermächteRechte und Verantwortlichkeiten ausdrücklich auch gegenüber den Drittstaaten, wie ich meine, bekräftigt worden ist. 
Die Frage, Herr Bernhardt, die sich mir in diesem Zusammenhang stellt, ist die: Wie deuten wir diese ViermächteRechte? Ich glaube, wir können sie als rein völkerrechtliche Rechtspositionen auch ohne eigene ,staatsrechtliche Aufladung " deuten, als eine Sperre gegenüber einem vollständigen Abschluß des Dismembrations- bzw. Sezessionsprozesses. Für eine derartige Rechtswirkung bedarf es nicht der Qualifikation dieser Viermächte-Rechte und Verantwortlichkeiten als quasi deutsches Staatsrecht, ein Verständnis, welches sicher nach 1949 schwieriger geworden ist. Hinzu kommt, daß wohl auch Elemente vertraglicher Bestätigung von unserer Seite aus in diese Viermächte-Rechte und Verantwortlichkeiten eingeflossen sind, so daß die Frage berechtigt erscheint, ob ihre ursprüngliche besatzungsrechtliche Natur noch erhalten geblieben ist. Wie immer man diese Rechte und Verantwortlichkeiten der vier Hauptsiegermächte jedoch deutet: Ihre Existenz und ihr Rechtsgehalt stehen einer endgültigen Auflösung von "Deutschland als Ganzem" entgegen. Ich komme damit auf ein wichtiges Element der Rechtslage Deutschlands zu sprechen, das auch in der Literatur zutreffend mit der „Nichtendgültigkeit" des Auflösungsprozesses, mit der Nichtendgültigkeit aller territorialen Verfügungen über den Bestand Deutschlands umschrieben wird. Hierfür ist die Fortexistenz der Viermächte-Rechte und Verantwortlichkeiten das ganz wesentliche Element. Sie haben in diesem Zusammenhang auch noch als weiteres Element erwähnt, daß die Bevölkerung der beiden deutschen Staaten, das deutsche Volk, noch nicht Gelegenheit gehabt hat, sich zu der Frage Einheit oder Nichteinheit zu äußern. Auch insbesondere darin läßt sich ein wesentliches Element erblicken für die Folgerung: Es handelt sich um einen noch nicht abgeschlossenen Desintegrationsvorgang. Eine Bestätigung dieser Rechtslage bilden, wie gesagt, die Unberührtheitsklauseln in den Ostverträgen, das ViermächteAbkommen über Berlin und die Bestätigung der ViermächteRechte und Verantwortlichkeiten im Zusammenhang mit dem Beitritt der beiden deutschen Staaten in die Vereinten $\mathrm{Na}$ tionen.

Sicher lassen sich - und das haben Sie zu Recht hervorgehoben - die Besonderheiten im Verhältnis zwischen der Bundesrepublik und der DDR, etwa die Besonderheit des innerdeutschen Handels, der Status der ständigen Vertretungen, die Befugnis zur Beibehaltung einer deutschen Staatsangehörigkeit und andere, auch völkerrechtlich deuten. Damit ist jedoch die Frage nicht beantwortet, ob sie ausschließlich völkerrechtlichen Charakter haben oder gar haben müssen. Zur 
Beantwortung dieser Fragen treten bei einem derartigen Desintegrationsprozeß neben den schon erwähnten Rechtselementen auch der Zeitfaktor und die Ausgangslagen der Entwicklung als maßgeblich hinzu. Wir haben es hier eben mit einem Desintegrationsproze $\beta$ zu tun, bei dem zunächst die Vermutung für das Aufrechterhalten der bestehenden, auch staatsrechtlichen Elemente spricht: Diese Vermutung ist durch den Zeitablauf nicht widerlegt, sondern durch das Beharren der Vier Mächte auf ihren Rechten und Verantwortlichkeiten und durch maßgebliche Erklärungen der Bundesrepublik eher bekräftigt worden. Und ich würde - vielleicht im Gegensatz zu Herrn Mosler - doch die Zuordnung dieser Rechtselemente in einem Völkerrechtssubjekt und nicht nur in einem Regime oder Status sehen wollen.

Vielleicht darf ich zum Abschluß noch zwei kleine Bemerkungen anfügen: Kommen Sie, Herr Bernhardt, nicht doch wieder, indem Sie das Wiedervereinigungsgebot und damit Elemente des Grundgesetzes zur Geschäftsgrundlage des Grundlagenvertrages machen und den Brief zur deutschen Einheit ausklammern wollen, auf Positionen zurück, die Sie vorher als für den Vertragspartner nicht bindend aussondern wollten?

Der Nation-Begriff, so wie ihn Herr Achterberg in seinem Referat als metajuristisch klassifiziert hat, ist für Völkerrechtler sicher ein juristischer Begriff, nämlich Anknüpfungspunkt für das Selbstbestimmungsrecht. $\mathrm{Er}$ ist ein die beiden deutschen Staaten übergreifender Ansatz für eine Rechtsträgerschaft, kann also nicht nur als rein metajuristisch klassifiziert werden. Schließlich: Staatsvolk ohne Staat ist für mich keine nachvollziehbare Vorstellung.

Schiedermair: Herr Vorsitzender, meine Dame, meine Herren! - Ich habe mich gefreut, daß in dem Referat von Herrn Bernhardt ein ganz eindeutiges Bekenntnis zum rechtlichen Fortbestand Deutschlands und zur Identitätsthese enthalten war. Ich bin immer der Meinung gewesen, daß die Fortbestands- und Identitätsthese am besten der Praxis und den Realitäten - den oft beschworenen Realitäten - gerecht werden, wie sie durch die Viermächte-Politik der Nachkriegszeit geschaffen worden sind. Die Eigentümlichkeit im Referat von Herrn Bernhardt scheint mir nun darin zu bestehen, daß die Fortbestands- und Identitätsthese nur noch auf die Bundesrepublik Deutschland bezogen werden. Dies bedeutet, daß die DDR aus dem Bezugssystem zu Deutschland als Ganzem herausgenommen ist. Daraus ergibt sich als logische Konse- 
quenz, daß die inneren Beziehungen zwischen den Teilen Deutschlands, was die DDR und die Bundesrepublik angeht, nur noch völkerrechtlicher Natur sind. Dies ist - in eine rechtliche Kurzformel übersetzt - nichts anderes als die These, $\mathrm{da} B$ hier ein historischer Proze $B$ abgelaufen ist, der, hinsichtlich der DDR, in einer Sezession oder Dismembration geendet hat.

Ich will versuchen, diese sicherlich sehr nachdenkenswerte These auf die Probe zu stellen, und will mich dabei an die völkerrechtliche Praxis halten; denn nur in dieser Praxis begegnen wir - um es noch einmal zu betonen - den Realitäten. Angesichts der uns auferlegten Redezeitbegrenzung sehe ich bewußt von den Fragen des innerdeutschen Handels und der deutschen Staatsangehörigkeit $a b$ und beschränke mich auf drei Beispiele:

Das erste Beispiel ist das Londoner Schuldenabkommen; es enthält bekanntlich eine Schuldenregelung mit der Bundesrepublik Deutschland und gleichzeitig ein Moratorium, in dem steht, daß natürlich die Frage der Kriegsschulden endgültig nur mit einem anderen Partner als der Bundesrepublik Deutschland geregelt werden könne. Wer aber ist dieser andere? Wer ist hier der Schuldner? Die Antwort kann nur lauten: Gesamtdeutschland oder: Deutschland als Ganzes. Hier gibt es - und das ist aktuelle Politik und aktuelle Rechtslage; denn das Moratorium des Londoner Schuldenabkommens gilt ja fort - hier gibt es also noch ein Haftungsobjekt, das mit der Identität zwischen Bundesrepublik und Deutschem Reich nicht erschöpfend beschrieben ist. Dieses Haftungsobjekt ist Deutschland als Ganzes, in das, zumindest nach dem Willen der drei Westmächte, auch die DDR mit einbezogen ist.

Das zweite Beispiel ist die innerdeutsche Grenze. Diese Grenze wurde in konsequenter Anwendung der vorgetragenen Sezessionsthese als rein völkerrechtliche Grenze apostrophiert. Kann man das wirklich sagen? Selbstverständlich sind auf diese Grenze völkerrechtliche Regeln, wie etwa das Gewaltverbot und dergleichen, anwendbar. Aber wie sieht es mit der aktuellen Praxis aus? Wir wissen, daß die innerdeutsche Grenzkommission gearbeitet hat, und das Erstaunliche dabei ist, daß diese Kommission nur sehr begrenzte Befugnisse hatte. Die Kommission hatte nicht das Recht, wie das bei anderen Staaten üblich ist, über die Grenze zu verfügen, und das ist doch typisch für völkerrechtliche Grenzen, daB sie als Gegenstand der staatlichen Souveränität durch Grenzverträge zediert oder auf sonstige Weise verändert werden können. Demgegenüber hatte die innerdeutsche Grenzkommission nur die 
Befugnis, eine Grenzmarkierung vorzunehmen, während alles, was die Bestimmung der Grenze, die Festlegung oder „limitation" angeht, in den Zuständigkeitsbereich der Vier-Mächte fällt. Angesichts dieses Befundes kann ich die innerdeutsche Grenze nur als klassische Demarkationslinie deuten, die nach wie vor unter einem Besatzungsregime steht. So wenigstens sieht die Praxis der Vier-Mächte aus, die die Befugnis der Bundesrepublik oder der DDR, über die innerdeutsche Grenze $\mathrm{zu}$ verfügen, schlicht bestreiten.

Mein drittes Beispiel ist Berlin. Wie steht es mit Berlin und der Sezessionsthese? Wie steht es vor allem mit Ostberlin? Wo und wie ist denn hier der von Ihnen, Herr Bernhardt, angenommene Sezessionsproze $\beta$ verlaufen? Ganz sichtbar, einige Meter weiter entlang der Mauer, so daß wir davon ausgehen müßten, daß Ostberlin von dem Sezessionsprozeß miterfaßt worden ist? Oder ist ganz Berlin nach wie vor in das Bezugssystem Deutschland als Ganzes mit einbezogen und demgemäß von dem Sezessionsprozeß ausgenommen? Sie haben, Herr Bernhardt, mit Recht angenommen, daß die Viermächte-Verantwortung für ganz Berlin fortbesteht, aber diese ViermächteVerantwortung für ganz Berlin bedeutet doch, daß der Status Berlins ohne das fortbestehende Deutschland als Ganzes nicht denkbar ist. Das Zuordnungssubjekt der Viermächte-Verantwortung ist und bleibt das fortbestehende Deutschland. Deshalb ist mir auch die von Herrn Bernhardt vorgelegte These 22 nicht ganz klar geworden. Nachdem Sie, Herr Bernhardt, zunächst die Viermächte-Verantwortung und damit das Besatzungsstatut auf ganz Berlin bezogen haben, scheinen Sie in der These 22 dieses Besatzungsstatut auf Westberlin zu reduzieren. In der Tat ist in Westberlin eine vorerst unauflösliche Gemengelage von Staats- und Völkerrecht unverkennbar. Warum aber gilt dies nicht auch für Ostberlin, wenn Ostberlin nach wie vor unter die Viermächte-Verantwortung fällt? $\mathrm{Da}$ scheint mir ein Problem zu liegen. - Ähnliches gilt auch für die vorgelegte These 12: Sie haben, Herr Bernhardt, mit Recht gesagt, daß in Berlin die Gemengelage zwischen Staats- und Völkerrecht fortbestehe, doch sei dies ein Sonderfall. Meine Damen und Herren, ich glaube, Berlin ist mit dem Begriff Sonderfall nicht gut gekennzeichnet. Berlin ist der typische, klassische Fall, in dem das Bezugssubjekt Deutschland als Ganzes zum Vorschein kommt und praktisch sichtbar wird. Ich glaube, wir leisten der Berlin-Frage keinen guten Dienst, wenn wir sie im Bezugsfeld von Regel und Ausnahme etwas in den Hintergrund schieben. 
Zum Schluß möchte ich eine persönliche Bemerkung anfügen, die nichts mit dem Referat und dem Referenten zu tun hat. Mir geht es bei dieser Bemerkung vielmehr darum, meine eigene Position verständlich zu machen. Daher meine Frage, warum wir denn eigentlich in der völkerrechtlichen Argumentation an dem Konzept Deutschland als Ganzem und an der Gemengelage von Staats- und Völkerrecht in den innerdeutschen Beziehungen festhalten? Ich fürchte, daß der Verzicht auf die Gemengelage und damit auf die staatsrechtlichen Qualitäten in den Beziehungen der deutschen Teile zueinander, da $B$ der Verzicht auf den staatsrechtlichen Charakter dieser Beziehung tendenzmäßig schlicht und einfach zu einer Internationalisierung der deutschen Frage führt. Dies aber ist für Berlin eine Lebensfrage, denn die Internationalisierung würde für Berlin den Status einer freien Stadt bedeuten, und das ist - wie auch die völkerrechtliche Praxis lehrt - eine lebensgefährliche These. Im übrigen finde ich das immer etwas peinlich oder, um es genauer zu formulieren, fände ich es peinlich, wenn wir dahin kämen, daß wir das Festhalten an dem Konzept von Deutschland als Ganzem mit seiner Gemengelage nur noch der Volksrepublik China oder - wie geschehen - dem High Court of Singapore überlassen.

Vorsitzender: Vielen Dank, Herr Schiedermair! - Ich glaube, Herr Bernhardt, Sie sind nicht nur mit der Gemengelage, sondern auch sonst vielfältig gefordert, aber auch Herr Achterberg ist beispielsweise durch Herrn Häberle angesprochen.

Bernhardt: Zu der letzten Bemerkung von Herrn Schiedermair möchte ich sagen, daß weder das politische Eintreten Chinas für die Wiedervereinigung noch eine Entscheidung des High Court of Singapur uns von der Pflicht entbinden können, die rechtliche Entwicklung und die gegenwärtige Rechtslage genau zu prüfen. Beide Stimmen betreffen nicht die hier zur Debatte stehenden Gemengelagen von Staats- und Völkerrecht in Deutschland.

Sicher stehen wir, worauf Herr Böckenförde hingewiesen hat, bei der Nachkriegsentwicklung in Deutschland vor einem präzedenzlosen Vorgang. Deshalb war es auch nach meiner Ansicht lange Zeit notwendig, von einer Gemengelage von Staats- und Völkerrecht auszugehen. Ich habe die Frage zu beantworten versucht, ob diese Gemengelage heute noch fortbesteht. Dabei kommt es auf eine Würdigung des gegenwärtigen Bestandes an Rechtsnormen und Tatsachen an. Bei dieser Würdigung komme ich zu dem Ergebnis, daß ein Gemenge staatsrechtlicher und völkerrechtlicher Normen — im Sinne 
auch von Herrn Meessen - nicht mehr existiert, und da $\beta$ jetzt zwei deutsche Staaten nebeneinander auf der Basis des Völkerrechts existieren. Der Status der beiden deutschen Staaten ist aber völkerrechtlich noch immer mit gravierenden Hypotheken belastet, nämlich hinsichtlich der Wiedervereinigung und einer Friedensregelung und hinsichtlich Berlins.

Dabei habe ich die größten Bedenken, die Vier-MächteRechte über die Grundentscheidungen zur deutschen Frage hinaus auch auf die Probleme und Auseinandersetzungen des Alltags im deutsch-deutschen Verhältnis zu erstrecken. Sicher ist bei der innerdeutschen Grenze die deutsche Frage insgesamt angesprochen, und deshalb gibt es keine alleinige Verfügungsbefugnis der beiden deutschen Staaten. Wenn wir aber die Vier-Mächte-Rechte darüber hinaus generell und in Einzelfragen als Grundlage der heutigen deutschen Situation ansehen, besteht die Gefahr, daß jede der Vier Mächte auf die gesamte staatliche und verfassungsrechtliche Entwicklung Einfluß zu nehmen versucht. Diese Gefahr muß man sehen.

Nun zu den Bemerkungen von Herrn Mosler und von Herrn Geck. Durch die Vier-Mächte-Rechte und -Verantwortlichkeiten im von mir relativ eng umschriebenen Sinn ist ein Status für das früher zum Deutschen Reich gehörende Gebiet geschaffen worden und nicht nur eine vertragliche Beziehung normaler Art. Es handelt sich um Statusvereinbarungen, die wohl erga omnes wirken, sowohl gegenüber den beiden deutschen Staaten als auch gegenüber dritten Staaten.

Von meiner Position aus wäre es schließlich möglich und wünschenswert, wenn es in Zukunft gelänge, die in meinen Augen zur Zeit fehlenden staatsrechtlichen Elemente neu zu schaffen, durch zunehmende Kooperation, durch Absprachen und anderes mehr. Es ist eine Aufgabe der Zukunft, wieder eine Gemengelage $\mathrm{zu}$ schaffen, und dazu können kulturelle Kontakte und viele andere außerrechtliche Verbindungen einen Beitrag leisten.

Arhterberg: In den bisherigen Diskussionsbeiträgen ist vorwiegend die völkerrechtliche Problematik und damit der Kompetenzbereich von Herrn Bernhardt angesprochen worden; ich kann mich deswegen verhältnismäBig kurz fassen. Herr Mosler, Sie haben darauf hingewiesen, daß Deutschland nur ein begrenzt staatsrechtlicher Befund ist und hierdurch den staatsrechtlichen dem völkerrechtlichen gegenüberstellt. Wenn ich es recht sehe, haben Sie unter den Diskussionsrednern damit als erster die Gemengelage angesprochen, obwohl Sie den Begriff selbst nicht verwandt haben. Ich möchte Ihre Utberlegun- 
gen noch dahin ergänzen, daß Deutschland nach meiner Auffassung nicht nur einen staatsrechtlichen, sondern auch einen staatstheoretischen Befund bildet. Dies versuchte ich im ersten Drittel meines Referates herauszuarbeiten. Und wenn dem so ist, dann haben wir den Übergang zu dem Diskussionsbeitrag von Herrn Häberle, dem ich darin zustimme, daß wir bei der Erfassung der Nation und ihrer Besonderheiten auch eine kulturwissenschaftliche Methode zugrunde legen müssen. Allerdings darf man dabei Nation nicht auf „Kulturnation" reduzieren, sondern muß mancherlei weitere Gemeinsamkeiten einbeziehen, und zwar auch - Sie selbst, Herr Häberle, hatten mancherlei literarische Beispiele gebracht - die Frage der gemeinsamen Sprache. Ich sage das deswegen mit Bedacht, weil sich die neuere Rechtstheorie auch mit Sprachtheorie beschäftigt und es dabei eine Richtung gibt, die sich mit der Entwicklung von Plansprachen befaßt: Ich erinnere an die Arbeiten von Ilmar Tammelo. Gelänge die Ausarbeitung von Plansprachen, so hätte dies zur Folge, daß sprachliche Besonderheiten, wie sie eine Nation kennzeichnen, geringer werden und allmählich verloren gehen. In der Entwicklung solcher Vorhaben, wie Plansprachen auszuarbeiten, würde ich also deutlich desintegrierende Vektoren sehen, obwohl sie als solche nicht gedacht sein mögen. Herr Böckenförde, Herr Meessen und Herr Ress, Sie haben in Thren Diskussionsbeiträgen die Gemengelage in den Vordergrund gestellt. Ich möchte als NichtVölkerrechtler dazu nicht allzu viel sagen, aber mich würde doch interessieren, worin eigentlich diese Gemengelage bestehen soll, wie also die Frage nach der präzisen Abgrenzung des Völkerrechts und des Staatsrechts in den Beziehungen der beiden deutschen Staaten zu beantworten ist. Ich meine, daß diese Frage auch damit in Verbindung $\mathrm{zu}$ bringen ist, von welcher Deutschland-Theorie man ausgeht: Die Identitätstheorie scheint mir mehr für völkerrechtliche Beziehungen zu sprechen, während die Dachtheorie solche staatsrechtlicher Natur zuläßt, wie sie etwa in einem Bundesstaat bestehen. Wenn man von der Identitätstheorie ausgeht, Herr Böckenförde, dann braucht die Konsequenz noch nicht dieienige zu sein, daß die DDR „draußen“ ist. Das gemeinsame Staatsvolk kann trotzdem erhalten bleiben, und ich vermag der These von Herrn Ress nicht zu folgen, Staatsvolk ohne Staat sei undenkbar. Ein solcher Zustand mag zwar pathologisch sein, doch kann durchaus noch ein Staatsvolk vorhanden sein. wenn die Staatsgewalt und damit - zumindest von den Prämissen der Drei-Elemente-Lehre aus - der Staat nicht mehr besteht. Zöge das Bestehen des Staatsvolks automatisch dasienige des Staats nach sich, so brauchte man die drei Elemente überhaupt 
nicht. Ich bin kein Verfechter der Drei-Elemente-Lehre, über diese Konsequenz aber muß man sich klar sein. Nach meiner Auffassung ist Staatsvolk ohne Staat eine nachvollziehbare Vorstellung, und knüpft man - wie ich zu entwickeln versuchte - die Staatsangehörigkeit an das Staatsvolk, so braucht die DDR nicht „draußen“ zu sein, vielmehr besteht auf dem Weg über das gemeinsame Staatsvolk - unbeschadet der Frage, ob es noch einen gemeinsamen Staat gibt oder nicht - die Möglichkeit der Annahme einer gemeinsamen Staatsangehörigkeit. Herr Ress, Sie haben schließlich gesagt, die Nation im völkerrechtlichen Sinne sei ein Rechtssubjekt. Ich möchte diese Frage dahingestellt lassen. Ist sie aber ein solches, so spricht das nur noch eher dafür, daß sie auch als Element verwendbar ist, um die Beziehungen zwischen den beiden deutschen Staaten zu verstärken.

Quaritsch: Den Kern des Problems hat Herr Böckenförde bereits freigelegt. Das moderne Völkerrecht ist nach Herkunft und Eigenart angelegt auf die Existenz selbständiger Staaten. Diese Voraussetzung ist in Mitteleuropa seit Kriegsende nicht mehr gegeben. Die deutsche Zweistaatlichkeit ist ein Resultat fortdauernder Fremdbestimmung; sie würde sofort verschwinden, sobald die Deutschen die deutschen Angelegenheiten selbst regeln könnten. Wer bei seinen rechtlichen Deduktionen diesen dreißigjährigen Grundtatbestand ignoriert, übersieht diejenige Realität, auf der alle anderen "Realitäten" beruhen. Auf das Verhältnis der zwei deutschen Staaten zueinander lassen sich deshalb die völkerrechtlichen Regeln nur entsprechend und nur anwenden, um einen friedlichen modus vivendi zu ermöglichen. - Rechtspositionen sind geistige Realitäten. Sie können von den sichtbaren Fakten der Grenzpfähle und Uniformen nicht schon nach dreißig Jahren „überholt" werden. Im Rechtsleben der Völker gelten nicht die Verjährungsfristen des BGB. Irland und die Iren, aber auch andere Völker bezeugen das zähe Leben unterdrückter Rechtsansprüche. Wenn das Völkerrecht die elementaren Wahrheiten der Völkergeschichte außer acht läßt oder außer acht lassen muß, dann wäre diese Disziplin für unser Thema an diesem Ort ungeeignet.

Vorsitzender: Vielen Dank, Herr Quaritsch! - Wollten Sie dazu direkt einen Satz sagen, Herr Bernhardt?

Bernhardt: Ohne daß ich Experte hinsichtlich des irischen Standpunkts bin, schätze ich die dortige Rechtsauffassung so ein, daß man den Anspruch auf Wiedervereinigung mit Nordirland aufrechterhält, aber die völkerrechtliche Zugehörigkeit Nordirlands zum Vereinigten Königreich nicht bestreitet. Im 
übrigen gibt es auch im Bereich des irischen Staatsangehörigkeitsrechts interessante Parallelen zu unseren Problemen, aber darauf kann ich hier nicht eingehen.

v. Münch: Ich lese nur aus der Irischen Verfassung vor, Art. 2, wo es heißt: „Das nationale Territorium besteht aus der ganzen Insel Irland und ihren Inseln in dieser territorialen Umgebung".

Vorsitzender: Ähnliche Anklänge sind in Art. 23 GG vorhanden. - Herr Rumpf, bitte!

Rumpf: Herr Vorsitzender, verehrte Kollegen! Man konnte in den letzten dreißig Jahren den Eindruck haben, daß zum Thema Deutschlands Rechtslage sich die deutsche Staatsrechtslehre nicht mehr fortbewegt hat, daß sie stagnierte. Die Referate von heute, insbesondere das von Herrn Bernhardt, haben mir den erfreulichen Eindruck bereitet, daB dem nicht so ist, $\mathrm{da} ß$ noch neue Gedanken und neue Ausblicke hier möglich sind und daß gewissermaßen Fenster geöffnet werden in die Wirklichkeit. - Ich kann daher also nur dem Referat von Herrn Bernhardt meine Zustimmung, bis auf einzelne Punkte, die es aber jetzt nicht lohnt, sich darüber aufzuhalten, erklären. Insbesondere meine ich, daß die Zukunft der Deutschlandfrage nicht mehr darin liegen kann, die These vom Fortbestand des Deutschen Reiches weiterhin zu verkünden, weiter daran festzuhalten, sondern vielmehr in einer Belebung des Nationsbegriffes, was ja auch bei einigen Kollegen hier schon angeklungen ist. Wenn man Gelegenheit hat, im Ausland über die Deutschland-Theorie und Deutschlands Rechtslage zu referieren, dann fällt es einem immer äußerst schwer, die amtliche Theorie noch plausibel zu machen, insbesondere die Auffassung, daß das Deutsche Reich als Völkerrechtssubjekt noch bestünde. Herrn Bernhardt ist zuzustimmen, da die Realitäten eben einfach stärker sind als unsere Versuche zur Überspielung durch Festhalten an Fiktionen. Es dürfte für ausländische Beobachter aber auch interessant sein, einmal die Verhandlungen der heutigen Sitzung zu vergleichen mit denen, die 1954 zum Thema „Der deutsche Staat im Jahre 1945 und seither" stattgefunden haben. Damals gab es nur wenige, aber immerhin prominente Stimmen, die die Fortbestandstheorie in Zweifel zogen - Apelt, Nawiasky, Abendroth.

Auf der anderen Seite standen die beiden berühmten Referate, die ja dann Schule gemacht haben. Aber gerade diese Referate können eigentlich uns heute $A n l a B$ geben, einmal zu einer staatsrechtstheoretischen Selbsterkenntnis zu finden, $d . h$. 
also einmal zu überlegen, mit welchen Argumenten ist denn hier eigentlich operiert worden? Mir sind zwei Zitate in die Hände gefallen, die ich bei der Gelegenheit erwähnen möchte: Das eine ist ein Wort von Heinrich Triepel, der in seiner berühmten Rektoratsrede von 1926 über Staatsrecht und Politik sagte: „Es ist nicht zu leugnen, daß manchmal die wissenschaftliche Objektivität des Publizisten, der literarisch in die politischen Kämpfe seiner Zeit hineinzogen wurde, nicht nur verdächtigt..., sondern wirklich in Gefahr gebracht worden ist." - Das andere Zitat ist von Freiherrn v. d. Heydte, der das erste Referat 1954 gehalten hat und der mit dem Selbstbekenntnis endete: „Es ist mir nicht möglich gewesen, bei der Antwort auf die große Schicksalsfrage Deutschlands nur den juristischen Sachverstand sprechen zu lassen. In dieser Frage spricht bei mir - und ich glaube bei uns allen - ob wir es wahrhaben wollen oder nicht - stets auch das Herz mit."

Nun sind wir hier in einer Gelehrtenversammlung, und man sollte also doch erwarten, daß nüchterne, sachliche $\mathrm{Ob}$ jektivität die Richtschnur ist. Aber es wird ja doch immer wieder - das klang auch bei dem Einwurf von Herrn Schiedermair mit an - von lebensbedrohenden Thesen gesprochen, d. h. daß sehr stark pragmatische Gesichtspunkte, politischpragmatische Gesichtspunkte in den Vordergrund geschoben werden. Die haben sicherlich ihre Berechtigung; sie sollten aber die nüchterne juristische Analyse nicht trüben. Und die gerade begrüße ich bei Herrn Bernhardt. - Im übrigen, meine ich, sollte man nicht befürchten, daß damit das Anliegen der deutschen Einheit preisgegeben würde. Es gibt andere Wege, auch juristische Möglichkeiten - Herr Bernhardt hat das auch angedeutet - , und es gibt den Begriff der Nation, der uns meines Erachtens weiter in die Zukunft weist als die Theorien, die in den 50er Jahren aufgestellt und dann mit verschiedenen Variationen immer wieder abgewandelt worden sind. Danke!

Frowein: Herr Vorsitzender, meine Dame, meine Herren! Ich möchte zunächst der These von Herrn Bernhardt in bezug auf die völkerrechtliche Qualität der innerdeutschen Grenze auch deswegen zustimmen, weil ich es gewesen bin, der innerhalb der deutschen Presse als etwas außerhalb der Verfassung stehend angesehen worden ist, weil er diese Auffassung in diesem Gebäude etwas näher dargelegt hat. Dieses bedeutet, wie ich meine, nicht - und da wende ich mich an Herrn Quaritsch und Herrn Schiedermair, daß die Fragen, inwieweit Deutschland als eine auch staatsrechtliche Einheit wieder entstehen oder als Bezug staatsrechtlicher Normen noch heute re- 
levant sein könnte, damit auch schon beantwortet wäre. Die irische Verfassung muß man weiterlesen, und man stellt dann fest, da $B$ die Rechtsordnung Irlands sich beschränkt auf das Territorium der Republik Irland; Irland bestreitet nicht, da $B$ es sich um eine völkerrechtliche Grenze handelt. Genauso wenig, meine ich, haben wir Anlaß, nach den Entwicklungen, die Herr Bernhardt so eingehend geschildert hat, das zu bestreiten. - Zu der Problematik der Oder-Neiße-Gebiete würde ich gerne zu dem Gesagten den Satz hinzufügen, daß hier der Art. I des Warschauer Vertrages in seiner Bedeutung zu beachten ist. Gleichzeitig - und da muß ich Herrn Häberle nun sehr deutlich widersprechen - darf in meinen Augen nicht der Fehler gemacht werden, völkerrechtliche Normierungen durch eine - Sie gestatten mir hier den offenen Ausdruck - an dieser Stelle meines Erachtens nicht angebrachte Phantasie dahin auszudeuten, daß gewissermaßen - und ich simplifiziere bewußt - die Marienburg als nicht mehr deutsch angesehen oder Kant in seiner Eigenschaft als Preuße und Deutscher in Frage gestellt werden könnte. Ich sage das mit dieser Simplifizierung, um deutlich zu machen, daß man die aktuelle Rechtslage und das Problem Kulturnation dringend auseinanderhalten sollte, um solchen Gefahren nicht zu erliegen. - Hinsichtlich der Inland-Ausland-Problematik meine ich, daß Herrn Bernhardt gefolgt werden sollte und jeweils im einzelnen Fall festgestellt werden muß, wo die Anknüpfungspunkte liegen. Allerdings müssen sie meines Erachtens nachgewiesen werden, und im Umsatzsteuerbereich geht es wohl gerade darum, sie nachzuweisen. Die Gemengelage - das ist der zweite Punkt ist von Herrn Bernhardt im Prinzip verabschiedet worden. Herr Mosler hat den Ausdruck "Status" und „Statusregelungen" bevorzugt. Ich würde das auch tun, würde aber meinen, daß von daher alles Interesse besteht, die Gemengelage, die auch von Herrn Bernhardt als möglich bezeichnet worden ist, nicht eo ipso zu verabschieden, sondern eine Analyse des Befundes vorzulegen und von daher zu fragen: wie ist denn diese Analyse? Bei dieser Analyse läßt sich, wie ich meine, zeigen, $\mathrm{da} B$ an der Gemengelage mehr dran ist, als deutlich geworden ist - z. T. ist es schon erwähnt worden. Die Anknüpfung von Drittstaaten und vor allen Dingen auch die Anknüpfung im EG-Recht ist ein wichtiges Beispiel. Ich bin auch nicht so sicher, ob man wirklich sagen kann, daß die DDR in vollem Umfang - wenn man ihr konkludentes Verhalten zugrundelegt diese These verabschiedet hat. Es läßt sich etwa in der Behandlung von Bundesrepublikanern - ich benutze das Wort mit der Schwierigkeit, die das Problem enthält — bei ihrem 
Utberwechseln in die DDR nach meiner Kenntnis nach wie vor zeigen, aber es gibt auch weitere Beispiele. Schließlich meine ich, daß unsere Behandlung des Art. 116 GG richtigerweise - und ich glaube, da decke ich mich auch mit Ihnen nur zu verstehen ist auf dem Hintergrund von solchen bestehenden rechtlichen Anknüpfungspunkten. - Lassen Sie mich als drittes schließlich ein Wort zur Berlin-Problematik sagen: Ich meine, die Berlin-Regelung ist ein typisches Beispiel für eine solche Status-Regelung, und sie ist ja dadurch besonders gekennzeichnet, daß hier der Transit zwischen der Bundesrepublik Deutschland und Berlin geregelt ist in einem Vertrag, der nicht abgeschlossen worden ist unter direkter Beteiligung desjenigen Staates, der sich als voll souverän für diese Fragen geriert, nämlich der DDR. Das ist in meinen Augen auch ein besonders gutes Beispiel dafür, daß hier in der Tat Rechtswirkungen fortbestehen, die wir jedenfalls nicht leicht verabschieden dürfen und die mit dem Wort "Status" wohl am besten qualifiziert sind.

Zieger: Die Crux unseres Themas liegt darin zu wissen, daß die deutsche Frage auf absehbare Zeit nicht zu lösen sein wird, vielfach aber die Neigung wächst, das Deutschlandproblem an den normalen Maßstäben der Dogmatik zu messen. Einige Beiträge in der Diskussion haben das deutlich gemacht, wenn man meint, die normative Kraft des Faktischen tendiere auch bei der offenen deutschen Frage dahin, den Realitäten rechtliches Gewicht zu verleihen. Es ist richtig, daß es im Völkerrecht derartige Effektivitätsvorstellungen gibt, indessen ist das Völkerrecht mehr der Tradition verhaftet, als daß es sogleich auf Veränderungen reagierte; es ist eher eine Traditionsrecht denn ein Reaktionsrecht.

Es ist gerade für die deutsche Rechtslage kennzeichnend, daß durch ein feines Gespinst von Vorbehaltserklärungen, die in allen auf Deutschland bezogenen Vertragswerken auf westlicher wie auf östlicher Seite anzutreffen sind, die juristischen Ausgangspositionen bekräftigt worden sind, um zu verhindern, daß sich die Faktizitäten in das Normative umsetzen.

Zur These 7 von Herrn Bernhardt wäre zu fragen: was ist das Objekt der Vier-Mächte-Rechte in Deutschland, gibt es neben oder über den beiden deutschen Staaten ein Völkerrechtssubjekt "Gesamtdeutschland"? Herr Bernhardt hält letzteres für kaum noch begründbar. Im Ergebnis kann dem wohl zugestimmt werden, allerdings hatte ich den Eindruck, da $B$ dieses Resultat im Referat aus einem Standpunkt gewonnen worden ist, der in der Nähe der Schrumpfstaatstheorie liegt und bei dem die DDR als ein nur noch unter den Vorbehalten 
der Alliierten stehender, im übrigen selbständiger Staat begriffen wird. Dem könnte nicht gefolgt werden. Wenn man fragt, was heute unter „Deutschland“ zu verstehen ist, so besteht der erste gedankliche Schritt darin, an die Formel der „zwei Staaten in Deutschland" zu denken, die sich in der Regierungserklärung vom Oktober 1969 findet, als Bestandteil der allgemeinen politischen Aussage, daß die DDR als Staat zur Kenntnis genommen wird, allerdings nur als „Staat in Deutschland"; eine völkerrechtliche Anerkennung dieses andoren deutschen Staates durch die Bundesrepublik Deutschland sei darum ausgeschlossen.

Diese politische These läßt sich ins Normative übersetzen. Die Bundesrepublik Deutschland ist territorial ein Teil des Völkerrechtssubjektes „Deutschland“, das die Alliierten — nicht die Deutschen - gebietsmäßig auf den Stand vom 31. Dezember 1937 begrenzt haben. Darauf nehmen die Vier-MächteRechte allenthalben Bezug, auch die östliche Macht, die gewiß nicht zufällig ihre in der DDR stationierten Truppen „Gruppe der sowjetischen Streitkräfte in Deutschland" (nicht: in der DDR!) bezeichnet. Wenn man die Identitätslinie zu dem Deutschland bis 1945 bejaht, kann es nicht neben oder über der Bundesrepublik Deutschland und der DDR ein drittes Völkerrechtssubjekt „Deutschland“ geben. Auch die DDR gehört zu diesem Völkerrechtssubjekt Deutschland. Das Verhältnis beider Staaten in Deutschland zueinander läßt sich nicht mit den herkömmlichen völkerrechtlichen Begriffen und Anerkennungen definieren, vielmehr müssen hier deutsch-deutsche Besonderheiten in Rechnung gestellt werden. Der Satz von Herrn Achterberg, über die Frage der Identität der DDR mit Deutschland könnten nicht die Organe der Bundesrepublik, sondern nur die der DDR entscheiden, ist so nicht zutreffend. Denn hier liegen gerade die alliierten Vorbehalts- und Verfügungsrechte. Wenn wir uns darauf beziehen, machen wir uns ein Argument aus den alliierten Rechtspositionen zu eigen. Herr Ress hat bereits darauf aufmerksam gemacht, daß der Prozeß der Abspaltung - Sezession, Emanzipation oder wie immer man ihn nennen will - nicht abgeschlossen ist. Die DDR hat sich gewissermaßen nur mit einem Fuß verselbständigen können, mit dem anderen wird sie festgehalten. Sie kann sich nicht aus eigenem Recht völlig herauslösen, die Alliierten - auch die Sowjetunion - verhindern den rechtlichen Abschluß dieses Abspaltungsprozesses. Das ganze Beiwerk der Unberührtheitsklauseln in den Ostverträgen, im Grundvertrag, bis zu dem UN-Beitritt beider deutscher Staaten, zielt darauf, diesen elementaren Punkt festzuhalten. Das ist es letzten Endes wohl auch, Herr 
Bernhardt, was uns berechtigt, den $\S 25$ des Reichs- und Staatsangehörigkeitsgesetzes in den Gebieten östlich von Oder und Neiße als heute noch möglich aufrechtzuerhalten.

Noch ein Wort in die Richtung dessen, was Herr Schiedermair zu Berlin gesagt hat. Berlin ist kein Sonderproblem, Berlin ist der Kristallisations- und Interpretationspunkt für die Rechtslage Deutschlands. Die Gemengelage staats- und völkerrechtlicher Elemente ist in Berlin nur sichtbarer als im übrigen Deutschland. Wehrpflicht und Wahlrecht werden in Berlin durch alliiertes Recht überlagert, hingegen haben die Berliner dieselbe deutsche Staatsangehörigkeit wie im übrigen Deutschland.

Wenn die beiden Staaten in Deutschland liegen, kann es sich bei der innerdeutschen Grenze nicht um eine klassische völkerrechtliche Grenze handeln. Die Formulierungen des Bundesverfassungsgerichts im Grundvertragsurteil zur rechtlichen Qualität dieser Grenze sind oft und heftig kritisiert worden. Das Gericht hat sich aber wohl nur mißverständlich ausgedrückt. Im Zusammenhang mit anderen Aussagen in dem Urteil, insbesondere über die Völkerrechtssubjektivität der Deutschen Demokratischen Republik, ist der Satz über die Grenze zur DDR eigentlich nur in dem Sinne zu verstehen, daß die innerdeutsche Grenze nicht eine völkerrechtliche Grenze wie zwischen zwei sich völkerrechtlich und diplomatisch anerkennenden Rechtssubjekten sein kann. Nur das hat das Bundesverfassungsgericht zum Ausdruck bringen wollen.

Zusammenfassend läßt sich sagen: die alliierten Vorbehaltsrechte, die sich - wie im Referat bemerkt - auf ganz Berlin beziehen, bieten damit zugleich eine Klammer für die beiden Staaten in Deutschland. Das Verfassungsrecht der DDR und der Bundesrepublik Deutschland wird durch alliierte Rechtspositionen überlagert. Diese Gemengelage zeigt sich vor allem für Berlin (West), stellvertretend für Deutschland insgesamt.

Vorsitzender: Vielen Dank, Herr Zieger! - Wir dürfen die Gelegenheit benützen, den Herrn Bundespräsidenten und Kollegen Carstens auf das herzlichste zu verabschieden!

Zuleeg: Ich möchte vorausschicken, daß ich mit der Grundlage und mit den Einzelthesen des Referats von Herrn Bernhardt einverstanden bin. Es ist dadurch gekennzeichnet, daß verfassungsrechtliche Positionen zurückgedrängt werden. Ich will den Versuch unternehmen, die theoretische Grundlage dafür etwas zu ergänzen. 
Wenn Herr Bernhardt auf dem Standpunkt steht, daß auf verfassungsrechtlicher Ebene das Völkerrecht zu berücksichtigen sei und die Realitäten bis zu einem gewissen Grad hingenommen werden müßten, dann besteht eine verschiebbare Grenze; die Gegenposition von Herrn Quaritsch hat das ja angedeutet. Meine These lautet, daß es einen teilweisen Vorrang völkerrechtlicher Rechtspositionen gibt, und zwar insoweit, als diese auf dem Grundsatz der Effektivität beruhen. Das bedeutet keine Auslieferung an die Faktizität; es sind völkerrechtliche Regeln, die hier dem Verfassungsrecht vorgehen. Der Grund dafür liegt im Zweck der Völkerrechtsordnung, den Frieden aufrechtzuerhalten, eine Friedensordnung zu gewährleisten, und diese Friedensordnung wird im Grundgesetz durch die Präambel anerkannt.

An zwei Punkten kann ich das illustrieren. Das erste Beispiel betrifft den Fortbestand des Deutschen Reiches in den Grenzen von 1937. Diese Annahme auf verfassungsrechtlicher Basis ermöglicht es, die Verpflichtung, sich mit der Oder-NeißeGrenze abzufinden und sie als endgültig zu betrachten, wieder in Frage zu stellen. Wenn man den Grundsatz der Effektivität mit einrechnet, ist das Deutsche Reich in den Grenzen von 1937 keine Realität mehr, und ich vermag Herrn Achterberg nicht zu folgen, daß ein irgendwie geartetes Surrogat in einem verselbständigten Staatsvolk noch übrig bleibt.

Als zweites Beispiel dient die Stellung Ostberlins. Art. 23 GG beansprucht die Geltung des Grundgesetzes in Groß-Berlin. Wenn man die völkerrechtlichen Regeln mit einbezieht, stößt diese Vorschrift des Grundgesetzes auf die Grenze der territorialen Herrschaft und muß demgegenüber zurücktreten. Vielen Dank!

Rauschning: Meine Dame, meine Herren Kollegen! - Ich darf zunächst zurückkommen auf das, was Herr Ress mit angedeutet hat: Wir gehen aus von der These von Herrn Bernhardt, nämlich These 8 , von der Identitätstheorie. Dann ergibt sich aber die Konsequenz, daß wir es mit einer Sezession der DDR zu tun haben und daß die nicht abgeschlossen ist. Ich sollte einige weitere Gesichtspunkte dazu erläutern:

Zum einen: Selbst im Grundvertrag ist in Art. 4 und in Art. 6 in den Formulierungen deutlich ein Anhalt dafür zu finden, daß es sich nicht um normale Verhältnisse handelt. Wenn es dort heißt, die Bundesrepublik Deutschland und die Deutsche Demokratische Republik gehen davon aus, daß keiner der beiden Staaten den anderen international vertreten oder 
in seinem Namen handeln kann, dann steht das mit den Kompromißformeln der ersten Artikel in Einklang, die eben nicht zu einer Erklärung des rein völkerrechtlichen Verhältnisses kommen. Das heißt auch: Die Geschäftsgrundlage hier war, daß die Bundesrepublik Deutschland dem Vertrag nur hat zustimmen können, wenn die DDR auch hinnimmt diese gewisse Offenheit. Ich meine zweitens, daß unser Selbstverständnis - damit knüpfe ich an Herrn Häberle und Herrn Dürig an - hier eine Rolle spielt, und zwar - und da kann ich mich Herrn Bernhardt doch wieder anschließen - nicht im Wege der Auslegung, aber im Wege der Geschäftsgrundlage. Dazu gehört auch das vom Bundesverfassungsgericht formulierte Selbstverständnis und - das erscheint mir weiterhin wichtig - auch unsere Praxis, die - wie ja z. T. ausgeführt ist - von der DDR ja konkludent weitgehend akzeptiert ist. Auch das Selbstverständnis des obersten Staatsorgans der DDR, des Volkes, scheint in diese Richtung $z u$ deuten, was sich manifestiert darin, daß die DDR-Staatsführung die Mauer immer noch für notwendig hält. Das heißt also: Dieses Staatsorgan ist bei dem Bekenntnis zum Abschluß der Sezession nicht so weit gediehen; die Effektivität auch der ständig aktuellen Bindungen, z. B. im Binnenhandel, ist schon betont worden. Dann meine ich, daß wir weiterhin natürlich rechtliche Gemeinsamkeiten haben, z. B. im Substrat der Positionen der vier Siegermächte. Damit möchte ich mich - in Zustimmung zu Ihrer These 8 - gegen Ihre These 12 aussprechen und betonen, daß ich nicht meine, daß wir damit in Konflikt zur Rechtsprechung des Bundesverfassungsgerichts stehen.

Ich möchte nur noch zur Schlußthese etwas sagen, zur Frage der Wiedervereinigung und zur Frage der Rechtsposition. Rechtspositionen haben auch im Völkerrecht eine zunehmende und dauerhafte Position, je mehr sichergestellt ist, daß die Rechtsverletzung nicht durch Gewaltmaßnahmen oder durch Selbsthilfe ins Reine gebracht werden kann. Die These von der notwendigen und sehr eiligen Effektivität des Völkerrechts stammt aus einer Zeit, in der man sagen konnte: Wenn ein Staat das mit Macht nicht in einer absehbaren Zeit bereinigen kann, dann hat er eben die Position darin verloren. Aber: Gerade wenn ich an die Stimson-Doktrin erinnern kann und an die Position, daß das ganze Völkerrecht sanktionslos wird, wenn man nicht am Rechtstitel festhält, dann kommt es auf diese Bedeutung an. Ich darf in dem Sinne sagen, daß es sicherlich beim Wiedervereinigungsgebot einen weiten Gestaltungsspielraum gibt, aber daß er überschritten ist, wenn man meint, die These effek- 
tiv zu befolgen, daß man Annäherung durch Trennung mit Aufgabe von Rechtspositionen verbindet.

Ich danke Ihnen!

Küchenhoff: Meine Dame, meine Herren! - Herr Bernhardt hat wiederholt ausgeführt - ich zitiere nach der These 7 -, daß die Annahme eines Völkerrechtssubjekts Gesamtdeutschland neben oder über den real-existierenden beiden deutschen Staaten kaum noch begründbar ist, auch nicht etwa durch Nationalbewußtsein oder Zusammengehörigkeitsgefühl über die Grenzen. Ich möchte dazu zunächst eine kurze interpretationshistorische Bemerkung machen: als wir bei Mangoldt-Klein uns mit dem Begriff Deutschland in der Überschrift in der Mitte der 50er Jahre auseinanderzusetzen hatten, kamen wir zu einer spezifischen Begründung der Dachtheorie im gesamtdeutschen Staatsbewußtsein des Deutschen Volkes; wir hatten damals schon schwerste dogmatische Bedenken und Mitte der 60er Jahre waren wir uns einig - d. h. natürlich auch Friedrich Klein an erster Stelle -, daß diese Konstruktion eigentlich überholt sei und mithin auch die Dachtheorie damals schon, Mitte der 60er Jahre, erledigt sei, soweit sie im Mangoldt-Klein seinerzeit vertreten worden ist. Nun hat uns aber Herr Achterberg heute zweimal - und deshalb wollte ich hierzu doch etwas sagen - zwar nicht die gesamtdeutsche Staatlichkeit, aber den Fortbestand einer gemeinsamen deutschen Staatsangehörigkeit aus dem Fortbestand des Staatsvolks begründet, und zwar unabhängig von der jeweiligen Auffassung über einen Fortbestand oder Nicht-Fortbestand des Deutschen Reiches; er hat es so begründet, daß es zwar keinen Staat ohne Staatsvolk, aber sehr wohl ein Staatsvolk ohne Staat geben könnte; und - so wird man dann ergänzen müssen - auch eine Staatsangehörigkeit könnte es ohne Staat geben. Ich halte eine solche Annahme für ganz und gar unhaltbar, rechtsdogmatisch ebenso wie rechts- und staatstheoretisch. Die Begründung, da $B$ kein Staat da sei, wenn eines der Elemente fehle, das Fehlen einer Staatsgewalt aber das Vorhandensein eines Staatsvolkes nicht ausschließt - so kann man das vielleicht präzisieren, was vorgetragen wurde - übersieht doch, wenn man schon die Drei-Elementen-Lehre zugrundelegt, daß zu dieser doch gehört eine Wechselbezüglichkeit der Elemente und des Ganzen, und zwar in dem Sinne, daß erst beim Vorhandensein aller drei Elemente, die den Staat konstituieren, aus einem Gebiet das Staatsgebiet, aus einer Herrschaftsmacht die Staatsgewalt und aus einer Bevölkerung das Staatsvolk wird; und mit der Unhaltbarkeit der gegenteiligen Begründung von Herrn 
Achterberg entfällt meines Erachtens auch seine Begründung für die Annahme einer gemeinsamen deutschen Staatsangehörigkeit.

Bothe: Zunächst zu dem hier teilweise apostrophierten Streit zwischen Völkerrechtlern und Verfassungsrechtlern: Worum geht es eigentlich verfassungsrechtlich? Das sollte man doch noch einmal klar sagen: Es geht darum, wieviel verfassungsrechtlich an deutschlandpolitischen Positionen nun eigentlich im Grundgesetz festgeschrieben ist. Die Frage, die sich daran knüpft, ist: Brauchen die politischen Entscheidungsträger in der Bundesrepublik das Korsett der Verfassung, um nicht auf deutschlandpolitische Abwege zu geraten, mit der weiteren Folge, daß ein etwaiges deutschlandpolitisches Defizit, das in der Regierungspolitik zu entdecken wäre, dann vom Bundesverfassungsgericht wieder aufgefüllt werden könnte. Ich habe gewisse Bedenken, ob das notwendig ist, und würde in diesem Sinne eher der Auffassung von Herrn Bernhardt zuneigen, daß man gerade in dieser Frage den politischen Entscheidungsträgern etwas mehr Vertrauen entgegenbringen und etwas mehr Spielraum zubilligen sollte.

Ferner ein Wort zu der "Gemengelage" und den Präzedenzfällen: Präzedenzfälle haben es an sich, daß sie nie ganz den Fall, den man mit ihrer Hilfe lösen will, abdecken. Deshalb ist es ein beliebtes Spiel, bei jedem Präzedenzfall zu fragen, ob er paßt oder nicht - er paßt nie ganz. Man muß nun herausdestillieren, was gemeinsam ist und was nicht. In diesem Sinne haben wir - bei aller Unvollkommenheit der Präzedenzfälle natürlich in der internationalen Praxis, in der Geschichte der internationalen Beziehungen, durchaus Präzedenzfälle für Gemengelagen zwischen Staats- und Völkerrecht, die dann aber jeweils auch ihre individuellen, spezifischen Merkmale haben. Man muß darum solche Prozesse der Desintegration, die wir in den internationalen Beziehungen oft beobachtet haben, immer sehr konkret sehen und dann Punkt für Punkt vorgehen. Das ist hier mehrfach gesagt worden, ich möchte es nur ganz kurz für die Frage der alliierten Vorbehalte noch einmal tun: Ich glaube, man muß den Deutschlandvorbehalt im allgemeinen und den Berlinvorbehalt im besonderen doch unterscheiden. Herr Bernhardt hat den Deutschlandvorbehalt allgemein als eine völkerrechtliche Hypothek bezeichnet, mit der die beiden deutschen Staaten belastet sind; ich meine, dem muß man zustimmen. Was nun Berlin angeht, ist die Situation möglicherweise doch eine andere: In Gesamtberlin haben wir einen Restbestand der Übernahme der obersten Gewalt durch die Alliier- 
ten am Ende des Zweiten Weltkrieges. Wenn ich die herrschende Lehre richtig verstanden habe, wurde diese UUbernahme dieser höchsten Gewalt immer verstanden als ein aliud zu einer normalen Besetzung, als eine Ausübung deutscher Staatsgewalt, während eine ,normale" Besatzungsgewalt fremde Staatsgewalt ist. Deshalb ist die Ausübung solcher gemeinsamer alliierter Gewalt zunächst ein restliches staatsrechtliches Element. Hat sich die irgendwann in dem Prozeß geändert, so wie sich die alliierten Vorbehaltsrechte für Deutschland insgesamt gewandelt haben? Das möchte ich für Gesamtberlin nicht annehmen; hier würde ich eben einen Restbestand deutscher Staatsgewalt, so wie sie 1945 von den Alliierten übernommen worden ist, sehen.

Vorsitzender: Dankeschön! - Wir sind damit mit dem groBen Komplex des Gesamtstatus Deutschlands unter besonderer Mitberücksichtigung der völkerrechtlichen Gesichtspunkte am Ende, den wir unter den Stichworten der Gemengelage und der Rechtssubjektivität wohl einigermaßen umfassend, soweit es in einer solchen Diskussion möglich ist, beleuchtet haben.

Wir haben nun einige Wortmeldungen zu Einzelkomplexen der Rechtslage Deutschlands, und zwar von Herrn Doehring zur Staatsangehörigkeit, von Herrn Tomuschat zum Selbstbestimmungsrecht, von Herrn Kewenig zur Oder-Neiße-Linie und von Herrn Bayer zum Inland - Ausland - Streit bei der Umsatzsteuer. Anschließend wollten Herr Ipsen und Herr Hailbronner freundlich genug sein, den Bogen zu den mehr innerstaatlichen Problemen zu schlagen.

Doehring: Ich möchte jetzt nach diesen langen theoretischen Ausführungen etwas konkreter werden und mich der Staatsangehörigkeitsfrage zuwenden; ich möchte auch mit dieser $\mathrm{Zu}$ wendung nachweisen, daß die Anwendung von Völkerrecht nicht immer nur eine Belastung bedeutet, sondern auch hilfreich sein kann. Die Ausführungen von Herrn Bernhardt scheinen den Eindruck erweckt zu haben, als hätte er das Völkerrecht als eine Belastung der Deutschlandfrage ausgegeben; das muß aber nicht so sein. Konkret geht es um die These 17, die Herr Bernhardt vorgetragen hat; er sagt dort: Dritte Staaten sind völkerrechtlich befugt, den diplomatischen Schutz der DDR-Bewohner durch die Bundesrepublik auch dann anzuerkennen, wenn die DDR dem widerspricht. Ich glaube, nach längeren Utberlegungen sagen zu können - und wir haben früher auch oft darüber gesprochen -, daß es sich nicht um eine Befugnis, sondern um eine Pflicht dritter Staaten handelt. Dabei 
gehe ich davon aus, daß zwei deutsche Staatsangehörigkeiten bestehen, daß die Staatsangehörigkeit der DDR nicht zu leugnen ist, da $\beta$ aber die bundesrepublikanische Staatsangehörigkeit sich auch auf die DDR-Bürger erstreckt. Dieses Ergebnis läßt sich mit dem Brief zur deutschen Einheit begründen, mit der noch nicht abgeschlossenen Deutschlandfrage durch die vier Mächte und mit dem noch nicht abgeschlossenen Friedensvertrag. Wenn das so ist, dann haben die DDR-Bürger jedenfalls eine doppelte Staatsangehörigkeit, wenn man von der Möglichkeit einer gesamtdeutschen als einer dritten Staatsangehörigkeit absieht. Die doppelte Staatsangehörigkeit berechtigt deren Inhaber, sich auf diejenige Staatsangehörigkeit zu berufen, die sie für ihren Schutz in Anspruch zu nehmen wünschen. Bedenken dagegen, daß sich ein DDR-Bürger auf die bundesrepublikanische Staatsangehörigkeit berufen könnte, kämen nur aus dem Gesichtspunkt des genuine link in Betracht. Dieses Argument ist aber hier nicht verwendbar, sondern jeder dritte Staat muß es akzeptieren, wenn ein Doppelstaatler sich auf eine seiner beiden Staatsangehörigkeiten beruft. Eine Ausnahme besteht nur insoweit, als eine der Staatsangehörigkeiten nicht gegen die andere in Anspruch genommen werden kann. Die genuine-link-Theorie, begründet im Nottebohm-Fall durch den Internationalen Gerichtshof, ist hier unanwendbar, denn der Internationale Gerichtshof hat ihrer nur bedurft, um Mißbrauch zu verhindern. Ich glaube aber, daß es um Mißbrauchverhinderung hier nicht geht. Man könnte also einem DDR-Bürger bei dieser Anknüpfung, die heute noch durch den Brief zur deutschen Einheit und durch die Ausklammerung der Staatsangehörigkeitsfrage aus den gesamten Beziehungen zwischen DDR und Bundesrepublik besteht, nicht untersagen, sich auf den ganz normalen Fall der Inanspruchnahme doppelter Staatsangehörigkeit zu berufen. Ich meine, das Völkerrecht ergibt, daß die Inanspruchnahme einer der beiden Staatsangehörigkeiten, also auch der bundesrepublikanischen, gerechtfertigt ist; ein Mißbrauch läge nicht vor, und die DDR könnte nicht behaupten, der Internationale Gerichtshof habe auch für diesen Fall entschieden, daß das engere Lebensband unabdingbar das ausschlaggebende Kriterium sein müsse.

Tomuschat: Angeregt durch die Diskussion möchte ich auf drei Punkte eingehen, und zwar zunächst zum Komplex „Gemengelage“. Der Ausdruck "Gemengelage" scheint mir außerordentlich verwirrend zu sein. Man gewinnt den Eindruck, daß es bei vielen Problemen eigentlich keine genaue Lösung gebe, sondern alles einen unentwirrbaren Knäuel bilde. Diese Vor- 
stellung wäre aber schief und sollte zurechtgerückt werden. Auf der Ebene des Verfassungsrechts muß zunächst bestimmt werden, was das Grundgesetz sagt. Auf der Ebene des Völkerrechts ist dann anschließend zu prüfen, ob die so gewonnene Konstruktion international vertreten werden kann, ohne da $\beta$ die Bundesrepublik sich den Vorwurf zuzieht, sie verstoße gegen geltende völkerrechtliche Normen. Völkerrechtliche Argumente lassen sich nicht einfach beiseite wischen mit einer großen Geste und der schlichten Behauptung, Deutschland sei eben immer anders! Das wäre Ausdruck einer gewissen Hybris und für einen Staat wie die Bundesrepublik keine mögliche politische Haltung. Außerdem gibt das Grundgesetz ja bekanntlich in mehreren Bestimmungen eindeutig eine völkerrechtsfreundliche Haltung zu erkennen; es hat also von vornherein seine Bereitschaft erklärt, sich den völkerrechtlichen Geboten anzupassen.

Auf der anderen Seite läßt sich nicht leugnen, daß das Völkerrecht in manchen Bereichen eine gewisse Flexibilität aufweist. Verträge sind nicht immer eindeutig, und die Regeln des völkerrechtlichen Gewohnheitsrechts weisen ebenfalls eine gewisse Spannweite auf, wobei sie allerdings heute weniger auf Präjudizien beruhen als auf generellen axiomatischen Rechtsetzungen, die vor allem aus den Gremien der Vereinten Nationen hervorgehen. Es muß also stets Staatsrecht mit Völkerrecht konfrontiert werden, wobei es zu einer Wechselwirkung kommt. Beides kann sich miteinander in Einklang bringen lassen, es können mitunter aber auch Brüche und Verwerfungen auftreten.

Mein zweiter Punkt konkretisiert sich in zwei Einzelfragen. Herr Bernhardt hat in Leitsatz $15 \mathrm{sehr}$ vorsichtig formuliert, daß die Bundesrepublik nicht völkerrechtswidrig handele, wenn sie die Deutschen in der DDR und in den Ostgebieten als Staatsangehörige in Anspruch nehme, soweit sie jedenfalls diese Personen nicht mit Pflichten belaste. Meine Frage geht nun dahin - und sie wird natürlich hervorgerufen durch die These, daß es kein Gesamtdeutschland mehr gebe: Sind es nun eigentlich noch Deutsche im Sinne des Grundgesetzes, eventuell mit gemindertem Status, oder sind es Personen einer fremden Staatsangehörigkeit? Auch der Leitsatz 20 ist wiederum sehr vorsichtig gefaßt. Es heißt dort, die Bundesrepublik dürfe keinen Anspruch erheben auf Rückgabe der Ostgebiete. Die Frage lautet hier: Welchen Status besitzen diese Gebiete?

Ich wollte an sich noch einen dritten Punkt aufwerfen: Gibt es materielle Voraussetzungen für die Ausübung des Selbst- 
bestimmungsrechts und damit für die Wiederherstellung der deutschen Einheit, gelten etwa die Grundsätze des SolangeBeschlusses? Bedarf es einer gemeinsamen Wertverbundenheit? Gelten solche Prinzipien nur für eine Ausübung des Selbstbestimmungsrechts, die in geordneten Bahnen verläuft, oder muß man sich die Verwirklichung des Selbstbestimmungsrechts in jedem Falle als einen revolutionären Vorgang vorstellen?

Kewenig: Herr Vorsitzender, ich kann ganz kurz sein, da Herr Frowein und Herr Doehring meine wichtigsten Anliegen schon erörtert haben. Zunächst zur These 20 von Herrn Bernhardt: Mein Hinweis wäre nur der, daß man vielleicht bei den Gebieten jenseits von Oder und Neiße etwas deutlicher, als es in der These geschehen ist, unterscheiden muß zwischen den Gebieten unter sowjetischer Herrschaft und denen, die heute zu Polen gehören. Ich glaube, daß Art. 3 des deutsch-sowjetischen Vertrages und Art. 1 des deutsch-polnischen Vertrages unterschiedliche völkerrechtliche Wertungen nahelegen und auch unterschiedliche staats- und völkerrechtliche Konsequenzen haben.

Meine zweite Bemerkung kann ebenso kurz sein: Ich habe in der Diskussion hier das Gefühl gewonnen, daß - Herr Doehring hat es schon gesagt - viel von dem, was die Staatsund Völkerrechtler zur Rechtslage Deutschlands vortragen, von denjenigen Kollegen, die ausschließlich das Staatsrecht vertreten, als belastend empfunden wird. Für mich entstand ein bißchen der Eindruck, als ob vielfach nur die "Nur-Staatsrechtler" als die verständigen und guten Deutschen angesehen wurden. Ich möchte dazu nur feststellen - und das so hervorragende Referat von Herrn Bernhardt hat das ja mit aller Deutlichkeit belegt: Es geht uns allen darum, ein möglichst zutreffendes und zuverlässiges Bild von der Rechtslage Deutschlands zu zeichnen. Nach der Auffassung der Völkerrechtler ist dies nicht möglich, ohne das Völkerrecht und die Beschränkungen, die es für Deutschland als Ganzes bereithält, dabei zu berücksichtigen. Staats- und Völkerrecht sind nicht zwei getrennte Rechtsordnungen, um die man sich jeweils ganz nach Belieben kümmert oder auch nicht, sie bedingen sich vielmehr gegenseitig, bilden eine Einheit. Vielen Dank!

Vorsitzender: Vielen Dank, Herr Kewenig! - Es gehört wohl zum Berufsrisiko der Völkerrechtler, durch die Mitberücksichtigung der externen Gesichtspunkte einige Elemente hereinzubringen, die in der inneren Diskussion, staatsrechtlich wie politisch, gelegentlich als etwas fremdartig empfunden werden. Es 
gibt berühmte Beispiele auch von Völkerrechtlern aus der Weimarer Zeit - ich nenne nur Schücking - , die unter diesem Schicksal zu leiden hatten. Weswegen sollte es den Völkerrechtlern der Bundesrepublik besser ergehen?

Quaritsch: Es wäre gewiß unüblich, Herr Kewenig, würde ein Diskutant seine Kollegen in der Vereinigung nach guten und schlechten Deutschen sortieren; ich habe das auch nicht getan. Das mir zu unterstellen, ist in dieser Vereinigung aber ebenso unüblich.

Vorsitzender: Vielen Dank, Herr Quaritsch! - Wenn ich Herrn Frowein richtig verstanden habe, bezog sich seine Bemerkung auf Vorgänge, die zwar zu anderer Zeit in diesem Gebäude einmal stattgefunden haben, aber nicht heute in dieser Versammlung. Wir brauchen diese Dinge jetzt wohl nicht zu sehr verfolgen.

Bayer: Herr Bernhardt, ich wollte nicht nur kurz etwas zur Umsatzsteuer sagen, sondern auch noch $\mathrm{zu}$ einem anderen Punkt; ich hoffe, Herr Vorsitzender, Sie erlauben!

Wenn ich Sie richtig verstanden habe, Herr Bernhardt, dann unternehmen Sie doch den Versuch, einen materiell ausgefüllten Begriff des „Deutschen“, vielleicht deutlicher: des „Bundesdeutschen " oder des „Bundesrepublikaners" zu entwickeln. Und um dazu zu gelangen, berufen Sie sich auf die bundesdeutsche Gesetzgebung, also etwa auf die Wehrpflicht- und auf die Steuergesetzgebung.

Ich lasse die Wehrpflichtgesetzgebung an dieser Stelle beiseite; da haben wir in der Tat den Begriff des „Deutschen“ und man mag sich fragen, wie der nun im einzelnen auszulegen ist. Ich möchte Ihnen nur entgegenhalten, daß Sie sich für Ihre These mit Sicherheit nicht auf das Steuergesetz - auf die Steuergesetzgebung - berufen können, und zwar deshalb nicht, weil uns in der Steuergesetzgebung eben der Begriff des „Deutschen" nicht begegnet, allgemeiner ausgedrückt, das Personalitätsprinzip hier keine Bedeutung hat, das Ganze sich vielmehr, von wenigen Ausnahmen abgesehen, auf das Prinzip der Territorialität gründet, und zwar mit der Folge, daß etwa ein Bürger der DDR, der in der Bundesrepublik arbeitet, seit jeher und bestimmt auch in Zukunft hier der Einkommensteuer unterworfen ist. Wollen Sie diesen Bürger, im Sinne Ihrer Terminologie, als „Deutschen“, als „Bundesdeutschen“ bezeichnen? Doch wohl nicht! 
Das zu dem einen Punkte; der zweite Punkt: Das Umsatzsteuerrecht. Sie sind in Ihrem Referat ausgegangen von dem Gedanken einer lebenden Verfassung; eine Verfassung lebt und muß so, wie sie lebt, verstanden werden. Ich meine nur, und da unterscheide ich mich wohl von Ihnen, daß wir ein Stück Leben dieser Verfassung auch im Umsatzsteuerrecht haben, das Umsatzsteuerrecht geradezu ein Beispiel für lebendiges Verfassungsrecht ist: Die Bundesrepublik Deutschland wäre, bundesstaatsrechtlich gesehen, etwas anderes, gäbe es nicht die regelmäßigen Auseinandersetzungen um den Verteilungsschlüssel betr. die Umsatzsteuer!

Das ist das eine - das andere: Es geht um die Frage nach dem räumlichen Geltungsbereich des Umsatzsteuergesetzes. In der Tat: Wir haben die Formel „Grenzen des Deutschen Reiches vom 31. 12. 1937" - das ist Inland im Sinne des Umsatzsteuergesetzes. Nun meine ich bloß, man sollte bedenken, daß es sich ja insoweit nur um einen vergilbten Gesetzestext handelt, das, was daraus folgt, vielmehr auch auf anderem beruht, beispielsweise - und zwar bis in die jüngste Zeit hinein - auf der Rechtsprechung des obersten deutschen Steuergerichts. Und der Bundesfinanzhof ist in meinen Augen auch ein Stück unserer lebenden Verfassung. Wir sollten also vielleicht diese Formel doch ernstnehmen, so wie sie nun einmal in der Rechtsprechung gehandhabt wird.

Sie haben natürlich recht: Die Bundesrepublik Deutschland erhebt den Umsatzsteueranspruch aus Umsätzen, die beispielsweise in der DDR getätigt werden, nicht; aber das beruht ja nun auf einem ganz anderen Umstand, nämlich das beruht auf Verwaltungsrichtlinien, die ihrerseits wieder - ich erinnere an das einschlägige Schreiben des Bundesfinanzministers vom 1. Juni letzten Jahres - in einer bloßen Billigkeit gründen. Billigkeit ist ihrem Wesen nach Gnade, und ich glaube, aus Gnade kann man nicht etwas ableiten für die Interpretation von Recht, Völkerrecht, Staatsrecht.

Eine letzte Bemerkung: Vielleicht sollte man in diesen ganzen Komplex auch die Utberlegung miteinbeziehen, daß das Umsatzsteuerrecht, auch was seinen räumlichen Geltungsbereich anbetrifft, in einer engen Verknüpfung mit dem Zollrecht steht; und was das Zollrecht anbetrifft, so hat die DDR nie ein Interesse daran gehabt, Zollausland zu sein. Wie sollten wir heute eigentlich ein Interesse von ihr daran anerkennen, umsatzsteuerrechtlich nicht mehr Inland sein zu wollen? - Dankeschön! 
Vorsitzender: Vielen Dank, Herr Bayer! - Herr Ipsen, Sie wollten uns helfen, die Brücke sozusagen von dem Schwerpunkt Bernhardt zu dem Schwerpunkt Achterberg zu schlagen! Bitteschön.

H. P. Ipsen: Frau Kollegin, meine Herren Kollegen! Herr Doehring hat in seinem Aufsatz im Deutschen Verwaltungsblatt zur Vorbereitung dieser Tagung auf den Zielkonflikt - so hat er es formuliert - hingewiesen, der entstehen könne zwischen dem Wiedervereinigungsgebot der Präambel und der Europäischen Integration. In den formulierten Leitsätzen erscheint der Umstand, daB die Bundesrepublik europäisch integriert ist, überhaupt nicht. In den Ausführungen der beiden Herren Referenten sind dazu Bemerkungen gemacht worden. Herr Doehring hat das Problem gestellt, ob die U'bertragung von Souveränitätsrechten in ihrem Ausma $B$ so weit gehen könnte, daß das Wiedervereinigungsgebot dadurch verletzt oder in Frage gestellt würde. Die beiden Herren Referenten haben im wesentlichen übereinstimmend - und zwar Herr Bernhardt in den Ausführungen zu den Leitsätzen 13 und 25 und Herr Achterberg in einem anderen Zusammenhang zu Nr. 13 - die Auffassung vertreten, die ich billige, wonach die weitere Entwicklung in den Möglichkeiten breiter politischer Gestaltungsspielräume sich vollziehen dürfte und könnte - bis hin zu der Einsicht, daß auch eine absolute Trennung beider deutscher Staatlichkeiten vorübergehend akzeptiert werden dürfe, ohne dadurch ein etwa geltendes Wiedervereinigungsgebot zu verletzen. Ich erwähne dies deswegen, weil bei der Vorbereitung der Europawahlen in den Diskussionen immer wieder dieses Thema angesprochen worden ist und ich bei meinen WahlWerbereden, die ich landauf und landab gehalten habe - mit dem Erfolg, daß die Wahlbeteiligung natürlich beträchtlich gestiegen ist! -, zu antworten pflegte: drei Momente unserer europäischen Integration tragen dazu bei, unsere Attraktivität gen Osten zu steigern oder uns in dieser Richtung zu behaupten, nämlich einmal das Verhaiten zum COMECON, auch zu einzelnen Staaten des Ostblocks; zum anderen eröffnet die Integration die Möglichkeit zum innerdeutschen Handel mit der DDR; und daB die Bundesrepublik in einer Verfassungshomogenität des westeuropäischen Raumes steht, erleichtert letztlich unsere Position gegenüber der anderen Seite, ohne eine Endentscheidung zu präjudizieren. Ich möchte also beiden Herren Referenten beipflichten in ihrer Meinung, und zwar großzügiger und großräumiger, als Herr Doehring diese Frage sehr pointiert gestellt hat, daß die künftige Entwicklung in der Inte- 
gration, die ja einen Prozeßcharakter hat, nicht zu einem jetzt schon beschreibenden Zielkonflikt mit einem Wiedervereinigungsgebot führen dürfte. Ein weiteres Argument dazu verdanke ich einem Gespräch mit Herrn Böckenförde: es ist wahrscheinlich auch nicht tunlich, einen solchen Zielkonflikt zu diskutieren oder als existent $\mathrm{zu}$ bezeichnen, weil damit möglichen anderen Positionen anderer Seiten Waffen in die Hand geliefert werden, die wir besser nicht liefern sollten.

Nun zwei Bemerkungen, die übergehen zu der Gesamtthematik und der Arbeitsteilung zwischen den beiden Referenten. Wir haben ja gesehen - und der bisherige Umfang der Diskussion bestätigt das -, daß bei der Stoffaufteilung Herr Bernhardt offensichtlich das bessere Los gezogen hat. Ich weiß nicht - ich habe mit Herrn Achterberg nicht darüber gesprochen -, wie wohl er sich eigentlich gefühlt hat bei der Bearbeitung seines Parts. Ich hätte mich jedenfalls wenig wohl gefühlt, und Sie werden ja alle den Eindruck gehabt haben, daß das, was Herr Achterberg uns zu seinem Teil auf der Grundlage seines Themaverständnisses sagen konnte - ja, wie soll ich mich ausdrücken? -, nicht himmelstürzend sein konnte. Es sollte bedacht werden, daß ein Referent auch durch die Arbeitsteilung in eine sehr schwierige Situation geraten kann - jedenfalls dann, wenn der Referent, wie hier, über „30 Jahre Grundgesetz" spricht und nicht über „Deutschland" -, eben 30 Jahre nach dem Inkrafttreten und der Geltung und Wandlung des Grundgesetzes und seiner Staatlichkeit. Wenn ich mir überlege, daß ein junger Kollege, der sich uns vorstellen wollte, den Arbeitspart von Herrn Achterberg zu bewältigen gehabt hätte und im gleichen Themaverständnis nicht mehr herunterholen konnte von den Sternen, wäre das nicht zu seinem Nutzen ausgefallen - ich hoffe, mich verständlich zu machen. Herr Achterberg hat sich im übrigen seine Aufgabe auch nicht gerade erleichtert. Denn seine Neigung, sich zunächst einmal methodisch auszubreiten, statt die von ihm angewendete Methode in der Sache selbst zur Geltung zu bringen - und dies, obwohl wir sie kennen -, hat ihn dazu verleitet, die Breite des Themas noch weiter auszudehnen.

Endlich: seine Neigung - und nun spreche ich im Sinne unseres leider abwesenden Kollegen Scheuner, der uns zu diesem Thema schon einmal ins Gebet genommen hat -, seine Neigung, neuartige Fremdwörter einzuführen, hat die Verständigungsmöglichkeiten auch nicht erhöht. Ich habe lange überlegt, was „Transindividuen" sind. Transvestiten - ja, das habe ich inzwischen gelernt! Ich habe aus dem Zusammenhang nur entnehmen können, daß damit offenbar das gemeint ist, was 
wir im schlichten Hochdeutsch als „Verbände“ bezeichnen oder auch ,intermediäre Gewalten“, wenn es denn gelehrt sein muß.

Lieber Herr Achterberg, wenn Sie bei dieser Themaaufteilung und bei Ihrem Themaverständnis nicht mehr bringen konnten als das, was anläßlich der Grundgesetz-Jubiläen (auch schon zum 25jährigen) schon ausgebreitet worden ist, wenn Sie sich dann noch mit diesem methodischen Vorspann belasteten und uns die Dinge so vortrugen, wie Herr Scheuner es gar nicht gern gehört haben würde - dann entstehen diese Schwierigkeiten, von denen ich sprach. Haben Sie bitte Verständnis, daß ich mich so im Klartext ausdrückte, aber ich möchte vermeiden, daß noch einmal ein Kollege in eine derart schwierige Lage kommt. Daß unser Korreferent das Thema seines Verständnisses gemeistert hat, verdient unsere Anerkennung.

Hailbronner: Noch ein Wort zur viel beschworenen Gemengelage zwischen Völkerrecht und Staatsrecht. In der bisherigen Diskussion konnte der Eindruck entstehen, daß das völkerrechtliche Bild dem staatsrechtlichen Bild entgegengesetzt wird und das Völkerrecht zur Korrektur des staatsrechtlichen Befundes verwendet wird. Man kommt dann dazu, daß es nur noch Beziehungen zwischen souveränen Staaten gibt und daß uneingeschränkt völkerrechtliche Prinzipien über Nichteinmischung, gegenseitige Achtung der Gebietshoheit und Personalhoheit Anwendung finden. Die staatsrechtlichen Konstruktionen des Bundesverfassungsgerichts erweisen sich dann auf dem Hintergrund des Völkerrechts als nicht haltbar.

Mehr oder weniger unausgesprochen liegt dem zugrunde, da $B$ wir die komplexe deutsche Rechtslage völkerrechtlich nur mit dem Recht der zwischenstaatlichen Beziehungen erfassen können. Genau dies ist aber das Problem. Die Frage ist, ob wir wirklich auch bei der völkerrechtlichen Beurteilung der deutschen Rechtslage uneingeschränkt vom Recht der zwischenstaatlichen Beziehungen ausgehen können und alles in den Raster unbeschränkter staatlicher Souveränitätsrechte einordnen dürfen. Für die Beantwortung dieser Frage gibt das Völkerrecht nur beschränkt Hilfestellung. Die Berufung auf angebliche Realitäten ist häufig ein Scheinargument. Es gibt zahlreiche Fallkonstellationen der Funktionsunfähigkeit von Staaten, des Auseinanderbrechens von Staaten und des Zusammenschlusses von Staaten, bei denen nur eingeschränkt von der Anwendbarkeit des Rechts zwischenstaatlicher Beziehungen ausgegangen werden kann. Die Frage, inwieweit die völkerrechtlichen Regeln über die zwischenstaatlichen Beziehungen hier anwendbar sind, kann in diesen Fällen nicht ohne Rück- 
sicht auf den staatsrechtlichen Befund getroffen werden. Es gibt also auch eine Gemengelage, bei der der völkerrechtliche Anschein vom staatsrechtlichen Befund her korrigiert werden muß. Das Völkerrecht zwingt uns keineswegs dazu, uneingeschränkt in diesen Situationen vom Recht der zwischenstaatlichen Beziehungen auszugehen.

Meines Erachtens liegt bei der Rechtslage Deutschlands eine derartige Situation vor. In beschränktem Umfang sind zwischen der Bundesrepublik Deutschland und der DDR völkerrechtliche Beziehungen entstanden; sie ändern aber nichts daran, daß der Proze $ß$ der Abwicklung des Deutschen Reiches noch nicht als abgeschlossen angesehen werden kann. Eindeutige Präzedenzfälle im Völkerrecht gibt es hierfür nicht. Das Völkerrecht kann sich aber in diesem Punkt nicht über die immer wieder auch beim Grundvertrag bekräftigten Vorbehalte hinwegsetzen, daß es noch regelungsbedürftige Sachverhalte gibt, bei denen wir nicht einfach von der Anwendung zwischenstaatlicher Rechtsregeln ausgehen können. Man mag das Sonderbeziehungen nennen. Entscheidend ist, daß man anerkennt, daß das Völkerrecht keine zwingenden Regeln darüber enthält, daß der Prozeß der Abwicklung des Deutschen Reiches bereits jetzt als abgeschlossen betrachtet werden müßte. Anderenfalls könnten wir völkerrechtlich weder eine gesamtdeutsche Staatsangehörigkeit noch unsere besondere Verantwortung für das, was im anderen Teil Deutschlands geschieht, rechtfertigen.

Freilich kann man die deutsche Rechtslage nicht statisch auf einen Punkt fixiert völkerrechtlich erfassen, sondern man muß sie als Prozeß begreifen, bei dem zum gegenwärtigen Zeitpunkt noch nicht feststeht, ob endgültig nur noch das zwischenstaatliche Recht übrigbleibt oder ob staatsrechtliche Prinzipien wieder stärker zur Geltung kommen. Dazu gehört aber auch die politische Verdeutlichung staatsrechtlicher Positionen vor der internationalen Offentlichkeit. Dazu gehört auch, daß man in internationalen Organisationen und besonders bei den Vereinten Nationen nicht nur einen pauschalen Hinweis in der jährlichen Rede des Bundesaußenministers auf die Wiedervereinigung Deutschlands anbringt und im übrigen die „querelle allemande" möglichst nicht auf den Tisch bringt, sondern daß man in geeigneter Form darauf hinweist, daß die deutsche Frage nach wie vor der Lösung harrt. Auch das beeinflußt den völkerrechtlichen Befund.

Vorsitzender: Ihr Beitrag hat noch einmal gezeigt, Herr Hailbronner, daß die Beerdigung der Gemengelage, die Herr Bernhardt vorhatte, sich doch als schwierig erweist. - Herr Bern- 
hardt, wollen Sie Ihr späteres Schlußwort jetzt noch einmal entlasten?

Bernhardt: $\mathrm{Zu} 4$ Fragen, die in der Diskussion aufgeworfen worden sind, möchte ich etwas sagen. Zunächst zur Staatsangehörigkeit und zur Rechtsstellung der Deutschen: Ich glaube in der Tat, daß wir den Anspruch aufrechterhalten können und müssen, daß die Bewohner der DDR und die Deutschen jenseits der Oder-Neiße-Linie Deutsche im Sinne des Grundgesetzes sind. Das, glaube ich, habe ich sehr klar gesagt und zugleich versucht, den jetzigen Inhalt dieses Status zu umschreiben. Ich möchte von einer Staatsangehörigkeit im Wartestand sprechen, in dem Sinne, da $\beta$ nur dann, wenn die Betreffenden sich an die Organe der Bundesrepublik wenden können, dieser Status aktualisiert wird. In diesem Umfang können wir völkerrechtlich und müssen wir staatsrechtlich an unserer Position festhalten.

Zweitens: die Frage nach dem Status der Gebiete jenseits der Elbe. Aus meinem Referat ergibt sich, daß m. E. die DDR ihr eigenes Staatsgebiet hat, aber auch insoweit mit den Vier-MächteVorbehalten belastet ist. Hinsichtlich der Gebiete jenseits der Oder-Neiße-Linie würde ich, anders vielleicht als es bei Herrn Kewenig anklang, keinen Unterschied machen zwischen den Gebieten, die unter polnischer Herrschaft stehen, und den Gebieten unter sowjetischer Herrschaft. Zwar enthält bekanntlich das Potsdamer „Abkommen“ insoweit gewisse Differenzierungen, aber ich meine nicht, daß im einen oder anderen Fall schon endgültige rechtliche Entscheidungen gefällt wurden.

Nun zu der Umsatzsteuer und zum Zoll. Da ging es mir nur darum, die Probleme etwas aus dem gesamtdeutschen Himmel herunterzuholen und auch insoweit mehr Raum für politische Entscheidungen zu lassen. Ich bin ganz dafür, soweit wie möglich keine Zollgrenzen zu ziehen, aber ich habe Zweifel, ob das verfassungsrechtlich ausgeschlossen wäre.

Schließlich zur europäischen Entwicklung: Diesen Komplex habe ich ganz bewußt aus meinem Referat ausgeklammert. Nur in meinem Ausblick habe ich etwas dazu gesagt. Ich mußte diese Fragen einmal aus zeitlichen Gründen beiseite lassen, zum anderen aber auch deshalb, weil man die zukünftige Entwicklung hier nicht übersehen kann. Es kann in Zukunft durchaus Konflikte zwischen dem Wiedervereinigungsgebot und der europäischen Einigung geben - darauf hat wohl Herr Doehring in seinem Aufsatz hinweisen wollen -, aber die Entwicklung kann auch in eine andere Richtung gehen. Darauf hat Herr Ipsen zu Recht aufmerksam gemacht. 
Vorsitzender: Wir kommen nunmehr endgültig zu den Grundlinien der inneren verfassungsrechtlichen Entwicklung seit 1949. — Gnädige Frau, darf ich zunächst Sie bitten!

Staff: Ich möchte zu dem methodischen Ansatz des Referats von Herrn Achterberg Stellung nehmen, der mir weit mehr als ein rein methodischer zu sein scheint. Das Referat setzt mit einem Zitat von Jaspers an, ohne daß Methode oder Inhalt Jasperscher Philosophie weitergedacht werden. Achterberg bezieht sich vielmehr in seinem Referat nicht auf Jaspers, sondern auf Heideggers Ganzheitsphilosophie und den in ihr enthaltenen "Jargon der Eigentlichkeit", wie Th. W. Adorno die sprachliche Verhüllung Heideggerscher Ideologie gekennzeichnet hat. Das Referat bringt in vielfachen Wendungen Begriffe wie „metakonstitutionel1", ,metazeitlich“, „,metajuristisch“, stets bezogen auf die Nation, die als „Inbegriff der Gemeinsamkeit", gesehen wird, wobei das Gemeinschaftliche „Integrationsfaktor" sein soll. In diesem Zusammenhang zitiert der Referent Renan und Smend; nicht zitiert werden Hauriou und Carl Schmitt, obgleich deren gründungstheoretischer Ansatz im gesamten Referat unrevidiert durchgehalten wird. Das wird z. B. deutlich, wenn Begriffe wie ,freiheitlich-demokratische Grundordnung" als vorgegebene Werte hingenommen werden. Für mich ist unter der freiheitlich-demokratischen Grundordnung das Normgefüge unserer Verfassung zu verstehen, ein Normgefüge, das in einer Demokratie allein dem Parlament und dem Bundesverfassungsgericht in einem gewissen Ausmaß zur Interpretation offen steht. Nicht umsonst war Carl Schmitt Gegner des Rechtspositivismus und ich erwähne das, weil es mir wichtig erscheint, auf den demokratischen Konsens abzustellen, in dem Verfassung sich in konkreten Normen verwirklicht.

Von daher ist die vom Referenten nur kurz gestreifte Parlamentarismus-Kritik, von daher auch die Arbeit der Verfassungs-Enquête zu verstehen. Wenn eine positive Bilanz im Hinblick auf „30 Jahre Grundgesetz“ zu ziehen ist, so kann sie für mich nicht darin bestehen, auf Grundwerte zu rekurrieren, denen immer ein Irrationales anhaftet, sondern darin, daß es möglich sein muß, Konflikte aufzunehmen und sie in einem demokratischen Prozeß zu lösen. Wenn Herr Stern gestern sagte, wir befänden uns hier im Reichstagsgebäude in einer ,idealen Wirklichkeit", so möchte ich daran erinnern, daß diese "ideale Wirklichkeit" in einem hohen $\mathrm{MaB}$ durch unsere Geschichte belastet ist. Wir haben - vielleicht - die Chance, auf demokratischem Wege eine idealere Wirklichkeit zu schaffen, als sie bisher durch das Reichstagsgebäude symbolisiert wird. 
H. P. Ipsen: Meine Herren! Zur Geschichte der Vereinigung: Das war das erste Wort aus weiblichem Munde in unserer Vereinigung, seit sie existiert!

Zacher: In dem Referat Achterberg haben mich nicht die komplizierten Begriffe gefangen, die Herrn Ipsen so beschäftigt haben, auch nicht die komplizierten Grundlegungen. Vielmehr ist mir einer der einfachsten Sätze von Herrn Achterberg besonders zu Herzen gegangen. Am Ende Ihres Referates haben Sie, Herr Achterberg, ungefähr - ich kann das natürlich nicht wörtlich zitieren - folgendes gesagt: daß sich die Situation geändert habe, das sei eine Binsenwahrheit. Ich möchte demgegenüber sagen: für mich ist das nicht nur eine Binsenwahrheit; sondern für mich ist das die Butter aufs Brot.

Ich glaube, das Thema dieses Tages kann man, so wie es gestellt war, nur in der Dialektik von Herausforderung und Antwort erörtern - genauer: in einem Viertaktsystem von (1) Herausforderung, (2) Bedingungen der Antwort, (3) Antwort und (4) Veränderung sowohl der Herausforderungen wie der Bedingungen der Antwort durch die Antwort. Ferner muß man, glaube ich, die Spannung betonen, die im Thema liegt, indem das Thema einerseits von Deutschland - also von Deutschland „als Ganzem" und so wohl auch von dem Volk, das im ganzen Deutschland lebt - andererseits vom Grundgesetz spricht, das einen Staat verfaßt hat, der nur einen Teil des Volkes in einem Teil jenes Landes umfaßt. In diesem methodischen und sachlichen Rahmen würde ich das gestellte Thema so ausdifferenzieren, da $\mathrm{B}$ ich frage: welche Herausforderungen hat die deutsche Nation - auch "als Ganze" - an den Staat, den allein das Grundgesetz verfassen konnte, den westdeutschen "Teilstaat", über diese Zeit von 30 Jahren hin gerichtet. Welche Antworten hat das Grundgesetz gegeben, und welche Antworten wurden unter dem Grundgesetz gegeben? Wie haben sich die Herausforderungen geändert? Wie haben sich die Bedingungen geändert, die das Grundgesetz geschaffen hat, um den Staat instandzusetzen, den veränderten Herausforderungen Rechnung zu tragen? Wie haben sich die Antworten verändert? Und schließlich müßte man auch fragen, wo das Grundgesetz sowohl die Antwort als auch die Bedingungen einer Antwort dieses Staates schuldig geblieben ist.

In diesem Sinne hat Herr Bernhardt die zentrale Problematik der Außenpolitik dargestellt, indem er gesagt hat: als das Grundgesetz gemacht wurde, hat das Volk noch "als Ganzes" nach seiner Zukunft gefragt. Inzwischen sind 30 Jahre vergangen. Wir haben uns daran gewöhnt, daß das Grundgesetz die 
Antwort auf diese Zukunft nur für einen Teil Deutschlands und der deutschen Nation geben konnte. Wir haben uns in vielem auf diese neuen Realitäten eingerichtet, haben Verträge auf dieser Grundlage geschlossen usw. Ebenso hat sich die internationale Gemeinschaft daran gewöhnt. Das ist eine wesentliche Veränderung. Und welche Antwort hat nun das Grundgesetz auf diese Veränderung bereit? Sie, Herr Bernhardt, haben auch sehr stark nach dem Völkerrecht gefragt, aber doch auch nach der Antwort des Grundgesetzes. Soweit bestätigt mich Ihr Vorgehen in der von mir für notwendig gehaltenen Konzeption.

Gleichwohl war damit schon die außenpolitische Dimension nicht ausgeschöpft. Am Anfang des in Frage stehenden Zeitraums war unsere Bundesrepublik ja ein „unmündiges völkerrechtliches Kind", das überhaupt nicht nach außen wirken konnte. Aber dann wurde sie hineingeführt in eine Integration, die gerade auch diese Lage der deutschen Nation neu strukturiert hat. Sie wurde hineingeführt in eine supranationale Organisation, in internationale Organisationen, in die völkerrechtliche internationale Interaktion und auch in der Sache in internationale Verantwortung. Das Grundgesetz mußte sich dem immer wieder anpassen, sich neuen Fragen stellen. Eine andere Linie, noch im internationalen Zusammenhang, wäre die folgende. Am Anfang waren wir - das ist bei Herrn Bernhardt angeklungen - ein Volk, das die zurückflutenden und von Hitler hereingeführten Massen einer sehr weit verstandenen deutschen Nation aufnehmen mußte. Die Antwort des Grundgesetzes darauf war Art. 116. Inzwischen sind wir ein Volk, das seinen Lebensraum mit vielen Angehörigen anderer Länder teilt, die nicht Hitler, sondern die eine ganz neue internationale „Völkerwanderung“ zu uns geführt hat. Für diese Leute haben wir keinen Art. 116 GG. Das Grundgesetz ist bisher eine spezifische Antwort auf die Herausforderung, die in der sehr wirksamen Präsenz vieler Ausländer in der Bundesrepublik liegt, schuldiggeblieben. Soviel an Bermerkungen zur internationalen Dimension des Themas.

Nun aber wäre zu fragen, wie sich dieses Spiel von Herausforderung, Bedingungen der Antwort, Antwort und Veränderung der Herausforderungen und der Bedingungen der Antwort in der innenpolitischen Dimension vollzogen hat. Welche Antworten hat das Grundgesetz auf die innenpolitische Herausforderungen gegeben? Wie wurde das Grundgesetz den Veränderungen angepaßt - durch Änderung, durch neue, oft auch sehr freie Interpretation, die eher der Entdeckung neuer Inhalte gleichkommt? Hier erst begänne, wie Sie wohl verstehen 
werden, mein Thema - das Thema meines Diskussionsbeitrags. Aber ich möchte die Geduld des Herrn Vorsitzenden nicht überfordern. Und so möchte ich nur noch einige Kategorien andeuten, von denen man sich hier hätte leiten lassen können. Ein Beispiel wäre die Entwicklung der „Knappheiten“. Am Anfang war die allgemeine Not. Das Grundgesetz hat darauf gar keine Antwort gegeben. Dann kam der Úbergang - die Freisetzung der wirtschaftlichen Entwicklung. Das Grundgesetz hat dafür Bedingungen gesetzt. Es hat die "Befreiung" der Wirtschaft zugelassen. Und diese „Befreiung" erwies sich als Pfad zur Prosperität. Schon sehr früh finden wir hier die Wirtschaftsverfassungsdiskussion: wo soll die Bemühung um Gleichheit einsetzen? Diese erste Wirtschaftsverfassungsdiskussion lief auf Freiheit hinaus, aber der Wohlfahrtsstaat korrigierte die Entwicklung in Richtung auf Gleichheit. Als Wirtschaftsund Wohlfahrtsstaat eine gewisse Sättigung erreicht zu haben schienen, veränderten sich sowohl die Wirtschaftsverfassung als auch die Diskussion um die Wirtschaftsverfassung. Die Verantwortung des Staates für wirtschaftliche Sicherheit und Wirtschaftswachstum wurde artikuliert. Dem folgte alsbald eine neue Diskussion um mehr Gleichheit, um den Leistungsstaat, um Teilhaberechte usw. Während in jener Phase Knappheit fast vergessen wurde, stehen wir jetzt vor ganz neuen „Knappheiten". Die Erdölkrise hat etwas davon gezeigt. Von einer anderen Knappheit, der Knappheit an heiler Umwelt, werden wir morgen reden. Ganz neue Güter werden knapp. Das Grundgesetz hat darauf überhaupt keine Antwort, weil der Menschheit noch gar keine Erfahrungen mit diesen "Knappheiten“ vorliegen. Daneben sehen wir immer deutlicher eine ganz andere Knappheit, auf die keine Verfassung antworten kann; denn sie ist eine Herausforderung nicht an den Staat, sondern an die Gesellschaft. Ich meine den Dienst des Menschen am Menschen.

In diesem Sinne könnte man aus einer an sich endlosen Zahl weiterer Kategorien auswählen: die technologischen Veränderungen, Entwicklungen des Bildungswesens, den Gestaltwandel von Stabilität und Mobilität, die verkehrs- und kommunikationstechnische Relativierung räumlicher Distanz, die gewaltigen kommunikativen Veränderungen usw. Aber natürlich kann ich keines dieser Beispiele hier noch weiter verfolgen. Ich habe ohnedies für die große Geduld des Herrn Vorsitzenden zu danken. 
Badura: Herr Vorsitzender, verehrte Damen und Herren! Der Bericht von Herrn Bernhardt hat die Staatspraxis zur deutschen Frage geschildert und vor allem die völkerrechtlichen, aber auch die verfassungsrechtlichen Maßstäbe erläutert; er war eigentlich eine lebendige Widerlegung von dem, was Herr Achterberg unter Abschnitt B beschrieben hat, nämlich, daß der Staat ein "Subsystem der Gesellschaft" sei. Es ist für uns Staatsrechtler höchst belehrend, den klaren und berechenbaren Worten eines Völkerrechtlers zu lauschen und zu erkennen, daß offenbar der Tatbestand des Staates und seine besonderen Friedensfunktionen erfaßbar sind, während wir in der materialen Verfassungslehre überhaupt nicht mehr wissen, was der Staat ist und von einem „Subsystem der Gesellschaft" sprechen. Dieses Wort ist allgemein bekannt - es stammt ja nicht von Ihnen - , aber sowohl wenn man die juristische und politische Seite der deutschen Frage betrachtet, wie wenn man allgemein sich überlegt, wie der politische und kulturelle und geschichtliche Tatbestand des Staates erfaßt werden soll, muß man sich fragen, ob dafür eine solche Beschreibung irgendeinen Nutzen abwirft. Ich bezweifle das; ich kann mir nicht vorstellen, daß sich daraus etwas Besonderes ableiten ließe.

Herr Zacher hat das Füllhorn der Themen auszuschütten begonnen, das in den 30 Jahren Grundgesetz und in den 30 Jahren seit Gründung der beiden deutschen Staaten ein Problem hätte sein können - das kann man von dem Referenten, glaube ich, nicht verlangen, daß er das alles behandelt. Nur eine Frage, die vielleicht doch eine juristische Frage ist, hätte mich interessiert: Es sind zwei Bewegungen zu beobachten, wenn wir das Verfassungsrecht über diese $30 \mathrm{Jahre}$ hinweg betrachten. Einmal eine Bewegung, die die Interpretation, vor allem die Interpretation der Gerichte, von dem - durch die Gunst oder Ungunst der Verhältnisse - immer weiter wegführt, was ursprünglich in der Verfassung geregelt worden ist oder was zumindestens explizit in der Verfassunggebung gemeint war. Etwa unsere heutige Grundrechtsinterpretation ist ja sicherlich an einem völlig anderen Punkte, als damals zu ihrem Beginn. Das ist eine Bewegung. Eine zweite Bewegung ist, daß nicht unbeträchtliche Teile unserer politischen und staatlichen Wirklichkeit überhaupt hinauswandern aus dem, was durch die Verfassung geregelt ist und was überhaupt noch als "staatlich" bezeichnet werden kann, etwa die Fragen des Verteilungskampfes, die Fragen der vielfältigen Autonomien im Bildungswesen, auch im Kommunikationssystem, auch im Wirtschaftsleben. 
Diese Tatbestände $\mathrm{zu}$ beschreiben, würde vielleicht nicht schwerfallen, aber meine Frage geht dahin: Nach welchen Regeln eigentlich läßt sich bestimmen, ob derartige Bewegungen eine normative Bedeutung haben können? Kann man sich wirklich damit begnügen, Herr Achterberg, daß man darauf hinweist, daß das Bundesverfassungsgericht den wesentlichen Inhalt dieser Vorgänge und heutigen Rechtsinhalte bestimmt hat? Ist die Prozeßordnung des Bundesverfassungsgerichts denn die Regel, nach der die Veränderungen des Verfassungsrechtes sich abspielen oder wie würden Sie sagen, daß man in der Lage ist, juristisch - nicht im allgemeinen systemtheoretischen und sonstigen Erwägungen, sondern juristisch das beschreiben kann, was eigentlich eine legale Fortentwicklung aufgrund dieser sich ändernden Verhältnisse ist - unter den speziellen Aspekten, die Ihnen hier gestellt waren: Deutschland nach 30 Jahren Grundgesetz.

Bachof: Aus Herrn Achterbergs buntem Strauß einzelne Dinge herauszugreifen, mag willkürlich erscheinen; aber die beiden Leitsätze 18 und 19 scheinen mir einen Widerspruch oder mindestens eine Ergänzung einfach notwendig zu machen.

Als Erstes: Herr Achterberg meint eine Unterbilanz bei der theoretischen Bewältigung der Sozialstaatlichkeit im Verhältnis zur Rechtsstaatlichkeit feststellen zu können. Darüber mag sich streiten lassen. Nicht akzeptabel ist aber seine Begründung für diese Behauptung. Man kann hier nicht Fliegenbeine zählen, nicht 50 Seiten des Rechtsprechungskommentars zum Grundgesetz einerseits gegen 6 Seiten dieses Kommentars andererseits aufrechnen! Spätestens seit Ernst Forsthoff wissen wir doch, daß die Frage der unmittelbaren Vollziehbarkeit von freiheitsverbürgenden (,rechtsstaatlichen") Normen und von leistungsgewährenden (,,sozialstaatlichen") Normen eine jeweils völlig andere, und daß infolgedessen auch die Rolle der Rechtsprechung eine in diesen Bereichen jeweils verschiedene ist. Wenn man aber schon zählt, dann hätte man hier mindestens auch die Rechtsprechung der Sozialgerichte mit einbeziehen müssen. Jedoch ist die ganze Methode des Zählens hier inadäquat.

Wichtiger ist mir ein Zweites: Ich teile nicht den rechtsstaatlichen Optimismus der These 18. Es mag zwar richtig sein, daB wir dogmatisch einen Geländegewinn an Rechtsstaatlichkeit zu verzeichnen haben. Aber, meine Herren Kollegen, dem steht doch ein tatsächlicher Verfall an Rechtsstaatlichkeit gegenüber, der, wenn wir über „Deutschland nach 30 Jahren 
Grundgesetz" sprechen, meines Erachtens nicht unerwähnt bleiben darf! Herr Heckelmann hat es uns ja gestern abend erst wieder ins Gedächtnis gerufen; er hat dabei auch die unrühmliche Rolle mancher Hochschullehrer erwähnt. Das Problem der Rechtsstaatlichkeit in den 40er und 50er Jahren war die Wiederherstellung der Bindung der Staatsgewalt an das Gesetz; heute stellt sich das Problem ganz anders. Jenes Problem ist im wesentlichen bewältigt, auch wenn es einige Rückfälle gibt - darüber will ich jetzt nicht sprechen. Aber zur Rechtsstaatlichkeit gehört auch - das ist das Problem unserer Tage - die Rechtstreue der Bürger. Wie aber steht es damit? Weite Teile unserer Bürger heute stehen dem Gesetz, stehen dem Richterspruch und überhaupt dem Recht bestenfalls gleichgültig, oft aber ablehnend, ja feindlich gegenüber bis hin zur offenen Bekämpfung. Und was noch schlimmer ist: Wie verhalten sich unsere Staatsorgane, wie verhalten sich Politiker, Professoren, Richter, Anwälte dazu? Sie stekken den Kopf in den Sand, sie treiben Vogel-Strauß-Politik, sie dulden diese Dinge aus Feigheit, aus Bequemlichkeit, aus Opportunismus - wenn sie sie nicht mitunter sogar unterstützen. $D a$ sehe ich die Gefahr für den Rechtsstaat! Nun meinen Sie bitte nicht, daß ich nach "law und order" rufen und meinen würde, man müsse nur kräftig durchgreifen, um alles das rasch wieder in Ordnung zu bringen. In Ordnung gebracht werden muß das schon, aber man muß vor allem überlegen, welches die Ursachen dieser Erscheinungen und wie sie abzustellen sind. Und hier meine ich in der Tat, daß wir von einer Unterbilanz - nicht einer theoretischen, aber einer faktischen Unterbilanz - an Sozialstaatlichem sprechen können, einer Unterbilanz vor allem in den 50er und 60er Jahren, und besonders, daß damals für die Herstellung der Chancengleichheit auf dem Arbeits-, auf dem Bildungs-, auf dem Wirtschaftssektor usw. zu wenig getan wurde. Mir scheint, daß hier einige der Ursachen für das heute noch weitergärende Unbehagen an unserem Staat liegen. In den letzten Jahren ist in dieser Hinsicht sicher mehr getan worden etwas ungeordnet dann freilich und oft überstürzt, aber ich hoffe, jedenfalls nicht zu spät. Rechtsstaat und Sozialstaat gehören zusammen. Ich habe vor 26 Jahren vor dieser Vereinigung einmal dem Sinne nach gesagt, wer nur den Rechtsstaat wolle und nicht auch den Sozialstaat, der werde mit dem Sozialstaat zugleich auch den Rechtsstaat verlieren. Vielleicht ist es nicht unangemessen, daran zu erinnern.

Zusammenfassend: Die entscheidend wichtige Aufgabe unserer Tage ist es, dem Rechtsverfall Einhalt zu tun, die Ver- 
läßlichkeit des Rechts und die Treue zum Recht wiederherzustellen, vor allem aber unsere junge Generation dazu zu bringen, daß sie den Rechtsstaat aus Utberzeugung bejaht.

Grimm: Meine Damen und Herren! Herr Achterberg hat als Leitgesichtspunkt für sein Referat die Frage gewählt: Hat sich das Grundgesetz in den dreißig Jahren seiner Geltung bewährt? Das ist ein Gesichtspunkt, den das Thema selbst nahelegt. Ich glaube freilich, daß sich die Antwort nur geben läßt, wenn man das Grundgesetz auf diejenigen Probleme bezieht, welche im Lauf dieser dreißig Jahre entstanden sind. Das ist mir in methodischer Hinsicht so wichtig, daß ich - obwohl Herr Zacher sich ähnlich geäußert hat - darauf noch einmal insistieren möchte. Hätte Herr Achterberg die Korrelation zwischen der Problemebene und der Bewährungsfrage hergestellt, dann wäre das Bild wohl weniger harmonistisch ausgefallen, als er es gezeichnet hat. Ich kann das wegen des Zeitdrucks, unter dem wir stehen, nicht näher ausführen, sondern muß mich auf ein Stichwort beschränken. Es lautet „Funktionswandel des Staates" oder besser gesagt "Ausweitung der Staatsaufgaben". Hätte man diesen Ansatz gewählt, so wäre schnell sichtbar geworden, daß - in der Reihenfolge, die Herr Achterberg selbst zugrundegelegt hat - allenthalben erhebliche Schwierigkeiten für das Grundgesetz aufgetaucht sind: bei den Staatszielbestimmungen und Verfassungsprinzipien, Demokratie, Rechtsstaat, Sozialstaat, Föderalismus; bei den Grundrechten; bei den Organisationsnormen. Herr Bachof hat soeben über den Rechtsstaat gesprochen. Beim Föderalismus beispielsweise hätte sich gezeigt, daß zahlreiche neuartige Anforderungen an den Staat wie die Wirtschaftslenkung oder der Umweltschutz grenzüberschreitender Natur sind und daher, wie wir alle wissen, zu einer grundlegenden Umformung des Bundesstaats geführt haben. Das kann man hinnehmen, darf aber nicht übersehen, daß durch die Verflechtungen im BundLänder-Verhältnis ein wesentliches Prinzip der Verfassung, nämlich das Konkurrenzprinzip, entwertet wird, bis nicht mehr lokalisierbar ist, wem staatliche Maßnahmen zuzurechnen sind, wo die Verantwortungen liegen und woran man später seine Wahlentscheidung orientieren soll. Ähnlich verhält es sich beim Demokratieprinzip. Unter den Planungs- und Steuerungsanforderungen an den Staat wandelt sich die Struktur von Rechtsnormen. Bei fast allen modernen Aufgaben, die der Staat legislatorisch zu bewältigen hat, stellt man fest, wie wenig es noch gelingt, das Verhalten der Verwaltung durchgängig zu normieren, und wie sehr sich der Gesetzgeber darauf zu- 
rückziehen muß, Zielvorgaben zu nennen. Das bedeutet trotz wachsenden Normausstoßes, daß der Einfluß des Parlaments auf die Verwaltung sinkt, daß sie aber auch der Regierungsaufsicht entgleitet und sogar die Gerichtskontrolle mangels justiziabler Maßstäbe gelockert wird. Sie dürfen mir glauben, daß ich noch viele Themen aufzählen könnte, um meine methodologische Eingangsbemerkung zu belegen. Ich verzichte darauf und bekräftige zum Schluß nur nochmals, daß, wie mir scheint, allein von den tatsächlichen Problemen her die Bewährung der verfassungsrechtlichen Normen ermittelt werden kann.

Jarass: Meine Dame, meine Herren! Ich möchte an den Beitrag von Herrn Badura anknüpfen und ihn verknüpfen mit der These 15 von Herrn Achterberg und das Ganze ein bißchen vertiefen - Stichworte: "Richterliche Selbstbeschränkung“, "political-questions-doctrine“. Diese Frage ist in den letzten Jahren meist im Blick auf bestimmte Entscheidungen untersucht worden. Doch bitte ich meine Thesen nicht als nachträgliche Anmerkung zu diesen Urteilen $\mathrm{zu}$ verstehen. Vielmehr geht es mir um die Sache selbst. Was die political questionsdoctrine angeht, würde ich Herrn Achterberg zustimmen, jedenfalls dann, wenn man damit bestimmte Fragen der Rechtsprechung des Bundesverfassungsgerichts schlechthin entziehen will. So sehr es angebracht sein mag, da $B$ bei bestimmten Dingen das Wort des Gesetzgebers großes Gewicht hat, gravierende Mißstände müssen überprüfbar bleiben. Doch andererseits ergeben sich auch gravierende Probleme, wenn die Verfassungsrechtsprechung sich nicht fortgesetzt in richterlicher Selbstbeschränkung übt. Lassen Sie mich zwei Punkte ansprechen, die in der allgemeinen Diskussion kaum erwähnt werden:

Das eine Problem ist das geringe Potential der Verfassungsrechtsprechung zur Änderung des Standpunktes, verglichen mit dem Parlament. In der Konkretisierung von Verfassungsnormen spiegelt sich nicht nur das Bemühen, bestimmte essentielle Grundwerte zu wahren. Die Konkretisierung, ganz gleich, ob sie durch Parlament oder Verfassungsgericht erfolgt, ist auch und unvermeidlich von gesellschaftspolitischen Standpunkten geprägt, ohne daß der gegenteilige Standpunkt bereits die Grundwerte verletzen müßte. Aus diesem Grunde weist unser politisches System Mechanismen auf, die den unterlegenen Standpunkten jedenfalls die Chance geben, zu herrschenden zu werden. Der wichtigste ist die Zuordnung von Regierung und Opposition. Sie macht einen Wechsel der Standpunkte ohne große Schwierigkeiten möglich. Die unterlegene gesellschaftliche Gruppe braucht also nicht zu verzagen. 
Im Bereich des Bundesverfassungsgerichts ist das alles viel schwieriger. Sicherlich ist das Gericht nicht an die eigenen Vorentscheidungen gebunden. Es kann von ihnen offen oder versteckt abweichen. Doch wohnt ihm ein starkes Beharrungsmoment inne. Wenn das Bundesverfassungsgericht eine bestimmte Frage entschieden hat, dann sieht es für den unterlegenen Standpunkt sehr viel schwieriger aus, in absehbarer Zeit noch zum Zuge zu kommen. Daß das um so problematischer ist, je mehr sich das Bundesverfassungsgericht in politischen Detailfragen bewegt, liegt auf der Hand. Problematisch ist diese Eigenart des Bundesverfassungsgerichts aber v. a. deswegen, weil den Entscheidungen des Bundesverfassungsgerichts eine weitreichende Bindungswirkung zukommt. Ich würde daher Herrn Bernhardt zustimmen, wenn er die Erstreckung der Bindungswirkung auf die Urteilsgründe in Frage gezogen hat.

Das zweite Problem hängt mit dem Thema der „checks and balances" zusammen. Die Beziehung von Bundesverfassungsgericht und Parlament ist nicht symmetrisch. Das Bundesverfassungsgericht kann durch ein einfaches Urteil gesetzgeberische Entscheidungen aufheben. Der Gesetzgeber kann dagegen die Linie des Bundesverfassungsgerichts allein durch eine Verfassungsänderung korrigieren. Das führt dazu, daß das Konzept der checks and balances in erster Linie zu Lasten des Gesetzgebers geht. Der Gedanke, der hinter diesem Konzept steht, nämlich die Erkenntnis, daß niemand unfehlbar ist und daher, soweit er Macht hat, der Kontrolle bedarf, ist aber auch auf das Bundesverfassungsgericht anwendbar.

Nun mag diese Einseitigkeit zwangsläufig anmuten. Wie soll denn der Gesetzgeber anders als über eine Verfassungsänderung Einfluß auf die Verfassungsrechtsprechung nehmen können? Hier gibt es durchaus Möglichkeiten. Lassen Sie mich eine aus dem amerikanischen Bereich anführen. Wenn der Supreme Court eine gesetzgeberische Entscheidung im Hinblick auf vom Gesetzgeber nicht bedachte Folgen aufgehoben hat, dann besteht durchaus die Möglichkeit, daß das Gericht eine Wiederholung der Entscheidung durch den Gesetzgeber akzeptiert, mit der Begründung, daß nunmehr deutlich geworden sei, daß der Gesetzgeber auch zu diesen Folgen stehe. Ich bin mir bewußt, daß damit die klassische Zuordnung Verfassungsrecht und Gesetzesrecht in gewissem Umfang in Frage gestellt wird. Es gibt so etwas wie einen Einfluß des Gesetzesrechts auf das Verfassungsrecht, richtiger: Auf die Konkretisierung des Verfassungsrechts. Doch ist diese Folgerung m. E. 
ohnehin unvermeidlich. Im übrigen sollte unsere Frage nicht auf dieser rechtstheoretischen Ebene angegangen werden. So wie es beim Streit um den Gesetzesbegriff nicht um eine rechtstheoretische, sondern um eine staatsrechtliche Auseinandersetzung geht, so sollte auch diese Frage auf der Ebene angegangen werden, wo sie hingehört: Auf der Ebene der $\mathrm{Zu}-$ ordnung von Verfassungsgericht und Parlament.

Hollerbach: Ich möchte zu guter Letzt noch den Blick lenken auf eine Dimension, die man vielleicht bei Herrn Achterberg hätte erwarten können: Ich meine das Staatskirchenrecht. Ich weise darauf hin, nicht um jetzt ein Steckenpferd zu reiten, sondern gerade unter der Prämisse von Herrn Achterberg, der nach Stabilitäts- und Kontinuitätsfaktoren Ausschau gehalten hat. Das Staatskirchenrecht ist ja im Hinblick auf die Utbernahme des Normenbestandes aus der Weimarer Reichsverfassung ein Stabilitäts- und Kontinuitätsfaktor ganz besonderer Art. Freilich verbindet sich damit eine Frage, die sich nun wiederum an Herrn Bernhardt wendet, denn gerade hier ergeben sich Probleme, wenn wir nicht bloß an den Binnenaspekt denken; die Frage z. B.: Wie steht es mit Bindungen der Bundesrepublik einerseits, des Heiligen Stuhles andererseits an Normen des Reichskonkordats? Nehmen Sie als brisantes Stichwort: Änderung der Diözesangrenzen. Sind wir hier noch im Bereiche der Gemengelage von Staatsrecht und Völkerrecht, oder sind wir hier nun schon in dem rein völkerrechtlichen Bereich? Ich glaube, man sollte im Sinne von Herrn Frowein dieses Feld auch einbeziehen in jene von ihm zu Recht geforderte Analyse einzelner Befunde. Ich möchte schlieBen mit der kurzen Bemerkung, daß ich diesen Hinweis deshalb für einigermaßen wichtig hielt, weil ja nun gerade auch auf diesem Gebiet - um mich der Ausdrucksweise von Herrn Quaritsch zu bedienen - noch geistige Realitäten am Werke sind, um deren Berücksichtigung es geht.

Vorsitzender: Vielen Dank, Herr Hollerbach! - Wir kommen zu den Schlußworten, wobei nach den Gepflogenheiten der Vereinigung Herrn Achterberg das erste Wort gebührt.

Achterberg: Meine Dame und meine Herren! Es tut mir leid, daß ich mich wegen der Kürze der Zeit nicht mit der gebotenen Sorgfalt sämtlichen Diskussionsbeiträgen zuwenden kann. Besonders bedauere ich dies hinsichtlich des rechtsphilosophischen und rechtstheoretisch interessanten Beitrags von Frau Staff. Außer Hauriou und Carl Schmitt, die Sie erwähnt haben, wäre 
auch noch Kelsen zu nennen. Sie selbst haben auf Demokratie und Wertrelativismus hingewiesen; der Verbindung beider hat gerade er sich besonders zugewandt. Ich möchte dazu nicht mehr sagen, als daß ich die freiheitliche demokratische Grundordnung nicht in die Disposition des Parlaments und des Bundesverfassungsgerichts gestellt sehe. Die Demokratie gehört zu den unveränderlichen Bestandteilen des Grundgesetzes, sie steht allenfalls zur Verfügung des Souveräns selbst, nicht aber von Staatsorganen; und es kommt auch nicht so sehr auf einen Konsens unter den Bürgern an, sofern nicht die Totalrevision der Verfassung zur Diskussion steht, über die wir hier aber nicht zu sprechen brauchen. Die Beiträge von Herrn Zacher, von Herrn Grimm und von Herrn Hollerbach haben die Problematik des Themas in vollem Umfange aufscheinen lassen. Selbstverständlich kann man darüber streiten, welche Auswahl getroffen ist und mit welcher Methode der Referent an seine Aufgabe herangegangen ist. Man kann das Grundgesetz darauf durchmustern, was es sonst noch alles für unser Thema ergibt; da ließe sich gewiß noch allerhand auffinden. Ich stimme auch Ihnen zu, Herr Bachof, daß Seitenzahlen im Kommentar von Leibholz-Rinck allein nicht ausreichen, um die Bedeutung des Sozialstaatsprinzips zu belegen; ich habe sie nur erwähnt, um die drastische Diskrepanz zwischen der Behandlung des Rechtsstaats- und derjenigen des Sozialstaatsgrundsatzes aufzuzeigen. An dieser Stelle habe ich überdies mein Referat kürzen müssen, weil ich sonst die Zeit nicht hätte einhalten können. Man könnte auf den Ausbau der sozialen Sicherung, man könnte auf die Sozialgerichtsbarkeit, man könnte auch auf die soeben in der neuesten Abhandlung von Herrn Leisner aufgeworfene Frage vertieft eingehen, ob die Flexibilität des Grundgesetzes so groß ist, daß eine Volksfürsorge eingeführt werden könnte. Außer dem Staatskirchenrecht, Herr Hollerbach, gibt es demnach auch sonst noch manches, was zu dem Thema gesagt werden kann. Herr Badura, Sie würden gern noch etwas dazu hören, wie die legale Fortentwicklung unter dem Grundgesetz juristisch beschreibbar ist: Sie ist beispielsweise beschreibbar durch den Hinweis auf die verschiedenen Verfassungsänderungen, die erfolgt sind, sie ist auch beschreibbar durch die Hervorhebung, daß untergesetzliche Konkretisierungen Rückstrahlungen auf die Verfassungsebene ausgeübt haben, sie stellt sich schließlich durch die Rechtsprechung des Bundesverfassungsgerichts dar. Alles dies konnte angesichts der Weite des Themas nicht voll ausgeschöpft werden, wie Herr Ipsen mit Recht hervorgehoben hat. Mir ist von der Möglichkeit, auf die Entwicklung unter dem Grundgesetz weiter einzugehen, deshalb nicht 
mehr übriggeblieben, weil es der Wunsch des Vorstands war, da $\beta$ in beiden Referaten auch auf die Rechtslage Deutschlands eingegangen werden sollte - dies geschah im staatstheoretischen Teil meines Beitrags.

Ihnen allen danke ich für Ihre Aufmerksamkeit und für Ihre Diskussionsteilnahme; darin möchte ich auch diejenigen von Ihnen einschließen, die schweigend die Diskussion verfolgt haben und dadurch ihr Interesse an dem Thema bekundet haben. Mein besonderer Dank gilt Herrn Bernhardt, aber auch dem Vorstand, der uns keine weitere Vorgabe gemacht hat außer der erwähnten. Zwischen uns hat, wie gesagt, auch keine weitere Absprache stattgefunden. Ich glaube, daß gerade dies die Möglichkeit eröffnet hat, ohne weitere Beschränkungen die Referate so vorzutragen, wie dies geschehen ist, und ich meine, daß sie sich inhaltlich ergänzt haben.

Bernhardt: Ich bitte um Verständnis, daß ich zu keinem einzelnen Diskussionsbeitrag jetzt noch Stellung nehmen kann, auch nicht zu dem sehr wichtigen Hinweis von Herrn Hollerbach. Ich muß mich auf wenige grundsätzliche Bemerkungen beschränken.

Wesentlich scheint mir folgendes zu sein. Es besteht m. E. ein weitgehender Grundkonsens hinsichtlich der Zielsetzung, nämlich daß unser Ziel die langfristige Überwindung des gegenwärtigen Zustandes ist und daß wir uns immer wieder Gedanken darüber machen müssen, auf welche Weise und mit welchen rechtlichen Mitteln dieses Ziel erreicht werden kann, nämlich die Wiedervereinigung und die Überwindung der Mauer. Einigkeit besteht wohl auch darüber, daß die Vier-Mächte-Verantwortung und die Forderung nach Selbstbestimmung rechtliche Grundlagen für diese Ziele abgeben. Wenn man von diesem Grundkonsens ausgeht, gibt es zwei Wege, dieses Ziel zu verfolgen. Der eine Weg besteht darin, daß man an dem Völkerrechtssubjekt Gesamtdeutschland und an fortbestehender gesamtdeutscher Staatlichkeit sowie an einer Gemengelage von Staatsrecht und Völkerrecht festhält, und daß man dies auch bei einer Vielzahl von Einzelfällen des rechtlichen Alltags hervorkehrt. Das ist der eine Weg. Der andere Weg, den ich für besser vertretbar und begründbar halte, besteht darin, daß man durch eine Rücknahme verschiedener Rechtspositionen und rechtlicher Bindungen der politischen Entfaltung des Staates und den politischen Entscheidungen der staatlichen Organe mehr Raum läßt, als es bisher in der Diskussion über Deutschlands Rechtslage oft geschehen ist. 
Ich danke für die Diskussionsbeiträge zu meinen Ausführungen und für die Anregungen, die ich in großer Zahl erlebt habe.

Vorsitzender: Meine Dame und meine Herren! Dem Vorstand bleibt Dank im Namen aller an die beiden Herren Referenten! Der kritische Großmeister unserer Vereinigung, Herr Ipsen, hat einmal gesagt, daß es die Aufgabe dieser Verhandlungen sei, das öffentliche Recht ein wenig von der Stelle zu bewegen. Man konnte weite Strecken des Referates von Herrn Bernhardt, aber auch der Diskussion als eine nicht unerhebliche Herausforderung an die offizielle Deutschland-Doktrin des Bundesverfassungsgerichts empfinden. Insofern haben wir wohl im Sinne der Ipsenschen Maxime zu arbeiten versucht. Auf der anderen Seite war ein wichtiger Ton - das klang bei Herrn Achterberg und verschiedenen Diskussionsrednern an - der Gedanke an die Erhaltung der größeren deutschen Kulturnation. Dazu gehörte irgendwie auch der Streit um die "Gemengelage“.

Man kann das Thema „Deutschland“ in einem über die Bundesrepublik hinausreichenden Sinne nach 30 Jahren weiterhin auf die Tagesordnung setzen. Das hat der heutige Tag gezeigt. Deutschland ist - wie man es einmal gesagt hat - immer noch mehr als ein Hotel gleichen Namens in Leipzig. - Hiermit darf ich unsere Verhandlungen für heute schließen. 
